\title{
Solid Acid Catalysts for Endothermic Fuels
}

\author{
A Dissertation \\ Presented to \\ the faculty of the School of Engineering and Applied Science \\ University of Virginia
}

in partial fulfillment

of the requirements for the degree

Doctor of Philosophy by

Benjamin Huang

May 2017 


\section{APPROVAL SHEET}

This Dissertation

is submitted in partial fulfillment of the requirements for the degree of Doctor of Philosophy

Author Signature: Saspanise thary

This Dissertation has been read and approved by the examining committee:

Advisor:

Committee Member: Roseanne Ford

Committee Member: Harsha Chelliah

Committee Member: Joshua Choi

Committee Member: William Epling

Accepted for the School of Engineering and Applied Science:

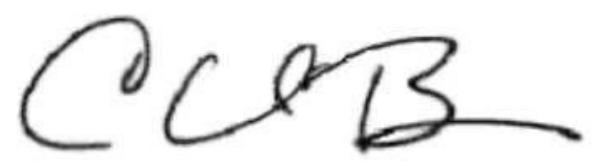

Craig H. Benson, School of Engineering and Applied Science

May 2017 


\begin{abstract}
Vehicles traveling at high supersonic and hypersonic flight speeds experience high thermal heat loads from aerodynamic heating that exceed the heat sink capacity of existing thermal management systems. Conventional thermal management systems are limited by the physical heat sink capacity of hydrocarbon fuels. One method to increase the heat sink capacity of hydrocarbon fuels is to carry out endothermic reactions on the hydrocarbon fuel near the heat load. The breaking of $\mathrm{C}-\mathrm{C}$ bonds over a catalyst, otherwise known as catalytic cracking, is an endothermic reaction that can provide a substantial heat sink for so called endothermic fuels. Understanding the effects of catalyst porosity and hydrocarbon molecular structure for catalytic cracking under supercritical conditions is necessary for the rational design of catalyst/fuel pairings for endothermic fuels. In this study, reactions of linear, branched, and cyclic hydrocarbons were performed over micro- and mesoporous solid acid catalysts under supercritical conditions. Measurements of intrinsic rate parameters were used to develop a fundamental understanding of the reaction mechanism under supercritical conditions.
\end{abstract}

Reactions of n-hexane and n-dodecane over zeolites H-ZSM-5 and H-Y, and mesoporous aluminosilicate Al-MCM-41 were performed under supercritical conditions in a single passed fixed bed reactor system. Results indicated the product distribution of the reaction was strongly influenced by bimolecular reactions and the hydrocarbon chain length. Rate measurements conclusively showed that H-ZSM-5 had the highest turnover frequency (TOF), normalized by the number of $\mathrm{H}^{+}$active sites evaluated by n-propylamine decomposition, for cracking linear hydrocarbons (n-hexane and n-dodecane). In contrast, reactions of n-hexane over H-Y and AlMCM-41 resulted in primarily isomerization products. The difference in product distribution for n-hexane reactions over H-ZSM-5 and H-Y was attributed to the smaller pores of H-ZSM-5. 
Cracking of cyclic hydrocarbons was explored during an evaluation of the H-Y/JP-10 catalyst/fuel pairing in both fixed bed and micro-flow tube reactor (MFTR) systems. The fixed bed reactor results revealed that cyclopentadiene and cyclopentene were the primary pyrolytic and catalytic cracking products of JP-10 (exo-tetrahydrobicyclopentadiene). Product analysis suggested that, at higher conversions, cyclopentadiene and cyclopentene undergo molecular growth reactions to form heavier molecular weight polyaromatic hydrocarbons. The importance of cyclopentadiene and cyclopentene during pyrolytic and catalytic cracking of JP-10 was also observed in the MFTR system at ambient pressure. The product distribution from the MFTR results was used to compare the endothermic cooling potential of pyrolytic and catalytic cracking of JP10. Catalytic cracking of JP-10 did not increase endothermic cooling capacities at low conversions and exhibited a high tendency for coke formation at high conversions. These characteristics suggest that $\mathrm{H}-\mathrm{Y} / \mathrm{JP}-10$ is an unattractive catalyst/fuel pairing for endothermic fuels.

Cracking of branched hydrocarbons, mixtures of branched and linear hydrocarbons, and military jet fuel, JP-8, over micro- and mesoporous aluminosilicate catalysts was also investigated. The smaller pores of H-ZSM-5 prevented the diffusion and subsequent cracking of branched molecules in the zeolite interior. In comparison, non-microporous amorphous silica-alumina (ASA) exhibited a higher TOF during cracking of a branched fuel mixture relative to its pure components. A preliminary investigation suggested that ASA exhibited promising stability compared to H-ZSM-5 during cracking of JP-8.

For comparison, a series of non-microporous mixed-oxide solid acid catalysts based on tungstated zirconia $\left(\mathrm{WO}_{\mathrm{x}} / \mathrm{ZrO}_{2}\right)$ was synthesized, characterized, and tested in the cracking of $\mathrm{n}$ dodecane. Characterization results indicated that as the composition of $\mathrm{W}$ was increased in the series, $\mathrm{WO}_{\mathrm{x}}$ domains on the zirconia surface also increased in size. Reaction experiments revealed 
that $\mathrm{WO}_{\mathrm{x}} / \mathrm{ZrO}_{2}$ catalysts were orders of magnitude less active than aluminosilicate materials on a per catalyst mass basis. Furthermore, $\mathrm{WO}_{\mathrm{x}} / \mathrm{ZrO}_{2}$ catalysts exhibited a loss of activity over time due to coke formation that was similar to aluminosilicate materials. Thus, $\mathrm{WO}_{\mathrm{x}} / \mathrm{ZrO}_{2}$ catalysts are not considered to be attractive for catalyzing the cracking of endothermic fuels.

In summary, cracking of several different hydrocarbons over solid acid catalysts with various pore sizes and compositions was studied under supercritical conditions. Whereas zeolite H-ZSM-5 exhibited the highest rate for cracking of linear hydrocarbons, zeolite H-Y was superior to that of H-ZSM-5 for cracking of military fuel JP-10 because the pore size of H-ZSM-5 was too small to accommodate the fuel. This work illustrates the importance of proper catalyst/fuel pairing for endothermic fuel cracking reactions. 


\section{Acknowledgments}

First and foremost, I would like to thank Dr. Robert J. Davis for his support, direction, and encouragement during this research. His combination of knowledge, kindness, and sense of humor is truly unrivaled and I am grateful for the opportunity to have learned from him. I would also like to thank Dr. Peng Bai and Dr. Matthew Neurock, for their invaluable contributions to this project. I am grateful to Dr. Ujuma Shrestha and Dr. Harsha Chelliah, for their collaboration and leadership throughout this project. I would like to acknowledge the source of funding for this work, the Air Force Office of Scientific Research (AFOSR FA9550-12-1-0496).

I would like to thank numerous members of the UVA Chemical Engineering Department: Drs. Green, Ford, Choi and Epling for their efforts as members of my PhD committee. Ms. Vickie Faulconer, Ms. Teresa Morris, Ms. Jennifer Davis, and Mr. Ricky Buchanan deserve credit for all of their incredible support throughout the years. There is no better staff in the world.

I would like to take a moment to recognize my fellow Davis Lab members: Dr. Heng Shou for teaching me about the wonders of BNL, Dr. Juan Lopez-Ruiz for being my first Davis Lab mentor, Dr. Derek Falcone (and his better thirds Katie and Cairo) for all the laughs, and Dr. Sabra Hanspal and Dr. Kehua Yin for being part of the greatest office of all time. I want to thank future Drs. Zachary Young, James Kammert, Nick Kaylor, Jiahan Xie, and Gordon Brezicki for helping make Davis Lab Best Lab ${ }^{\mathrm{TM}}$.

I would like to thank Evelina Khakimova for all of her patience and love during this process. Finally, I am truly grateful to my parents for all of their support. Their hard work and sacrifice provided the foundation that made all of this possible. 


\section{Table of Contents}

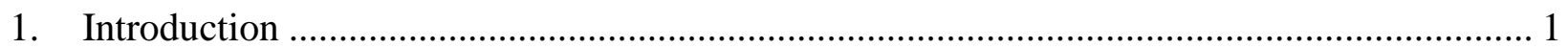

$1.1 \quad$ Endothermic Fuels for Advanced Aircraft .............................................................. 3

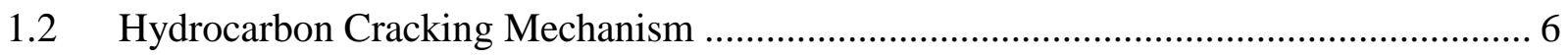

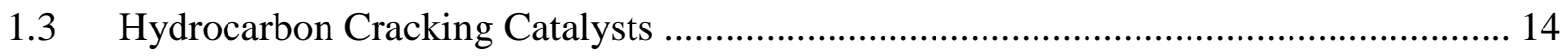

2. Hydrocarbon Cracking Over Aluminosilicate Catalysts ....................................................... 21

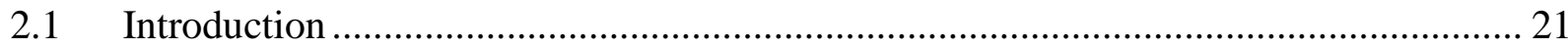

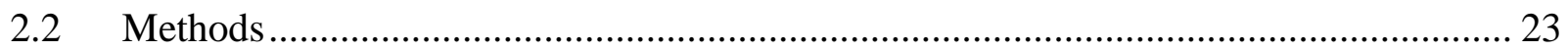

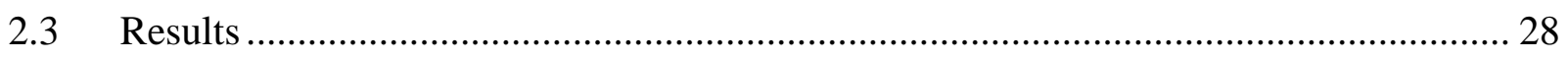

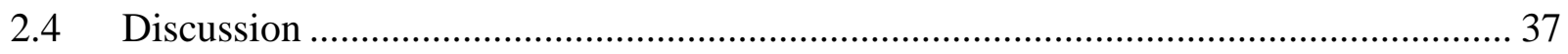

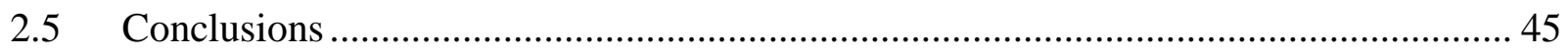

3. Catalytic Cracking of JP-10 over H-Y Under Supercritical Conditions ................................ 46

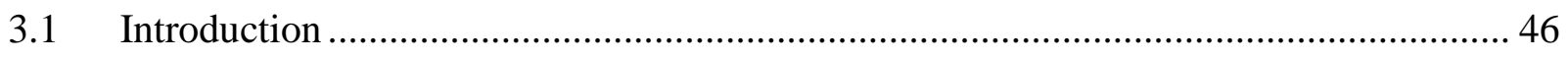

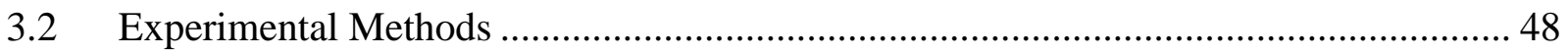

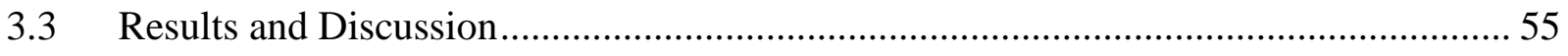

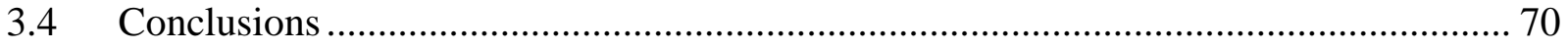

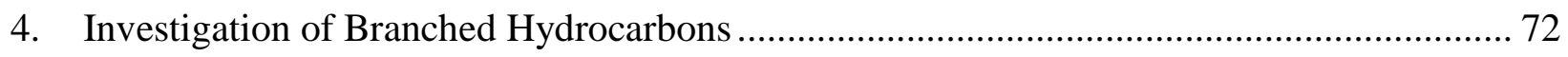

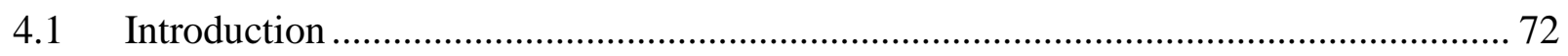

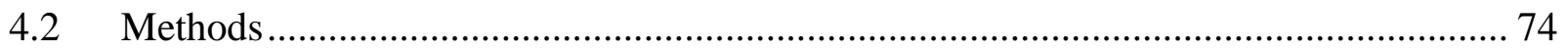

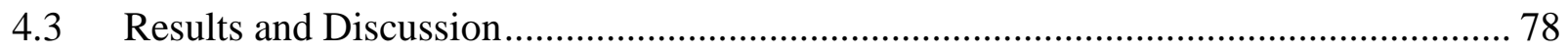




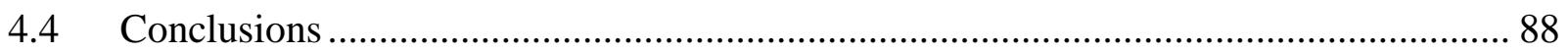

5. Synthesis, Characterization, and Reactor Studies of $\mathrm{WO}_{\mathrm{x}} / \mathrm{ZrO}_{2}$ Catalysts for Endothermic

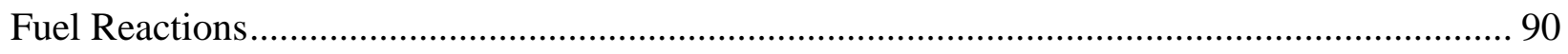

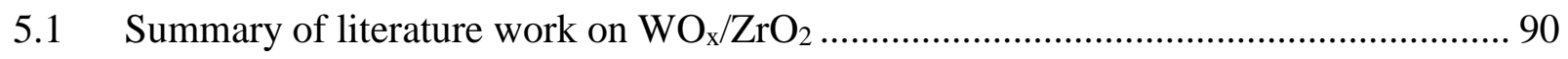

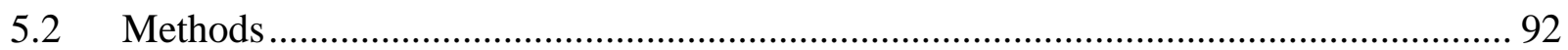

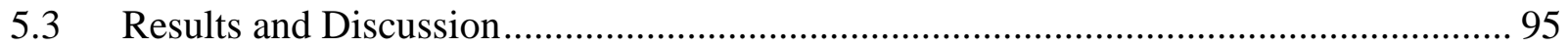

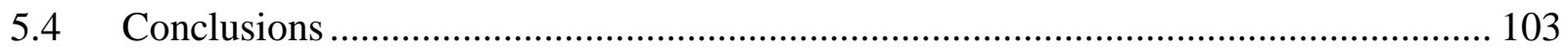

6. Conclusions and Future Directions....................................................................... 104

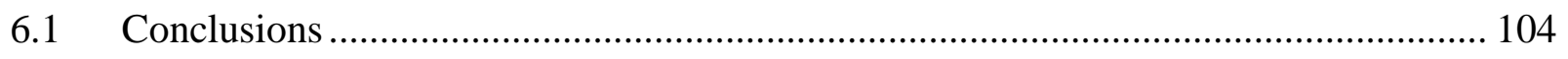

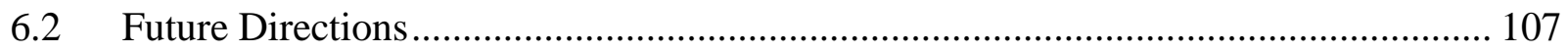

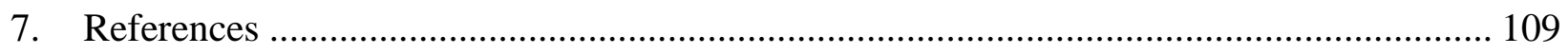

Appendix A. Supporting information for Chapter 2 ................................................... 123

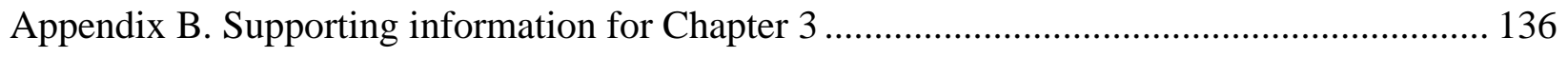

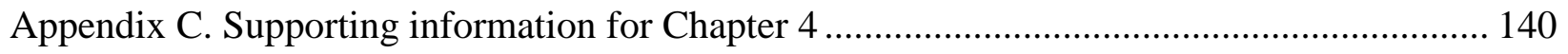

Appendix D. Supporting information for Chapter 5 ................................................. 144

Appendix E. Experimental Details ........................................................................ 150 


\section{List of Figures}

Figure 1-1. Carbenium (left) and carbonium (right) ions in catalytic cracking........................ 7

Figure 1-2. Protonated cyclopropyl intermediate during n-butane isomerization. ................... 10

Figure 1-3. Hydride transfer of a carbenium ion with another alkane ................................. 10

Figure 1-4. $\beta$-scission of a carbenium ion to form propylene and another carbenium ion. ......... 11

Figure 1-5. Simplified reaction network in zeolite-assisted cracking of hydrocarbon molecules.

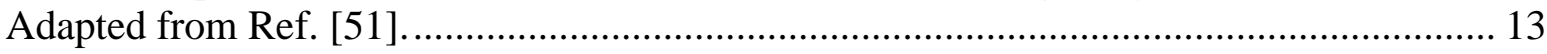

Figure 1-6. Structure of a Brønsted acid site on aluminosilicate catalysts [68]....................... 16

Figure 1-7. Proposed interaction of silanol groups with $\mathrm{Al}^{3+}$ sites on silica alumina [60]......... 16

Figure 1-8. Comparison of structure and pore diameter of various zeolites. Reproduced from

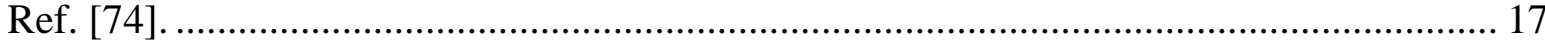

Figure 2-1. Normalized TOF of n-hexane conversion versus time on stream over H-ZSM-5 at $588 \mathrm{~K}(\boldsymbol{\Delta})$ and $\mathrm{H}-\mathrm{Y}$ at $673 \mathrm{~K}(\bullet)$, both at $6 \mathrm{MPa}$.

Figure 2-2. a) TOF and b) normalized TOF of n-dodecane cracking versus time on stream over $\mathrm{H}-\mathrm{ZSM}-5$ at $588 \mathrm{~K}(\boldsymbol{\Delta})$ and $698 \mathrm{~K}(\bullet)$ at $6 \mathrm{MPa}$.

Figure 2-3. Conversion of n-dodecane versus time on stream over Al-MCM-41 $(\boldsymbol{\Delta})$ and HZSM-5 (•) at $748 \mathrm{~K}$ and $6 \mathrm{MPa}$. A background conversion of $3 \%$ has been subtracted from the results.

Figure 2-4. Hydride-transfer transition states for n-butane to 1-propoxy (left) and 2-propoxy (right).

Figure 2-5. Transition-state structures for isomerization of hex-3-oxide to 3-methylpent-2-oxide (left) and for $\beta$-scission of 4-methylpent-2-oxide (right).

Figure 2-6. Adsorption isotherms of n-hexane and n-dodecane in a) H-ZSM-5 and in b) H-Y. The dotted square indicates the tested feed pressures of n-hexane or n-dodecane. The dashed line indicates the Brønsted-site density for the tested zeolite.

Figure 2-7. a) Arrhenius-type plots for reactions of n-hexane over H-ZSM-5 ( $\boldsymbol{\Delta})$ and $\mathrm{H}-\mathrm{Y}(\bullet)$ at $6 \mathrm{MPa}$. b) Arrhenius-type plots for reactions of n-dodecane over H-ZSM-5 ( $\Delta$ ), H-Y (•) and Al-MCM-41 (घ) at $6 \mathrm{MPa}$.

Figure 3-1. Schematic of experimental setup showing: 1 - nitrogen gas cylinder; 2 - mass flow controllers; 3 - micro-flow reactor in vented high-pressure enclosure chamber; 4 - fuel atomizer; 5 - atomizer housing; 6 - liquid fuel pump; 7 - fuel reservoir; 8 - quartz 
microprobe; 9 - needle valve; 10 - dry ice bath; 11 - GC system; 12 - pressure gauge; 13 vacuum pump. This figure was provided by U. Shrestha.

Figure 3-2. Schematic of atmospheric pressure micro-flow tube reactor with three $1 \mathrm{~mm}$ rods coated with H-Y zeolite and placed in the hot section. This figure was provided by $\mathrm{U}$. Shrestha.

Figure 3-3. Background pyrolysis conversion for ( $\boldsymbol{\Delta})$ n-dodecane and ( $\boldsymbol{(}) \mathrm{JP}-10$ versus temperature. Reaction conditions: total system pressure: $6 \mathrm{MPa}$ and liquid hydrocarbon feed rate: $1.2-3.0 \mathrm{~cm}^{3} \mathrm{~min}^{-1}$. 55

Figure 3-4. TOF of JP-10 cracking versus time on stream over $\mathrm{H}-\mathrm{Y}$ zeolite at $718 \mathrm{~K}$ and $6 \mathrm{MPa}$ and $\sim 3 \%$ conversion.

Figure 3-5. Arrhenius-type plot for the reaction of JP-10 over H-Y under supercritical conditions.

Figure 3-6. TOF (left) and normalized TOF (right) of cracking of JP-10 over H-Y under supercritical conditions versus time on stream at $16 \%$ and $78 \%$ conversion. Reaction conditions: $\mathrm{T}=748 \mathrm{~K}, \mathrm{P}=6 \mathrm{MPa}$, and a JP-10 feed flow rate of $2.4 \mathrm{~cm}^{3} \mathrm{~min}^{-1}$.

Figure 3-7. Comparison of major species yield from JP-10 pyrolysis as a function of hot-section temperature, for 1\% JP-10 in nitrogen (by moles) at residence time $400 \mathrm{~ms}$ and pressure 1 atm. $\nabla$ and + represents $\mathrm{H}-\mathrm{Y}$ zeolite loadings of $5 \mathrm{mg}$ and $7 \mathrm{mg}$, respectively; $O$ represents without $\mathrm{H}-\mathrm{Y}$ zeolite catalyst; dashed line represents numerical predictions using a detailed chemical kinetic model proposed by Gao et al. [177] without catalytic reactions. 64

Figure 3-8. Comparison of minor species yield from JP-10 pyrolysis as a function of hot-section temperature, for 1\% JP-10 in nitrogen (by moles) at residence time $400 \mathrm{~ms}$ and pressure 1 atm. $\nabla$ and + represents $\mathrm{H}-\mathrm{Y}$ zeolite loadings of $5 \mathrm{mg}$ and $7 \mathrm{mg}$, respectively; $\bigcirc$ represents without H-Y zeolite catalyst; dashed line represents numerical predictions using a detailed chemical kinetic model proposed by Gao et al. [177] without catalytic reactions.

Figure 3-9. GC chromatogram during homogeneous and catalytic pyrolysis at $\mathrm{T}=800 \mathrm{~K}$ and $\mathrm{T}=960 \mathrm{~K}$ respectively. The residence time is kept fixed at $\mathrm{t}_{\mathrm{res}}=0.4 \mathrm{~s}$

Figure 3-10. GC-MS chromatogram during homogeneous and catalytic pyrolysis at $\mathrm{T}=800 \mathrm{~K}$ and $\mathrm{T}=960 \mathrm{~K}$ respectively. The residence time is kept fixed at $\mathrm{t}_{\mathrm{res}}=0.4 \mathrm{~s}$. 66

Figure 3-11. Reaction path flux analysis of JP-10 pyrolysis indicating the key reactions that JP10 radical and key species such as hydrogen, methane and propylene identified in experiments at $\mathrm{T}=960 \mathrm{~K}$ and residence time of 0.4 seconds 68

Figure 3-12. Reaction path flux analysis of R8 (JP-10 radical) pyrolysis indicating the key reactions that lead to the species such as allene, ethylene, cycopentadiene, and cyclopentene identified in experiments at $\mathrm{T}=960 \mathrm{~K}$ and residence time of 0.4 seconds. 
Figure 3-13. Reaction path flux analysis of R6 (JP-10 radical) indicating the key reactions that lead to toluene identified in experiments at $\mathrm{T}=960 \mathrm{~K}$ and residence time of 0.4 seconds.... 69

Figure 3-14. Reaction path flux analysis of R5 (JP-10 radical) indicating the key reactions that lead to 1,3-butadiene and cyclohexadiene identified in experiments at $\mathrm{T}=960 \mathrm{~K}$ and residence time of 0.4 seconds

Figure 4-1. Skeletal formulas, IUPAC names, and chemical formulas for isooctane and isododecane.

Figure 4-2. Cracking TOF of $\mathrm{n}$-dodecane $\left(\mathrm{nC}_{12}\right)$, isooctane (isoC 8 ), isododecane (isoC 12 ), a $50 / 50 \mathrm{~mol} . \%$ mixture of isooctane and $\mathrm{n}$-dodecane (iso $\mathrm{C}_{8} / \mathrm{nC}_{12}$ ), and a $50 / 50 \mathrm{~mol} . \%$ mixture of isododecane and $\mathrm{n}$-dodecane $\left(\right.$ isoC $_{12} / \mathrm{nC}_{12}$ ) over $\mathrm{H}-\mathrm{ZSM}-5$ at $698 \mathrm{~K}$ and $3 \mathrm{MPa}$. 78

Figure 4-3. Cracking TOF of $\mathrm{n}$-dodecane $\left(\mathrm{nC}_{12}\right)$, isooctane (iso $\left.\mathrm{C}_{8}\right)$, and a 50/50 mol.\% mixture of isooctane and $\mathrm{n}$-dodecane (isoC $\mathrm{C}_{8} / \mathrm{nC}_{12}$ ) over $\mathrm{ASA}$ at $698 \mathrm{~K}$ and $3 \mathrm{MPa}$.

Figure 4-4. Cracking TOF of n-dodecane, isooctane, and a 50/50 mol.\% mixture of isooctane and n-dodecane over $\mathrm{H}-\mathrm{Y}$ and $6 \mathrm{MPa}$.

Figure 4-5. Arrhenius-type plot for the cracking of a 50/50 mol. $\%$ mixture of n-dodecane and isooctane (top) and n-dodecane (bottom) over $\mathrm{H}-\mathrm{Y}$ at $6 \mathrm{MPa}$. The dashed line indicates the critical temperature of $n$-dodecane $\left(T_{c}=658 \mathrm{~K}\right)$.

Figure 4-6. Arrhenius-type plot for the cracking of n-dodecane $(\boldsymbol{\Delta})$, isooctane $(\bullet)$, and a 50/50 mol.\% mixture of n-dodecane and isooctane (ם) over $\mathrm{H}-\mathrm{Y}$ at $6 \mathrm{MPa}$.

Figure 4-7. a) Dependence of rates of formation for gas-phase products of n-dodecane cracking over H-ZSM-5 on time on stream at 698 K. b) Dependence of rates of formation for gasphase products of n-dodecane cracking over ASA on time on stream at $698 \mathrm{~K}$. Reaction conditions: Total system pressure $=4 \mathrm{MPa}$, liquid feed flow rate $=0.2 \mathrm{~cm}^{3} \cdot \mathrm{min}^{-1}$.

Figure 5-1. $\mathrm{XRD}$ patterns of $\mathrm{WO}_{\mathrm{x}} / \mathrm{ZrO}_{2}$ catalysts and $\mathrm{ZrO}_{2}$ support. Patterns are offset for

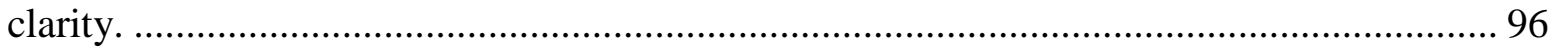

Figure 5-2. Optical absorption edge energies of $\mathrm{WO}_{\mathrm{x}} / \mathrm{ZrO}_{2}$ catalysts. .................................. 97

Figure 5-3. Raman spectra of $\mathrm{WO}_{\mathrm{x}} / \mathrm{ZrO}_{2}$ catalysts. Spectra offset for clarity........................ 98

Figure 5-4. Cracking of $\mathrm{n}$-dodecane over $20 \% \mathrm{WO}_{\mathrm{x}} / \mathrm{ZrO}_{2}$ at supercritical conditions. Reaction conditions: $\mathrm{T}=698 \mathrm{~K}$; total system pressure $=4 \mathrm{MPa}$, liquid feed flow rate $=0.2 \mathrm{~cm}^{3} \cdot \mathrm{min}^{-1}$.

Figure 5-5. Comparison of $\mathrm{W} \mathrm{L}_{\mathrm{III}} \mathrm{XANES}$ for fresh and spent $20 \% \mathrm{WO}_{\mathrm{x}} / \mathrm{ZrO}_{2}$ catalysts compared to a reference $\mathrm{W}$ foil.

Figure 5-6. Thermogravimetric analysis (TGA) profile of spent $20 \% \mathrm{WO}_{\mathrm{x}} / \mathrm{ZrO}_{2}$ catalyst in $10 \%$

$\mathrm{O}_{2}$, balance He. 
Figure 5-7. Cracking of $\mathrm{n}$-dodecane over $20 \% \mathrm{WO}_{\mathrm{x}} / \mathrm{ZrO}_{2}$ compared to aluminosilicate catalysts at supercritical conditions. Reaction conditions: $\mathrm{T}=698 \mathrm{~K}$; total system pressure $=4 \mathrm{MPa}$, liquid feed flow rate $=0.2 \mathrm{~cm}^{3} \cdot \mathrm{min}^{-1}$. 102

Figure A-1. Adsorption isotherms of hexane (left column) and dodecane (right column) isomers in H-ZSM-5 at $T=590 \mathrm{~K}$ (top row) and in $\mathrm{H}-\mathrm{Y}$ at $T=675$ and $695 \mathrm{~K}$ (bottom row), respectively. The orange lines denote the feed pressure, while the violet lines indicate the upper limit of the partial pressure for the isomer products, by assuming that linear alkanes are only converted via isomerization reactions.

Figure A-2. A representative snapshot of adsorbed n-dodecane molecules in H-ZSM-5 at $T=$ $590 \mathrm{~K}$ and $p=10 \mathrm{MPa}$. The silicon, oxygen, and carbon atoms are shown in yellow, red, and gray, respectively, and hydrogen atoms are omitted for clarity. In order to maximize packing and further saturate the channels, n-dodecane has to be localized either within two zig-zag or two straight channels (I-shape), or within a zig-zag channel and a straight channel (L-shape).

Figure A-3. Arrhenius-type plot for reactions of n-hexane over H-Y at $6 \mathrm{MPa}$. TOFs calculated from the products of isomerization and cracking reactions are represented by ( $\mathbf{\square})$. TOFs calculated from only the products of cracking reactions are represented by $(\bullet) \ldots \ldots \ldots \ldots \ldots . . .135$

Figure B-1. a) TOF and b) normalized TOF of JP-10 cracking versus time on stream over H-Y (•) and Al-MCM-41 (घ) at $718 \mathrm{~K}$ and $6 \mathrm{MPa}$ and $\sim 3 \%$ conversion. 138

Figure B-2. Arrhenius-type plots for reactions of JP-10 over H-Y (•) and Al-MCM-41 (匹) at 6 $\mathrm{MPa}$ 138

Figure C-1. GC Chromatogram for JP-8. 143

Figure D-1. Absorption edge energy $\left(\mathrm{E}_{0}\right)$ of $20 \% \mathrm{WO}_{\mathrm{x}} / \mathrm{ZrO}_{2}$ determined by the intercept of a linear fit to the absorption edge.

Figure D-2. Raman spectra of $\mathrm{m}-\mathrm{ZrO}_{2}$ and $\mathrm{WO}_{3}$. 146

Figure D-3. MS traces for propylene and hexene/hexane during n-propylamine decomposition over $20 \% \mathrm{WO}_{\mathrm{x}} / \mathrm{ZrO}_{2}$.

Figure D-4. a) MS traces for propylene and hexene/hexane during n-propylamine decomposition over H-ZSM-5. b) MS trace for a propylene pulse used to calibrate the propylene MS signal.

Figure E-1. Schematic diagram of the upward-flow fixed bed reactor. 150

Figure E-2. Schematic diagram of setup used for the n-propylamine decomposition experiments. Gas flows were measured using mass flow controllers (MFCs) and decomposition products were analyzed using a mass spectrometer (MS). 150 


\section{List of Tables}

Table 1-1. Characteristics and properties of military jet fuels JP-7, JP-8, and JP-10 [7,8] ......... 4

Table 1-2. Minimum ignition energies of relevant hydrocarbons (Pressure, $0.1 \mathrm{MPa}$ ) [10,11].... 5

Table 1-3. Critical properties of n-hexane, n-dodecane, isooctane, and isododecane [13].......... 6

Table 1-4. Effect of chain length on the relative reactivity of alkenes to alkanes [36,37]........... 8

Table 1-5. Heats of adsorption, apparent and intrinsic energies of activation for the cracking of $\mathrm{n}$ -

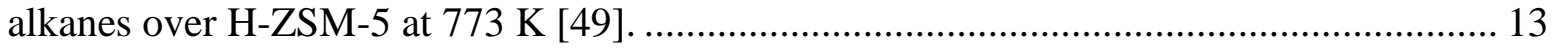

Table 2-1. Properties of aluminosilicate catalysts. ............................................................. 28

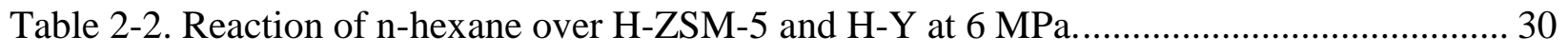

Table 2-3. Reaction of n-dodecane over H-ZSM-5, H-Y and Al-MCM-41 at 6 MPa. .............. 31

Table 3-1. Properties of H-Y zeolite used in this study................................................... 54

Table 3-2. Experimental conditions explored for fixed bed and micro-flow reactor studies. ...... 54

Table 3-3. Results at 10 min TOS from the pyrolytic conversion of JP-10 over inert $\mathrm{ZrO}_{2}$ in a

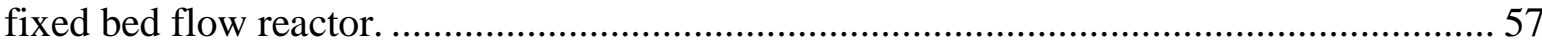

Table 3-4. Results at 10 min TOS from the conversion of JP-10 over H-Y in a fixed bed flow

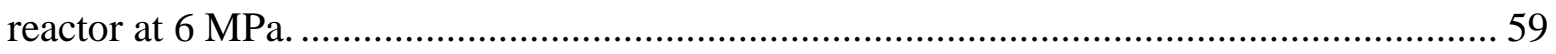

Table 3-5. Effect of conversion on JP-10 cracking product selectivity over H-Y at $748 \mathrm{~K}$ and 6

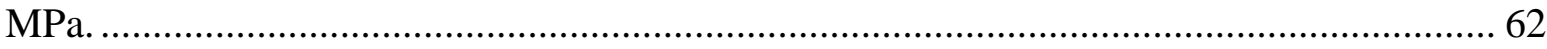

Table 3-6. Comparison of endothermic vs. sensible enthalpy from JP-10 pyrolysis with and

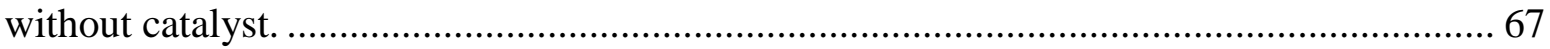

Table 4-1. Properties of aluminosilicate catalysts. ......................................................... 77

Table 4-2. Reaction of isooctane, n-dodecane, and a 50/50 mol.\% mixture of isooctane and n-

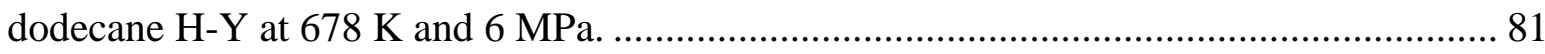

Table 4-3. Reaction of a 50/50 mol.\% mixture of isooctane and n-dodecane over H-Y at $6 \mathrm{MPa}$. 84

Table 5-1. Characterization of synthesized $\mathrm{WO}_{\mathrm{x}} / \mathrm{ZrO}_{2}$ catalysts.......................................... 98

Table A-1. Results at 10 min TOS from conversion of n-hexane on H-ZSM-5..................... 123 
Table A-2. Results at 10 min TOS from conversion of n-hexane on H-Y.

Table A-3. Results at 10 min TOS from conversion of n-hexane on H-Y. 125

Table A-4. Results at 10 min TOS from conversion of n-hexane on Al-MCM-41. 126

Table A-5. Effect of pressure on results at 10 min TOS from conversion of $n$-hexane on H-ZSM5.

Table A-6. Effect of pressure on results at 10 min TOS from conversion of n-hexane on H-Y. 128

Table A-7. Results at 10 min TOS from conversion of n-dodecane on H-ZSM-5. 129

Table A-8. Results at 10 min TOS from conversion of $\mathrm{n}$-dodecane on H-Y. 130

Table A-9. Results at 10 min TOS from conversion of n-dodecane on Al-MCM-41.

Table A-10. Results at 10 min TOS from cracked products during conversion of $n$-hexane on $\mathrm{H}-$ $\mathrm{Y}^{*}$...... 134

Table B-1. Cracking of JP-10 over H-ZSM-5 and H-Y at $733 \mathrm{~K}$ and $6 \mathrm{MPa}$. 136

Table B-2. Results at 10 min TOS from the conversion of JP-10 over Al-MCM-41 in a fixed bed flow reactor at $6 \mathrm{MPa}$. 137

Table B-3. Notable products during moderate and high conversion of JP-10 over H-Y.* 139

Table C-1. Cracking of isooctane, $\mathrm{n}$-dodecane, and a 50/50 mol.\% mixture of isooctane and ndodecane over H-ZSM-5 at $698 \mathrm{~K}$ and $3 \mathrm{MPa}$.

Table C-2. Cracking of isooctane, n-dodecane, and a 50/50 mol.\% mixture of isooctane and ndodecane over ASA at $698 \mathrm{~K}$ and $3 \mathrm{MPa}$.

Table C-3. Results at 10 min TOS from conversion of $\mathrm{n}$-dodecane on $\mathrm{H}-\mathrm{Y}$. 142

Table D-1. Absorption edge energies $\left(\mathrm{E}_{0}\right)$ of various $\mathrm{WO}_{\mathrm{x}}$ standard compounds 145

Table D-2. Measurement of Brønsted-acid site density of H-ZSM-5. 148

Table D-3. Results at 10 min TOS from conversion of n-dodecane over $20 \% \mathrm{WO}_{\mathrm{x}} / \mathrm{ZrO}_{2}$ at $698 \mathrm{~K}$ and $4 \mathrm{MPa}$. 


\section{Introduction}

Advanced high supersonic (Mach 3-5) and hypersonic (Mach > 5) vehicles have received considerable attention for their potential to function as high speed missiles, dramatically reduce aircraft travel time, and provide affordable space access. A major complication in the development and implementation of such vehicles is the thermal management issues that arise at high supersonic and hypersonic speeds. Vehicles designed for high supersonic and hypersonic flight must incorporate an active cooling system, but not a dedicated one to avoid overweighting the vehicle [1]. Currently, the main method of active cooling uses the onboard fuel as the primary coolant by circulating the fuel behind the walls of various aircraft components and removing waste heat before the injection of fuels to the combustion chamber.

One technology that has been the focus of numerous investigations is endothermic fuels. Endothermic fuels increase the heat sink capacity of heavy hydrocarbon fuels by incorporating both the physical heat sink capacity from the sensible enthalpy of the hydrocarbon fuel and the chemical heat sink capacity from undergoing decomposition into hydrocarbon products that are also fuels. Catalytic cracking of endothermic fuels has generated interest due to its potential to produce molecules with favorable ignition properties. Solid acid catalysts, and zeolites in particular, are well known to be effective for catalyzing hydrocarbon cracking reactions necessary for endothermic fuel cracking. The versatility of the zeolite framework and its ability to tune the reaction mechanism and product distribution by changing the zeolite pore structure offers tremendous potential for endothermic fuels. 
The overall goal of this work is to develop a fundamental understanding of how hydrocarbon molecular structure and catalyst porosity affects cracking rates during the catalytic cracking of hydrocarbons under supercritical conditions.

The objectives of this dissertation are outlined below:

1) Experimentally explore catalyst/fuel pairings that promote endothermic fuel cracking reactions under supercritical conditions.

2) Understand the influences of catalyst porosity and hydrocarbon molecular structure to optimize catalyst/fuel pairings for carbon-carbon bond cracking:

a. Measure kinetic parameters (e.g. turnover frequencies, apparent activation energies) of the catalytic cracking reaction under supercritical conditions.

b. Examine the effect of catalyst porosity by testing microporous zeolites (H-ZSM-5, H-Y), mesoporous aluminum-substituted Mobil Composition of Matter-41 (AlMCM-41), non-microporous amorphous silica-alumina (ASA), and nonmicroporous tungstated zirconia $\left(\mathrm{WO}_{\mathrm{x}} / \mathrm{ZrO}_{2}\right)$

c. Examine the effect of different hydrocarbon molecular structures using linear alkanes (n-hexane, n-dodecane), branched alkanes (isooctane and isododecane), and military fuels (JP-8 and JP-10).

In the remainder of this chapter, the history of endothermic fuels and the relevant components to this technology are discussed. The details of the hydrocarbon cracking mechanism and a background of solid acid catalysts are presented. In the next two chapters, fundamental investigations on the effect of hydrocarbon chain length (Chapter II) and the effect of cyclic hydrocarbons (Chapter III), on cracking rates over micro- and mesoporous aluminosilicate catalysts using experimental and theoretical approaches is reported. In Chapter IV, the cracking of 
branched hydrocarbons (isooctane and isododecane) and mixtures of branched and linear hydrocarbons over micro- and mesoporous aluminosilicate catalysts is discussed. A brief investigation of the cracking behavior of a real military jet fuel, JP-8, which is a mixture of linear, branched, and cyclic hydrocarbons, is also included. The relative performance of $\mathrm{WO}_{\mathrm{x}} / \mathrm{ZrO}_{2}$ for hydrocarbon cracking compared to aluminosilicate materials is presented in Chapter V.

\subsection{Endothermic Fuels for Advanced Aircraft}

Current aircraft circulate hot air from the compressor to the fuel tanks and use the sensible heat capacity of the fuel as a heat sink. The cooled air is then recirculated to various thermally stressed systems such as the engine components, electronics, and hydraulics [2]. The WrightPatterson Research and Development Center analyzed the cooling requirements of current military aircraft and determined that the F-15, with a top speed of approximately Mach 2.5, exhibits a maximum heat load of approximately $12,660 \mathrm{~kJ} \mathrm{~min}^{-1}$. It is expected that next-generation vehicles, with flight speeds greater than Mach 5 will be required to absorb upwards of $38,000 \mathrm{~kJ} \mathrm{~min}^{-1}$ [3]. The dramatic increase in thermal load with Mach number requires the development of advanced cooling technologies that can increase the cooling capacity of the hydrocarbon fuel [4].

Current fuel systems in military aircraft operate under high pressure to ensure adequate flow of fuel to the engine under all operating conditions. For example, the JP-8 fuel used in the fuel system of the current F-15 experiences pressures up to 27.6 MPa and temperatures as high as $450 \mathrm{~K}$ for residence times up to 20 minutes [5]. These pressures are above the critical pressures of current commercial and military jet fuels. The thermal loads of next generation vehicles are much greater and result in much higher fuel temperatures. According to Edwards [6], the fuel for next 
generation hypersonic aircraft may need to withstand temperatures on the order of $813 \mathrm{~K}$ or higher, which is far greater than the critical temperature of current commercial and military jet fuels, listed in Table 1-1. Based on the designs for current military aircraft, it is expected that the hydrocarbon fuels in the fuel systems of next generation hypersonic vehicles will be subject to supercritical pressures and temperatures.

Table 1-1. Characteristics and properties of military jet fuels JP-7, JP-8, and JP-10 [7,8].

\begin{tabular}{|c|c|c|c|}
\hline & JP-7 & JP-8 & JP-10 \\
\hline Approximate Formula & $\mathrm{C}_{12} \mathrm{H}_{25}$ & $\mathrm{C}_{11} \mathrm{H}_{21}$ & $\mathrm{C}_{10} \mathrm{H}_{16}$ \\
\hline H/C Ratio & 2.1 & 1.9 & 1.6 \\
\hline $\begin{array}{c}\text { Critical Pressure } \\
\text { (MPa) }\end{array}$ & 2.1 & 2.3 & 3.7 \\
\hline $\begin{array}{c}\text { Critical Temperature } \\
(\mathbf{K})\end{array}$ & 672 & 683 & 698 \\
\hline \multicolumn{4}{|c|}{$\begin{array}{c}\text { Average Composition } \\
\text { (vol.\%) }\end{array}$} \\
\hline Aromatics & 0.1 & 18 & -- \\
\hline Cycloalkanes & 32 & 35 & 100 \\
\hline Alkanes & 65 & 45 & -- \\
\hline Alkenes & -- & 2 & -- \\
\hline
\end{tabular}

Endothermic fuels increase the heat sink capability of heavy hydrocarbon fuels by performing endothermic reactions on the hydrocarbon fuel. Dehydrogenation (C-H bond breaking) and cracking ( $\mathrm{C}-\mathrm{C}$ bond breaking) represent two endothermic fuel reactions that have potential for active cooling purposes.

Catalytic reforming of endothermic fuels has generated interest as a method to increase the heat sink capabilities of hydrocarbon fuels by selectively enhancing the rate of dehydrogenation and cracking. For example, the catalytic dehydrogenation of model naphthenic fuels, such as methylcyclohexane (MCH) into toluene and hydrogen, has been examined since the 1960s. Lander and Nixon calculated the full endothermic potential for the catalytic dehydrogenation of 
supercritical methylcyclohexane to be $457 \mathrm{~kJ} \mathrm{~mol}^{-1}$, over an order of magnitude greater than the cooling potential of JP-8 fuel systems [4]. However, the emphasis on catalytic dehydrogenation has decreased as the dehydrogenation of naphthenic molecules generates higher molecular weight products, which tend to have unfavorable ignition properties [9]. Lighter unsaturated gaseous hydrocarbons, such as ethylene and acetylene, have lower ignition energies than heavier liquid hydrocarbons, presented in Table 1-2.

Table 1-2. Minimum ignition energies of relevant hydrocarbons (Pressure, 0.1 MPa) [10,11].

\begin{tabular}{cc}
\hline Fuel & $\begin{array}{c}\text { Minimum ignition energy } \\
\left(\mathbf{1 0}^{-\mathbf{4}} \text { joules }\right)\end{array}$ \\
\hline Methane & 2.8 \\
Acetylene & 0.17 \\
Ethylene & 0.70 \\
Ethane & 2.6 \\
Propylene & 2.8 \\
Propane & 2.6 \\
n-Hexane & 2.9 \\
Cyclohexane & 2.2 \\
Benzene & 2.1 \\
Dodecane & 10 \\
JP-8 & 20 \\
\hline
\end{tabular}

Cracking of military fuels has been demonstrated to improve the ignition properties of the fuel. Nagley et al. [12] reported that a cracked JP-8 with a liquid to gas conversion ratio of $30 \%$ exhibited a $20 \%$ reduction in ignition time. Thus, the focus of this work will be on catalytic cracking rather than dehydrogenation of endothermic fuels. Critical properties of surrogate fuel molecules used in this study are listed in Table 1-3. 
Table 1-3. Critical properties of n-hexane, n-dodecane, isooctane, and isododecane [13].

\begin{tabular}{ccccc}
\hline & n-hexane & n-dodecane & isooctane & isododecane \\
\hline $\begin{array}{c}\text { Formula } \\
\text { Critical Pressure }\end{array}$ & $\mathrm{C}_{6} \mathrm{H}_{14}$ & $\mathrm{C}_{12} \mathrm{H}_{26}$ & $\mathrm{C}_{8} \mathrm{H}_{18}$ & $\mathrm{C}_{12} \mathrm{H}_{26}$ \\
$\begin{array}{c}\text { (MPa) } \\
\text { Critical Temperature } \\
(\mathbf{K})\end{array}$ & 3.0 & 1.8 & 2.6 & 1.9 \\
\hline
\end{tabular}

\subsection{Hydrocarbon Cracking Mechanism}

The catalytic cracking of hydrocarbons involves converting hydrocarbons into smaller hydrocarbons over solid acid catalysts at high temperature. It is one of the most important processes in the petroleum refining industry due to its flexibility in handling the variety of crude feedstocks that need to be refined. Catalytic cracking has become increasingly important as refineries deal with a growing diversity of feedstocks such as heavier crudes and lighter shale oil and gas. This flexibility is promising for endothermic fuels because hydrocarbon jet fuels can have dramatically different compositions, as presented in Table 1-1.

Catalytic cracking was introduced by Houdry in 1936 and was revolutionized by the fluid catalytic cracking (FCC) process in 1942 [14]. Since then, industrial and academic researchers have worked to develop a fundamental understanding of the process. While thermal and catalytic cracking both involve breaking of carbon-carbon bonds, there are key differences in the product distributions of the two processes [14]. First, the selectivities towards methane, ethane, and ethylene are significantly higher during thermal cracking compared to catalytic cracking. Second, rapid isomerization resulting in branched products and a higher selectivity towards propylene are seen during catalytic cracking. While thermal cracking proceeds via free radical intermediates, the difference in the product distribution suggests that the catalytic cracking occurs via a non-free 
radical mechanism. In the late 1940s, Greensfelder [15] and Thomas [16] independently proposed a carbenium ion mechanism that could explain several characteristics of catalytic cracking. For a more thorough and detailed history of the development of the hydrocarbon cracking mechanism, please consult the referenced reviews [17-22]. It is generally accepted today that catalytic cracking occurs over acid sites and involves the formation of carbocation transition states that are in equilibrium with covalently bonded surface alkoxy species, which can be regarded as intermediates $[23,24]$. Thus, an understanding of carbocations is crucial to the understanding of catalytic cracking.

Carbocations can be described as organic cations with the charge associated with a carbon atom [25]. Two key carbocations in catalytic cracking are carbenium and carbonium ions, pictured below in Figure 1-1.
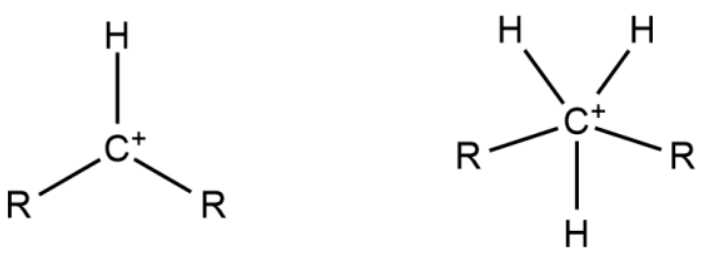

Figure 1-1. Carbenium (left) and carbonium (right) ions in catalytic cracking.

Carbonium ions are positively charged penta-coordinated carbon atoms. They are formed from a protolytic attack on saturated hydrocarbons at either the $\mathrm{C}-\mathrm{H}$ or $\mathrm{C}-\mathrm{C}$ bond [26-31]. Increasing the chain length of the hydrocarbon increases the number of possible $\mathrm{C}-\mathrm{H}$ or $\mathrm{C}-\mathrm{C}$ bonds that can interact with the catalyst [32]. However, cracking rates of alkanes increase non-linearly with carbon chain length, shown in Table 1-4 [33]. The driving force behind this phenomenon is discussed later in this chapter. 
For monomolecular cracking, Haag and Dessau proposed that an alkane is protonated by a Brønsted acid site to form a carbonium ion as a transition state, which then collapses to form a surface-bound carbenium ion and releases either an alkane or dihydrogen [34]. The pair of products formed depends on which bonds break as the carbonium ion collapses. However, results for monomolecular cracking exhibit very low selectivity toward dihydrogen [34]. This behavior was explained by Corma et al., who showed that structures leading to cracking (attack on the C-C bond) are more stable than those leading to the formation of dihydrogen (attack on the $\mathrm{C}-\mathrm{H}$ bond). In addition, the protonation of the $\mathrm{C}-\mathrm{C}$ bond between two secondary carbon atoms was approximately $50 \mathrm{~kJ} \mathrm{~mol}^{-1}$ more stable than protonation of a C-C bond involving a primary carbon atom [32,35]. The Haag-Dessau mechanism for cracking requires the protonation of the alkane by the catalyst for each turnover of the cycle. In contrast, the carbenium ion that is formed from this reaction can participate in a bimolecular catalytic cracking mechanism and this mechanism dominates as the concentration of carbenium ions increases.

Another method to form a carbenium ion is from the interaction of an alkene with a Brønsted acid site. Alkenes are very reactive in the cracking process and the relative reactivity of alkanes to alkenes is listed in Table 1-4. In addition, the cracking reactivity of alkenes increases dramatically with an increase in carbon chain length [36].

Table 1-4. Effect of chain length on the relative reactivity of alkenes to alkanes [36,37].

\begin{tabular}{ccccc}
\hline Cn of linear feed & $\mathbf{C}_{5}$ & $\mathbf{C}_{6}$ & $\mathbf{C}_{\mathbf{7}}$ & $\mathbf{C}_{\mathbf{8}}$ \\
\hline $\begin{array}{c}\text { Alkene Rate constant } \\
\left(\mathbf{s}^{-1}\right)\end{array}$ & 9.5 & 230 & 1820 & 5730 \\
$\begin{array}{c}\text { Alkane Rate Constant } \\
\left(\mathbf{s}^{-1}\right)\end{array}$ & 0.29 & $0.84-0.88$ & 1.49 & 2.25 \\
$\mathbf{R}$ (alkene)/R (alkane) & 32 & $260-275$ & 1220 & 2550 \\
\hline
\end{tabular}


A number of reactions can take place once a carbocation is formed. These reactions include charge isomerization, chain isomerization, hydride transfer, and formation and breaking of carboncarbon bonds. Charge isomerization and skeletal isomerization occur via intramolecular reactions. Charge isomerization of carbenium ions takes place by hydrogen transfer along the hydrocarbon chain and occurs rapidly to form the most stable carbocations. Skeletal isomerization can take place via methyl shifts to generate more highly branched carbenium ions (branching rearrangements) or lead to interconversions of isomers where the position of a tertiary carbon within the molecule is changed (non-branching rearrangement). The rate of branching rearrangements is usually about 1000 times smaller than that of hydrogen transfer along the hydrocarbon chain [17].

A key characteristic of catalytic cracking is the formation of branched products. The stability of carbenium ions plays a critical role in this process. The free energy of ion formation decreases with an increase in degree of substitution on the carbenium ion [38]. Calorimetric measurements have shown that the difference in stability between tertiary and secondary carbenium ions is about $54 \mathrm{~kJ} \mathrm{~mol}^{-1}$ and the difference in stability between secondary and primary carbenium ions is about $71 \mathrm{~kJ} \mathrm{~mol}^{-1}$ [31]. Brouwer and Oelderik [39] proposed that methyl shifts occur through protonated cyclopropane rings as an intermediate and avoid the formation of an unstable primary carbenium ion. Once the protonated cyclopropyl intermediate, shown in Figure $1-2$, is formed, any carbon-carbon bond in the ring can be broken. Non-branching rearrangements are believed to occur through the same protonated cyclopropyl intermediate, however branching arrangements have higher activation energies and require higher temperatures [35]. Thus, nonbranching rearrangements are much faster than branching arrangements. McCaulay reported that 
for n-hexane isomerization in the presence of a liquid superacid, non-branching rearrangements were $10^{4}-10^{5}$ times faster than branching rearrangements [40].

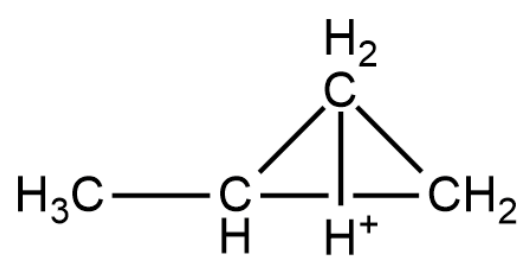

Figure 1-2. Protonated cyclopropyl intermediate during n-butane isomerization.

Another key reaction involving carbenium ions is hydride transfer. Hydride transfer, shown in Figure 1-3, is a bimolecular reaction that involves the abstraction of a hydride from another hydrocarbon molecule by the surface carbenium ion.<smiles>[R]CC=CC([R])C</smiles>

Figure 1-3. Hydride transfer of a carbenium ion with another alkane.

If the hydrocarbon molecule is an alkane, then the hydride transfer reaction results in the surface carbenium ion desorbing as an alkane and the formation of another carbenium ion that continues the reaction chain. As each carbenium ion can act as a chain propagator, bimolecular reactions dominate at conversions greater than a few percent. It has been shown that the hydride transfer reaction is very fast $[39,41]$ and that the rate of abstraction of a secondary hydrogen by a tertiary carbenium ion is roughly independent of chain length for normal alkanes [31]. The tertiarytertiary hydride transfer is even faster than the secondary-tertiary, which in turn is faster than the primary-secondary transfer [42]. This shows that hydride abstraction is accelerated by neighboring groups, which encourage the stabilization of the resultant ion [31]. 
In the bimolecular cracking mechanism, a carbenium ion undergoes a hydride transfer reaction with an alkane, forming another carbenium ion, which cracks by $\beta$-scission. $\beta$-scission is cleavage of the $\mathrm{C}-\mathrm{C}$ bond $\beta$ to the position of the carbon containing the charge. $\beta$-scission of a carbenium ion results in the formation of an alkene and another carbenium ion. This reaction, shown in Figure 1-4, can occur repeatedly along the hydrocarbon chain and results in the production of propylene, the other key characteristic of catalytic cracking.
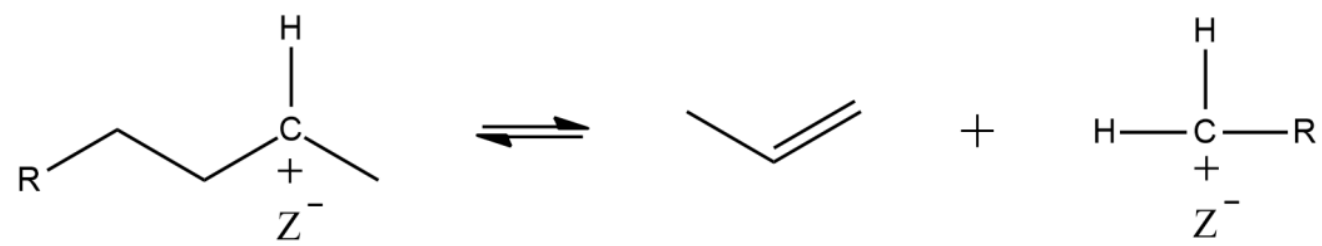

Figure 1-4. $\beta$-scission of a carbenium ion to form propylene and another carbenium ion.

The stability of the carbenium ion formed plays a crucial role in cracking because the formation of primary carbenium ions is not favored. A route that involves isomerization to produce branched species which then crack without producing a primary carbenium ion was proposed by Schulz and Weitkamp $[43,44]$. However, an argument against their theory is that isomerization would first produce a monobranched isomer. In this case, $\beta$-scission would result in a primary carbenium ion [45]. Sie proposed a new mechanism for acid-catalyzed cracking that directly linked cracking and isomerization via the same protonated cyclopropyl intermediates [45-47]. The new mechanism presents a path that avoids the formation of primary carbenium ions, explains the high selectivity towards branched products and propylene, and accounts for the low selectivity of $\mathrm{C}_{1}$ and $\mathrm{C}_{2}$ molecules. This mechanism also explains the increase in cracking reactivity with hydrocarbons with carbon numbers above 6 because the smallest alkane that can be cracked via this mechanism is $\mathrm{C}_{7}$ [48]. Highly branched alkanes also cannot be cracked via this mechanism and would require isomerization to a more suitable structure. 
Another form of bimolecular cracking is oligomerization cracking. The oligomerization cracking scheme involves the oligomerization of a carbenium ion with an alkene molecule followed by $\beta$-scission and hydride transfer [20]. This path explains the formation of products with carbon chains greater than the feed molecule. If $\beta$-scission and hydride transfer do not occur during the oligomerization cracking cycle, carbenium ions can undergo repeated addition reactions with unsaturated species and cyclization reactions to generate high molecular weight hydrocarbons on the surfaces of catalysts. These deposits can cover acid sites and plug the pores of the catalyst and result in a loss of catalyst activity. During FCC operation, the deactivated catalyst is fed to a regenerator where air is used to burn off the coke deposits and regenerate the catalyst. This process would not be feasible for endothermic fuels.

The key reactions detailed above all occur at different rates simultaneously in a complex reaction network. A simplified schematic of this reaction network is detailed in Figure 1-5.

Due to the complex nature of the hydrocarbon cracking mechanism, most of the fundamental work in catalytic cracking for petroleum refining has been done on pure shorter chain molecules at low conversions. These studies have quantified the intrinsic parameters of the monomolecular cracking reaction. Narbeshuber et al. [49] investigated the monomolecular conversion of propane to n-hexane over H-ZSM-5 between 723 and $823 \mathrm{~K}$. Extrapolated adsorption parameters were used to calculate an intrinsic activation energy for carbon-carbon bond cleavage, which was independent of hydrocarbon chain length and the position of the carboncarbon bond to be cleaved. These findings are shown in Table 1-5. Their findings were confirmed by Li et al. [50], who simultaneously measured surface coverages and monomolecular cracking rates to directly determine intrinsic cracking rates and activation energies. 


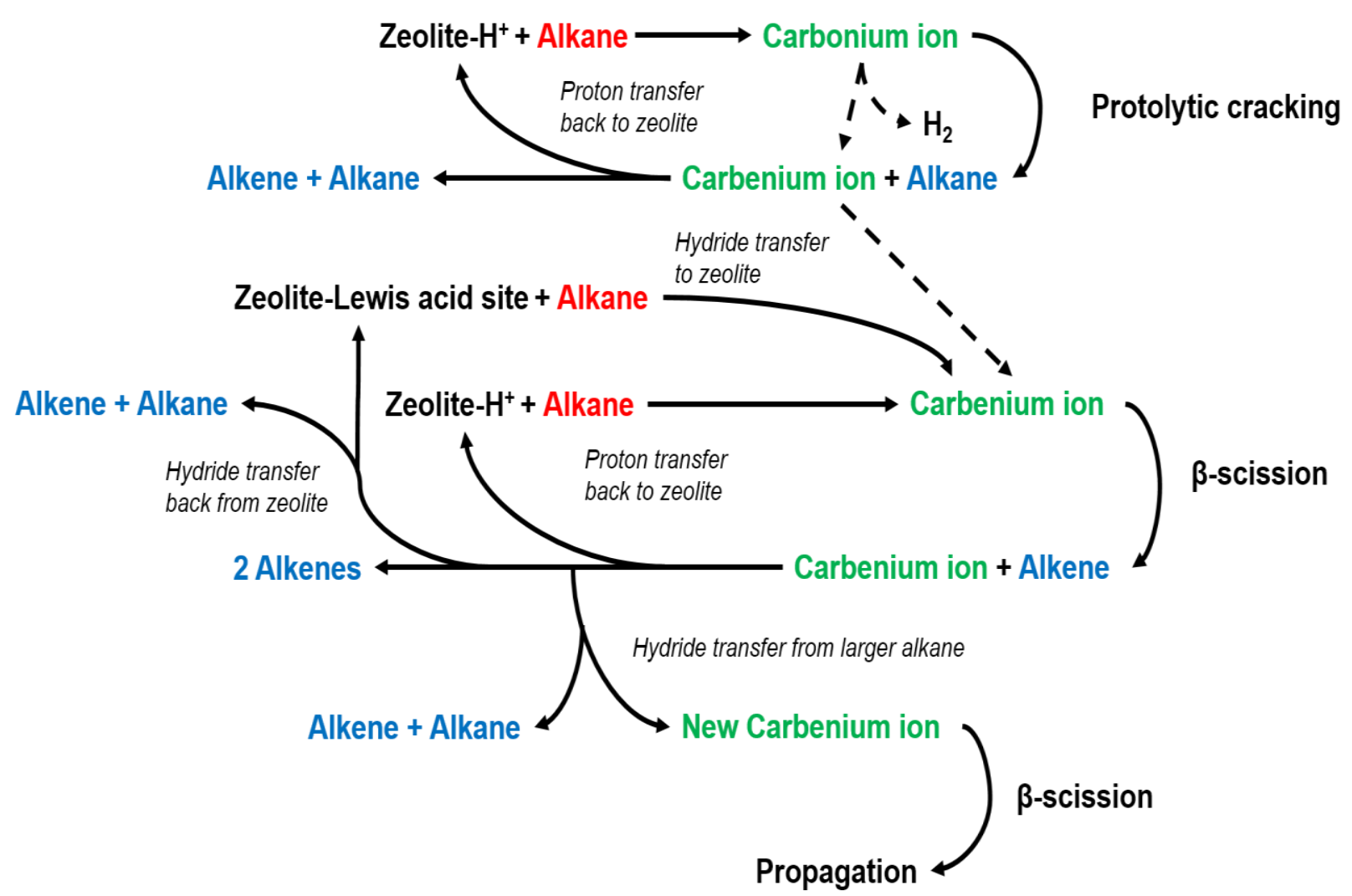

Figure 1-5. Simplified reaction network in zeolite-assisted cracking of hydrocarbon molecules. Adapted from Ref. [51].

Table 1-5. Heats of adsorption, apparent and intrinsic energies of activation for the cracking of n-alkanes over H-ZSM-5 at $773 \mathrm{~K}$ [49].

\begin{tabular}{cccc}
\hline Reactant & $\begin{array}{c}\text { Heat of Adsorption } \\
\text { kJ mol-1 }\end{array}$ & $\begin{array}{c}\mathbf{E}_{\mathbf{a}} \text { app } \\
\mathbf{k J ~ m o l}^{\mathbf{1}}\end{array}$ & $\begin{array}{c}\mathbf{E}_{\mathbf{a}} \text { int } \\
\mathbf{k J ~ m o l}^{\mathbf{1}}\end{array}$ \\
\hline Propane & 43 & 155 & 198 \\
n-Butane & 62 & 135 & 197 \\
n-Pentane & 74 & 120 & 194 \\
n-Hexane & 92 & 105 & 197 \\
\hline
\end{tabular}

Both monomolecular and bimolecular cracking paths occur simultaneously during typical operating conditions. Riekert and Zhou [52] studied the kinetics of cracking of n-hexane and ndecane over H-ZSM-5 and H-Y and developed a mathematical model for the relative contributions of the monomolecular and bimolecular cracking paths. At temperatures above $673 \mathrm{~K}$ and partial 
pressures below $2 \mathrm{kPa}$, reactions of $\mathrm{n}$-decane and n-hexane over $\mathrm{H}-\mathrm{ZSM}-5$ and $\mathrm{H}-\mathrm{Y}$ can be described by a first-order kinetic expression, indicating the absence of bimolecular processes under these conditions. This was attributed to the lower surface coverage of carbenium ions at higher temperatures. Dumesic and coworkers developed kinetic models for isobutane and 2methylhexane cracking over USY zeolite that accounted for carbenium ion initiation, $\beta$-scission, oligomerization, olefin desorption, isomerization, and hydride transfer reactions [53-55]. Their work also suggested that initiation reactions (monomolecular cracking) play a critical role in the high-temperature cracking of hydrocarbons. This was because the coverage of surface acid sites by adsorbed hydrocarbon species is very low at high temperatures and near-ambient pressures. It is clear that the surface coverage of hydrocarbon species is important for understanding hydrocarbon cracking paths, however, little is known about the surface coverage of hydrocarbon species under supercritical conditions.

\subsection{Hydrocarbon Cracking Catalysts}

\subsubsection{Amorphous Silica-Alumina Catalysts}

Acid catalysts are needed to produce the carbocations necessary for cracking reactions. Liquid acids are capable of producing carbocations but corrosion, separation of phases, and challenges with recovery of the catalyst make liquid or homogenous catalytic cracking impractical [56]. The first heterogenous cracking catalysts used by the petroleum refining industry were natural clays, but issues with catalyst stability and deactivation spurred development of alternative catalysts [57]. It was soon found that artificial clays, such as amorphous synthetic combinations of silica and alumina (silica-alumina), silica-magnesia, and silica-zirconia had higher activity and 
better product distribution than natural clays. Of these combinations, silica-alumina showed the highest activity for catalytic cracking [58].

There are several different methods for the preparation of amorphous silica-alumina (ASA) cracking catalysts [59-61]. One of the more common preparation methods involves the combination of a silica hydrogel with an aluminum sulfate solution, followed by the hydrolysis and precipitation of the aluminum salt by the addition of aqueous ammonia. The mixture is then washed, dried, and calcined. There are many variables during synthesis that can affect the characteristics of the catalyst. For example, changing the reagent concentrations by operating with excess silica at low $\mathrm{pH}$ will favor the formation of Al-O-Si bonds [62]. However, a balance is required as low $\mathrm{pH}$ values result in the formation of a low-surface-area material [63].

The pore-size distribution of the ASA catalyst has great influence on its activity. An important factor that can affect the pore-size distribution of the catalyst is the aging time of the gel [63]. Another method to control the pore size of ASA catalysts is by employing bulky tetraalkylammonium ions as the counterions to the aluminate ions in the gel [64]. An example of this method is the use of cetyltrimethylammonium as a structure directing agent to synthesize the ordered mesoporous amorphous silica alumina catalyst known as Al-MCM-41 [65].

The structure and surface characteristics of ASA catalysts affect the activity of the catalyst. Amorphous silica-alumina catalysts have no defined long-range structure and thus appear amorphous to X-ray crystallography. The structure consists of a random three-dimensional network of interconnected silica and alumina tetrahedral. The bulk and surface composition of ASA can vary depending on the synthesis. Plank and Drake reported that the bulk of the aluminum for their ASA samples was present on the surface $[63,66]$, however, other reports suggest a more uniform distribution $[67,68]$. 
The origin of acidity in ASA catalysts is complicated, as acid sites on ASA can vary in acid strength, steric surroundings, and other properties. The wide distribution of acid strength suggests that multiple types of acid sites are present, but the range of pore sizes and chemical composition can make it difficult to identify acid sites during reaction [60,69-71]. However, it is well accepted that the presence of aluminum atoms in the silica network on the surface of ASA catalysts results in Brønsted acid sites. Acid sites are formed when an aluminum atom substitutes for a silicon atom in the tetrahedral structure via oxygen bridges which results in a negative charge that is compensated by $\mathrm{H}^{+}$, shown in Figure 1-6. These Brønsted acid sites are similar in strength to those in zeolites $[69,72]$, but the number of these strong acid sites is very low $\left(<10 \mu \mathrm{mol} \mathrm{g} \mathrm{g}^{-1}\right)$. The surface also contains a weaker form of Brønsted acid site at a typical density of 50-150 $\mu \mathrm{mol} \mathrm{g}^{-1}$. The structure of these sites is still under debate, but it is hypothesized that they involve the interaction of strong Lewis acid sites with silanol groups [60], shown in Figure 1-7.

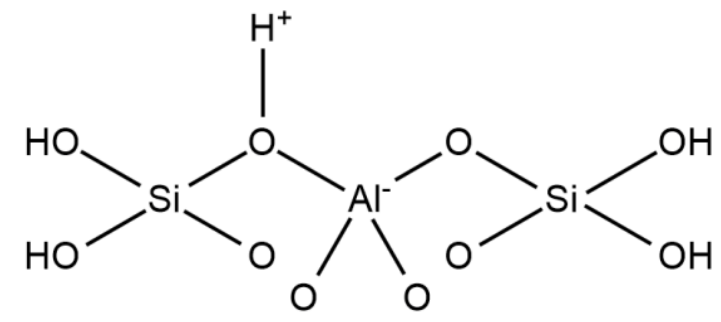

Figure 1-6. Structure of a Brønsted acid site on aluminosilicate catalysts [68].<smiles>O[Si](O)(O)O[IH+]</smiles><smiles></smiles>

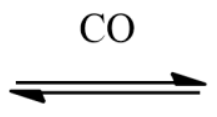<smiles>O=C(CO[Si]([O-])(O)O)[Al](O)(O)O[Si](O)(O)O</smiles>

Figure 1-7. Proposed interaction of silanol groups with $\mathrm{Al}^{3+}$ sites on silica alumina [60]. 


\subsubsection{Crystalline Aluminosilicate (Zeolite) Catalysts}

The introduction of zeolite catalysts in the early 1960s represented a major milestone in the history of catalytic cracking. Zeolites are crystalline, microporous frameworks consisting of a network of silica $\left(\mathrm{SiO}_{4}\right)$ and alumina $\left(\mathrm{AlO}_{4}\right)$ tetrahedral that are linked by shared oxygen atoms. The presence of aluminum atoms in tetrahedral configurations causes a negative charge to appear on each aluminum atom and the charge compensating protons are the actives sites on the catalyst. There are over 40 natural occurring zeolites and more than 150 synthetic zeolites with various channel configurations, pore diameters, and ring configurations [73]. A comparison of the structure and pore diameter of some common zeolites is shown in Figure 1-8 [74]. This work focuses on the use of Y Faujasite and ZSM-5.

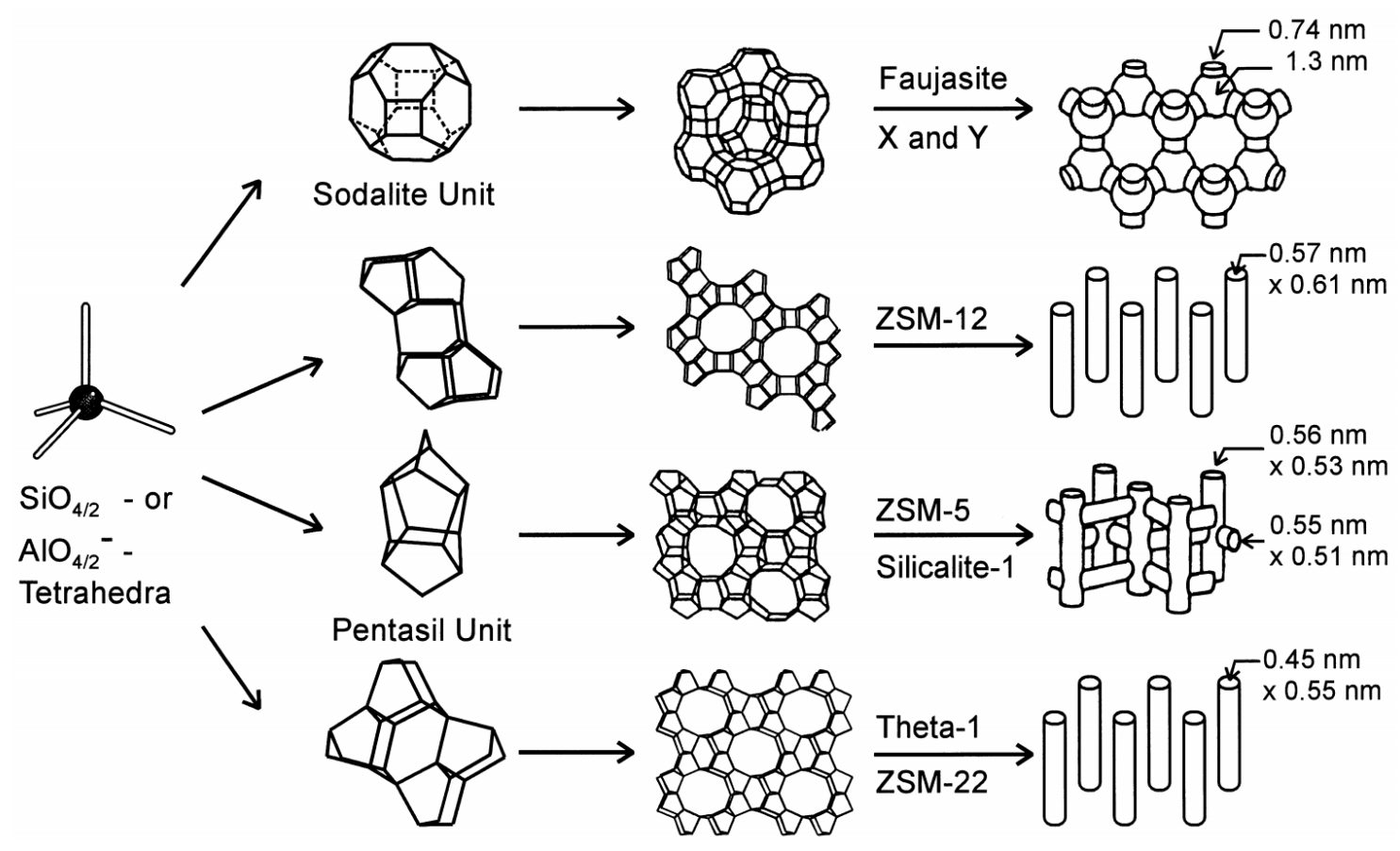

Figure 1-8. Comparison of structure and pore diameter of various zeolites. Reproduced from Ref. [74]. 
The faujasite structure is composed of silica and alumina tetrahedra which are located at the vertices of a truncated octahedron. The octahedron is known as a sodalite cage and four sodalite cages are arranged in a tetrahedral configuration around a fifth sodalite cage. The five sodalite cages are joined together by hexagonal prisms and are the building blocks of faujasite zeolites. The openings of the cage are $0.74 \mathrm{~nm}$ in diameter and the inside of the cage is $1.2 \mathrm{~nm}$ in diameter [75].

The framework of ZSM-5 differs from that of faujasite zeolite. First, the building blocks of ZSM-5 consist of eight five-membered rings known as a pentasil unit. These rings join together and form chains, which are connected to form sheets, and linked together to develop a threedimensional framework structure. Second, two intersecting channel systems run through the framework of ZSM-5. One channel system is sinusoidal and runs parallel to the [001]-face of the ZSM-5 unit cell. The dimensions of this channel are approximately $0.55 \mathrm{~nm} \times 0.51 \mathrm{~nm}$. The other channel system is straight and runs parallel to the [010]-face of the ZSM-5 unit and has dimensions of approximately $0.56 \times 0.53 \mathrm{~nm}$ [76]. The different structures of the two channel system can lead to differences in adsorption and diffusion behavior of hydrocarbons depending on chain length and degree of branching [77-80]. For example, while linear alkanes are free to move in both channel systems, branched alkanes are trapped within the intersection of the zig-zag and straight channels of the zeolite [79].

The synthesis of zeolites has been well documented in patents, publications, and reviews [81-85]. The general procedure involves the preparation of alumino-silicate gels from aqueous solutions of sodium aluminate, sodium silicate, and sodium hydroxide. The gels are then crystallized at temperatures ranging from 333-523 $\mathrm{K}$ at atmospheric pressure. In the case of ZSM5, a templating agent such as tetrapropylamine bromide can be can be used $[86,87]$. After the 
crystallization process is complete, the sodium ions can be readily exchanged by other cations. The protonic form is prepared in an indirect way because the framework of the zeolite is sensitive to low-pH solutions. At low $\mathrm{pH}$, the aluminum ions are removed from the crystalline framework and the structure collapses, leaving an amorphous material [88]. Therefore, the sodium ions are first exchanged by $\mathrm{NH}_{4}{ }^{+}$ions, which are then decomposed by calcination at $773 \mathrm{~K}$, leaving behind protons in place of the original sodium. These protons are Brønsted acid sites and stabilize a charge imbalance that is generated when silicon with a formal valence of four, is replaced with aluminum with a formal valence of three. This structure was shown previously in Figure 1-6. In general, the amount of Brønsted acid sites in a zeolite can be adjusted by changing the $\mathrm{Si} / \mathrm{Al}$ ratio within the framework. Factors such as inaccessible $\mathrm{Al}$ atoms, the presence of cations other than protons as charge-balancing cations, or extra-framework aluminum can lower the number of acid sites compared to the framework aluminum concentration [89].

Although the origin of Brønsted acid sites on ASA and zeolites is similar, rates for numerous reactions are greater over zeolites than over ASA [90-92]. For example, Corma et al. reported that n-heptane cracking rates over an ultra-stable version of Y zeolite (USY) were an order of magnitude greater than over an ASA catalyst [90]. This difference in activity is partly due to the greater strength of acid sites on zeolites [60]. However, reaction rates can vary greatly depending on the zeolite framework, even though acid sites on different zeolites are similar in acid strength. Differences in activity among zeolites are due to the microporous environment surrounding the acid sites. The pore sizes of zeolites are on the order of molecular diameters and can control the diffusion of reactants and products. In addition, the internal cages surrounding zeolite acid sites can stabilize certain transition states while excluding others [37,93-97]. The difference in activity and selectivity of various zeolites is a result of different zeolite frameworks 
and the extent to which they can solvate substrates and transition states through van der Waals interactions [97].

The thermal stability of the catalyst is important for endothermic fuel applications due to the high temperatures that are expected during operation. The thermal stability of aluminosilicate cracking catalysts has been well-investigated because typical commercial cracking reactors operate between 773 and $873 \mathrm{~K}$ [98]. Investigations of the physical changes to the structure of aluminosilicate catalysts that occur as a result of anhydrous heat treatment have demonstrated the stability of these materials. Calcining of ASA at temperatures up to $1073 \mathrm{~K}$ results in only a small decrease in pore volume and surface area [99]. Zeolites are more resistant to heat and structural collapse does not occur in zeolites until temperatures as high as $1373 \mathrm{~K}$ are reached [100]. However, both catalysts are much less resistant to physical changes if the heat treatment is carried out in the presence of steam. Heat treatment of ASA in the presence of steam at temperatures as low as $873 \mathrm{~K}$ resulted in a loss of surface area leading eventually to a fused, nonporous, essentially inactive material [101]. Similarly, high temperature steaming of zeolites causes total structural collapse [102]. Overall, aluminosilicate catalysts have been proven to be highly active, thermally stable cracking catalysts and are suitable catalysts for endothermic fuel applications. 


\section{Hydrocarbon Cracking Over Aluminosilicate Catalysts}

This chapter is derived from a manuscript being prepared for publication and is co-authored by Drs. Peng Bai and Matthew Neurock of the University of Minnesota. The density functional theory calculations and molecular simulations described in this chapter were performed by Dr. Peng Bai.

\subsection{Introduction}

Advanced high supersonic (Mach 3-5) and hypersonic (Mach > 5) vehicles have received considerable attention for their potential to rapidly deliver payloads, to dramatically reduce aircraft travel time, and to provide affordable access to space. A major complication in the development and implementation of such vehicles involves thermal management issues that arise at high supersonic and hypersonic speeds. Much research and development has therefore been focused on using the fuel as the primary coolant by circulating it behind the walls of various aircraft components prior to injection to the combustion chamber $[4,6,7,103-105]$.

The use of so-called endothermic fuels represents one method to increase the heat sink capability of heavy hydrocarbons. Endothermic fuels incorporate both the physical heat sink capacity from the sensible enthalpy of the hydrocarbon and the chemical heat sink capacity from undergoing endothermic decomposition into smaller hydrocarbon products that can also be combusted. The fuel lines in these advanced aircraft operate at high pressure (3.4-6.9 MPa) and high temperature (above $673 \mathrm{~K}$ ), resulting in supercritical conditions for most heavy hydrocarbon fuels [106]. Under these conditions, heavy hydrocarbon fuels proceed to decompose via thermal cracking or pyrolysis and numerous studies have investigated the pyrolysis reactions of different types of fuels under relevant conditions [107-111]. These studies have revealed significant disadvantages of pyrolysis for endothermic cooling. First, a specific conversion (e.g., $60 \%$ for n- 
hexadecane) must be maintained to maximize the chemical heat sink because the product distribution of pyrolysis varies with temperature and cannot be controlled [4]. Second, high operating temperatures are required to reach a significant conversion because of the low thermal cracking rate (e.g., $3.2 \times 10^{-4} \mathrm{~s}^{-1}$ at $723 \mathrm{~K}$ for $\mathrm{n}$-dodecane) and high apparent activation energy (e.g., $259 \mathrm{~kJ} \mathrm{~mol}^{-1}$ for $n$-dodecane) [109].

Catalytic cracking of hydrocarbon fuels presents a possible solution to the problems with pyrolysis. Acid-catalyzed cracking of hydrocarbons has been well studied under conditions relevant for the petroleum industry, but fewer studies exist under the supercritical conditions relevant for endothermic fuel cracking. Several groups have demonstrated that the catalytic cracking of heavy hydrocarbon fuels over zeolite catalysts under supercritical conditions can provide substantial heat sink capacity compared to thermal cracking $[7,104,105,112,113]$.

Recent work by Luo et al. [114,115] investigated the effect of pressure on the reaction mechanism and intrinsic cracking rates of n-hexane over H-ZSM-5 and large pore zeolites. They determined that for a wide range of pressures and temperatures, rates for catalytic cracking of nhexane in H-ZSM-5 could be described by a single rate expression that accounts for the concentration of n-hexane within the pores. However, it was unclear why the intrinsic rate constant and rate expression did not change even though the observed distribution of cracked products shifted from that typical of monomolecular to one consistent with bimolecular cracking. Moreover, reactions of n-hexane over large pore zeolites produced primarily isomerization products and did not follow the simple Langmuir-Hinshelwood rate expression found with H-ZSM-5. Schreiner et al. [116] investigated the effects of temperature, pressure and weight hourly space velocity (WHSV) on the conversion of n-pentane over H-ZSM-5 and reported that conversion was dominated by bimolecular reactions under all reaction conditions investigated. They observed a 
decrease in activation energy (from 122 to $86 \mathrm{~kJ} \mathrm{~mol}^{-1}$ ) with increasing pressure (1 to $4 \mathrm{MPa}$ ) and concluded that although pentane and hexane conversion over H-ZSM-5 have similar trends in product selectivity with changing pressure, the differences in apparent activation energy suggest the conversion occurs via different reaction paths.

In this work, the effects of both hydrocarbon chain length and catalyst structure on the conversion of n-hexane and n-dodecane were investigated. The solid acid zeolites H-ZSM-5 and H-Y were chosen because they are conventional catalysts for industrial fluidized catalytic cracking units [117]. The mesoporous aluminosilicate Al-MCM-41 was selected to investigate the potential benefits of a mesoporous framework under supercritical conditions [118-121]. Dodecane was chosen because kerosene-based military jet fuels, such as JP-7 and JP-8, are primarily composed of hydrocarbons with between 6 and 16 carbon atoms per molecule [122]. Therefore, it is important to understand the effect of the hydrocarbon chain length on cracking rates and reaction mechanism. It was found that while n-hexane reactions over H-Y and Al-MCM-41 resulted in mainly isomerization, $\mathrm{n}$-dodecane reactions over the same catalysts resulted in cracking with an activation energy consistent with that of $\mathrm{C}-\mathrm{C}$ bond cleavage.

\subsection{Methods}

\subsubsection{Materials}

n-Hexane (Sigma-Aldrich, $\geq 99 \%$ purity) and n-dodecane (Sigma-Aldrich, $\geq 99 \%$ purity) were used as the feed. n-Tridecane (Sigma-Aldrich, 99\% purity anhydrous) was added as an external standard during gas chromatography (GC) analysis. n-Propylamine (Sigma-Aldrich, $\geq$ 99.0\% purity) was used for the temperature-programmed desorption/mass spectrometry (TGA- 
MS) analysis to determine the Brønsted-acid site density for the catalysts. The following gases were used for calcination, TGA-MS and GC operation: dry air (GTS-Welco), helium (GTS-Welco, 99.999\%), dihydrogen (GTS-Welco, 99.999\%), dinitrogen (GTS-Welco, 99.999\%) and propylene (GTS-Welco, PY60).

The $\mathrm{NH}_{4}$-ZSM-5 (45881) and H-Y (45872) zeolites were purchased from Alfa Aesar. The Al-MCM-41 (643653) was purchased from Sigma-Aldrich. To test for background conversion, a pure $\mathrm{ZrO}_{2}$ sample was synthesized in the lab. Amorphous $\mathrm{ZrO}_{\mathrm{x}}(\mathrm{OH})_{4-2 \mathrm{x}}$ (MEL Chemicals, $\mathrm{XZO1501/09)}$ was calcined to $\mathrm{ZrO}_{2}$ in dry air $\left(100 \mathrm{~cm}^{3} \mathrm{~min}^{-1}\right)$ at $973 \mathrm{~K}$ at $10 \mathrm{~K} \mathrm{~min}^{-1}$, holding for $4 \mathrm{~h}$ before being pressed and sized using $-40 /+100(150-425 \mu \mathrm{m})$ sieves trays.

\subsubsection{Catalyst characterization}

The aluminosilicate catalysts used in this study were loaded into a quartz reactor and pretreated in $100 \mathrm{~cm}^{3} \min ^{-1}$ of $21 \% \mathrm{O}_{2}$ and balance He after heating to $823 \mathrm{~K} \mathrm{at} 5 \mathrm{~K} \mathrm{~min}^{-1}$ and holding for $2 \mathrm{~h}$. After the pretreatment, the catalysts were exposed to n-propylamine at $448 \mathrm{~K}$ for $15 \mathrm{~min}$ by passing $\mathrm{He}\left(30 \mathrm{~cm}^{3} \mathrm{~min}^{-1}\right)$ through an $\mathrm{n}$-propylamine saturator that was held in an ice bath. The catalyst sample was then purged at $448 \mathrm{~K}$ for $2 \mathrm{~h}$ under flowing $\mathrm{He}\left(100 \mathrm{~cm}^{3} \mathrm{~min}^{-1}\right)$ to remove excess n-propylamine. The catalyst sample was then heated to $873 \mathrm{~K}$ at $20 \mathrm{~K} \mathrm{~min}^{-1}$ under flowing He $\left(100 \mathrm{~cm}^{3} \mathrm{~min}^{-1}\right)$ and the mass spectrometer (MS) was used to track unreacted amine $(\mathrm{m} / \mathrm{e}=30)$, propylene $(\mathrm{m} / \mathrm{e}=41)$ and ammonia $(\mathrm{m} / \mathrm{e}=30)$. Previous work has shown that the Brønsted-acid site density can be quantified from the amount of amine that reacts between 650 and $725 \mathrm{~K}$ [89,123-125]. A known amount of propylene was introduced to the system using a six-way valve after each n-propylamine decomposition experiment to calibrate the propylene MS signal. 
Pore size distributions, calculated using the Barrett, Joyner and Halenda (BJH) method [126], were obtained by $\mathrm{N}_{2}$ adsorption measured at $77 \mathrm{~K}$ using a Micromeritics ASAP 2020 automated analyzer.

\subsubsection{Catalytic tests}

Hydrocarbon conversion reactions were carried out in an upward-flow fixed bed reactor under supercritical conditions. Catalysts were pressed and sized using -40/+100 (150-425 $\mu \mathrm{m})$ sieve trays. A titanium reactor (Grade 2 titanium from McMaster-Carr) with an outer diameter of $6.35 \mathrm{~mm}$ and an inner diameter (ID) of $4 \mathrm{~mm}$ was used to hold the catalyst that was supported between two glass wool plugs. Catalysts were heated in situ in flowing dry air $\left(100 \mathrm{~cm}^{3} \mathrm{~min}^{-1}\right)$ at $5 \mathrm{~K} \mathrm{~min}^{-1}$ to $823 \mathrm{~K}$ and holding at that temperature for $2 \mathrm{~h}$. Liquid hydrocarbon was fed to the reactor using a Teledyne Isco 260D high pressure syringe pump. A gas-liquid separator was used to collect liquid product between sampling intervals. Dinitrogen was used to purge the gas-liquid separator and to maintain the pressure in the system, which was controlled by a back-pressure regulator. The dinitrogen purge along with the gas-phase products were fed to a gas chromatograph (Shimadzu GC-2014) equipped with a flame ionization detector (FID). A Restek RT-QS-BOND ( $30 \mathrm{~m}, 0.53 \mathrm{~mm}$ ID, $20 \mu \mathrm{m}$ film thickness) column was used to separate the products. n-Tridecane (Sigma-Aldrich, 99\% purity anhydrous) was added to the liquid products as an external standard. The liquid products were injected into the GC using an AOC-20i auto sampler.

The peak areas of reactants and products identified by GC were used to determine the hydrocarbon feed conversion and selectivity of products. The conversion of hydrocarbon feed was calculated according to and defined as follows: 
Conversion $(\mathrm{C} \%)=\left(\frac{\sum n_{i} M_{i}}{x}\right) \times 100$

where $n_{i}$ is the number of carbon atoms in product $i, M_{i}$ is the molar ratio of product $i$ detected to the initial moles of hydrocarbon feed and $x$ represents the number of carbon atoms in the hydrocarbon feed.

The selectivity toward product $i$ was calculated on a molar basis and defined as follows:

$$
\text { Molar Selectivity }(\%)=\left(\frac{M_{i}}{\sum M_{i}}\right) \times 100
$$

The catalyst loading in the reactor depended on the activity of the particular catalyst and the mass was diluted with a corresponding amount of $\mathrm{ZrO}_{2}$ to keep the length of the catalyst bed constant at $5 \mathrm{~cm}$. The catalyst loading was varied to keep the overall conversion below $10 \%$ to ensure differential reactor conditions. Reactions with only a bed of $\mathrm{ZrO}_{2}$ were also run for all conditions used in this work to determine the amount of background conversion from pyrolysis. The hydrocarbon liquid feed rate was varied from $0.3 \mathrm{~cm}^{3} \mathrm{~min}^{-1}$ to $2.4 \mathrm{~cm}^{3} \mathrm{~min}^{-1}$, depending on the reaction temperature, to keep the background conversion below $0.5 \%$ at all times. The only exceptions to this were the high temperature experiments at $748 \mathrm{~K}$, where the background conversion was approximately $3 \%$ and the total conversion exceeded 10\%; however, the measurements at high temperature were not used to determine activation energies. Measurements used to determine activation energies were determined at the same hydrocarbon feed rate to hold the weight hourly space velocity (WHSV) constant, since it has been shown that WHSV can have an effect on product selectivity [116]. Rate is reported in terms of turnover frequency (TOF), which is calculated as the rate of hydrocarbon feed conversion normalized to the acid-site density reported in Table 2-1. 


\subsubsection{Theoretical calculations}

Periodic density-functional theory (DFT) calculations were performed using the Vienna Ab initio Simulation Package version 5.4.1 [127] with the PBE exchange-correlation functional [128]. The valence electron density was expanded using plane waves with a kinetic energy cutoff of $400 \mathrm{eV}$, while the core electrons were treated by the projected-augmented wave method [127]. Sampling of the unit cell was done at the $\Gamma$-point. To capture non-specific dispersive interactions, the Grimme-type D2 corrections were added to both energies and forces [129]. Structure optimizations were converged to below a force threshold of $0.05 \mathrm{eV} / \AA$, and transition states were first identified using the nudged-elastic band method [130] and subsequently refined using the dimer method [131]. All reactions were carried out in H-ZSM-5 with a single acid site per unit cell, with Al replacing Si at a T12 site.

Configurational-bias Monte Carlo simulations [80] in the grand-canonical ensemble (CBGCMC) were used to compute the amount of adsorption over a range of pressures, $p=10^{3}-10^{8}$ Pa. Separate calculations in the isobaric-isothermal ensemble were used to convert pressures to chemical potentials for use in the CB-GCMC simulations. To model the zeolite and alkanes, we used the transferable potentials for phase equilibria (TraPPE) force fields [132-134]. All sorbatesorbate interactions were evaluated explicitly to a cut-off distance of $1.4 \mathrm{~nm}$, and the long-range contributions were estimated via tail corrections [135]. The zeolite framework is treated as allsilica form and assumed to be rigid during the simulations, while sorbate molecules sample angle bending and dihedral motions. 


\subsection{Results}

\subsubsection{Catalyst characterization}

Table 2-1 summarizes the physico-chemical properties of the aluminosilicate samples used in this study. Previous work has demonstrated that the Brønsted-acid site density for H-ZSM-5 is approximately equal to the framework Al density [123], and the good agreement between the Brønsted-acid site density for H-ZSM-5 $\left(550 \mu \mathrm{mol} \mathrm{g}^{-1}\right)$ and the Al concentration of the sample used here $\left(600 \mu \mathrm{mol} \mathrm{Al} \mathrm{g}{ }^{-1}\right)$ validates the propylamine decomposition method for evaluating the other materials, which can have site densities lower than the $\mathrm{Al}$ content [136].

Table 2-1. Properties of aluminosilicate catalysts.

\begin{tabular}{|c|c|c|c|}
\hline Catalyst & $\begin{array}{c}\text { Pore Size } \\
(\AA)\end{array}$ & Si/Al Ratio $^{a}$ & $\begin{array}{l}\text { Brønsted-site } \\
\text { Density }^{\mathbf{b}} \\
\left(\mu \mathrm{mol} \cdot \mathrm{g}^{-1}\right)\end{array}$ \\
\hline H-ZSM-5 & $\sim 5.5^{\mathrm{c}}$ & $55: 1$ & 550 \\
\hline H-Y & $7.4^{\mathrm{c}}$ & $85: 1$ & 162 \\
\hline Al-MCM-41 & $27^{\mathrm{d}}$ & $39: 1$ & 83 \\
\hline
\end{tabular}

a. Based on manufacturer data

b. Brønsted acid site concentrations were determined by $n$-propylamine decomposition

c. Pore size from the Atlas of Zeolite Framework Types [137]

d. Pore size was determined by $\mathrm{N}_{2}$ adsorption measurements using the $\mathrm{BJH}$ method

\subsubsection{Catalytic conversion of $n$-hexane}

Conversion of n-hexane over H-ZSM-5 and H-Y was performed under supercritical conditions. The transient performance of the two samples is demonstrated in Figure 2-1. A mild deactivation of the catalyst was observed over H-ZSM-5 at $588 \mathrm{~K}$ after 40 minutes whereas a faster 
rate of deactivation was seen over $\mathrm{H}-\mathrm{Y}$ at $673 \mathrm{~K}$. Therefore, conversion and selectivity results were calculated from the initial product measurements collected at a time on stream (TOS) of 10 minutes.

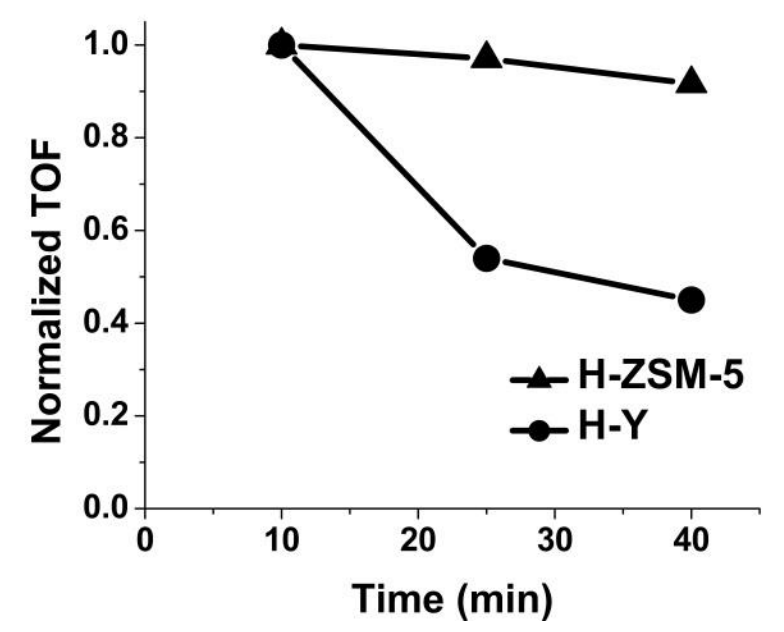

Figure 2-1. Normalized TOF of n-hexane conversion versus time on stream over H-ZSM-5 at $588 \mathrm{~K}(\boldsymbol{\Delta})$ and $\mathrm{H}-\mathrm{Y}$ at $673 \mathrm{~K}(\boldsymbol{O})$, both at $6 \mathrm{MPa}$.

The TOFs for n-hexane conversion as a function of pressure (4 to $6 \mathrm{MPa}$ ) over H-ZSM-5 and $\mathrm{H}-\mathrm{Y}$ are reported in Table A-5. The invariance of TOF over the pressure range studied indicated that the reaction was zero-order in hydrocarbon at the supercritical conditions used here. A summary of the rate and product distribution obtained from H-ZSM-5 at $588 \mathrm{~K}$ and $\mathrm{H}-\mathrm{Y}$ at 673 $\mathrm{K}$ is shown in Table 2-2. The zeolite structure has a dramatic effect on the product distribution from n-hexane conversion. The major products of the reaction over H-ZSM-5 were $\mathrm{C}_{4}$ and $\mathrm{C}_{5}$ species, with almost negligible amounts of methane, ethane and ethylene. In addition, there was significant isomerization of n-hexane to 2- and 3-methylpentanes and some formation of products with carbon chains greater than 6 . The major reaction over $\mathrm{H}-\mathrm{Y}$ was isomerization of $\mathrm{n}$-hexane to 2- and 3-methylpentanes and 2,3-dimethylbutane, with low selectivity to cracking products. Finally, H-ZSM-5 was a much more active catalyst for n-hexane conversion than H-Y, as 
evidenced by the difference in the TOF, even at a reaction temperature that was $85 \mathrm{~K}$ lower. Results for n-hexane conversion over Al-MCM-41 can be found in Table A-4 and show a similar product distribution to that of n-hexane conversion over $\mathrm{H}-\mathrm{Y}$, but the TOF is substantially lower over AlMCM-41.

Table 2-2. Reaction of n-hexane over H-ZSM5 and $\mathrm{H}-\mathrm{Y}$ at $6 \mathrm{MPa}$.

\begin{tabular}{ccc}
\hline Catalyst & H-ZSM-5 & H-Y \\
\hline $\begin{array}{c}\text { Temperature } \\
(\mathbf{K})\end{array}$ & 588 & 673 \\
$\begin{array}{c}\text { Conversion } \\
(\boldsymbol{\%})\end{array}$ & 2.8 & 3.5 \\
TOF & & \\
$\left(\mathbf{s}^{\mathbf{- 1}}\right)$ & 0.24 & 0.08 \\
\hline \multicolumn{2}{c}{ Molar Selectivity (\%) } \\
\hline$\leq \mathbf{C}_{\mathbf{2}}$ & 0.1 & 0.2 \\
$\mathbf{C}_{\mathbf{3}}$ & 11 & 6.9 \\
$\mathbf{i} \mathbf{C}_{\mathbf{4}}$ & 11 & 4.8 \\
$\mathbf{C}_{\mathbf{4}}$ & 20 & 3.8 \\
$\mathbf{C}_{\mathbf{5}}$ & 29 & 11 \\
$\mathbf{i \mathbf { C } _ { 6 }}$ & 16 & 70 \\
$\geq \mathbf{C}_{\mathbf{7}}$ & 13 & 3.1 \\
\hline
\end{tabular}

\subsubsection{Catalytic conversion of n-dodecane}

Conversion of n-dodecane over H-ZSM-5, H-Y and Al-MCM-41 was performed at $6 \mathrm{MPa}$ to determine the effect of hydrocarbon chain length. The H-ZSM-5 catalyst was much more active for n-dodecane cracking than $\mathrm{H}-\mathrm{Y}$ and Al-MCM-41. A clear change in product selectivity over the larger pore materials was observed as the feed molecule was changed from n-hexane to ndodecane. As discussed earlier, isomerization of n-hexane to methylpentanes and 2,3dimethylbutane was observed over $\mathrm{H}-\mathrm{Y}$ and $\mathrm{Al}-\mathrm{MCM}-41$. Isomerization of $\mathrm{n}$-dodecane was 
negligible over any of the tested catalysts, but separation of structurally similar isomers may not be completely resolved by GC. The product distribution over H-Y and Al-MCM-41 was similar to that of H-ZSM-5, with the major products being $\mathrm{C}_{4}, \mathrm{C}_{5}$ and $\mathrm{C}_{6}$ molecules. The production of methane, ethane and ethylene was very low, especially over H-ZSM-5 at $588 \mathrm{~K}$. Negligible formation of products with carbon chains longer than 12 was seen at conversions lower than $10 \%$.

Table 2-3. Reaction of n-dodecane over H-ZSM-5, H-Y and AlMCM-41 at 6 MPa.

\begin{tabular}{|c|c|c|c|c|}
\hline Catalyst & \multicolumn{2}{|c|}{ H-ZSM-5 } & H-Y & Al-MCM-41 \\
\hline $\begin{array}{l}\text { Temperature } \\
\text { (K) }\end{array}$ & 588 & 698 & 693 & 683 \\
\hline $\begin{array}{c}\text { Conversion } \\
(\%)\end{array}$ & 5.4 & 8.1 & 5.4 & 5.6 \\
\hline $\begin{array}{c}\text { TOF } \\
\left(\mathbf{s}^{-1}\right)\end{array}$ & 0.44 & 1.4 & 0.44 & 0.19 \\
\hline \multicolumn{5}{|c|}{ Molar Selectivity (\%) } \\
\hline$\leq \mathrm{C}_{2}$ & trace & 0.2 & 0.2 & 0.3 \\
\hline $\mathbf{C}_{3}$ & 6.0 & 7.7 & 6.3 & 8.6 \\
\hline $\mathrm{iC}_{4}$ & 4.2 & 5.7 & 13 & 9.2 \\
\hline $\mathrm{C}_{4}$ & 16 & 18 & 9.6 & 16 \\
\hline $\mathrm{C}_{5}$ & 24 & 25 & 23 & 25 \\
\hline $\mathrm{C}_{6}$ & 19 & 17 & 19 & 17 \\
\hline $\mathbf{C}_{7}$ & 12 & 11 & 13 & 11 \\
\hline $\mathrm{C}_{8}$ & 9.3 & 8.3 & 7.8 & 7.1 \\
\hline C9 & 6.1 & 4.2 & 2.2 & 4.0 \\
\hline $\mathrm{C}_{10}$ & 2.5 & 2.8 & 2.6 & 0.9 \\
\hline $\mathbf{C}_{11}$ & 0.2 & 0.5 & 3.8 & 1.3 \\
\hline
\end{tabular}

The transient performance for n-dodecane cracking over H-ZSM-5 at $588 \mathrm{~K}$ and $698 \mathrm{~K}$ is summarized in Figure 2-2. Similar to n-hexane cracking, the deactivation was faster at the elevated temperature, but was not severe after 40 min on stream. 
a)

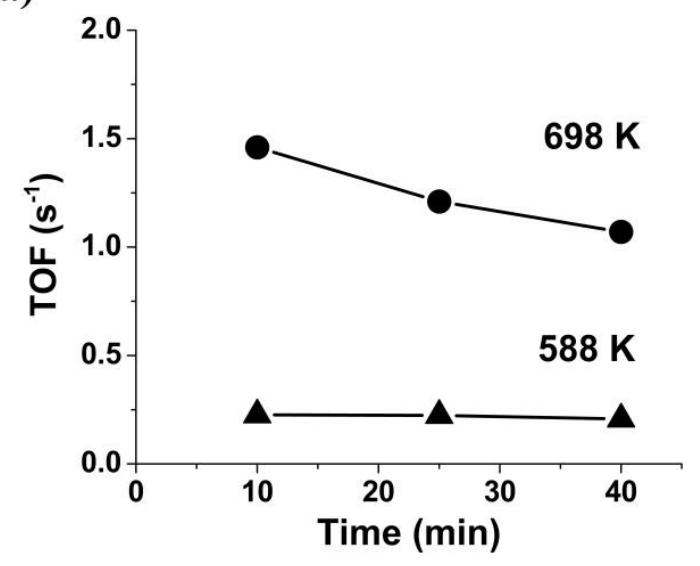

b)

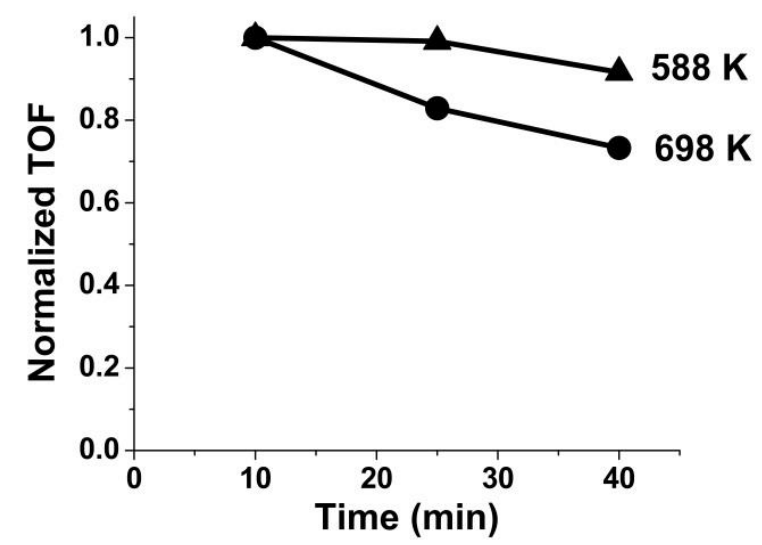

Figure 2-2. a) TOF and b) normalized TOF of n-dodecane cracking versus time on stream over $\mathrm{H}-\mathrm{ZSM}-5$ at $588 \mathrm{~K}(\boldsymbol{\Delta})$ and $698 \mathrm{~K}(\bullet)$ at $6 \mathrm{MPa}$.

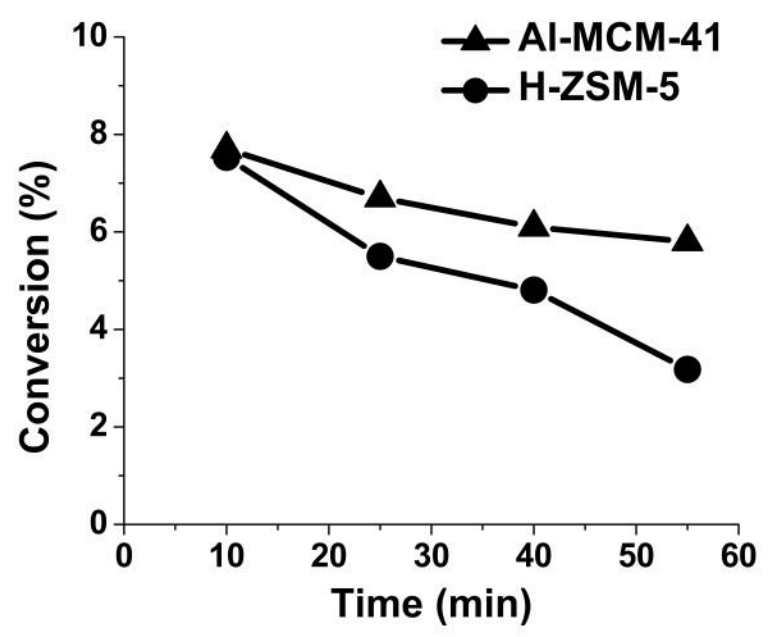

Figure 2-3. Conversion of $n$-dodecane versus time on stream over Al-MCM-41 ( $\boldsymbol{\Delta})$ and $\mathrm{H}$ ZSM-5 (•) at $748 \mathrm{~K}$ and $6 \mathrm{MPa}$. A background conversion of $3 \%$ has been subtracted from the results.

The deactivation over H-ZSM-5 was even more pronounced at $748 \mathrm{~K}$ although a high background conversion of 3\% was measured at this temperature. Trace amounts of olefins can lead to an acceleration in cracking rates [138-140]. Therefore, TOFs for reactions at high temperatures were not calculated since pyrolysis conversion leads to the production of paraffins and olefins in a 1:1 ratio [108]. Figure 2-3 compares the transient performance of $\mathrm{n}$-dodecane reaction over $\mathrm{H}$ - 
ZSM-5 and Al-MCM-41 at equivalent levels of initial conversion and the results suggest that AlMCM-41 deactivates slower than H-ZSM-5.

\subsubsection{Activation barriers for hydride transfer, isomerization, and $\beta$-scission reactions}

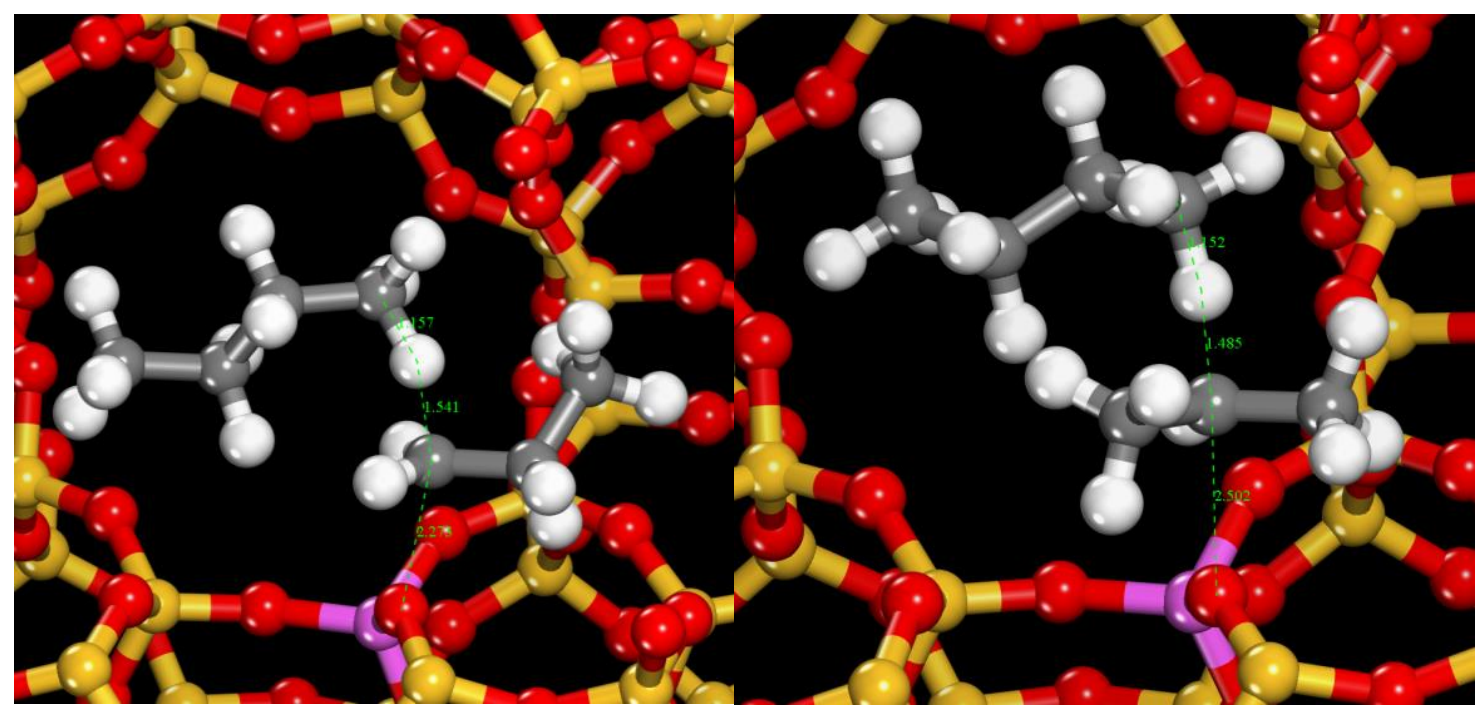

Figure 2-4. Hydride-transfer transition states for n-butane to 1-propoxy (left) and 2-propoxy (right).

The intrinsic activation barriers for hydride transfer, isomerization, and $\beta$-scission, three reactions that account for the major products observed in the experiments, were calculated using periodic density functional theory methods. The calculations were carried out using a model system with Al substitution at the T12 site in H-ZSM-5, located near an intersection where a straight channel along the crystallographic $b$-axis intersects with a zig-zag channel along the $a$ axis to create a locally more spacious pore interior. For H-ZSM-5, the largest cavity diameter is $0.66 \mathrm{~nm}$ with a pore limiting diameter of $0.51 \mathrm{~nm}$. We calculated the intrinsic activation energy for n-butane transferring a hydride to 1 -propoxide to be $115 \mathrm{~kJ} \mathrm{~mol}^{-1}$, while that for transferring to 2-propoxide is $124 \mathrm{~kJ} \mathrm{~mol}^{-1}$. Figure 2-4 shows that with 2-propoxide, its $\mathrm{CH}_{3}$ group cannot point 
away from the rest of the transition-state complex, and the backbone of n-butane cannot tilt up sufficiently to avoid close contact with the 2-propoxy fragment. At the same time, the $\mathrm{O}-\mathrm{C}$ distance is longer than with 1-propoxy $(0.25 v s .0 .23 \mathrm{~nm})$. Therefore, both sterics and the further separated charged species would destabilize the transition state, offsetting the stability gained from being a secondary carbenium ion. The intrinsic activation energies for n-butane transferring its secondary hydrogen to 1-propoxide and 2-propoxide are 96 and $105 \mathrm{~kJ} \mathrm{~mol}^{-1}$, respectively. For isomerization reactions, an intrinsic barrier of $94 \mathrm{~kJ} \mathrm{~mol}^{-1}$ was found for hex-3-oxide skeletal rearranging to form 3-methylpent-2-oxide, with its transition state resembling a di-substituted cyclopropane species (see Figure 2-5).

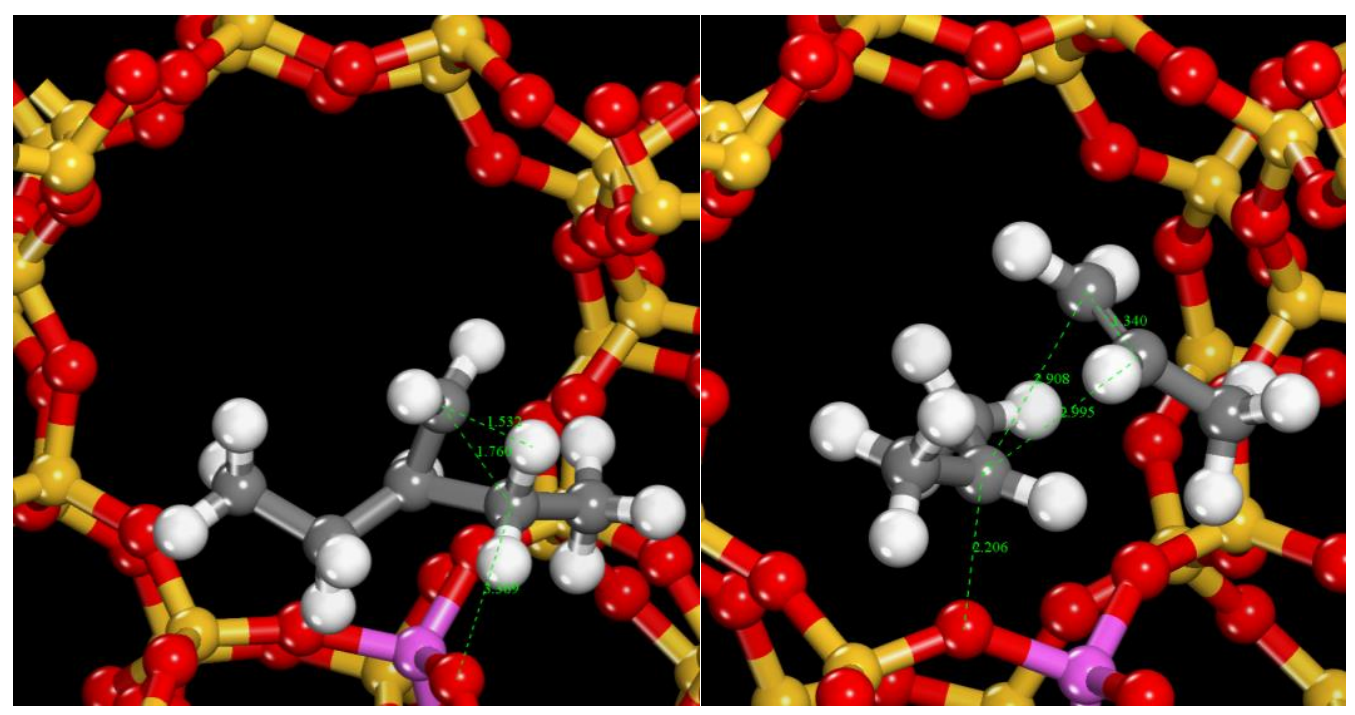

Figure 2-5. Transition-state structures for isomerization of hex-3-oxide to 3-methylpent-2-oxide (left) and for $\beta$-scission of 4-methylpent-2-oxide (right).

The low barrier for branching suggests that adsorbed hexyl species should be able to easily convert to a more stable isomer and allows for modes of $\beta$-scission that are not available to shorter hydrocarbons. Here, the intrinsic barriers were calculated to be $167 \mathrm{~kJ} \mathrm{~mol}^{-1}$ for $\beta$-scission of 4methylpent-2-oxide (secondary -> secondary; see Figure 2-5), and $177 \mathrm{~kJ} \mathrm{~mol}^{-1}$ for hex-2-oxide (secondary -> primary). 


\subsubsection{Adsorption of reactant and product molecules}

The reactant concentration inside catalyst pores can determine the reaction mechanism (e.g., mono- versus bi-molecular cracking) and account for the pressure dependence of rates (implying an intrinsic rate constant not varying with reactant coverage) [114,115]. The hightemperature, high-pressure reaction conditions used herein, however, preclude the possibility of direct measurements of adsorption isotherms. Instead, CB-GCMC simulations were adopted to calculate the amount of adsorption for hexane and dodecane isomers onto H-ZSM-5 and H-Y zeolites using the TraPPE-zeo force field. This methodology has been extensively validated to reproduce the adsorption and diffusion properties of alkanes across a wide range of temperatures and pressures, where experimental data do exist $[132,141]$. The complete set of isotherms is given in Figure A-1. At saturation, eight n-hexane molecules can fit into a unit cell of H-ZSM-5, occupying all four straight and four zig-zag channel segments. For H-Y, based on its simulated helium pore volume that is about 3.1 times the value of H-ZSM-5, a saturation loading of $\sim 24$ molecules per unit cell is expected. As shown in Figure 2-6, at cracking temperatures, increasing the reactant pressure above $1 \mathrm{MPa}$ has little effect on the concentration of n-hexane in H-ZSM-5 and of n-dodecane in either zeolite. The plateau for n-hexane in H-ZSM-5 around $Q=0.7 \mathrm{~mol} \mathrm{~kg}^{-}$

${ }^{1}$ (4 molecules per unit cell) is caused by commensurate freezing [79], where further uptake requires already adsorbed molecules to be "locked" in a single channel segment of the H-ZSM-5 framework and results in an entropy loss. 

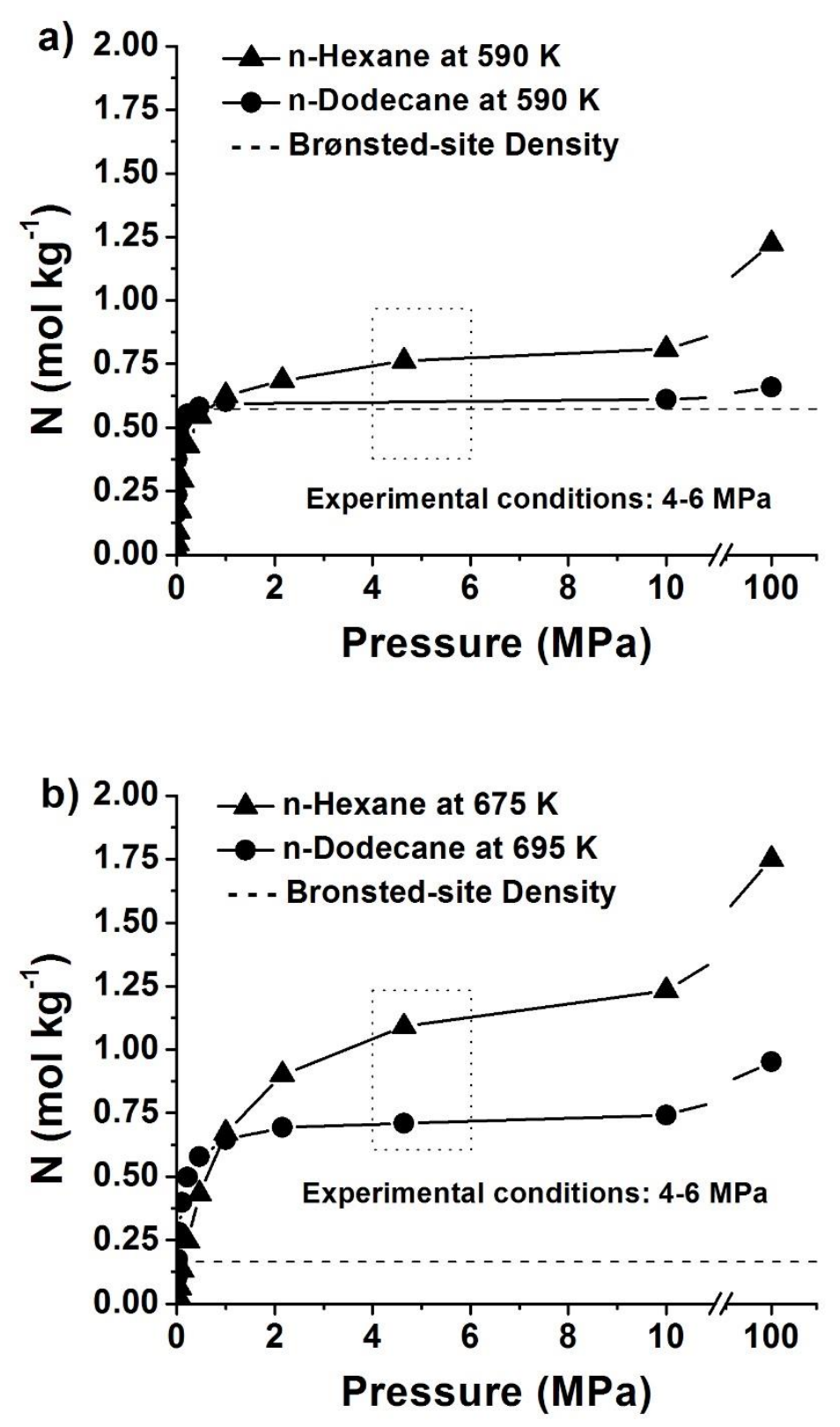

Figure 2-6. Adsorption isotherms of n-hexane and n-dodecane in a) H-ZSM-5 and in b) H-Y. The dotted square indicates the tested feed pressures of n-hexane or n-dodecane. The dashed line indicates the Brønsted-site density for the tested zeolite.

This phenomenon becomes more pronounced for $\mathrm{n}$-heptane and then disappears for longer alkanes. It is hence particularly interesting that a similar plateau was found for n-dodecane. Examination of the snapshots of molecules adsorbed in H-ZSM-5 indicates that the system 
undergoes a similar immobilization process during which a single chain of n-dodecane localizes completely within two channel segments and exhibits either I- or L-shape (Figure A-2). Such entropy-driven step transition is enhanced by the high temperatures encountered in the current study. While a well-ordered packing configuration was also found for n-dodecane in H-Y, no steps were found for n-hexane in this large-pore zeolite.

\subsection{Discussion}

The results of the catalytic conversion of n-hexane and n-dodecane at high pressures reveal that the cracking reactions over H-ZSM-5, H-Y and Al-MCM-41 most likely proceed via a bimolecular mechanism. The relatively low amounts of methane, ethane and ethylene detected and the formation of hydrocarbons with carbon chains longer than the parent molecule are consistent with the results reported by Luo et al.[115] and Schreiner et al. [116] and are indicative of a bimolecular mechanism. The same conclusion has also been reported by Williams et al. [142] during n-hexane cracking studies over USY zeolite at pressures well below the critical pressure of n-hexane. They observed a decrease in light gas formation (methane and ethane) when the nhexane pressure was increased from $0.1 \mathrm{kPa}$ to $6.2 \mathrm{kPa}$, which was attributed to a bimolecular cracking mechanism at high pressures. Likewise, structural isomerization of hydrocarbons has been shown to proceed via the same reaction intermediates as cracking [143,144], but under low temperature isomerization conditions, the reactive carbenium ions accept a hydride and desorb before C-C scission can occur. In a previous study, H-ZSM-5 was shown to be two orders of magnitude more active compared to $\mathrm{H}-\mathrm{Y}$ for $\mathrm{n}$-hexane cracking at $623 \mathrm{~K}$ and an n-hexane partial pressure of $5.3 \mathrm{kPa}$ [145]. In addition, unlike in larger-pore catalysts, where isomerized products can easily diffuse out of the solid framework, in H-ZSM-5 branched alkanes preferentially adsorb 
at the intersections and undergo a jump mechanism for diffusion. Branched hexane isomers have diffusivities in H-ZSM-5 that are $2-8$ orders of magnitude smaller than those for n-hexane and quickly decrease with loading, and will therefore have higher propensity to undergo further cracking. For example, various experimental techniques reported diffusivity for n-hexane to be $0.1-15 \times 10^{-10} \mathrm{~m}^{2} / \mathrm{s}$ at $T=373 \mathrm{~K}[146-148]$, for 2 - or 3-methylpentane $0.2-1 \times 10^{-12} \mathrm{~m}^{2} / \mathrm{s}$, for

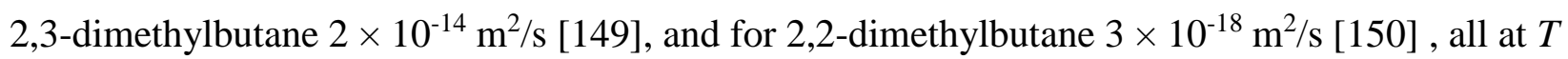
$=400 \mathrm{~K}$. Finally, the necessary hydride transfer step to remove branched alkoxides can become increasingly more difficult in H-ZSM-5 with bulkier and more substituted alkoxides, as discussed above in section 3.4. In H-ZSM-5, intersections are likely the only region that these hydride transfers can occur, so reactions to release isomerized products are also entropically disfavored (i.e., fewer sites / less pore volume that are able to carry out the transformation).

The rates for $n$-hexane conversion on the different zeolites also exhibited very different temperature dependencies, as shown by the Arrhenius-type plots in Figure 2-7a. At $6 \mathrm{MPa}$, the apparent activation energy for cracking of n-hexane over H-ZSM-5 was $157 \mathrm{~kJ} \mathrm{~mol}^{-1}$, while the apparent activation energy for reactions of $\mathrm{n}$-hexane over $\mathrm{H}-\mathrm{Y}$ was $61 \mathrm{~kJ} \mathrm{~mol}^{-1}$. This is in good agreement with Luo et al.[115] who reported an apparent activation energy of $170 \mathrm{~kJ} \mathrm{~mol}^{-1}$ for nhexane cracking over H-ZSM-5 and $58 \mathrm{~kJ} \mathrm{~mol}^{-1}$ for reactions of n-hexane over USY at $13.7 \mathrm{MPa}$. Given that the product selectivities under supercritical conditions suggest a bimolecular mechanism for cracking, it was surprising that a Langmuir-Hinshelwood rate expression representative of monomolecular cracking was able to describe n-hexane cracking in H-ZSM-5 over the entire pressure range. 

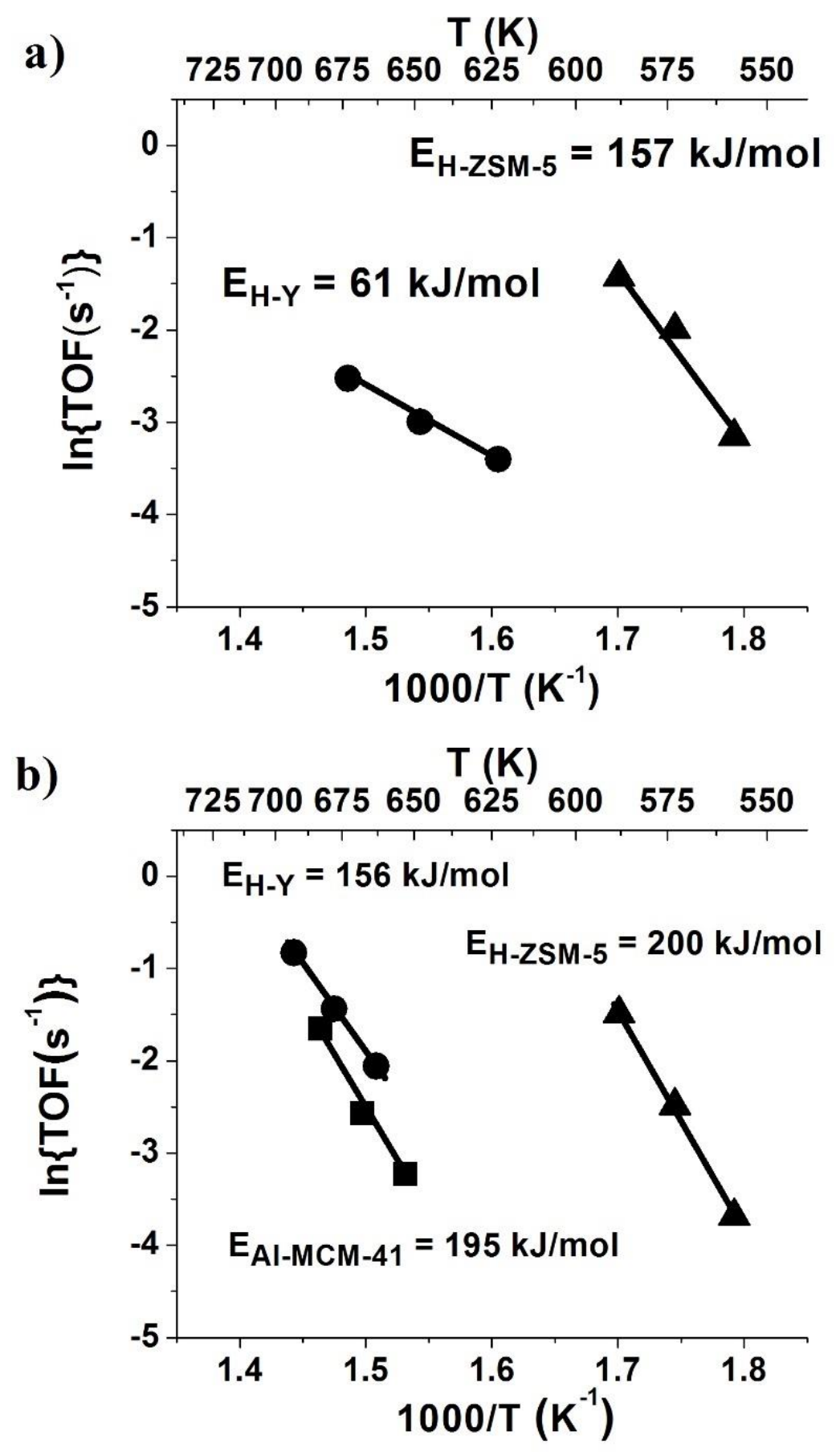

Figure 2-7. a) Arrhenius-type plots for reactions of n-hexane over H-ZSM-5 ( $\Delta)$ and H-Y $(\bullet)$ at $6 \mathrm{MPa}$. b) Arrhenius-type plots for reactions of n-dodecane over H-ZSM-5 ( $\mathbf{\Delta}), \mathrm{H}-\mathrm{Y}(\bullet)$ and Al$\mathrm{MCM}-41(\mathbf{\square})$ at $6 \mathrm{MPa}$. 
The rate law for a specific cracking mode $\mathrm{R} \rightarrow \mathrm{P}$ (e.g., breaking terminal $\mathrm{C}-\mathrm{C}$ bonds) may be written as

$$
r_{\mathrm{R} \rightarrow \mathrm{P}}=\sum_{i=1}^{\left[\mathrm{H}^{+}\right]}\left(k_{\mathrm{R}_{i} \rightarrow \mathrm{P}_{i}} \cdot[\mathrm{R}]_{i}\right)=\sum_{i=1}^{\left[\mathrm{H}^{+}\right]}\left(k_{\mathrm{R}_{i} \rightarrow \mathrm{P}_{i}} \cdot[\mathrm{R}] \cdot \rho_{i}\right)
$$

where $\left[\mathrm{H}^{+}\right]$is the number of bare acid sites per unit volume of the catalyst, $k_{\mathrm{R}_{i} \rightarrow \mathrm{P}_{i}}$ (unit: $\mathrm{s}^{-1}$ ) represents the intrinsic rate constant for site $i$, and $[\mathrm{R}]_{i}$ is the number of physisorbed reactants in the cage containing site $I$. Cages are defined as some continuous region of pore space such that a reactant molecule can easily approach any active sites located in the same cage but will have to overcome a free energy barrier (i.e., an activated diffusional process) to access active sites in other cages. The second equality above expresses $[\mathrm{R}]_{i}$ as the product of the total number of physisorbed reactants, [R], and a siting probability, $\rho_{\mathrm{I}}[151]$. If we define an average siting probability, $\bar{\rho}=\sum_{i=1}^{\left[\mathrm{H}^{+}\right]} \rho_{i} /\left[\mathrm{H}^{+}\right]$, and further assume the intrinsic reactivity to be similar for all acid sites, $k_{\mathrm{R}_{i} \rightarrow \mathrm{P}_{i}} \approx k_{\mathrm{int}}$, Equation (2-3) then simplifies to

$$
r_{\mathrm{R} \rightarrow \mathrm{P}} \approx k_{\mathrm{int}} \cdot[\mathrm{R}] \cdot \sum_{i} \rho_{i}=k_{\mathrm{int}} \cdot[\mathrm{R}] \cdot\left[\mathrm{H}^{+}\right] \cdot \bar{\rho}
$$

It is often assumed that $[\mathrm{R}]$ obeys a Langmuir isotherm

$$
[\mathrm{R}]=\frac{N_{A}^{\mathrm{sat}} K_{H} p_{A}}{1+K_{H} p_{A}}
$$

where $N_{A}^{\text {sat }}$ is the saturation loading, $K_{\mathrm{H}}$ is the Henry's constant for adsorption, and $p_{\mathrm{A}}$ is the hydrocarbon partial pressure $[115,152]$, resulting in 


$$
r_{\mathrm{R} \rightarrow \mathrm{P}}=k_{\mathrm{int}} \cdot\left[\mathrm{H}^{+}\right] \cdot \bar{\rho} \cdot \frac{N_{A}^{\mathrm{sat}} K_{H} p_{A}}{1+K_{H} p_{A}}
$$

In general, $\left[\mathrm{H}^{+}\right]$and $\bar{\rho}$ are pressure dependent, but two limiting cases are often discussed in the literature [115]. Indeed, as $p_{\mathrm{A}} \rightarrow 0$ and at low conversions, where monomolecular mechanism dominates, $\left[\mathrm{H}^{+}\right] \approx\left[\mathrm{H}^{+}\right]_{0}$ and the apparent rate constant contains a physisorption component $k_{\text {app }}=k_{\text {int }} \bar{\rho} N_{A}^{\text {sat }} K_{H}$. As pressure increases, however, the bimolecular mechanism prevails, and a large fraction of acid sites are expected to exist in the form of alkoxides. Therefore, the limit of $p_{\mathrm{A}} \rightarrow \infty$ for Equation (2-6) does not necessarily lead to $k_{\mathrm{app}}=k_{\mathrm{int}} \bar{\rho} N_{A}^{\text {sat }}$ and highpressure rate data do not generally yield the intrinsic rate constant for monomolecular cracking. Based on the energetics reported in Section 3.4, the rate-limiting step in the bimolecular mechanism is likely $\beta$-scission, and the rate law for a specific cracking mode $\mathrm{R} \rightarrow \mathrm{P}$ may be written as:

$$
r_{\mathrm{R} \rightarrow \mathrm{P}}=k_{\mathrm{int}}^{\prime} \cdot[\mathrm{ZOR}]
$$

where $k_{\text {int }}^{\prime}$ is the intrinsic rate constant for $\beta$-scission and [ZOR] is the concentration of an alkoxide species. The energetics suggest that isomerization and hydride transfer reactions are likely quasiequilibrated; as a result, the concentrations of various alkoxide species can be related to the concentrations of physisorbed alkanes, and hence to their partial vapor pressures, by an equilibrium relationship. Consequently, as $p_{\mathrm{A}} \rightarrow \infty,[\mathrm{ZOR}] \approx\left[\mathrm{H}^{+}\right]_{0}$ so that the measured activation energy for cracking would be equivalent to the intrinsic activation energy for $\beta$-scission. Luo et al. measured n-hexane cracking over H-ZSM-5 over a wide range of pressures (0.0067 to $13.7 \mathrm{MPa}$ ) and showed nearly zero-order behavior above $0.6 \mathrm{MPa}$. 
However, as Figure 2-6 indicates, the reaction conditions used here correspond to only partially loaded catalysts, but the plateaus in the adsorption isotherms lead to a range of pressures in which increasing the hydrocarbon pressure has little effect on the actual concentration of hydrocarbon in the zeolite pores. Therefore, nearly zero-order behavior would still be observed in this regime. It is worth noting, however, that although bi-molecular routes for cracking are often associated with lower activation barriers than mono-molecular routes, $\mathrm{C}_{6}$ species can only utilize a single mode of $\beta$-scission that does not involve primary carbenium ions (so-called type $\mathrm{C} \beta$ scission; see section 2.3.4), with a barrier of $167 \mathrm{~kJ} \mathrm{~mol}^{-1}$. As a comparison, we have previously calculated the intrinsic barriers for monomolecular cracking of n-butane to range from 170 - 190 $\mathrm{kJ} \mathrm{mol}^{-1}$ depending on the $\mathrm{C}-\mathrm{C}$ bond being broken and the location of acid sites. This difference in activation barriers between the two different cracking mechanisms is in fact well within experimental uncertainties and allows the reaction rates to be fit using a single rate equation as found in the experiment.

The cause for the lower activation energy seen for n-hexane conversion over $\mathrm{H}-\mathrm{Y}$ is relatively unclear. Luo et al. suggested that one possible explanation for the low activation barrier of $\sim 60 \mathrm{~kJ} \mathrm{~mol}^{-1}$ over BEA, MOR and USY zeolites is the high rate of n-hexane isomerization relative to cracking. Brouwer and Oelderik investigated the isomerization of 2-methylpentane with liquid super acid $\mathrm{HF}_{-} \mathrm{SbF}_{5}$ as the catalyst and reported that the activation energy for isomerizations during which the degree of branching changes via a protonated cyclopropane (PCP) intermediate is approximately $75 \mathrm{~kJ} \mathrm{~mol}^{-1}$ [39]. Beecher and Voorhies investigated n-hexane isomerization over H-MOR at $p=3.2 \mathrm{MPa}$ and $T=473-533 \mathrm{~K}$ and reported an activation energy of $102 \mathrm{~kJ} \mathrm{~mol}^{-1}$ [153]. Chica and Corma investigated n-hexane isomerization over H-MOR at $T=523-573 \mathrm{~K}$ and $p=70-162 \mathrm{kPa}$ and observed an apparent activation energy of $79 \mathrm{~kJ} \mathrm{~mol}^{-1}$, but concluded that 
the intrinsic activation energy was $171 \mathrm{~kJ} \mathrm{~mol}^{-1}$ by adding the heat of adsorption to the apparent activation energy [154]. However, the pressure at which the reaction was carried out may be too high for this treatment to be valid. Macht et al. obtained the rate constant for n-hexane isomerization over H-BEA at $T=473 \mathrm{~K}$, and deduced an intrinsic barrier of $\sim 162 \mathrm{~kJ} \mathrm{~mol}^{-1}$ by using the same DFT pre-exponential factor as calculated for $0.04 \mathrm{H}_{3} \mathrm{PW} / \mathrm{SiO}_{2}$ [155]. The DFT results reported in section 2.3.4 agree with other theoretical calculations, which have reported values for the isomerization of 2-pentene over H-ZSM-22 via a PCP intermediate $\left(98 \mathrm{~kJ} \mathrm{~mol}^{-1}\right)$ or via intramolecular hydrogen shift $\left(110 \mathrm{~kJ} \mathrm{~mol}^{-1}\right)$ [156]. Given the majority of the literature results mentioned above suggest that the barrier for isomerization via a PCP intermediate ranges from 75$102 \mathrm{~kJ} \mathrm{~mol}^{-1}$, high isomerization rates alone cannot explain the low activation energy seen for $\mathrm{n}$ hexane conversion over $\mathrm{H}-\mathrm{Y}$ under supercritical conditions $\left(61 \mathrm{~kJ} \mathrm{~mol}^{-1}\right)$.

To explain the case of $\mathrm{n}$-dodecane conversion, the propensity for carbenium ions above $\mathrm{C}_{6}$ to undergo C-C scission increases dramatically with hydrocarbon chain length $[157,158]$ and has been attributed to the availability of numerous facile cracking modes via tertiary carbenium ions rather than primary and secondary carbenium ions [45-47]. However, given that the barrier for isomerization via PCP intermediates is comparable with that of tertiary $\beta$-scission modes, it is surprising that a GC analysis of the reactor effluent was not able to detect a significant amount of $\mathrm{C}_{12}$ isomers. Although it is possible that the GC column and method used in this study may not be sensitive enough to distinguish structurally similar $\mathrm{C}_{12}$ isomers from the $\mathrm{n}$-dodecane feed, another possibility is that $\mathrm{C}_{12}$ species adsorb much more strongly than $\mathrm{C}_{6}$ species. As evidenced by the adsorption isotherms in Figure A-1, the equilibrium loadings of isomerized $\mathrm{C}_{12}$ products are rather large even at low conversions, and therefore $\mathrm{C}_{12}$ isomers are more likely to undergo further reactions than $\mathrm{C}_{6}$ isomers are. As the chain length of a product decreases, its adsorption strength 
weakens and its percentage in the product mixture increases. Correspondingly, the rates of ndodecane cracking over H-ZSM-5, H-Y and Al-MCM-41 exhibited similar temperature dependencies, as shown by the Arrhenius plots in Figure 2-7b. The activation energies for ndodecane cracking are similar to the intrinsic activation energy of hydrocarbon cracking of $~ 200$ $\mathrm{kJ} \mathrm{mol}^{-1}$ reported in the literature $[49,96,151]$. The activation energies for $\mathrm{n}$-dodecane cracking over H-Y and Al-MCM-41 were measured under supercritical conditions. However, conversion of n-dodecane over H-ZSM-5 at temperatures above the critical temperature $(\mathrm{T} \geq 658 \mathrm{~K})$ resulted in lower than expected TOFs, presumably due to mass transfer limitations. Therefore, an activation energy for n-dodecane cracking over H-ZSM-5 under supercritical conditions was not measured.

The differences in catalyst stability between H-ZSM-5 and Al-MCM-41 seen in Figure 2-3 may be attributed to the difference in pore size. Previous studies show that for certain hydrocarbon and catalyst pairings, the increased coke precursor solubility due to liquid-like densities of hydrocarbon fuels under supercritical conditions can mitigate catalyst deactivation [118-120,159]. The increased diffusivity from the larger catalyst pore size, coupled with the increased coke precursor solubility may allow coke precursors to be swept away before they can form coke. The TOFs for cracking of shorter hydrocarbon molecules are too low over large pore materials to be effective for endothermic fuels, but the TOFs for longer hydrocarbon molecules, such as ndodecane, are much higher. The results presented here indicate that a suitable catalyst and hydrocarbon fuel pairing under supercritical operating conditions may have potential for endothermic fuels. 


\subsection{Conclusions}

The acid-catalyzed cracking of n-hexane and n-dodecane over H-ZSM-5, H-Y and AlMCM-41 under high pressures showed that bimolecular reactions and hydrocarbon chain length control the product distribution. While n-hexane reactions over H-Y and Al-MCM-41 resulted in mainly isomerization, n-hexane reactions over H-ZSM-5 and n-dodecane reactions over all three catalysts resulted in cracking with an activation energy associated with the rate constant for C-C bond cleavage. Periodic DFT calculations suggest that isomerization should be facile, but the hydride transfer steps necessary for releasing isomerized alkoxides may become challenging in $\mathrm{H}$ ZSM-5 with highly substituted species. In addition, the diffusion coefficients were reported to be $2-8$ orders of magnitude smaller for branched alkanes in H-ZSM-5; both factors contribute to the qualitative difference in product selectivity for $n$-hexane conversion over the different catalysts. CB-GCMC simulations reveal a step-like adsorption isotherm for n-dodecane in H-ZSM-5 and HY zeolites, which has an origin similar to the commensurate freezing behavior known for n-hexane in H-ZSM-5, and is due to the entropy loss in order to maximize packing. The plateaus in the isotherms at pressures before saturation lead to the zero-order kinetics observed in the experiments.

\section{Acknowledgements}

We acknowledge support from Air Force Office of Scientific Research (AFOSR FA955012-1-0496) for funding and also Dr. Harsha Chelliah his support as project manager. Part of the computational resources were provided by the Minnesota Supercomputing Institute. 


\section{Catalytic Cracking of JP-10 over H-Y Under Supercritical Conditions}

This chapter is derived from a manuscript being prepared for publication and is co-authored by Drs. Ujuma Shrestha and Harsha Chelliah the Mechanical and Aerospace Engineering Department at the University of Virginia. The micro-flow tube reactor experiments were performed by Dr. Ujuma Shrestha.

\subsection{Introduction}

One of the main challenges facing high supersonic (Mach 3-5) and hypersonic vehicles (Mach > 5) is the cooling of the combustion chamber of the engine. The current strategy for liquid hydrocarbon fueled high supersonic and hypersonic vehicles is to pass the fuel on board the vehicle through heat exchanger panels along the combustion chamber walls to absorb the excess heat, prior to injection into the combustion chamber [4]. Endothermic liquid hydrocarbon fuels aim to increase the heat sink potential of liquid hydrocarbon fuels by incorporating the sensible enthalpy of the fuel and the chemical heat sink capacity from undergoing endothermic chemical reactions.

Several groups have demonstrated that the catalytic cracking of heavy hydrocarbon fuels over zeolite catalysts under supercritical conditions can provide substantial heat sink capacity $[7,104,105,160]$. Huang et al. examined the cracking of JP-7 over a zeolite catalyst under supercritical conditions ( $978 \mathrm{~K}$ and $4.1 \mathrm{MPa}$ ) and reported a physical heat sink of $388 \mathrm{~kJ} \mathrm{~mol}^{-1}$ and a chemical heat sink of $178 \mathrm{~kJ} \mathrm{~mol}^{-1}$ [104], assuming an average molecular weight of $166 \mathrm{~g} \mathrm{~mol}^{-1}$ for JP-7 [161]. This technology was successfully implemented in the test flights of the Boeing X51, which reached flight speeds up to Mach 5.1 [162]. However, development of endothermic fuel and catalyst pairings that provide greater heat sink capacity are desired to achieve even faster flight speeds. 
JP-10 (exo-tetrahydrodicyclopentadiene) is a high-energy, nearly single-component hydrocarbon fuel used in air-breathing missiles. It has superior thermal stability compared to conventional liquid hydrocarbon military fuels such as JP-8 [163]. Previous research concluded that a fuel with high thermal stability, JP-7, had a greater heat sink capacity and less carbon formation, or coking, than JP-8 [104]. Thus, JP-10 has garnered significant interest over the years as an attractive candidate for endothermic fuels. The thermal cracking, or pyrolysis, of JP-10 has been well studied under conditions relevant for endothermic fuels [163-168], but fewer studies exist for the catalytic cracking of JP-10 [105,163,169]. Huang et al. [104] compared the gas-phase product distribution, heat sink capacity, and coke deposition results for the cracking of JP-7, JP-8, and JP-10 over a zeolite catalyst under supercritical conditions using a benchtop reactor setup with a residence time of $1.2 \mathrm{~s}$ and reported that JP-10 had a lower chemical heat sink $\left(90 \mathrm{~kJ} \mathrm{~mol}^{-1}\right)$ than JP-7 (178 kJ mol $\left.{ }^{-1}\right)$ and JP-8 (137 kJ mol-1). Cooper and Shepherd [163] examined JP-10 cracking over $\mathrm{H}-\mathrm{Y}$ zeolite and reported the overall conversion and product distribution under supercritical conditions using a benchtop reactor setup with a residence time ranging from $330-1570 \mathrm{~s}$. This study aims to expand upon the existing work by examining the intrinsic rates and reaction mechanism for the catalytic cracking of JP-10 under supercritical conditions. These results are compared to the results obtained in a micro-flow reactor capable of flow conditions simulative of endothermic fuel applications. 


\subsection{Experimental Methods}

\subsubsection{Flow reactor experiments with fixed bed reactor}

\subsubsection{Materials}

JP-10 (Batch 11 POSF7478, Dixie Chemical Company) was used as the feed. n-Tridecane (Sigma-Aldrich, 99\% purity anhydrous) was added as an external standard during gas chromatography (GC) analysis. n-Propylamine (Sigma-Aldrich, $\geq 99.0 \%$ purity) was used for the temperature-programmed desorption/mass spectrometry (TGA-MS) analysis to determine the Brønsted-acid site density for the catalysts. The following gases were used for calcination, TGAMS and GC operation: dry air (GTS-Welco), helium (GTS-Welco, 99.999\%), dihydrogen (GTSWelco, 99.999\%), dinitrogen (GTS-Welco, 99.999\%) and propylene (GTS-Welco, PY60).

H-Y (45872) zeolite was purchased from Alfa Aesar and sized using -40/+100 (150 - 425 $\mu \mathrm{m})$ sieves trays. To test for background conversion, a pure $\mathrm{ZrO}_{2}$ sample was synthesized in the lab. Amorphous $\mathrm{ZrO}_{\mathrm{x}}(\mathrm{OH})_{4-2 \mathrm{x}}$ (MEL Chemicals, $\mathrm{XZO1501/09)}$ was calcined to $\mathrm{ZrO}_{2}$ in dry air $\left(100 \mathrm{~cm}^{3} \mathrm{~min}^{-1}\right)$ at $973 \mathrm{~K}$ at $10 \mathrm{~K} \mathrm{~min}^{-1}$, holding for $4 \mathrm{~h}$ before being pressed and sized using $40 /+100(150-425 \mu \mathrm{m})$ sieves trays.

\subsubsection{Catalyst Characterization}

The $\mathrm{H}-\mathrm{Y}$ zeolite used in this study was loaded into a quartz reactor and pretreated in 100 $\mathrm{cm}^{3} \mathrm{~min}^{-1}$ of $21 \% \mathrm{O}_{2}$ and balance $\mathrm{He}$ at $823 \mathrm{~K}_{\text {at }} 5 \mathrm{~K} \mathrm{~min}^{-1}$, holding for $2 \mathrm{~h}$. After the pretreatment, the catalyst was exposed to n-propylamine at $448 \mathrm{~K}$ for $15 \mathrm{~min}$ by passing $\mathrm{He}\left(30 \mathrm{~cm}^{3} \mathrm{~min}^{-1}\right)$ 
through an n-propylamine saturator that was held in an ice bath. The catalyst sample was then purged at $448 \mathrm{~K}$ for $2 \mathrm{~h}$ under flowing $\mathrm{He}\left(100 \mathrm{~cm}^{3} \mathrm{~min}^{-1}\right)$ to remove excess $\mathrm{n}$-propylamine. The catalyst sample was then heated to $873 \mathrm{~K}$ at $20 \mathrm{~K} \mathrm{~min}^{-1}$ under flowing $\mathrm{He}\left(100 \mathrm{~cm}^{3} \mathrm{~min}^{-1}\right)$ and the mass spectrometer $(\mathrm{MS})$ was used to track unreacted amine $(\mathrm{m} / \mathrm{e}=30)$, propylene $(\mathrm{m} / \mathrm{e}=41)$ and ammonia $(\mathrm{m} / \mathrm{e}=30)$. Previous work has shown that the Brønsted-acid site density can be quantified from the amount of amine that reacts between 650 and $725 \mathrm{~K}$ [89,123-125]. A known amount of propylene was introduced to the system using a six-way valve after each n-propylamine decomposition experiment to calibrate the propylene MS signal.

\subsubsection{Catalyst Testing in the Fixed Bed Reactor}

Hydrocarbon conversion reactions were carried out in an upward-flow fixed bed reactor under supercritical conditions. A titanium reactor (Grade 2 titanium from McMaster-Carr) with an outer diameter of $6.35 \mathrm{~mm}$ and an inner diameter (ID) of $4 \mathrm{~mm}$ was used to hold the catalyst bed that was supported between two glass wool plugs. Catalysts were heated in situ in flowing dry air $\left(100 \mathrm{~cm}^{3} \mathrm{~min}^{-1}\right)$ at $5 \mathrm{~K} \mathrm{~min}^{-1}$ to $823 \mathrm{~K}$ and holding at that temperature for $2 \mathrm{~h}$. Liquid hydrocarbon was fed to the reactor using a Teledyne Isco 260D high pressure syringe pump. A gas-liquid separator was used to collect liquid product between sampling intervals. Dinitrogen was used to purge the gas-liquid separator and to maintain the pressure in the system, which was controlled by a back-pressure regulator. The dinitrogen purge along with the gas-phase products were fed to a gas chromatograph (Shimadzu GC-2014) equipped with a flame ionization detector (FID). A Restek RT-QS-BOND (30 m, $0.53 \mathrm{~mm}$ ID, $20 \mu \mathrm{m}$ film thickness) column was used to separate the products. n-Tridecane (Sigma-Aldrich, 99\% purity anhydrous) was added to the liquid 
products as an external standard. The liquid products were injected into the GC using an AOC-20i auto sampler.

The peak areas of reactants and products identified by GC were used to determine the hydrocarbon feed conversion and selectivity of products. Identification of the heavier liquid phase products was performed by Galbraith Laboratories (Knoxville, TN) using gas chromatographymass spectrometry (GC-MS).

The peak areas of reactants and products identified by GC were used to determine the hydrocarbon feed conversion and selectivity of products. The conversion of hydrocarbon feed was calculated according to and defined as follows:

$$
\text { Conversion }(\mathrm{C} \%)=\left(\frac{\sum n_{i} M_{i}}{x}\right) \times 100
$$

where $n_{i}$ is the number of carbon atoms in product $i, M_{i}$ is the molar ratio of product $i$ detected to the initial moles of hydrocarbon feed and $x$ represents the number of carbon atoms in the hydrocarbon feed.

The selectivity toward product $i$ was calculated on a molar basis and defined as follows:

$$
\text { Molar Selectivity }(\%)=\left(\frac{M_{i}}{\sum M_{i}}\right) \times 100
$$

The catalyst loading in the reactor depended on the reaction operating conditions and the mass was diluted with a corresponding amount of $\mathrm{ZrO}_{2}$ to keep the length of the catalyst bed constant at $5 \mathrm{~cm}$. The catalyst loading was varied to keep the overall conversion below $10 \%$ to ensure differential reactor conditions. Reactions with only a bed of $\mathrm{ZrO}_{2}$ were also run for all conditions used in this work to determine the amount of background conversion from pyrolysis. The hydrocarbon liquid feed rate was varied from $0.3 \mathrm{~cm}^{3} \mathrm{~min}^{-1}$ to $3.0 \mathrm{~cm}^{3} \mathrm{~min}^{-1}$, depending on 
the reaction temperature, to keep the background conversion below $0.5 \%$ at all times. Measurements used to determine activation energies were determined at the same weight hourly space velocity (WHSV) to account for the effect that WHSV can have an effect on product selectivity [116]. Rates are reported in terms of turnover frequency (TOF), which is calculated as the rate of hydrocarbon feed conversion normalized to the acid-site density reported in Table 3-1.

\subsubsection{Micro-flow tube reactor experiments with wall-coated catalyst}

Figure 3-1 shows a schematic of the atmospheric pressure micro-flow tube reactor (MFTR) used to conduct experiments with wall-coated catalyst reported in this study. The reactor was fabricated using fused quartz tubing to minimize any catalytic wall reactions other than the H-Y zeolite catalyst, with a maximum safe operating temperature of about $1300 \mathrm{~K}$. The reactor is comprised of $0.4 \mathrm{~cm}$ inner diameter main tube through which inert nitrogen gas is supplied and two $0.1 \mathrm{~cm}$ inner diameter side tubes through which fuel is fed to the mixing region. The mixing region is about $0.2 \mathrm{~cm}^{3}$ with the exit plane bounded by a porous quartz frit. A $125 \mathrm{~cm}$ long helical section of $0.4 \mathrm{~cm}$ ID is used upstream of the mixing region to ensure complete heating of the main nitrogen carrier bath to the target temperature. The temperature of the two side fuel feeding tubes is controlled via a heating/cooling jacket. The constant temperature hot section is $37 \mathrm{~cm}$ long with excellent temperature control $( \pm 5 \mathrm{~K})$. The heating system is custom designed with modular high temperature ceramic electrical heaters (ThermCraft RH211/RH212). Because of the modular nature of the heating system design, the hot section length can be easily changed. The quartz reactor and the heating system sit on a V-shaped metal support and are enclosed inside a steel chamber which has been hydro tested to $10 \mathrm{MPa}$. Further details of the reactor including heat transfer analysis and verification of negligible catalytic wall effects can be found in ref. [170]. 


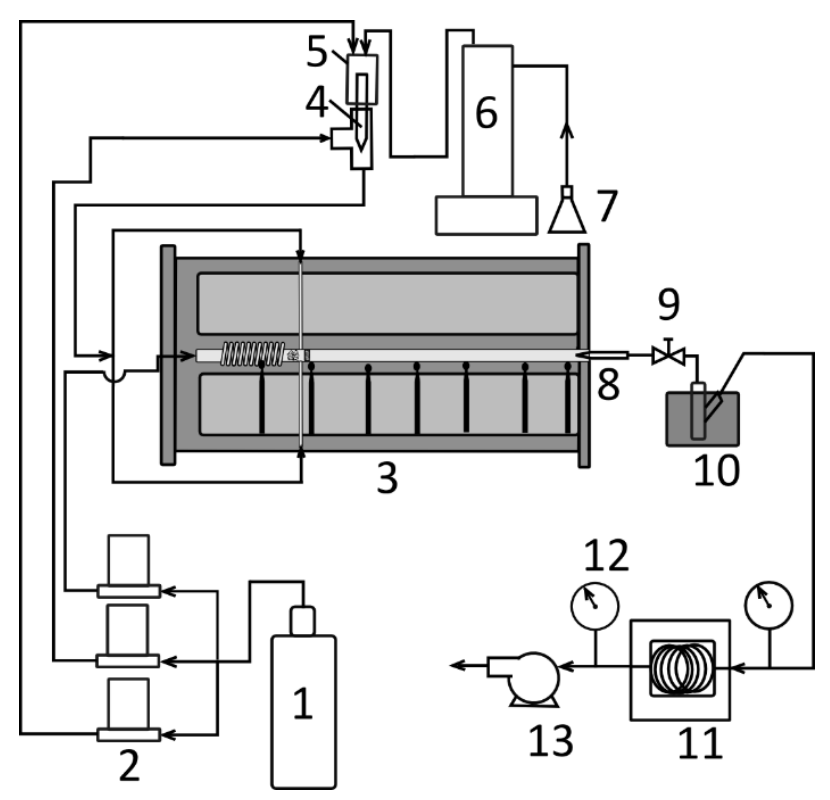

Figure 3-1. Schematic of experimental setup showing: 1 - nitrogen gas cylinder; 2 - mass flow controllers; 3 - micro-flow reactor in vented high-pressure enclosure chamber; 4 - fuel atomizer; 5 - atomizer housing; 6 - liquid fuel pump; 7 - fuel reservoir; 8 - quartz microprobe; 9 - needle valve; 10 - dry ice bath; 11 - GC system; 12 - pressure gauge; 13 - vacuum pump. This figure was provided by U. Shrestha.

Thermal decomposition study of JP-10 was conducted in the presence of three $1 \mathrm{~mm}$ diameter, H-Y zeolite coated quartz rods in the atmospheric pressure micro-flow tube reactor (see Figure 3-2). The quartz rods were fused together at three points along the length with space to allow free flow of molecules across the cross section. The experimental conditions explored for the present study are given in Table 3-2. In order to ensure proper interaction between fuel and catalyst, a relatively long residence time of $400 \mathrm{~ms}$ was selected.

A key challenge of the present JP-10 pyrolysis experiments is the pre-vaporization of the fuel without any condensation or pyrolysis until it reaches the hot test section. For the selected residence time, the fuel flow rates required to attain $1 \%$ fuel mole fraction with the inserted rods ranged from $0.01-0.014 \mathrm{~cm}^{3} \mathrm{~min}^{-1}$. Fuel flow rates were controlled using a liquid syringe pump (Tele-dyne ISCO Model 500D) with flow and pressure capabilities of $0.001-204 \mathrm{~cm}^{3} \mathrm{~min}^{-1}$ and 
0.07-26 MPa, respectively. The nitrogen gas (99.999\%, Praxair) flow rate was controlled using mass flow controllers (Sierra 100 series, with $1 \%$ accuracy).

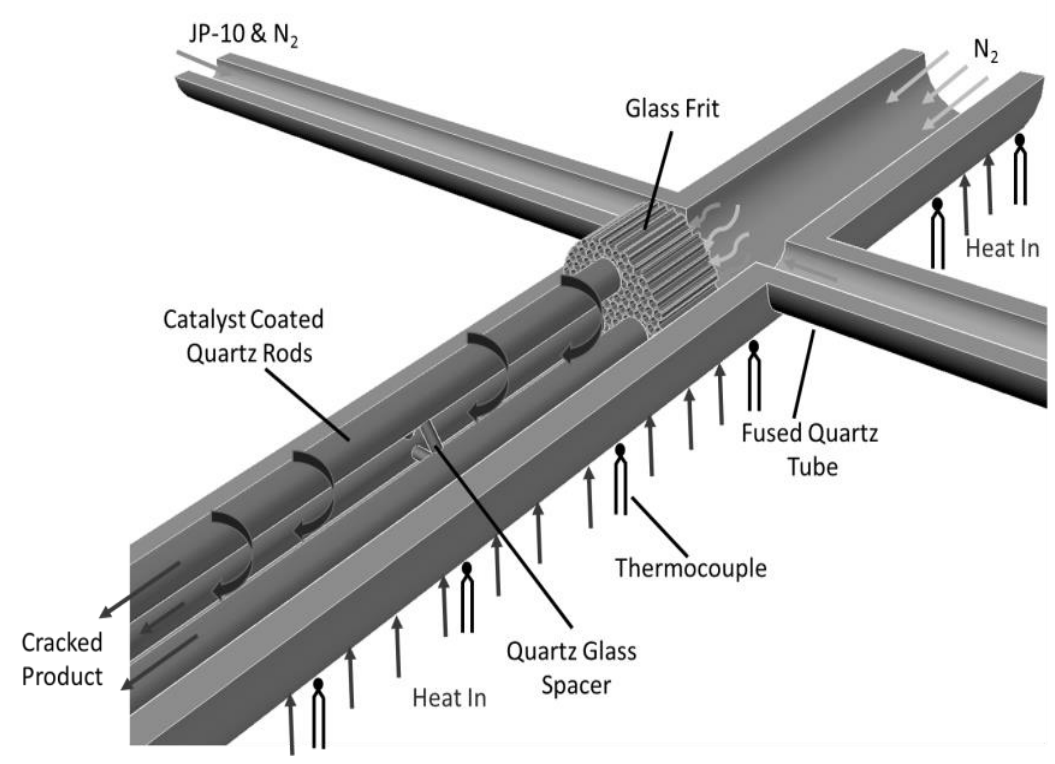

Figure 3-2. Schematic of atmospheric pressure micro-flow tube reactor with three $1 \mathrm{~mm}$ rods coated with H-Y zeolite and placed in the hot section. This figure was provided by U. Shrestha.

In order to ensure proper vaporization, the fuel was first atomized using an ultrasonic atomizer (with a mean droplet size of about 10-15 m) and transported in a heated nitrogen stream of $500-550 \mathrm{~K}$. The fraction of the nitrogen flow was maintained through the atomizer to eliminate any fuel deposition in the line and also to keep the atomizer at operating temperature. The uniform preheating of the fuel line was attained by wrapping individual heaters and properly insulating different sections of the fuel line up to the side feed tubes of the reactor. In addition, eight K-type thermocouples were incorporated inside each heater to monitor the temperature at various locations via a NI Labview software interface. For atmospheric pressure experiments reported here, the flow residence time was changed by varying the total volume flow rate or bulk flow velocity (see ref. [170] for further details), while the hot section temperature was controlled using the PID controllers. 
The species exiting the MFTR were quantified by continuous probing with a $75 \mu \mathrm{m}$ quartz probe tip and subsequent analysis via a Shimadzu GC-2014 equipped with FID and TCD detectors. The GC was equipped with a series of packed columns focused on measurements of $\mathrm{C}_{0}-\mathrm{C}_{4}$ species and the sample line was sent through a dry-ice/ethanol bath held at $202 \mathrm{~K}$ to condense any large hydrocarbon molecules before injection. Before each experimental run, the system was allowed to reach a steady state at a desired target temperature to eliminate any uncertainty arising from transient state conditions.

Table 3-1. Properties of H-Y zeolite used in this study.

\begin{tabular}{|c|c|c|c|}
\hline Catalyst & $\begin{array}{c}\text { Pore Size } \\
\text { (̊) }\end{array}$ & Si/Al 2 Ratio $^{a}$ & $\begin{array}{c}\text { Brønsted-site } \\
\text { Density }^{b} \\
\left(\mu \mathrm{mol} \cdot \mathrm{g}^{-1}\right)\end{array}$ \\
\hline $\mathrm{H}-\mathrm{Y}$ & $7.4^{\mathrm{c}}$ & $85: 1$ & 162 \\
\hline \multicolumn{4}{|c|}{$\begin{array}{l}\text { a. Based on manufacturer data } \\
\text { b. Brønsted acid site concentrations were determined by n-propylamine } \\
\text { decomposition } \\
\text { c. Pore size from the Atlas of Zeolite Framework Types [137] }\end{array}$} \\
\hline
\end{tabular}

Table 3-2. Experimental conditions explored for fixed bed and micro-flow reactor studies.

\begin{tabular}{cccccc}
\hline Reactor & $\begin{array}{c}\text { JP-10 } \\
(\% \text { by moles })\end{array}$ & $\begin{array}{c}\mathbf{N}_{2} \\
(\% \text { by moles })\end{array}$ & $\begin{array}{c}\text { Pressure } \\
(\mathbf{M P a})\end{array}$ & $\begin{array}{c}\text { Temperature } \\
(\mathbf{K})\end{array}$ & $\begin{array}{c}\text { Residence Time } \\
(\mathbf{s})\end{array}$ \\
\hline Fixed bed & 100 & 0 & 6 & $673-733$ & $5-13$ \\
Micro-flow & 1 & 99 & 0.1 & $700-980$ & 0.4 \\
\hline
\end{tabular}




\subsection{Results and Discussion}

\subsubsection{Flow reactor experiments with fixed bed reactor}

\subsubsection{Thermal stability of JP-10}

Conversion of JP-10 over an inert bed of $\mathrm{ZrO}_{2}$ was performed at $6 \mathrm{MPa}$ to investigate the thermal stability of the fuel under supercritical conditions in the fixed bed reactor system without an active catalyst. A comparison to n-dodecane, a surrogate fuel molecule for kerosene-based fuels such as JP-8, was included to emphasize the relatively high thermal stability of JP-10 and is shown in Figure 3-3.

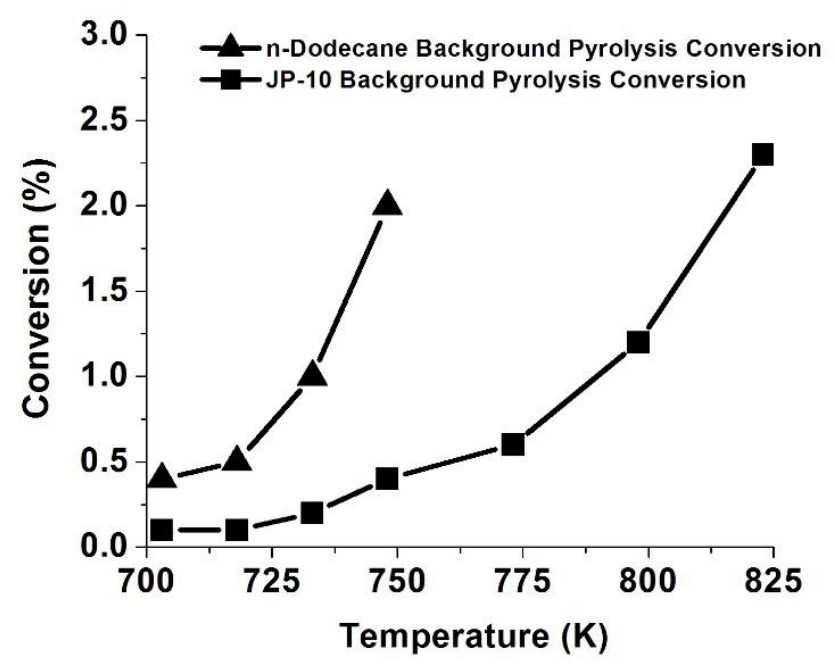

Figure 3-3. Background pyrolysis conversion for $(\boldsymbol{\Delta})$ n-dodecane and ( $(\mathbf{-})$ JP-10 versus temperature. Reaction conditions: total system pressure: $6 \mathrm{MPa}$ and liquid hydrocarbon feed rate: $1.2-3.0 \mathrm{~cm}^{3} \mathrm{~min}^{-1}$.

Under all tested reaction conditions, n-dodecane exhibited higher conversion via pyrolysis, or thermal cracking, than JP-10. It has been generally accepted that pyrolysis proceeds via a free radical chain mechanism and conversion will increase rapidly once a high enough temperature is 
reached and alkyl radicals begin to form and propagate [160]. A rapid increase in pyrolysis rate involving n-dodecane can be observed at temperatures greater than $718 \mathrm{~K}$, while the same behavior is not seen for JP-10 until $748 \mathrm{~K}$. The $30 \mathrm{~K}$ temperature shift in pyrolysis conversion demonstrates the high thermal stability of JP-10 relative to n-dodecane and presumably kerosene-based fuels.

The product distribution from the pyrolysis experiments in the fixed bed reactor at $733 \mathrm{~K}$ is detailed in Table 3-3. The predominant products formed were cyclopentene and cyclopentadiene. Minor products formed included propylene, cyclohexadiene, benzene, toluene, and naphthalene. Negligible conversion was measured below $733 \mathrm{~K}$. The results match those reported by Wohlwend et al. [171], who studied the decomposition of JP-10 in a stainless-steel flow reactor operating at a pressure of $3.4 \mathrm{MPa}$, temperatures between 473 and $923 \mathrm{~K}$, and a residence time of $1.8 \mathrm{~s}$. They reported that JP-10 begins to fragment slightly at $723 \mathrm{~K}$ and the major products formed are cyclopentadiene and cyclopentane. They observed isomerization of the JP-10 feed to its endo-isomer, however they did not report product yields. In the current study, the amount of isomerization during pyrolytic cracking at $733 \mathrm{~K}$ was not quantifiable due to the adamantane and endo-isomer impurities in the feed. These results demonstrate that catalytic experiments involving JP-10 can be performed in the fixed bed reactor system with minimal contribution from background pyrolysis activity at temperatures below $733 \mathrm{~K}$. 


\section{Table 3-3. Results at 10 min TOS from the pyrolytic conversion of JP-10 over inert $\mathrm{ZrO}_{2}$ in a fixed bed flow reactor.}

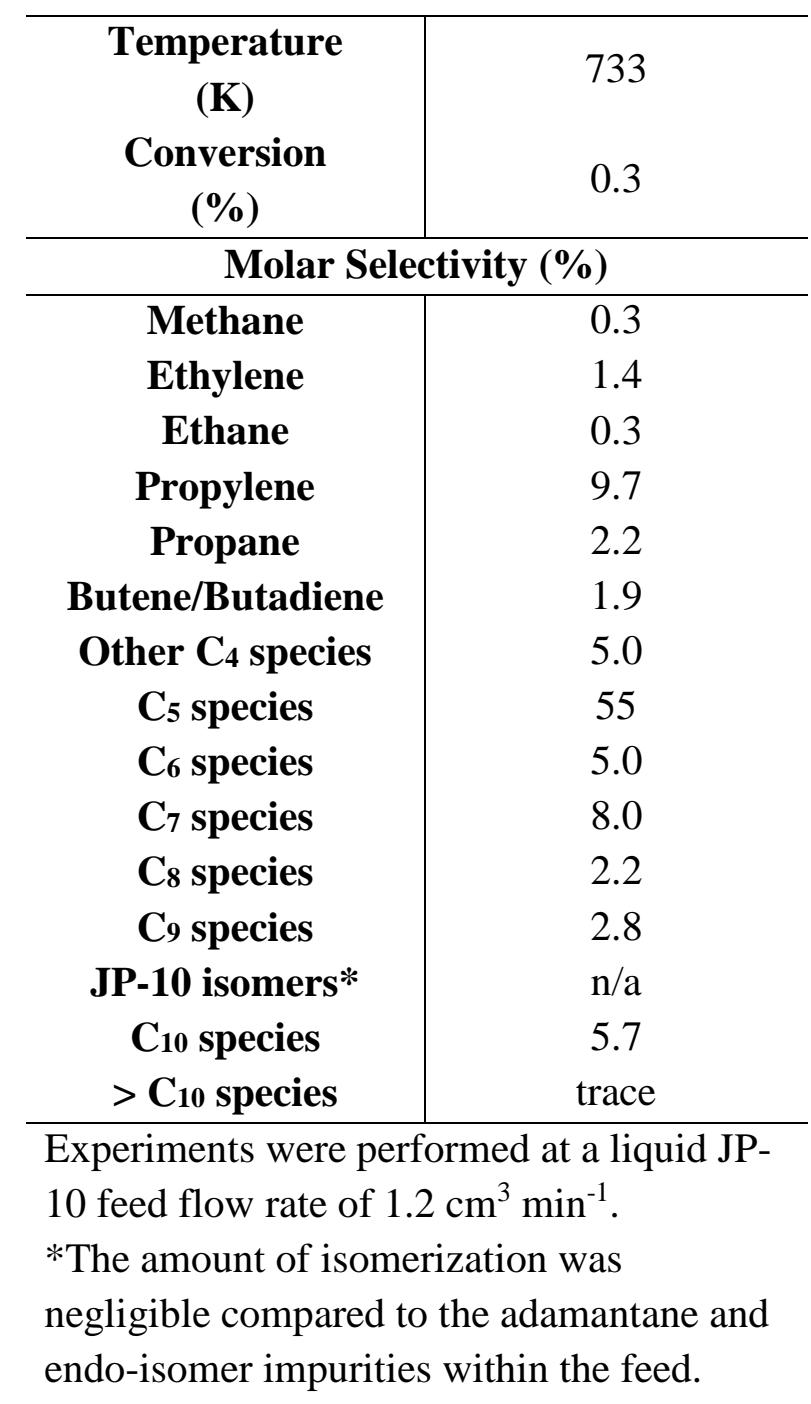

\subsubsection{Catalytic conversion of JP-10}

Catalytic conversion of JP-10 over H-Y zeolite was performed under supercritical conditions. The transient performance of the catalyst at $718 \mathrm{~K}$ is demonstrated in Figure 3-4 and demonstrates that deactivation of the catalyst was observed over 55 minutes time on stream (TOS). Similar behavior was seen at all tested temperatures and the results from Figure 3-4 demonstrate that deactivation is more severe at higher levels of conversion. TOF and selectivity results were 
calculated from the initial product measurements collected after 10 minutes TOS to minimize the effects of deactivation.

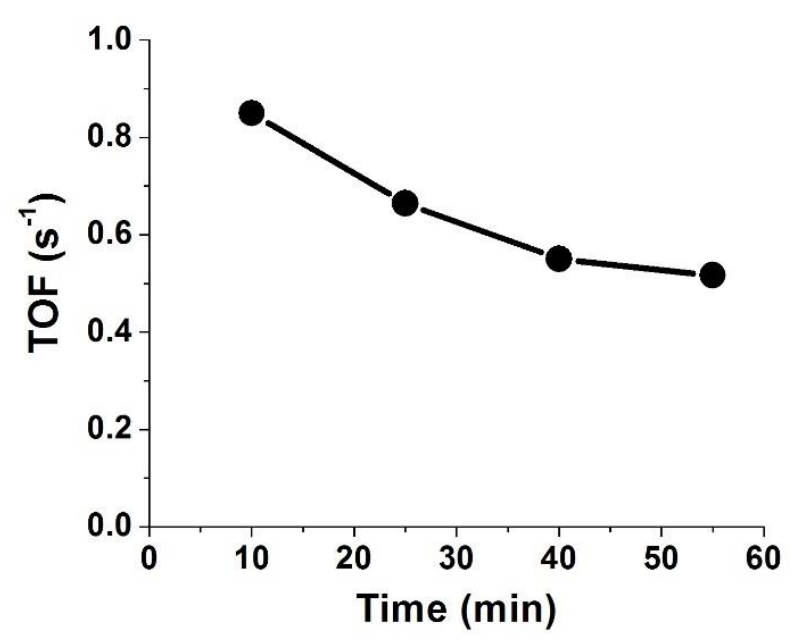

Figure 3-4. TOF of JP-10 cracking versus time on stream over H-Y zeolite at $718 \mathrm{~K}$ and $6 \mathrm{MPa}$ and $\sim 3 \%$ conversion.

The product distributions obtained from cracking of JP-10 over H-Y at from 703 to $733 \mathrm{~K}$ are shown in Table 3-4. Catalytic and pyrolytic cracking of JP-10 in the fixed bed reactor shared several characteristics. For example, cyclohexadiene, benzene, and toluene were formed with similar product selectivities during both pyrolytic and catalytic cracking at $733 \mathrm{~K}$. The major difference between the two processes at $733 \mathrm{~K}$ was the decreased selectivity towards cyclopentadiene and cyclopentene and the increased selectivity towards $\mathrm{C}_{10}$ species. GC-MS analysis, presented in Table B-3, revealed that these $\mathrm{C}_{10}$ species were various forms of substituted indenes and naphthalenes. It is well known that alkenes are highly reactive over acid catalysts and enter molecular growth cycles via oligomerization, alkylation, and hydride transfer reactions to form polycyclic aromatic hydrocarbons (PAHs) that bind strongly to the surface and lead to coke deposits [172-174]. 
Table 3-4. Results at 10 min TOS from the conversion of JP-10 over H-Y in a fixed bed flow reactor at $6 \mathrm{MPa}$.

\begin{tabular}{|c|c|c|c|}
\hline $\begin{array}{c}\text { Temperature } \\
\text { (K) }\end{array}$ & 703 & 718 & 733 \\
\hline $\begin{array}{c}\text { Conversion } \\
(\%)\end{array}$ & 3.6 & 2.6 & 3.0 \\
\hline $\begin{array}{c}\text { TOF } \\
\left(\mathbf{s}^{-1}\right)\end{array}$ & 0.84 & 1.2 & 3.3 \\
\hline \multicolumn{4}{|c|}{ Molar Selectivity (\%) } \\
\hline Methane & 0.1 & 0.1 & 0.1 \\
\hline Ethylene & 0.2 & 0.3 & 0.3 \\
\hline Ethane & 0.1 & 0.1 & 0.1 \\
\hline Propylene & 0.2 & 0.4 & 0.8 \\
\hline Propane & 2.4 & 2.4 & 2.1 \\
\hline Butene/Butadiene & 8.6 & 7.7 & 6.9 \\
\hline Other $\mathrm{C}_{4}$ species & 0.3 & 1.9 & 2.9 \\
\hline $\mathrm{C}_{5}$ species $^{1}$ & 12 & 14 & 17 \\
\hline C6 $_{6}$ species $^{2}$ & 9.0 & 10 & 12 \\
\hline $\mathrm{C}_{7}$ species $^{3}$ & 4.8 & 7.0 & 7.9 \\
\hline C8 species $^{4}$ & 0.9 & 2.5 & 2.7 \\
\hline C9 species & 1.0 & 1.3 & 3.4 \\
\hline $\mathrm{JP}-10$ isomers ${ }^{5}$ & 7.5 & 7.4 & 3.3 \\
\hline Other $C_{10}$ species $^{6}$ & 52 & 43 & 38 \\
\hline$>\mathrm{C}_{10}$ species & 0.7 & 1.9 & 2.5 \\
\hline
\end{tabular}

Experiments were performed at a liquid JP-10 feed flow rate of $1.2 \mathrm{~cm}^{3} \mathrm{~min}^{-1}$.

1. $\mathrm{C}_{5}$ species are mainly cyclopentene/cyclopentane, cyclopentadiene, and pentenes/pentane.

2. $\mathrm{C}_{6}$ species are mainly cyclohexadiene, 1,3 -hexadiene, and benzene.

3. $\mathrm{C}_{7}$ species are toluene and other unknown species.

4. $\mathrm{C}_{8}$ species are ethylbenzenes, xylene, and other unknown species.

5. JP-10 isomers do not include the JP-10 feed and the adamantane and endo-isomer impurities within the feed has been subtracted.

6. Other $\mathrm{C}_{10}$ species do not include the JP-10 feed and are substituted indenes and naphthalene

Anderson et al. [175] studied the treatment of cyclopentadiene over H-ZSM-5 zeolite at 393K and reported that the main products are methylindanes, tetralins, and higher aromatics (naphthalenes and phenanthrenes). Similar products can be formed during the treatment of $\mathrm{n}$ - 
hexane over H-ZSM-5 zeolite, but require a much higher reaction temperature of $593 \mathrm{~K}$ relative to that used for cyclopentadiene because of the high activation energy of n-alkane cracking ( 200 $\mathrm{kJ} \mathrm{mol}^{-1}$ ) $[49,50]$. It is likely that the substituted indenes and naphthalenes observed in the present study were formed from the secondary reaction of cyclopentadiene and cyclopentene. Furthermore, the high apparent activation energy observed for this reaction $\left(\sim 195 \mathrm{~kJ} \mathrm{~mol}^{-1}\right)$, shown in Figure 3-5, suggests that the $\mathrm{C}-\mathrm{C}$ bond cleavage necessary to form cyclopentadiene and cyclopentene is the kinetically-significant step. Similar results were seen during cracking of JP-10 over Al-MCM-41, which is discussed in Appendix B.

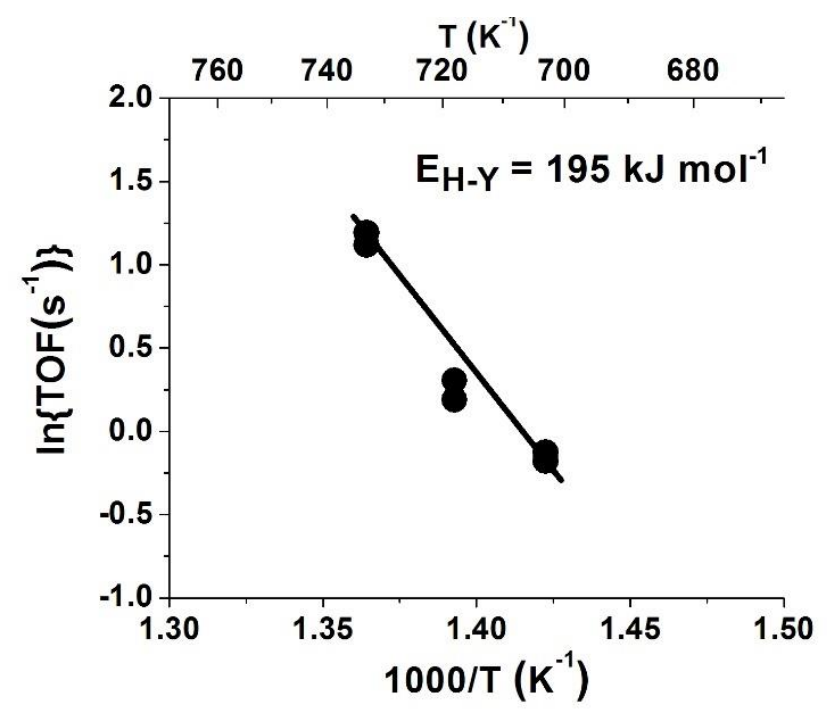

Figure 3-5. Arrhenius-type plot for the reaction of JP-10 over H-Y under supercritical conditions.

At lower levels of JP-10 conversion, H-Y zeolite exhibited moderate deactivation. In practice, high conversion levels are required to meet the heat sink requirements of hypersonic vehicles. Therefore, the conversion level was raised by increasing the catalyst loading from $54 \mathrm{mg}$ to $540 \mathrm{mg}$, presented in Figure 3-6. Observed TOFs at both high (78\%) and moderate (16\%) conversion at $748 \mathrm{~K}$, reported in Table 3-5, exhibited severe deactivation. Increasing the catalyst loading by a factor of 10 resulted in an increase in initial conversion by a factor of 4.9 . This 
demonstrates that severe deactivation can result in lower than expected conversion and, thus, heat sink capacity. This effect must be accounted for during endothermic fuels applications.
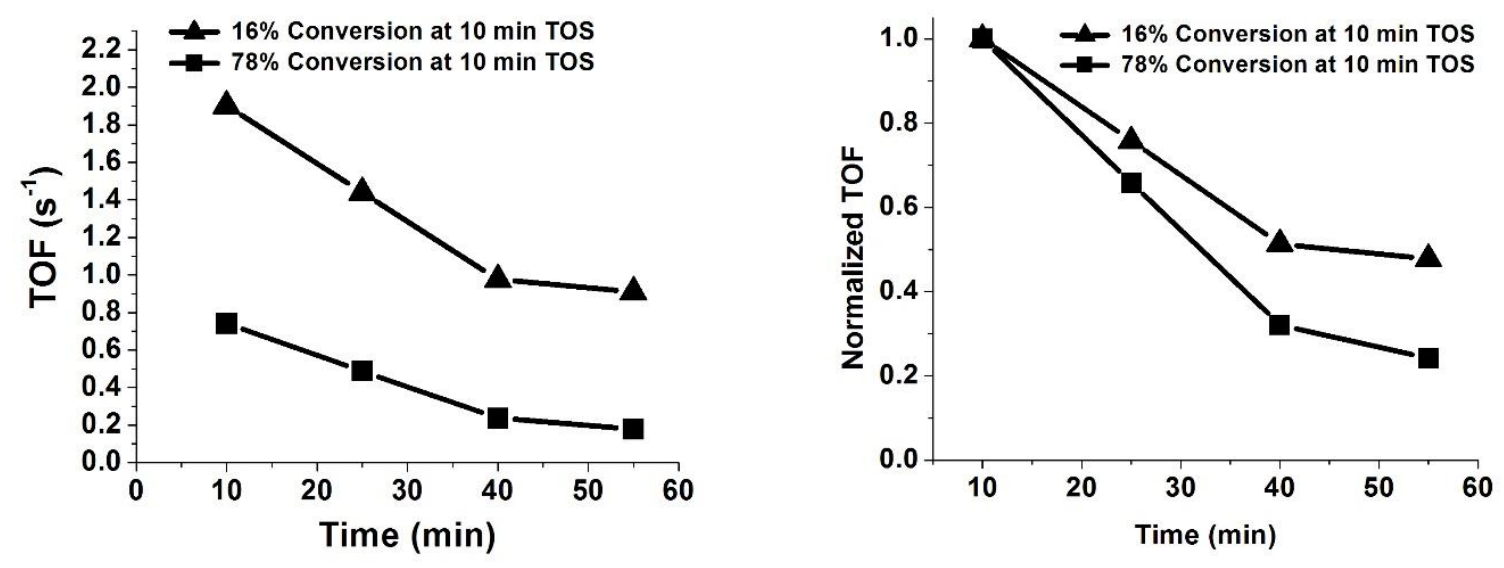

Figure 3-6. TOF (left) and normalized TOF (right) of cracking of JP-10 over H-Y under supercritical conditions versus time on stream at $16 \%$ and $78 \%$ conversion. Reaction conditions: $\mathrm{T}=748 \mathrm{~K}, \mathrm{P}=6 \mathrm{MPa}$, and a JP-10 feed flow rate of $2.4 \mathrm{~cm}^{3} \mathrm{~min}^{-1}$.

An analysis of the product distribution at high and low conversion at $748 \mathrm{~K}$, shown in Table $3-5$, revealed that the major products at low conversion were various forms of substituted indenes and naphthalenes. At higher levels of conversion, the product distribution shifted to alkyl substituted naphthalenes and phenanthrenes. This phenomenon was expected as higher levels of cracking generate a wider range of products that can act as alkylating agents. In addition, Anderson et al. [175] studied the treatment of cyclopentadiene over H-ZSM-5 and reported a shift from methylindanes to naphthalenes and higher aromatics at higher levels of conversion. Therefore, the change in product distribution at higher conversions is consistent with the theory that $\mathrm{C}_{10}$ products during cracking of JP-10 are formed from cyclopentadiene and cyclopentene.

A similar conclusion was reported by Vandewiele et al. for the pyrolytic cracking of JP-10 [176]. They stated that cyclopentadiene and cyclopentene were primary thermal decomposition 
products of JP-10 and that indene, naphthalene, and other PAHs were formed from secondary reactions of cyclopentadiene.

Table 3-5. Effect of conversion on JP-10 cracking product selectivity over $\mathrm{H}-\mathrm{Y}$ at $748 \mathrm{~K}$ and 6 MPa.

\begin{tabular}{|c|c|c|}
\hline $\begin{array}{c}\text { Conversion } \\
(\%) \\
\text { TOF } \\
\left(\mathbf{s}^{-1}\right)\end{array}$ & 1.9 & 0.74 \\
\hline \multicolumn{3}{|c|}{ Molar Selectivity (\%) } \\
\hline Methane & 0.1 & 0.5 \\
\hline Ethylene & 0.2 & 0.1 \\
\hline Ethane & 0.1 & 0.2 \\
\hline Propylene & 0.4 & 0.1 \\
\hline Propane & 2.6 & 2.9 \\
\hline Butene/Butadiene & 8.3 & 5.7 \\
\hline Other $\mathrm{C}_{4}$ species & 3.2 & 3.1 \\
\hline $\mathrm{C}_{5}$ species $^{1}$ & 16 & 12 \\
\hline C6 $_{6}$ species $^{2}$ & 14 & 15 \\
\hline $\mathrm{C}_{7}$ species $^{3}$ & 9.8 & 13 \\
\hline C8 species $^{4}$ & 5.0 & 9.2 \\
\hline C9 species & 2.5 & 5.0 \\
\hline JP-10 isomers ${ }^{5}$ & 1.4 & -- \\
\hline Other C10 species 6 & 32 & 19 \\
\hline$>\mathrm{C}_{10}$ species $^{7}$ & 4.4 & 15 \\
\hline
\end{tabular}

Experiments were performed at a liquid JP-10 feed flow rate of $2.4 \mathrm{~cm}^{3} \mathrm{~min}^{-1}$.

1. $\mathrm{C}_{5}$ species are mainly cyclopentene, cyclopentadiene, and pentenes/pentane.

2. $\mathrm{C}_{6}$ species are mainly cyclohexadiene, 1,3-hexadiene, and benzene.

3. $\mathrm{C}_{7}$ species are toluene and other unknown species.

4. $\mathrm{C}_{8}$ species are ethylbenzenes, xylene, and other unknown species.

5. JP-10 isomers do not include the JP-10 feed and the endo-isomer impurity within the feed has been subtracted. These species could not be identified during the high conversion experiment.

6. Other $\mathrm{C}_{10}$ species do not include the JP-10 feed and are compounds resembling substituted indenes and naphthalene

7. $>\mathrm{C}_{10}$ species include alkyl derivatives of aromatic products. 


\subsubsection{Flow reactor experiments with a wall coated micro-flow reactor}

A wall coated micro-flow reactor system was designed to better simulate the residence times experienced by endothermic fuels. Figure 3-7 and Figure 3-8 depict the comparison of experimental data obtained with and without catalyst and predicted results using a recently developed detailed homogeneous kinetic model [177]. The predicted results are obtained by integrating coupled species conservation equations assuming that highly diluted reacting fluid elements are advected without any mass transport across the interface, commonly known as the zero-dimensional computational model. The homogeneous reaction model consists of 691 species in 15,518 elementary reactions. The JP-10 model kinetic parameters have been validated based on shock tube data and flow reactor data $[167,177]$.

Figure 3-7 shows the major species; $\mathrm{C}_{3} \mathrm{H}_{6}, \mathrm{H}_{2}, \mathrm{C}_{2} \mathrm{H}_{4}, 1-\mathrm{C}_{4} \mathrm{H}_{8}, \mathrm{CH}_{4}$ and $\mathrm{C}_{4} \mathrm{H}_{6}$, while Figure 3-8 shows the minor species; $\mathrm{aC}_{3} \mathrm{H}_{4}, \mathrm{C}_{2} \mathrm{H}_{6}, \mathrm{pC}_{3} \mathrm{H}_{4}$, and $\mathrm{C}_{2} \mathrm{H}_{2}$. These species were consistent with the components identified in experiments conducted by Vandewiele et al. [176] and Gao et al. [177].

In addition to the species shown in the plots, species such as cyclopentene, benzene, 1, 3hexadiene, cyclohexadiene and toluene are some of other major species observed in the experiments (See GC and GCMS chromatograms in Figure 3-9 and Figure 3-10 respectively). At similar product yield, the addition of the catalyst significantly changed the product distribution. It was observed that the concentrations of hydrogen, methane, ethylene, ethane, acetylene, allene, propyne, cyclopentadiene and cyclopentene were reduced with addition of catalyst. In contrast, propylene, 1,3-butadiene, 1-butene, cyclohexadiene and 1,3-hexadiene were significantly increased with the addition of catalyst. 

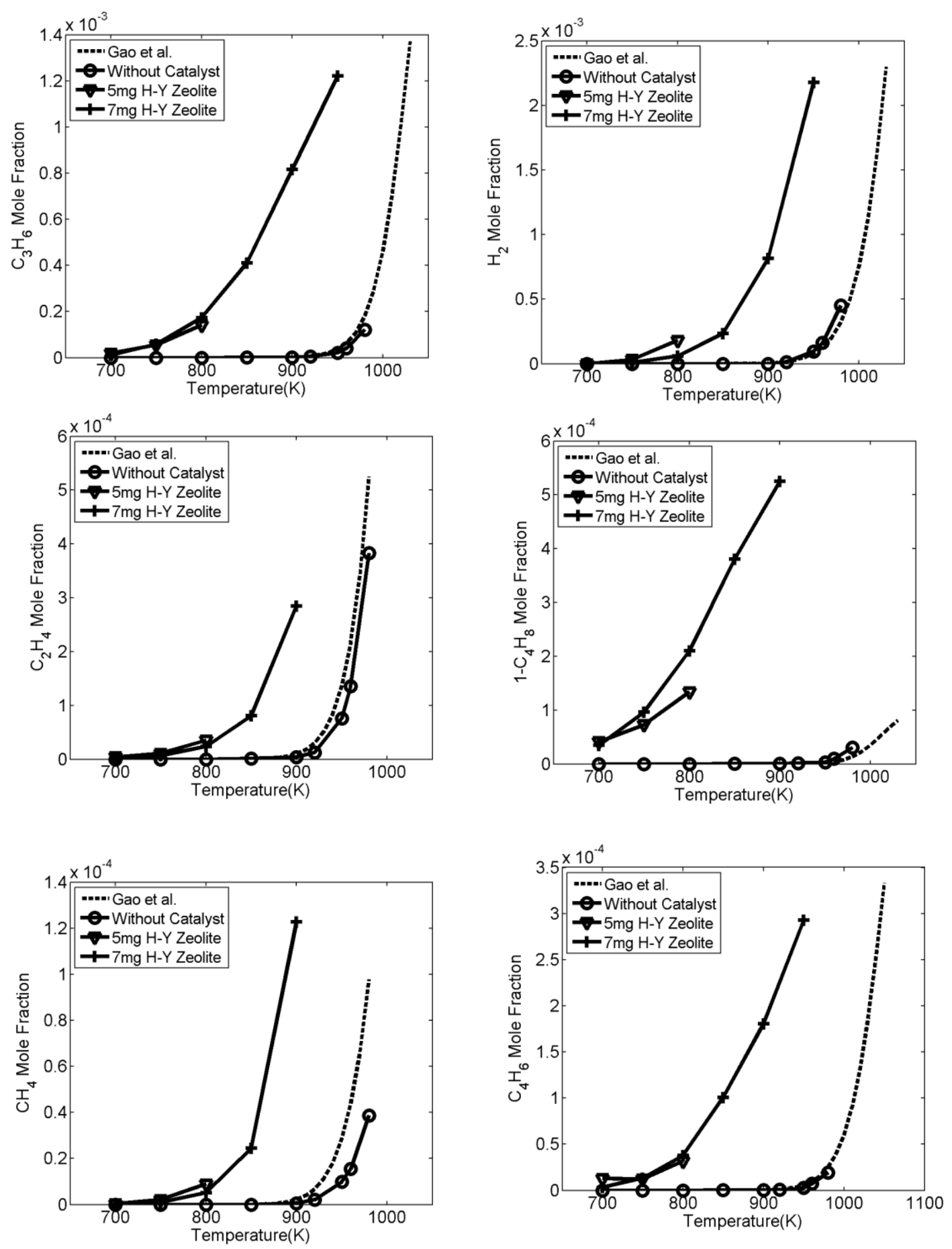

Figure 3-7. Comparison of major species yield from JP-10 pyrolysis as a function of hot-section temperature, for 1\% JP-10 in nitrogen (by moles) at residence time $400 \mathrm{~ms}$ and pressure $1 \mathrm{~atm}$. $\nabla$ and + represents $\mathrm{H}-\mathrm{Y}$ zeolite loadings of $5 \mathrm{mg}$ and $7 \mathrm{mg}$, respectively; $O$ represents without $\mathrm{H}-$ Y zeolite catalyst; dashed line represents numerical predictions using a detailed chemical kinetic model proposed by Gao et al. [177] without catalytic reactions. 

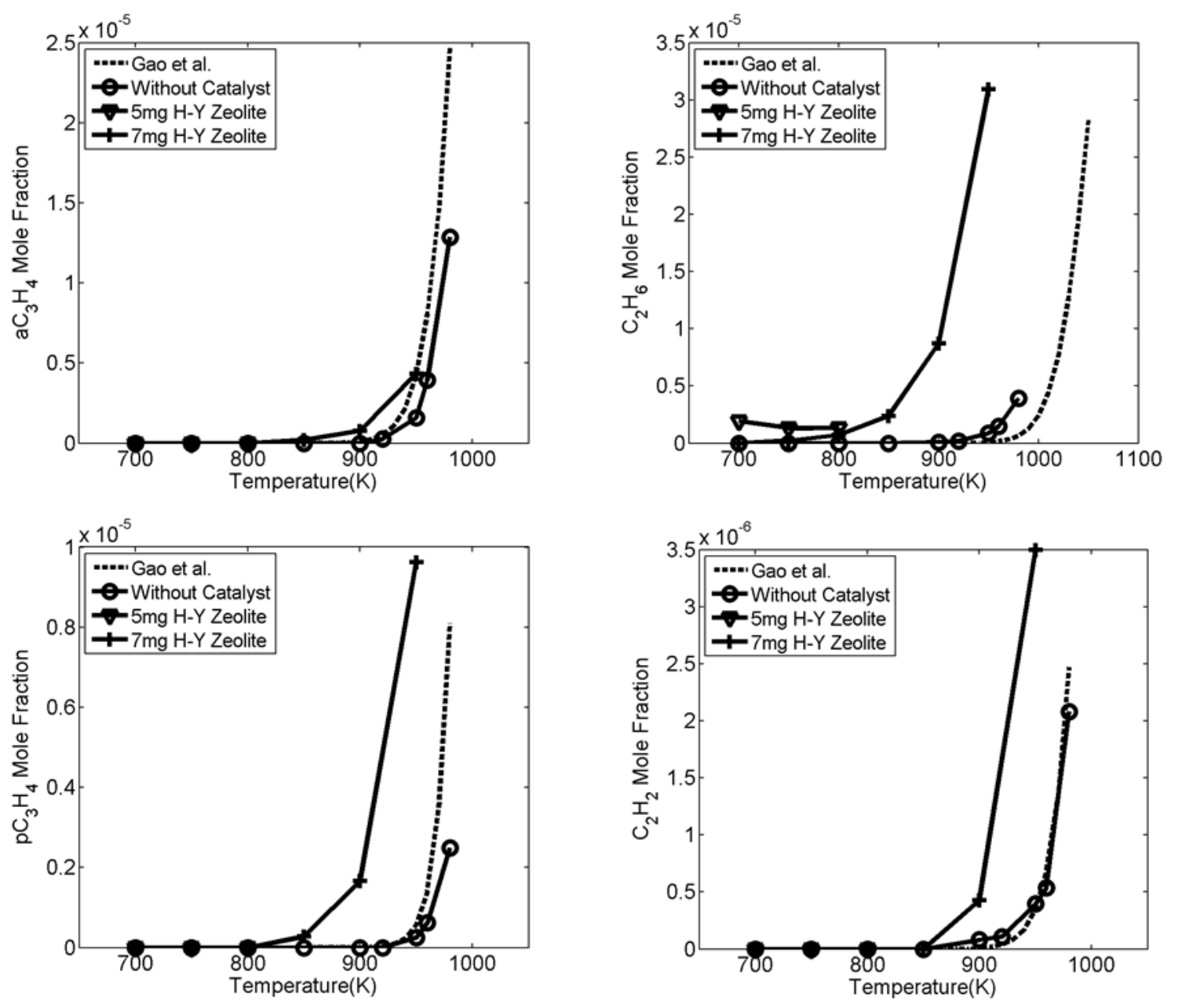

Figure 3-8. Comparison of minor species yield from JP-10 pyrolysis as a function of hot-section temperature, for 1\% JP-10 in nitrogen (by moles) at residence time $400 \mathrm{~ms}$ and pressure $1 \mathrm{~atm}$. $\nabla$ and + represents $\mathrm{H}-\mathrm{Y}$ zeolite loadings of $5 \mathrm{mg}$ and $7 \mathrm{mg}$, respectively; O represents without $\mathrm{H}$ Y zeolite catalyst; dashed line represents numerical predictions using a detailed chemical kinetic model proposed by Gao et al. [177] without catalytic reactions. 


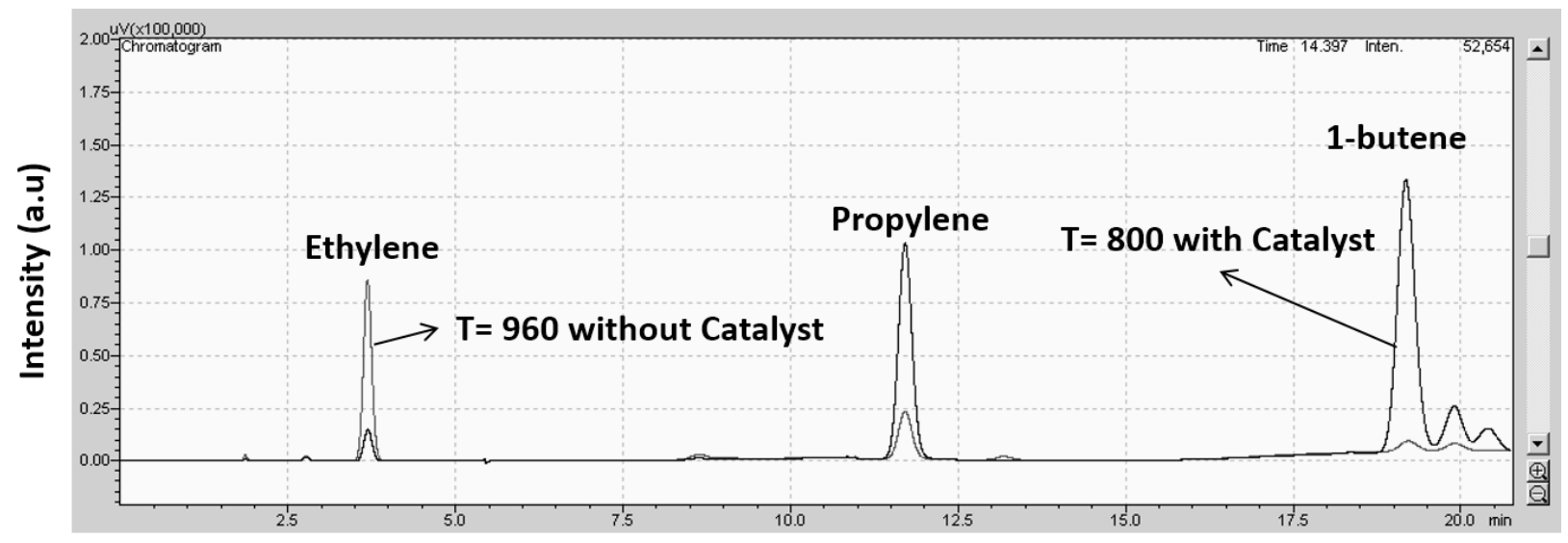

Retention time (min)

Figure 3-9. GC chromatogram during homogeneous and catalytic pyrolysis at $\mathrm{T}=800 \mathrm{~K}$ and $\mathrm{T}=960$ $\mathrm{K}$ respectively. The residence time is kept fixed at $\mathrm{t}_{\mathrm{res}}=0.4 \mathrm{~s}$.

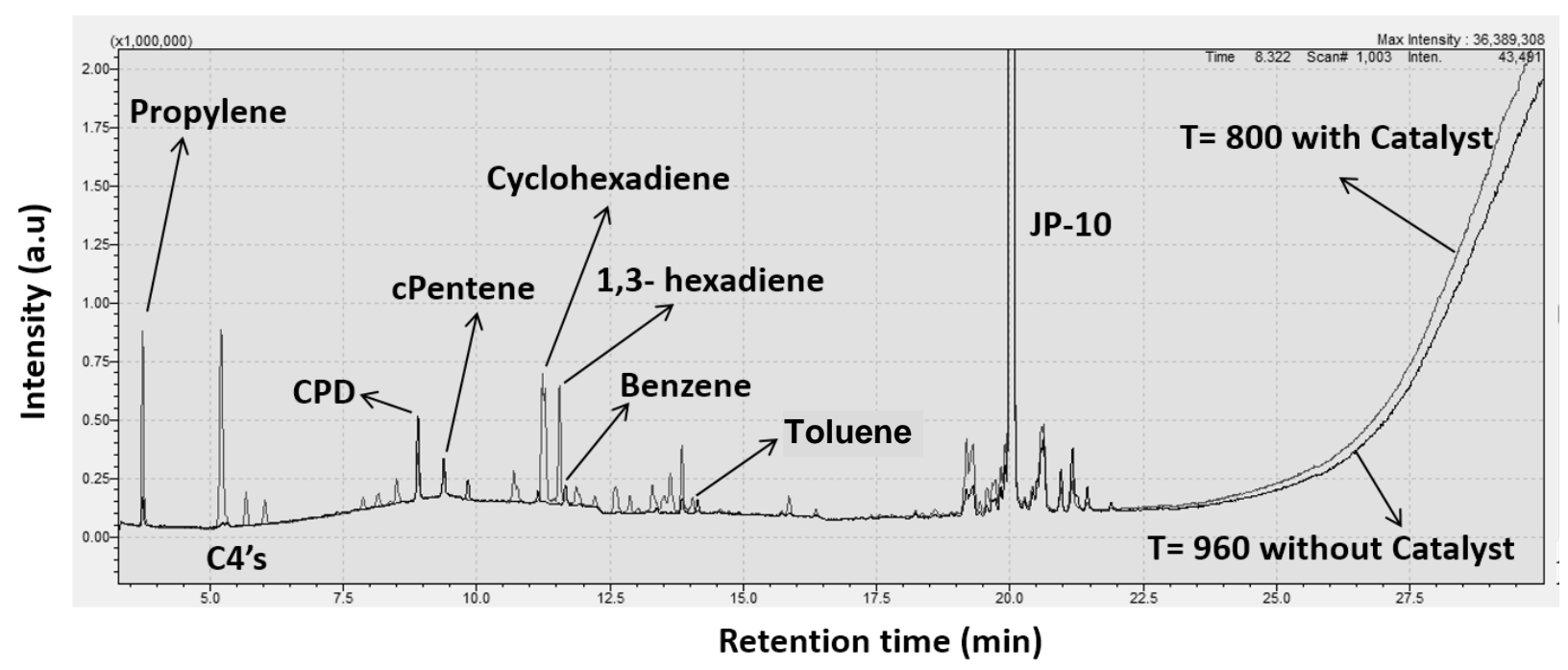

Figure 3-10. GC-MS chromatogram during homogeneous and catalytic pyrolysis at $\mathrm{T}=800 \mathrm{~K}$ and $\mathrm{T}=960 \mathrm{~K}$ respectively. The residence time is kept fixed at $\mathrm{t}_{\mathrm{res}}=0.4 \mathrm{~s}$.

Table 3-6 shows a comparison of estimated endothermicity at iso-conversion level of $3.13 \%$ with and without catalyst. Also shown in the table is the sensible cooling capacity $\left(\Delta h_{\text {sens }}\right)$ between $298.15 \mathrm{~K}$ and the iso-conversion temperature listed. The first key observation is that with catalyst the conversion occurs at a temperature about $188 \mathrm{~K}$ lower than without catalyst. Second, 
at this small conversion level, the endothermic cooling capacity is very small when compared with the sensible cooling capacity. More importantly, the species yield with catalyst results in no significant change in endothermic cooling capacity compared to without the catalyst.

Table 3-6. Comparison of endothermic vs. sensible enthalpy from JP-10 pyrolysis with and without catalyst.

\begin{tabular}{c|ccc}
\hline \multicolumn{1}{c}{ Condition } & $\begin{array}{c}\text { Iso-conversion } \mathbf{T} \\
(\mathbf{K})\end{array}$ & $\begin{array}{c}\text { Endothermic cooling } \\
\left(\mathbf{k J ~ m o l} \mathbf{~ m}^{-\mathbf{1}}\right)\end{array}$ & $\begin{array}{c}\text { Sensible cooling } \\
\left(\mathbf{k J ~ m o l}^{-1}\right)\end{array}$ \\
\hline Without catalyst & 960 & 5.9 & $3.0 \times 10^{2}$ \\
With catalyst & 772 & 6.0 & $2.1 \times 10^{2}$ \\
\hline
\end{tabular}

Figure 3-11 and Figure 3-12 describe the homogeneous reaction pathways that lead to the key species identified by the GC/FID/TCD/MS system at T=960K and residence time of $0.4 \mathrm{~s}$. The reaction flux paths were observed to be similar to JP-10 decomposition study reported by Gao et al. [177] at $\mathrm{T}=1000 \mathrm{~K}$. The main consumption of JP-10 occurs due to hydrogen abstraction to form JP-10 radicals (R1- R8) as shown in [177]. The hydrogen abstraction takes place due to the reaction of allyl, hydrogen and methyl radical with JP-10. Each hydrogen abstraction reaction follows a separate reaction pathways with different reaction flux to form JP-10 radicals, hydrogen, methane and propylene. These stable species are some of the major species observed in the present experiments (see Figure 3-7). Furthermore, it can be observed from that the most dominant channel that JP-10 decomposes into R8 (27\%) and R6 (19\%). 


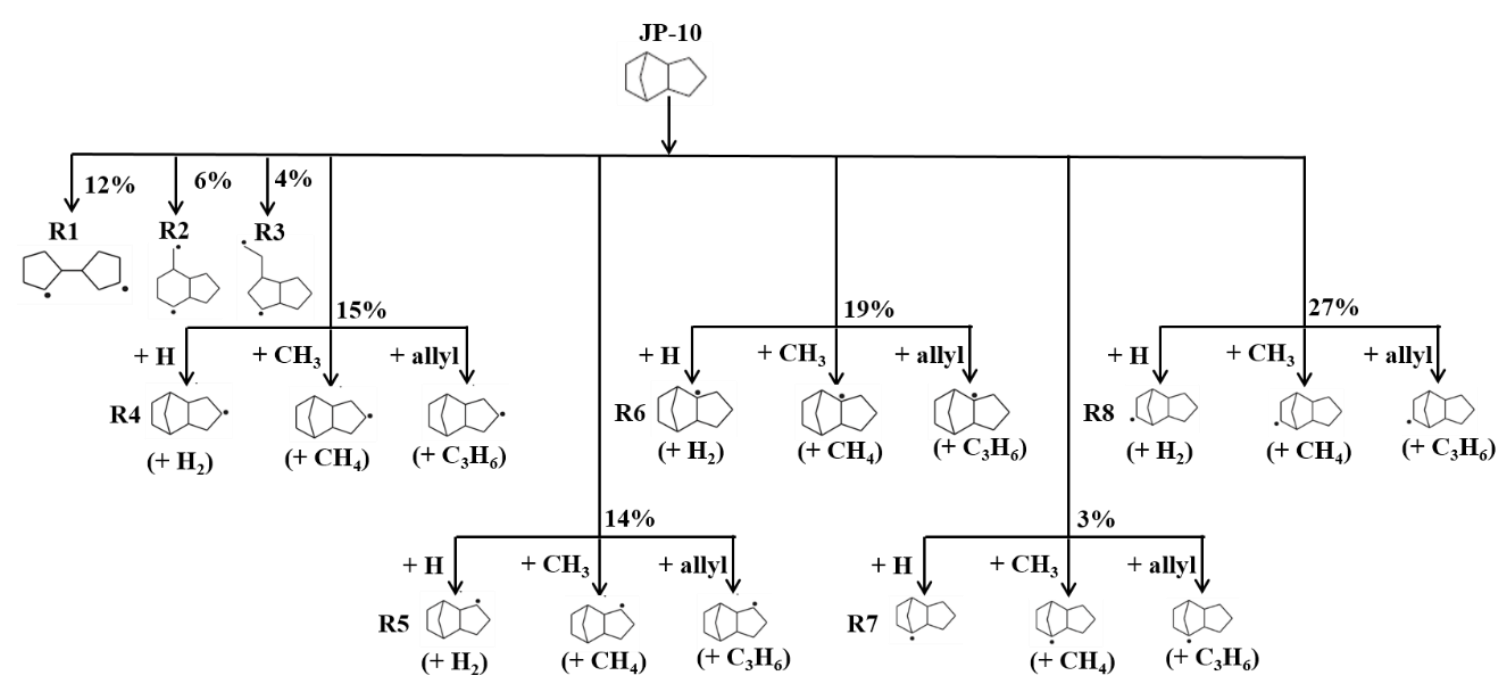

Figure 3-11. Reaction path flux analysis of JP-10 pyrolysis indicating the key reactions that JP10 radical and key species such as hydrogen, methane and propylene identified in experiments at $\mathrm{T}=960 \mathrm{~K}$ and residence time of 0.4 seconds

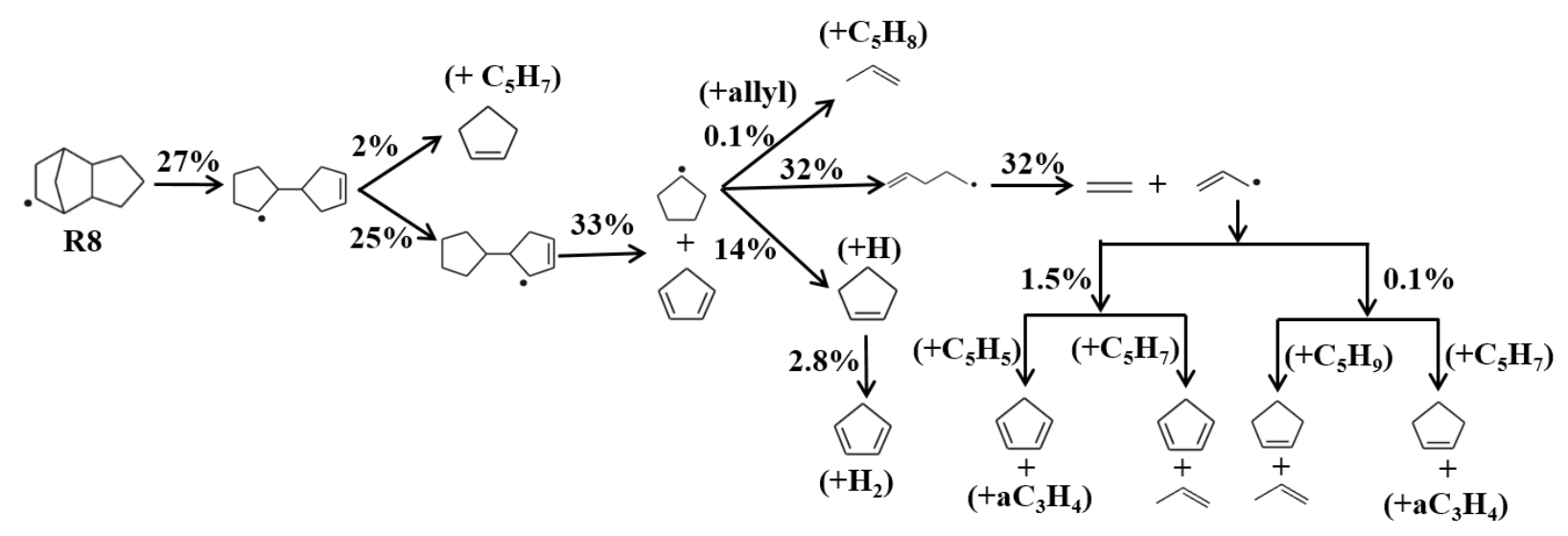

Figure 3-12. Reaction path flux analysis of R8 (JP-10 radical) pyrolysis indicating the key reactions that lead to the species such as allene, ethylene, cycopentadiene, and cyclopentene identified in experiments at $\mathrm{T}=960 \mathrm{~K}$ and residence time of 0.4 seconds.

The main consumption of JP-10 occurs due to hydrogen abstraction to form JP-10 radicals (R1- R8) as shown in [177]. The hydrogen abstraction takes place due to the reaction of allyl, hydrogen and methyl radical with JP-10. Each hydrogen abstraction reaction follows a separate reaction pathways with different reaction flux to form JP-10 radicals, hydrogen, methane and 
propylene. These stable species are some of the major species observed in the present experiments (see Figure 3-7). Furthermore, it can be observed from that the most dominant channel that JP-10 decomposes into R8 (27\%) and R6 (19\%).

The reaction path analysis for channel R8 is shown in Figure 3-12. It can be observed from this analysis that $33 \%$ of JP-10 decomposes into cyclopentyl and cyclopentadiene. One of the reaction paths for cyclopentyl leads to the formation of $14 \%$ cyclopentene and the other leads to the formation of ethylene and allyl radical. Both ethylene and cyclopentene were observed in the current experiments. Furthermore, the allyl radical reacts with various $\mathrm{C}_{5}$ molecules to form cyclopentadiene, cyclopentene, propylene and allene. These reaction pathways clearly explain the formation of ethylene, propylene and cyclopentadiene as major products and allene as minor products in the current experiments. The reaction path analysis for the R6 radical is shown in Figure 3-13. The path depicts the decomposition of JP-10 into toluene and methyl radical which was also observed in the current study.

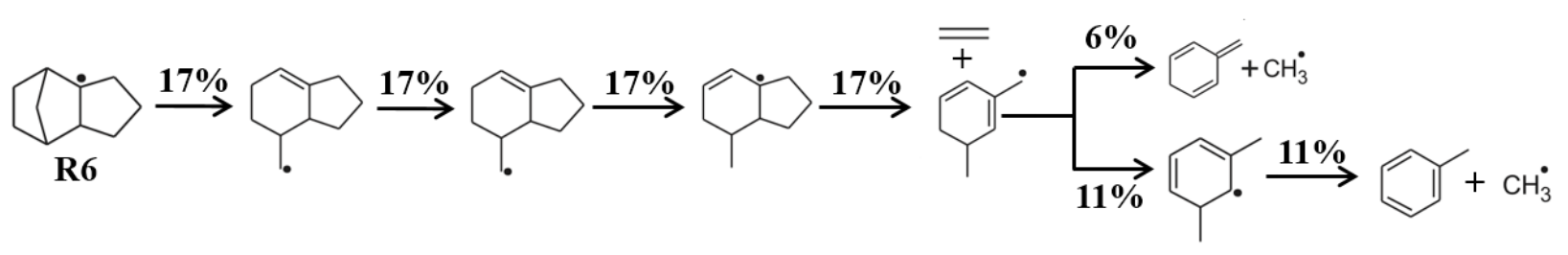

Figure 3-13. Reaction path flux analysis of R6 (JP-10 radical) indicating the key reactions that lead to toluene identified in experiments at $\mathrm{T}=960 \mathrm{~K}$ and residence time of 0.4 seconds.

Major species such ethylene and methane decreased while propylene, 1,3-butadiene and cyclohexadiene increased with the addition of the catalyst. This change in product distribution indicates a difference in major reaction paths with addition of catalyst. Without the catalyst, around 14\% of JP-10 decomposes into R5 (See Figure 3-11). The formation of 1,3-butadiene and cyclohexadiene can be observed by analysis of the R5 reaction path as shown in Figure 3-14 and 
approximately $1.8 \%$ on JP-10 decomposes into cyclohexenyl and 1-3, butadiene. Cyclohexenyl then converts into cyclohexadiene with $\mathrm{H}$ atom addition. The percentages given for the $\mathrm{R} 5$ reaction path analysis is without the catalyst and represent the small concentration of these species consistent with the homogeneous experiments. However, larger concentration of these species with addition of the catalyst indicate $\mathrm{R} 5$ as one of the major reaction pathways leading to cyclohexadiene and 1,3-butadiene. This phenomenon was observed in both the fixed bed and MFTR systems and demonstrates the extrapolation of rate models across a wide range of operating conditions.

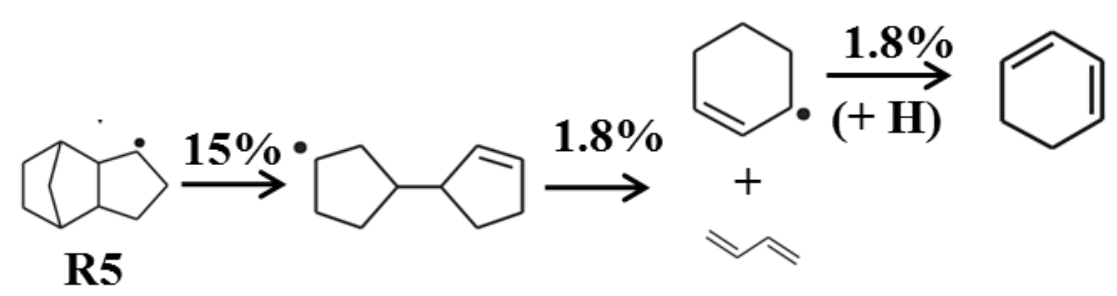

Figure 3-14. Reaction path flux analysis of R5 (JP-10 radical) indicating the key reactions that lead to 1,3-butadiene and cyclohexadiene identified in experiments at $\mathrm{T}=960 \mathrm{~K}$ and residence time of 0.4 seconds

\subsection{Conclusions}

The performance of catalytic cracking of JP-10 over H-Y was evaluated for its potential as an endothermic fuel. Reactor studies were performed using both a fixed bed reactor and MFTR to account for the challenging conditions necessary for endothermic fuels. Supercritical studies performed in the fixed bed reactor system confirmed the thermal stability of JP-10 compared to ndodecane and showed the importance of cyclopentadiene and cyclopentene in both pyrolytic and catalytic cracking. These results were also obtained using a MFTR under ambient pressure and a residence time more similar to that experienced by endothermic fuels. At similar levels of 
conversion, the change in product selectivity via catalytic cracking of JP-10 compared to pyrolytic cracking did not result in an improvement of the endothermic cooling capacity. However, the addition of H-Y coating did lower the cracking temperature by $188 \mathrm{~K}$. The lack of change in endothermic cooling potential and the high propensity for coke formation suggest that H-Y/JP-10 is not a suitable catalyst/fuel pairing for endothermic applications.

\section{Acknowledgements}

We acknowledge support from Air Force Office of Scientific Research (AFOSR FA955012-1-0496) for funding, Dr. Matthew Neurock and Dr. Peng Bai for their helpful discussions, and Jiahan Xie for his assistance with the reactor catalyst coating. 


\section{Investigation of Branched Hydrocarbons}

\subsection{Introduction}

In the previous two chapters, the behavior of linear and cyclic alkanes during catalytic cracking over solid acid catalysts was explored under supercritical conditions. Military jet fuels such as JP-7 or JP-8 are blend fuels containing linear, cyclic, and branched hydrocarbons [122,178]. For example, an analysis of military jet fuel, JP-8, revealed over 100 distinct linear, branched, and cyclic hydrocarbons ranging in carbon number from $\mathrm{C}_{6}$ up to $\mathrm{C}_{17}$ [122]. In this chapter, the cracking of branched hydrocarbons, shown in Figure 4-1 and mixtures of branched and linear hydrocarbons under supercritical conditions was used to determine the effect of substituted carbons on hydrocarbon cracking rates. In addition, a preliminary evaluation on the performance of H-ZSM-5 and ASA during cracking of JP-8 is included.

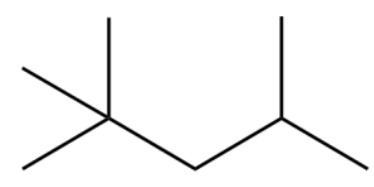

Isooctane

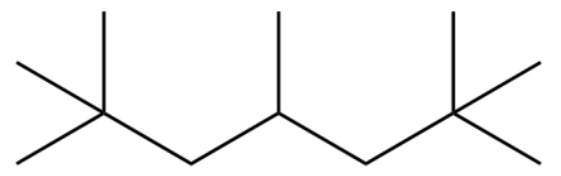

Isododecane

\section{2,2,4-trimethylpentane}

2,2,4,6,6-pentamethylheptane

Figure 4-1. Skeletal formulas, IUPAC names, and chemical formulas for isooctane and isododecane.

The bimolecular hydride transfer reaction is critical to hydrocarbon cracking because it transfers the charge on a carbocation to another molecule and continues the reaction chain. Hydride transfer has been shown to be extremely rapid between highly substituted carbons. For example, hydride transfer from a secondary carbon atom of an alkane to a tertiary carbenium ion requires 
an activation energy of $55 \mathrm{~kJ} \cdot \mathrm{mol}^{-1}$ while the transfer between two tertiary carbon atoms requires only $12 \mathrm{~kJ} \cdot \mathrm{mol}^{-1}[179]$. This is due to the relative stability of the carbenium ions involved in the reaction [31].

Pore restrictions in H-ZSM-5 limit access of bulky branched molecules such as isooctane and isododecane. In addition, bimolecular hydride transfer reactions may be restricted in the confined pores of H-ZSM-5. Namba et al. [180] observed that branched (2,2-dimethylbutane) and cyclic hydrocarbons (cyclohexane and toluene) inhibited the catalytic cracking of n-octane over H-ZSM-5 and attributed the effect to the diffusivity of branched and cyclic hydrocarbons. This effect was seen under supercritical conditions as well. Wang et al. [181] studied the influence of adding highly branched isododecane on the cracking of n-dodecane over H-ZSM-5 under supercritical conditions. They reported that the diameter of isododecane was larger than the pore size of the H-ZSM-5 channels, and was unable to access the acid sites in the zeolite pores. As a result, isododecane acts as an inert diluent in a binary mixture over H-ZSM-5. In contrast, branched hydrocarbons were shown to have a promotional effect on the pyrolytic cracking rates of other hydrocarbons. Edwards et al. [182] compared the thermal stability and coke deposition characteristics of a fuel comprised of predominantly linear paraffins against a synthetic fuel comprised of predominantly iso-paraffins. It was suggested that the increased reactivity of the synthetic fuel could be explained by the higher radical initiation rates of the branched alkanes. Li et al. [164] studied the thermal decomposition of JP-10, isooctane, and JP-10/isooctane binary mixtures and showed that isooctane can accelerate the decomposition of JP-10 and the formation of alkenes in the binary system. It is clear that branched hydrocarbons can promote pyrolytic cracking rates, but inhibit catalytic cracking rates due to diffusion limitations in H-ZSM-5. Therefore, while H-ZSM-5 is an active catalyst for catalytic cracking of linear alkanes, a larger 
pore material may be more suitable for military jet fuels. In this work, cracking of branched alkanes and mixtures of branched and linear alkanes was performed over micro- and mesoporous aluminosilicates with pore dimensions large enough to accommodate bulkier molecules under near-critical and supercritical conditions. A thorough understanding of the effect of branched alkanes on hydrocarbon cracking rates will provide valuable insight into the development of catalyst/fuel pairings for endothermic fuels.

\subsection{Methods}

\subsubsection{Materials}

Isooctane (Sigma-Aldrich, anhydrous, 99.8\% purity), isododecane (TCI America, 98.0\% purity), n-dodecane (Sigma-Aldrich, $\geq 99 \%$ purity), and JP-8 (Batch 13POSF10264, Wright Patterson Air Force Base) were used as the feed. n-Tridecane (Sigma-Aldrich, 99\% purity anhydrous) was added as an external standard during gas chromatography (GC) analysis. nPropylamine (Sigma-Aldrich, $\geq 99.0 \%$ purity) was used for the temperature-programmed desorption/mass spectrometry (TGA-MS) analysis to determine the Brønsted-acid site density for the catalysts. The following gases were used for calcination, TGA, and GC operation: dry air (GTS-Welco), helium (GTS-Welco, 99.999\%), dihydrogen (GTS-Welco, 99.999\%), dinitrogen (GTS-Welco, 99.999\%) and propylene (GTS-Welco, PY60).

The $\mathrm{NH}_{4}-\mathrm{ZSM}-5$ (45881) and H-Y (45872) zeolites were purchased from Alfa Aesar. The amorphous silica alumina (ASA) (343358) was purchased from Sigma-Aldrich. To test for background conversion, a pure $\mathrm{ZrO}_{2}$ sample was synthesized in the lab. Amorphous $\mathrm{ZrO}_{\mathrm{x}}(\mathrm{OH})_{4-2 \mathrm{x}}$ 
(MEL Chemicals, XZO1501/09) was calcined to $\mathrm{ZrO}_{2}$ in dry air $\left(100 \mathrm{~cm}^{3} \mathrm{~min}^{-1}\right)$ at $973 \mathrm{~K}$ at $10 \mathrm{~K}$ $\min ^{-1}$, holding for $4 \mathrm{~h}$ before being pressed and sized using -40/+100 (150 - 425 $\left.\mu \mathrm{m}\right)$ sieves trays.

\subsubsection{Catalyst characterization}

The aluminosilicate catalysts used in this study were loaded into a quartz reactor and pretreated in $100 \mathrm{~cm}^{3} \mathrm{~min}^{-1}$ of $21 \% \mathrm{O}_{2}$ and balance He after heating to $823 \mathrm{~K}$ at $5 \mathrm{~K} \mathrm{~min}^{-1}$ and holding for $2 \mathrm{~h}$. After the pretreatment, the catalysts were exposed to n-propylamine at $448 \mathrm{~K}$ for 15 min by passing $\mathrm{He}\left(30 \mathrm{~cm}^{3} \mathrm{~min}^{-1}\right)$ through an $\mathrm{n}$-propylamine saturator that was held in an ice bath. The catalyst sample was then purged at $448 \mathrm{~K}$ for $2 \mathrm{~h}$ under flowing $\mathrm{He}\left(100 \mathrm{~cm}^{3} \mathrm{~min}^{-1}\right)$ to remove excess n-propylamine. The catalyst sample was then heated to $873 \mathrm{~K}$ at $20 \mathrm{~K} \mathrm{~min}^{-1}$ under flowing He $\left(100 \mathrm{~cm}^{3} \mathrm{~min}^{-1}\right)$ and the mass spectrometer (MS) was used to track unreacted amine $(\mathrm{m} / \mathrm{e}=30)$, propylene $(\mathrm{m} / \mathrm{e}=41)$ and ammonia $(\mathrm{m} / \mathrm{e}=30)$. Previous work has shown that the Brønsted-acid site density can be quantified from the amount of amine that reacts between 650 and $725 \mathrm{~K}$ [89,123-125]. A known amount of propylene was introduced to the system using a six-way valve after each n-propylamine decomposition experiment to calibrate the propylene MS signal.

Pore size distributions, calculated using the Barrett, Joyner and Halenda (BJH) method [126], were obtained by $\mathrm{N}_{2}$ adsorption measured at $77 \mathrm{~K}$ using a Micromeritics ASAP 2020 automated analyzer.

\subsubsection{Catalytic tests}

Hydrocarbon conversion reactions were carried out in an upward-flow fixed bed reactor under supercritical conditions. Catalysts were pressed and sized using -40/+100 (150 - 425 $\mu \mathrm{m})$ 
sieve trays. A titanium reactor (Grade 2 titanium from McMaster-Carr) with an outer diameter of $6.35 \mathrm{~mm}$ and an inner diameter (ID) of $4 \mathrm{~mm}$ was used to hold the catalyst that was supported between two glass wool plugs. Catalysts were heated in situ in flowing dry air $\left(100 \mathrm{~cm}^{3} \mathrm{~min}^{-1}\right)$ at $5 \mathrm{~K} \mathrm{~min}^{-1}$ to $823 \mathrm{~K}$ and holding at that temperature for $2 \mathrm{~h}$. Liquid hydrocarbon was fed to the reactor using a Teledyne Isco 260D high pressure syringe pump. A gas-liquid separator was used to collect liquid product between sampling intervals. Dinitrogen was used to purge the gas-liquid separator and to maintain the pressure in the system, which was controlled by a back pressure regulator. The dinitrogen purge along with the gas-phase products were fed to a gas chromatograph (Shimadzu GC-2014) equipped with a flame ionization detector (FID). A Restek RT-QS-BOND (30 m, $0.53 \mathrm{~mm}$ ID, $20 \mu \mathrm{m}$ film thickness) column was used to separate the products. $\mathrm{n}$-Tridecane (Sigma-Aldrich, 99\% purity anhydrous) was added to the liquid products as an external standard. The liquid products were injected into the GC using an AOC-20i auto sampler.

The peak areas of reactants and products identified by GC were used to determine the hydrocarbon feed conversion and selectivity of products. The conversion of hydrocarbon feed was calculated according to and defined as follows:

$$
\text { Conversion }(\mathrm{C} \%)=\left(\frac{\sum n_{i} M_{i}}{x}\right) \times 100
$$

where $n_{i}$ is the number of carbon atoms in product $i, M_{i}$ is the molar ratio of product $i$ detected to the initial moles of hydrocarbon feed and $x$ represents the number of carbon atoms in the hydrocarbon feed. Conversion for the cracking of the 50/50 mol.\% mixture of isooctane and ndodecane was calculated assuming an average carbon number of 10 for the hydrocarbon feed.

The selectivity toward product $i$ was calculated on a molar basis and defined as follows: 
Molar Selectivity $(\%)=\left(\frac{M_{i}}{\sum M_{i}}\right) \times 100$

The catalyst loading in the reactor depended on the activity of the particular catalyst and the mass was diluted with a corresponding amount of $\mathrm{ZrO}_{2}$ to keep the length of the catalyst bed constant at $5 \mathrm{~cm}$. The catalyst loading was varied to keep the overall conversion below $10 \%$ to ensure differential reactor conditions. Reactions with only a bed of $\mathrm{ZrO}_{2}$ were also run for all conditions used in this work to determine the amount of background conversion from pyrolysis. The hydrocarbon liquid feed rate was varied from $0.3 \mathrm{~cm}^{3} \min ^{-1}$ to $1.2 \mathrm{~cm}^{3} \mathrm{~min}^{-1}$, depending on the reaction temperature, to keep the background conversion below $0.5 \%$ at all times. Measurements used to determine activation energies were determined at a constant weight hourly space velocity (WHSV), to account for the effect that WHSV can have on product selectivity [116]. Rate is reported in terms of turnover frequency (TOF), which is calculated as the rate of hydrocarbon feed conversion normalized to the acid-site density reported in Table 4-1.

Table 4-1. Properties of aluminosilicate catalysts.

\begin{tabular}{|c|c|c|c|c|}
\hline Catalyst & $\begin{array}{c}\text { Pore Size } \\
\text { (̊) }\end{array}$ & Si/Al 2 Ratio $^{a}$ & $\begin{array}{c}\text { Aluminum } \\
\text { Content }^{\mathrm{a}} \\
(\mathrm{wt} . \%)\end{array}$ & $\begin{array}{c}\text { Brønsted-site } \\
\text { Density }^{b} \\
\left(\mu \mathrm{mol} \cdot \mathrm{g}^{-1}\right)\end{array}$ \\
\hline H-ZSM-5 & $\sim 5.5^{c}$ & $55: 1$ & -- & 550 \\
\hline H-Y & $7.4^{\mathrm{c}}$ & $85: 1$ & -- & 162 \\
\hline ASA & $40-100^{d}$ & -- & 6.5 & 68 \\
\hline
\end{tabular}
a. Based on manufacturer data
b. Brønsted acid site concentrations were determined by n-propylamine decomposition
c. Pore size from the Atlas of Zeolite Framework Types [137]
d. Pore size was determined by $\mathrm{N}_{2}$ adsorption measurements using the BJH method 


\subsection{Results and Discussion}

Results from reactions of isooctane and isododecane over H-ZSM-5, shown in Figure 4-2, confirm that the branched molecules are much more difficult to crack than linear alkanes, presumably due to pore size restrictions. This was expected because the pores of H-ZSM-5 ( 5.4 $\AA)$ are smaller than the kinetic diameter of isooctane $(\sim 6.3 \AA)$ and isododecane [183]. However, the same trend was seen in Figure 4-3, albeit to a lesser extent, over ASA which has a wide distribution of pores ranging from $40-100 \AA$ that can readily accommodate isooctane. In this example, the difference in cracking activity between n-dodecane and isooctane is presumably due to the difference in carbon chain length. Greensfelder and Voge [184] reported that cracking rates of alkanes over an amorphous silica-alumina catalyst increased with carbon number and that $\mathrm{n}$ dodecane cracked at a rate approximately 3.8 times faster than isooctane.

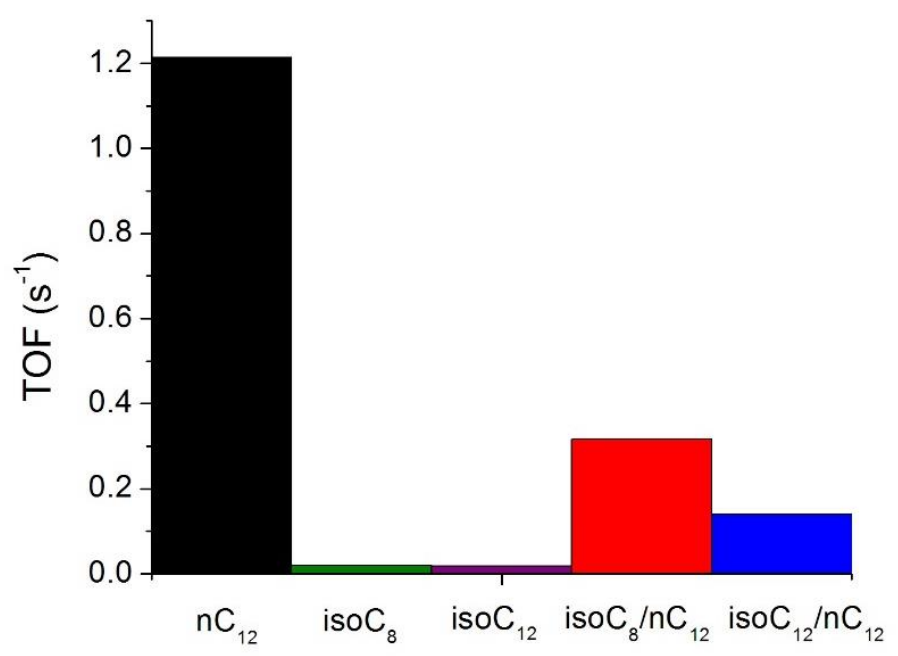

Figure 4-2. Cracking TOF of $\mathrm{n}$-dodecane $\left(\mathrm{nC}_{12}\right)$, isooctane $\left(\right.$ iso $\left.\mathrm{C}_{8}\right)$, isododecane (isoC $\left.\mathrm{C}_{12}\right)$, a 50/50 mol.\% mixture of isooctane and $\mathrm{n}$-dodecane $\left(\mathrm{isoC}_{8} / \mathrm{nC}_{12}\right)$, and a $50 / 50 \mathrm{~mol} \%$ mixture of isododecane and $\mathrm{n}$-dodecane (isoC $\mathrm{C}_{12} / \mathrm{nC}_{12}$ ) over $\mathrm{H}-\mathrm{ZSM}-5$ at $698 \mathrm{~K}$ and $3 \mathrm{MPa}$. 


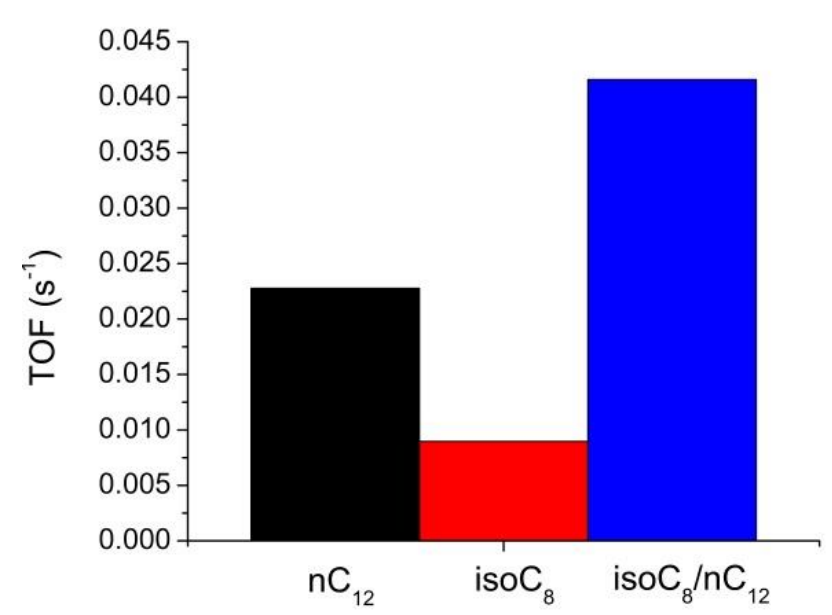

Figure 4-3. Cracking TOF of $\mathrm{n}$-dodecane $\left(\mathrm{nC}_{12}\right)$, isooctane (isoC $\left.\mathrm{C}_{8}\right)$, and a $50 / 50 \mathrm{~mol} \%$ mixture of isooctane and $\mathrm{n}$-dodecane (isoC $\mathrm{C}_{8} / \mathrm{nC}_{12}$ ) over ASA at $698 \mathrm{~K}$ and $3 \mathrm{MPa}$.

A 50/50 mol.\% mixture of a branched hydrocarbon (isooctane or isododecane) and ndodecane (50/50 mixture) was tested to determine if the branched hydrocarbon would have any promotional effect on linear hydrocarbon cracking rates. Previous work in the literature by Jiang et al. [185] investigated the pyrolytic cracking of mixtures of n-dodecane and isododecane under supercritical conditions and demonstrated that isododecane could accelerate the thermal decomposition of n-dodecane. In contrast to Jiang et al.'s pyrolytic cracking results, the presence of a branched molecule, isooctane or isododecane, inhibited n-dodecane cracking rates over $\mathrm{H}$ ZSM-5. No promotional effect was observed, presumably because the branched and linear alkanes were not present together in the pores of H-ZSM-5. However, as shown in Figure 4-3, the presence of isooctane promoted n-dodecane cracking rates over ASA, illustrating the importance of pairing the proper catalyst porosity and hydrocarbon molecular structure.

The catalytic conversion of n-dodecane, isooctane, and a 50/50 mixture was investigated over H-Y to determine the effect branched hydrocarbons have on catalytic cracking rates within a zeolite with pore dimensions large enough to accommodate bulkier molecules. A comparison of 
the TOFs for these reactions at 648,663 , and $678 \mathrm{~K}$ is plotted in Figure 4-4. The TOFs for the cracking of n-dodecane and isooctane over $\mathrm{H}-\mathrm{Y}$ are more than an order of magnitude higher than over ASA. This difference is due to ability of zeolites to confine alkanes and transition states and make adsorption enthalpy and entropy changes more negative, which increases turnover rates [186-189]. Interestingly, the presence of isooctane promoted n-dodecane cracking rates over H-Y at temperatures below $678 \mathrm{~K}$, but this effect disappeared at $678 \mathrm{~K}$ and above. It was expected that the tertiary carbon atom of isooctane would increase hydride transfer and cracking rates. However, it is unclear why this effect disappears at higher temperatures.

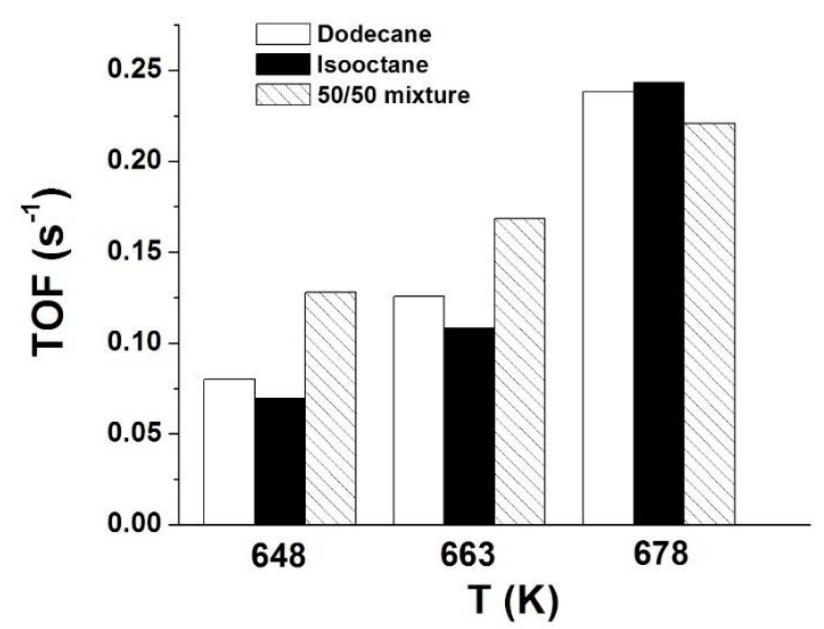

Figure 4-4. Cracking TOF of n-dodecane, isooctane, and a 50/50 mol.\% mixture of isooctane and n-dodecane over $\mathrm{H}-\mathrm{Y}$ and $6 \mathrm{MPa}$.

The product distribution observed during the cracking of the different feeds over $\mathrm{H}-\mathrm{Y}$ at $678 \mathrm{~K}$ is shown in Table 4-2. Isooctane cracking results in a high selectivity toward isobutane. The production of isobutene and isobutane from isooctane has been observed by others [190,191] and may be regarded as the reversal of the alkylation reaction whereby isooctane is formed from isobutene and isobutane. The absence of isobutene suggests that bimolecular hydride transfer and $\beta$-scission reactions are prevalent. Isobutane was also a major product formed during cracking of 
n-dodecane over $\mathrm{H}-\mathrm{Y}$, but to a much lesser extent. Cracking of $\mathrm{n}$-dodecane produced heavier $\mathrm{C}_{10}$ and $\mathrm{C}_{11}$ products that were only seen in trace amounts during cracking of isooctane. The product distribution during cracking of the 50/50 mixture from 648 to $708 \mathrm{~K}$, shown in Table 4-3, has characteristics of both isooctane and n-dodecane cracking. This observation suggests that both molecules are present and are cracked via bimolecular paths within the zeolite pores.

Table 4-2. Reaction of isooctane, n-dodecane, and a 50/50 mol.\% mixture of isooctane and n-dodecane $\mathrm{H}-\mathrm{Y}$ at $678 \mathrm{~K}$ and $6 \mathrm{MPa}$.

\begin{tabular}{|c|c|c|c|}
\hline Reactant & Isooctane & n-Dodecane & 50/50 Mix \\
\hline $\begin{array}{c}\text { Conversion } \\
(\%)\end{array}$ & 3.2 & 4.4 & 3.8 \\
\hline $\begin{array}{c}\text { TOF } \\
\left(s^{-1}\right)\end{array}$ & 0.24 & 0.24 & 0.22 \\
\hline \multicolumn{4}{|c|}{ Molar Selectivity (\%) } \\
\hline$\leq \mathrm{C}_{2}$ & trace & trace & trace \\
\hline $\mathbf{C}_{3}$ & 1.3 & 6.1 & 1.9 \\
\hline $\mathrm{iC}_{4}^{*}$ & 60 & 14 & 40 \\
\hline $\mathrm{C}_{4}$ & 6.1 & 8.6 & 13 \\
\hline $\mathrm{C}_{5}$ & 19 & 24 & 21 \\
\hline $\mathrm{C}_{6}$ & 3.0 & 18 & 9.4 \\
\hline $\mathrm{C}_{7}$ & 7.2 & 12 & 9.7 \\
\hline $\mathrm{Cr}$ & 3.0 & 7.5 & 4.1 \\
\hline C9 & 0.6 & 2.2 & 0.9 \\
\hline $\mathrm{C}_{10}$ & trace & 3.8 & 0.4 \\
\hline $\mathbf{C}_{11}$ & trace & 3.6 & 0.1 \\
\hline
\end{tabular}

$* \mathrm{iC}_{4}$ is predominantly isobutane. Only trace amounts of isobutene were detected.

The rates for cracking of the 50/50 mixture and n-dodecane over $\mathrm{H}-\mathrm{Y}$ under near-critical and supercritical conditions exhibited similar temperature dependencies at $6 \mathrm{MPa}$, as shown by the Arrhenius-type plots in Figure 4-5. Both Arrhenius-type plots show concave behavior with a kink near the critical temperature of $\mathrm{n}$-dodecane $(658 \mathrm{~K})$. At higher temperatures, the apparent activation energy for cracking of all feedstocks is approximately $150 \mathrm{~kJ} \mathrm{~mol}^{-1}$. This is in good 
agreement with the results reported in Chapter 2. DFT calculations showed that the activation energy for a bimolecular cracking path involving 2 secondary carbenium ions is $167 \mathrm{~kJ} \mathrm{~mol}^{-1}$. It is expected that a bimolecular cracking path involving a tertiary carbon atom (isobutene) would have a lower activation energy. At lower temperatures, the apparent activation energy is $82 \mathrm{~kJ} \mathrm{~mol}^{-1}$ for cracking of $\mathrm{n}$-dodecane and $66 \mathrm{~kJ} \mathrm{~mol}^{-1}$ for cracking of the 50/50 mixture. There are several possible causes for the non-linear behavior seen in Figure 4-5: experimental error in the data, a change in reaction mechanism, or transport effects. An investigation into these options suggests that transport effects may be the cause for the concave behavior of the Arrhenius-type plots.

First, one possible scenario is that the true temperature dependence of the reaction is linear, but appears skewed due to experimental error. The dominant source of error within the TOF measurements shown in the Arrhenius-type plots comes from the deactivation of the catalyst over time. The deactivation of the catalyst affects the precision of the measurement and the true TOF is likely higher than the reported values. There are many factors that contribute to deactivation, including conversion level and time on stream (TOS). TOF measurements at different operating conditions are taken after 10 minutes TOS and at approximately equal levels of conversion to mitigate the effects of deactivation. In general, experiments performed at lower temperature exhibit lower amounts of deactivation relative to experiments performed at higher temperature. Accounting for the error associated with deactivation would result in higher "real" TOF values at the higher temperatures, which would actually enhance the non-linear behavior seen in Figure 4-5. 


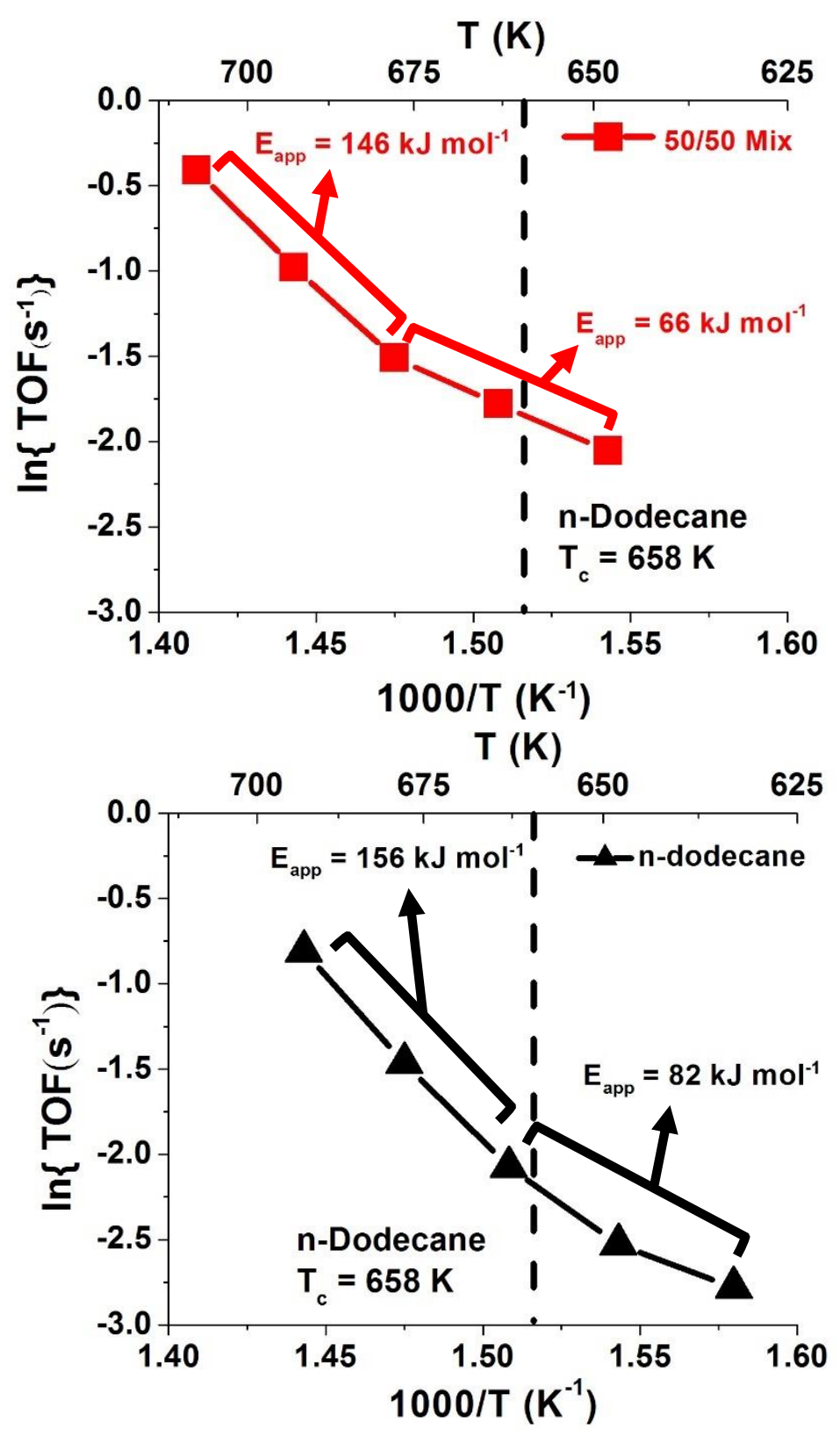

Figure 4-5. Arrhenius-type plot for the cracking of a 50/50 mol.\% mixture of n-dodecane and isooctane (top) and n-dodecane (bottom) over $\mathrm{H}-\mathrm{Y}$ at $6 \mathrm{MPa}$. The dashed line indicates the critical temperature of n-dodecane $\left(\mathrm{T}_{\mathrm{c}}=658 \mathrm{~K}\right)$.

Second, a change in reaction mechanism from a bimolecular cracking mechanism to a monomolecular cracking mechanism could explain the change in temperature dependence. An investigation of the product distribution, shown in Table 4-3, does not support this theory. A slight 
decrease in the product selectivity towards iso $\mathrm{C}_{4}$ products and a slight increase towards heavier $\mathrm{C}_{10}$ and $\mathrm{C}_{11}$ products was observed at higher temperatures. However, these products can come from both bimolecular and monomolecular cracking paths. The molar selectivity towards products that do not come from bimolecular cracking, $\leq \mathrm{C}_{2}$, was lower than $1 \%$ for all temperatures. In addition, the slight increase in selectivity towards these products at higher temperatures could be a result of increased pyrolytic cracking. The product distributions for cracking of $n$-dodecane over $\mathrm{H}-\mathrm{Y}$, shown in Table C-3, also do not exhibit any major changes with increasing temperature. The overall magnitude of these changes suggests that a major shift in reaction mechanism does not occur at these temperatures.

Table 4-3. Reaction of a 50/50 mol. \% mixture of isooctane and n-dodecane over $\mathrm{H}-\mathrm{Y}$ at 6 MPa.

\begin{tabular}{cccccc}
\hline $\begin{array}{c}\text { Temperature } \\
(\mathbf{K})\end{array}$ & $\mathbf{6 4 8}$ & $\mathbf{6 6 3}$ & $\mathbf{6 7 8}$ & $\mathbf{6 9 3}$ & $\mathbf{7 0 8}$ \\
\hline $\begin{array}{c}\text { Conversion } \\
(\boldsymbol{\%})\end{array}$ & 2.2 & 2.9 & 3.8 & 6.2 & 5.2 \\
$\mathbf{T O F}$ & & & & & \\
$\left(\mathbf{s}^{-\mathbf{1}}\right)$ & 0.13 & 0.17 & 0.22 & 0.38 & 0.66 \\
\hline & $\mathbf{M o l a r}$ Selectivity $\mathbf{( \% )}$ & & & \\
\hline $\mathbf{C}_{\mathbf{2}}$ & trace & trace & trace & 0.2 & 0.5 \\
$\mathbf{C}_{\mathbf{3}}$ & 2.9 & 3.0 & 1.9 & 1.4 & 3.3 \\
$\mathbf{i \mathbf { C } _ { \mathbf { 4 } }}$ & 44 & 41 & 40 & 31 & 32 \\
$\mathbf{C}_{\mathbf{4}}$ & 12 & 12 & 13 & 12 & 15 \\
$\mathbf{C}_{\mathbf{5}}$ & 20 & 20 & 21 & 30 & 27 \\
$\mathbf{C}_{\mathbf{6}}$ & 8.9 & 9.5 & 9.4 & 9.5 & 7.9 \\
$\mathbf{C}_{\mathbf{7}}$ & 8.8 & 8.6 & 9.2 & 6.2 & 5.6 \\
$\mathbf{C}_{\mathbf{8}}$ & 3.8 & 4.0 & 4.1 & 3.2 & 2.2 \\
$\mathbf{C}_{\mathbf{9}}$ & trace & 1.3 & 0.9 & 1.8 & 1.0 \\
$\mathbf{C}_{\mathbf{1 0}}$ & trace & 0.1 & 0.4 & 2.4 & 3.3 \\
$\mathbf{C}_{\mathbf{1 1}}$ & trace & 0.2 & 0.1 & 2.3 & 2.6 \\
\hline
\end{tabular}

Finally, transport effects could explain the non-linear behavior seen in Figure 4-5. Inhibition by diffusional limitations is common in catalysis and typically occurs at higher 
temperatures, where the rate of reaction becomes greater than the rate of mass transfer to the reactive surface. The opposite trend is seen in this study. Reaction rates appear to be inhibited at lower temperatures. Interestingly, the change in temperature dependence occurs near the critical temperature of n-dodecane $(658 \mathrm{~K})$. This observation suggests that the increase in reaction rates above $658 \mathrm{~K}$ may be associated with the transition from a liquid to supercritical phase. Pore diffusion in H-Y shows Knudsen-type behavior, which is governed by the mean free path in the pore space and is independent of both pressure and other molecules. However, Dvoyashkin et al. reported an increase in Knudsen-type pore diffusivities during transition from subcritical to supercritical conditions [192]. Therefore, enhanced diffusion under supercritical conditions may account for the break in the Arrhenius-type plot that was seen during cracking of n-dodecane and mixtures containing n-dodecane.

Isooctane does not exhibit non-linear behavior in its Arrhenius-type plot, shown in Figure 4-6.

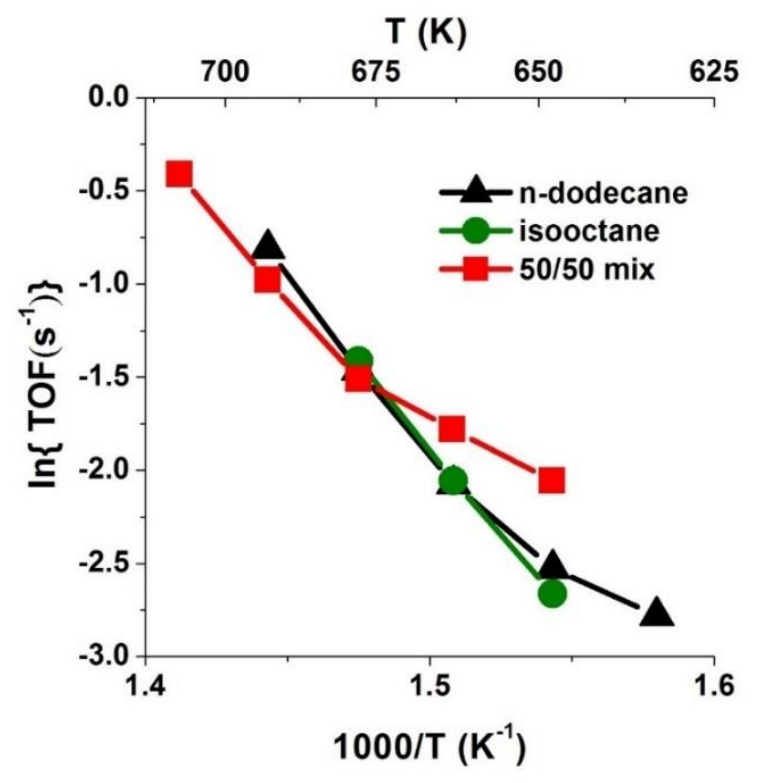

Figure 4-6. Arrhenius-type plot for the cracking of n-dodecane $(\boldsymbol{\Delta})$, isooctane $(\bullet)$, and a 50/50 mol.\% mixture of n-dodecane and isooctane (a) over $\mathrm{H}-\mathrm{Y}$ at $6 \mathrm{MPa}$. 
The critical temperature of isooctane is $544 \mathrm{~K}$. This is well below the reaction temperatures in the isooctane experiments and ensures that isooctane is under supercritical conditions. This observation is consistent with the theory that a transition from subcritical to supercritical conditions is responsible for the non-linear temperature dependence observed during cracking of n-dodecane and mixtures containing n-dodecane.

\subsubsection{Cracking of JP-8 over H-ZSM-5 and ASA}

The reactivity results for the cracking of JP-8 compared to the cracking of n-dodecane over H-ZSM-5 and ASA are shown in Figure 4-7. The analysis was limited to only the gas-phase products due to the large number of products $(>100)$ detected in the liquid-phase results, shown in Figure C-1. A comparison of the gas-phase products formed during JP-8 and n-dodecane cracking over H-ZSM-5 at $698 \mathrm{~K}$ revealed a similar rate of product formation at 0.5 hour TOS. However, the deactivation for cracking of JP-8 was noticeably more severe than for cracking of n-dodecane. In contrast, ASA exhibited both a similar rate of formation of gas-phase products and a similar deactivation profile for the cracking of JP-8 and n-dodecane.

Although cracking of JP-8 over H-ZSM-5 suffered from more severe deactivation, the rate of formation for gas-phase products per Brønsted acid site over H-ZSM-5 was still higher than that over ASA at all times. These results are in agreement with the results obtained previously for the cracking of n-dodecane, where non-microporous aluminosilicate catalysts exhibited greater stability over time compared to microporous H-ZSM-5, but were much less active. These results combined with the results from the investigation of branched hydrocarbons, suggest that while $\mathrm{H}-$ 
ZSM-5 is an excellent catalyst for the cracking of straight chain hydrocarbons, larger pore zeolites such as H-Y may be more suitable catalysts for endothermic fuel cracking of military jet fuels.
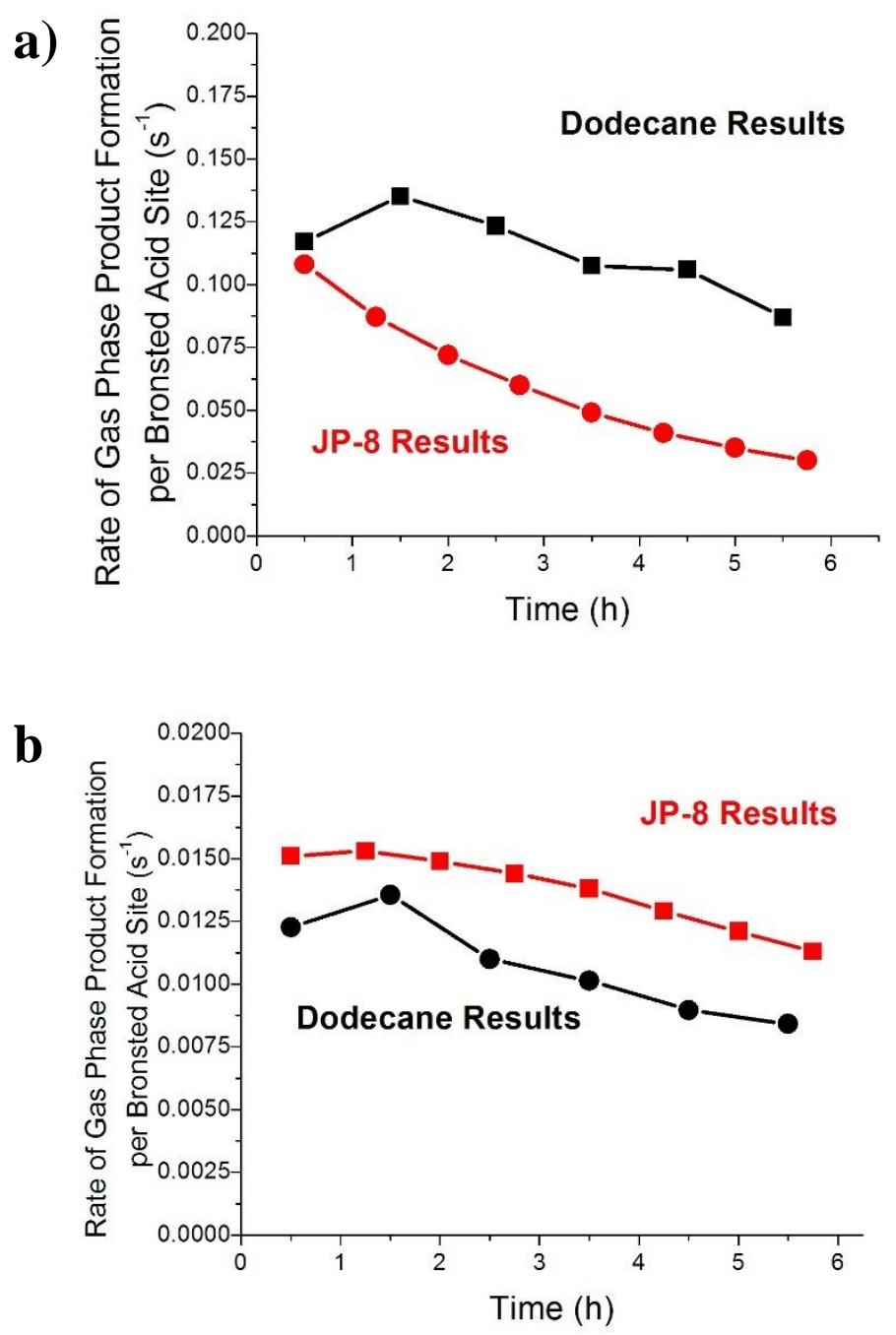

Figure 4-7. a) Dependence of rates of formation for gas-phase products of n-dodecane cracking over H-ZSM-5 on time on stream at 698 K. b) Dependence of rates of formation for gas-phase products of $\mathrm{n}$-dodecane cracking over ASA on time on stream at $698 \mathrm{~K}$. Reaction conditions: Total system pressure $=4 \mathrm{MPa}$, liquid feed flow rate $=0.2 \mathrm{~cm}^{3} \cdot \mathrm{min}^{-1}$. 


\subsection{Conclusions}

Cracking of branched hydrocarbons, binary mixtures of branched and linear hydrocarbons, and a military jet fuel, JP-8, was studied over micro- and mesoporous aluminosilicate catalysts under near-critical and supercritical conditions. Intrinsic rates (TOFs) and product distributions were used to understand the effect of hydrocarbon branching on cracking rates within different pore dimensions.

TOFs for cracking of isooctane and isododecane over H-ZSM-5 were nearly zero, which indicated that highly branched hydrocarbons cannot access the pores of H-ZSM-5. In addition, the presence of the branched molecule inhibited the cracking rate of the linear molecule during the cracking of a 50/50 mixture over H-ZSM-5. Thus, H-ZSM-5 may not be a suitable catalyst for military jet fuels. Cracking of the 50/50 mixture over mesoporous ASA was examined. The TOF for the cracking of the 50/50 mixture was higher than for the pure components. This suggested that branched molecules promoted cracking rates over catalysts with pore dimensions large enough to accommodate the branched molecules.

Cracking of the 50/50 mixture over the large-pore zeolite H-Y exhibited a promotional effect at lower temperatures, but the effect disappeared at higher temperatures. The cause for this phenomenon remains unclear but may be associated with a change in transport properties during transition from subcritical to supercritical conditions. The low selectivity toward isobutene during cracking of isooctane, n-dodecane, and the 50/50 mixture over H-Y suggested that bimolecular cracking paths were prevalent. The apparent activation energy of cracking at higher temperatures for all three feedstocks was $\sim 150 \mathrm{~kJ} \mathrm{~mol}^{-1}$. This value resembles the activation energy of $167 \mathrm{~kJ}$ 
mol $^{-1}$ that was calculated in Chapter 2 for secondary-secondary bimolecular hydride transfer followed by $\beta$-scission.

Cracking of a real military jet fuel, JP-8, over H-ZSM-5 and ASA was performed under supercritical conditions. Gas-phase product formation rates during cracking of JP-8 over H-ZSM5 exhibited severe deactivation compared to cracking of n-dodecane. In contrast, cracking of JP-8 over ASA demonstrated both a similar rate of formation of gas-phase products and a similar deactivation profile to cracking of n-dodecane. The cracking behavior of the real military fuel validates the findings obtained using surrogate fuel molecules and suggests that large pore zeolites may be promising catalysts for endothermic fuels. 


\section{Synthesis, Characterization, and Reactor Studies of $\mathrm{WO}_{\mathrm{x}} / \mathrm{ZrO}_{2}$ Catalysts for Endothermic Fuel Reactions}

\subsection{Summary of literature work on $\mathrm{WO}_{\mathrm{x}} / \mathrm{ZrO}_{2}$}

Although the petroleum refining industry typically uses solid acid zeolitic materials to crack hydrocarbons, the microporous nature of zeolites makes them highly susceptible to deactivation from coke formation. Non-microporous mixed metal-oxide solid acid catalysts have been well investigated in the literature for their potential to eliminate environmental concerns caused by the use of liquid acids in the chemical industry. In particular, sulfated zirconia (SZ), tungstated zirconia $\left(\mathrm{WO}_{\mathrm{x}} / \mathrm{ZrO}_{2}\right)$, and supported heteropolyacids (HPAs) have shown promising catalytic behavior due to their strong acidity. However, it has been shown that in liquid media at higher temperatures, SZ catalysts deactivate by leaching of active sites [193-196] It has also been shown that HPAs decompose through dehydration reactions at temperatures well below the endothermic fuel cracking temperature [197-201]. In contrast, $\mathrm{WO}_{\times} / \mathrm{ZrO}_{2}$ catalysts are structurally stable up to $1173 \mathrm{~K}$ with no mention in the literature of leaching of active site [202]. Thus, the focus of this chapter is to investigate $\mathrm{WO}_{\mathrm{x}} / \mathrm{ZrO}_{2}$ catalysts for endothermic fuel cracking.

$\mathrm{WO}_{\mathrm{x}} / \mathrm{ZrO}_{2}$ powders were first reported to contain strong acid sites by Hino and Arata in 1987 using low temperature n-butane and n-pentane isomerization experiments [203]. Active catalysts were prepared via wet impregnation of metatungstate solutions on $\mathrm{ZrO}_{\mathrm{x}}(\mathrm{OH})_{4-2 \mathrm{x}}$ followed by high temperature calcination at $1073 \mathrm{~K}$. Later studies have shown that the performance of $\mathrm{WO}_{\mathrm{x}} / \mathrm{ZrO}_{2}$ catalysts is very sensitive to the size of the $\mathrm{WO}_{\mathrm{x}}$ clusters on the surface.

Barton et al. [204] investigated the effect of $\mathrm{WO}_{\mathrm{x}}$ surface density on the rate of Brønsted acid catalyzed $o$-xylene to $m$ - and $p$-xylene isomerization over $\mathrm{WO}_{\mathrm{x}} / \mathrm{ZrO}_{2}$ catalysts and found 
maximum $o$-xylene isomerization turnover rates over $\mathrm{WO}_{\mathrm{x}}$ domains of intermediate size $\left(\mathrm{WO}_{\mathrm{x}}\right.$ surface density $10 \mathrm{~W} \cdot \mathrm{nm}^{-2}$ ). Wong et al. [205] examined the Brønsted acid catalyzed reaction $\mathrm{n}$ pentane isomerization over $\mathrm{WO}_{\mathrm{x}} / \mathrm{ZrO}_{2}$ catalysts and found maximum activity at surface tungsten density of $5.2 \mathrm{~W} \cdot \mathrm{nm}^{-2}$.

The mechanism of acid site formation on $\mathrm{WO}_{\mathrm{x}} / \mathrm{ZrO}_{2}$ catalysts is still unclear. It has been theorized that $\mathrm{WO}_{\mathrm{x}}$ clusters of intermediate size are able to delocalize a net negative charge caused by the slight reduction of $\mathrm{W}^{6+}$ centers in reactant environments containing $\mathrm{H}_{2}$ or hydrocarbons. This temporary in situ generated charge imbalance leads to the formation of Brønsted acid $\mathrm{W}^{6-}$ ${ }^{\mathrm{n}} \mathrm{O}_{3}\left(\mathrm{n}-\mathrm{H}^{+}\right)$centers on the zirconia surface [206]. Recently, Zhou et al. used high-angular dark-field imaging (HAADF) in an aberration-corrected STEM to investigate the nanoscale structures present in supported $\mathrm{WO}_{\mathrm{x}} / \mathrm{ZrO}_{2}$ catalysts. Co-impregnation tests with $\mathrm{WO}_{\mathrm{x}}$ and $\mathrm{ZrO} \mathrm{O}_{\mathrm{x}}$ precursors confirmed the importance of intimately mixed $\mathrm{WO}_{\mathrm{x}}$ and $\mathrm{ZrO}_{\mathrm{x}}$ entities within the clusters. By correlating structural observations with catalytic methanol dehydration activity measurements, they proposed that $0.8-1 \mathrm{~nm} \mathrm{WO}_{\mathrm{x}}$ clusters incorporating some zirconium cations are the most active species [207]. However, methanol dehydration probes both Brønsted and Lewis acid sites [208] and the mechanism of Brønsted acid site formation on $\mathrm{WO}_{x} / \mathrm{ZrO}_{2}$ catalysts is still unclear. Nevertheless, the results from the literature suggest that a wide range of $\mathrm{WO}_{\mathrm{x}} / \mathrm{ZrO}_{2}$ catalysts with varying $\mathrm{WO}_{\mathrm{x}}$ domain size will need to be synthesized and evaluated for endothermic fuel cracking. 


\subsection{Methods}

\subsubsection{Materials}

n-Dodecane (Sigma-Aldrich, $\geq 99 \%$ purity) was used as the feed. n-Tridecane (SigmaAldrich, 99\% purity anhydrous) was added as an external standard during gas chromatography (GC) analysis. The following gases were used for calcination, reduction, TGA, and GC operation: dry air (GTS Welco Medical Grade), dioxygen (GTS-Welco, 99.999\%), helium (GTS-Welco, 99.999\%), dihydrogen (GTS-Welco, 99.999\%), dinitrogen (GTS-Welco, 99.999\%).

To test for background conversion, a pure $\mathrm{ZrO}_{2}$ sample was synthesized in the lab. Amorphous $\mathrm{ZrO}_{\mathrm{x}}(\mathrm{OH})_{4-2 \mathrm{x}}$ (MEL Chemicals, XZO1501/09) was calcined to $\mathrm{ZrO}_{2}$ in dry air (100 $\mathrm{cm}^{3} \mathrm{~min}^{-1}$ ) at $973 \mathrm{~K}$ at $10 \mathrm{~K} \mathrm{~min}^{-1}$, holding for $4 \mathrm{~h}$ before being pressed and sized using $-40 /+100$ $(150-425 \mu \mathrm{m})$ sieves trays.

\subsubsection{Catalyst Synthesis}

Amorphous $\mathrm{ZrO}_{\mathrm{x}}(\mathrm{OH})_{4-2 \mathrm{x}}$ was impregnated to the point of incipient wetness with a solution of ammonium metatungstate hydrate $\left(\left(\mathrm{NH}_{4}\right)_{6} \mathrm{H}_{2} \mathrm{~W}_{12} \mathrm{O}_{40} \cdot \mathrm{xH}_{2} \mathrm{O}\right.$, Aldrich) to give the desired $\mathrm{W}$ wt.\%. The samples were dried in air at $383 \mathrm{~K}$ overnight and then treated in dry air $\left(100 \mathrm{~cm}^{3} \mathrm{~min}^{-}\right.$ ${ }^{1}$ ) at $973 \mathrm{~K}$ at $10 \mathrm{~K} \mathrm{~min}^{-1}$ and holding for $3 \mathrm{~h}$. 


\subsubsection{Catalyst characterization}

Elemental analysis of the $\mathrm{WO}_{\mathrm{x}} / \mathrm{ZrO}_{2}$ samples was conducted by Galbraith Laboratories, Inc. (Knoxville, $\mathrm{TN}$ ). The $\mathrm{W}$ content of the catalysts was measured using inductively coupled plasma optical emission spectroscopy (ICP-OES). Surface area and pore size distribution were calculated using the Brunauer, Emmett, Teller (BET) [209] and Barrett, Joyner and Halenda (BJH) [126] methods, respectively. The $\mathrm{N}_{2}$ adsorption isotherms were measured at $77 \mathrm{~K}$ using a Micromeritics ASAP 2020 automated analyzer. Powder X-ray diffraction (XRD) experiments were conducted on a PANalytical X'Pert Pro Multi-Purpose diffractometer using monochromatic $\mathrm{Cu} \mathrm{K} \alpha$ radiation $(\lambda=1.54 \AA)$. Scans were collected at $2 \theta=10-100^{\circ}$ with a $0.05^{\circ}$ step size.

Ultraviolet-visible diffuse reflectance spectra of the $\mathrm{WO}_{x} / \mathrm{ZrO}_{2}$ samples were collected on a Cary 3E UV-VIS spectrometer with an attached Labsphere DRA-CA-30 diffuse reflectance apparatus. The direct optical bandgap was calculated from the absorption threshold by methods detailed in Appendix D. The X-ray absorption spectra associated with the W-LI edge $(12,106 \mathrm{KeV})$ were recorded in the transmission mode on beamline X18B at the National Synchrotron Light Source, Brookhaven National Laboratory, Upton, New York. The storage ring operated with an energy of $2.58 \mathrm{GeV}$ ad $300 \mathrm{~mA}$. The $\mathrm{WO}_{\mathrm{x}} / \mathrm{ZrO}_{2}$ samples were ground into fine powders and spread over Kapton tape and compared to a pure W reference foil. The XAS data were processed using the Demeter software package [210].

Thermal gravimetric analysis (TGA) of the sample was conducted using a TA Instruments SDT Q600 in $10 \% \mathrm{O}_{2}$, balance $\mathrm{He}\left(100 \mathrm{~cm}^{3} \mathrm{~min}^{-1}\right)$. The temperature program was a simple linear ramp from $303 \mathrm{~K}$ to $1273 \mathrm{~K}$ at a rate of $5 \mathrm{~K} \mathrm{~min}^{-1}$. Approximately $20 \mathrm{mg}$ of sample was used. 


\subsubsection{Catalytic tests}

Hydrocarbon conversion reactions were carried out in an upward-flow fixed bed reactor under supercritical conditions. Catalysts were pressed and sized using $-40 /+100(150-425 \mu \mathrm{m})$ sieve trays. A titanium reactor (Grade 2 titanium from McMaster-Carr) with an outer diameter of $6.35 \mathrm{~mm}$ and an inner diameter (ID) of $4 \mathrm{~mm}$ was used to hold the catalyst that was supported between two glass wool plugs. Before reaction, catalysts were reduced in situ in flowing dihydrogen $\left(100 \mathrm{~cm}^{3} \mathrm{~min}^{-1}\right)$ while heating at $5 \mathrm{~K} \mathrm{~min}^{-1}$ to $773 \mathrm{~K}$ and holding at that temperature for $2 \mathrm{~h}$. Spent catalysts were regenerated by calcination in dry air $\left(100 \mathrm{~cm}^{3} \mathrm{~min}^{-1}\right)$ while heating at $5 \mathrm{~K} \mathrm{~min}^{-1}$ to $873 \mathrm{~K}$ and holding at that temperature for $2 \mathrm{~h}$. Following the calcination step, the catalysts were once again reduced in situ before reaction. Liquid hydrocarbon was fed to the reactor using a Teledyne Isco 260D high pressure syringe pump. A gas-liquid separator was used to collect liquid product between sampling intervals. Dinitrogen was used to purge the gas-liquid separator and to maintain the pressure in the system, which was controlled by a back pressure regulator. The dinitrogen purge along with the gas-phase products were fed to a gas chromatograph (Shimadzu GC-2014) equipped with a flame ionization detector (FID). A Restek RT-QS-BOND (30 m, 0.53 $\mathrm{mm}$ ID, $20 \mu \mathrm{m}$ film thickness) column was used to separate the products. A known amount of ntridecane (Sigma-Aldrich, 99\% purity anhydrous) was added to the liquid products as an external standard. The liquid products were injected into the GC using an AOC-20i auto sampler.

The peak areas of reactants and products identified by GC were used to determine the hydrocarbon feed conversion and selectivity of products. The conversion of hydrocarbon feed was calculated according to and defined as follows: 
Conversion $(\mathrm{C} \%)=\left(\frac{\sum n_{i} M_{i}}{x}\right) \times 100$

where $n_{i}$ is the number of carbon atoms in product $i, M_{i}$ is the molar ratio of product $i$ detected to the initial moles of hydrocarbon feed and $x$ represents the number of carbon atoms in the hydrocarbon feed.

The selectivity toward product $i$ was calculated on a molar basis and defined as follows:

Molar Selectivity $(\%)=\left(\frac{M_{i}}{\sum M_{i}}\right) \times 100$

The total catalyst loading in the reactor for all experiments was approximately $1 \mathrm{~g}$ and the length of the catalyst bed was $5 \mathrm{~cm}$. Reactions with only a bed of $\mathrm{ZrO}_{2}$ were also run for all conditions used in this work to determine the amount of background conversion from pyrolysis. The hydrocarbon liquid feed rate was held at $0.2 \mathrm{~cm}^{3} \mathrm{~min}^{-1}$, depending on the reaction temperature and the background conversion was below $0.5 \%$ at all times.

\subsection{Results and Discussion}

\subsubsection{Catalyst Characterization}

Five $\mathrm{WO}_{\mathrm{x}} / \mathrm{ZrO}_{2}$ catalysts of varying $\mathrm{W}$ weight loading, prepared via incipient wetness impregnation, were characterized using ICP-OES, XRD, UV-vis spectroscopy, $\mathrm{N}_{2}$ adsorption, and Raman spectroscopy to ensure that catalysts with a range of $\mathrm{W}$ surface densities were obtained.

Hino et al. [203] demonstrated that interaction between metatungstate groups and amorphous $\mathrm{ZrO}_{\mathrm{x}}(\mathrm{OH})_{4-2 \mathrm{x}}$ during synthesis is critical for creating active sites strong enough to perform n-pentane isomerization. Therefore, catalysts were synthesized using an amorphous 
$\mathrm{ZrO}_{\mathrm{x}}(\mathrm{OH})_{4-2 \mathrm{x}}$ support rather than crystalline $\mathrm{ZrO}_{2}$. XRD analysis, shown in Figure 5-1, revealed that non-impregnated $\mathrm{ZrO}_{\mathrm{x}}(\mathrm{OH})_{4-2 \mathrm{x}}$ support calcined at the $973 \mathrm{~K}$ resulted in both monoclinic and tetragonal $\mathrm{ZrO}_{2}$, while $\mathrm{W}$ impregnation led to the stabilization of tetragonal $\mathrm{ZrO}_{2}$, suggesting interaction between $\mathrm{W}$ and the $\mathrm{ZrO}_{2}$ support. $\mathrm{XRD}$ analysis also detected $\mathrm{WO}_{3}$ crystallites in $27 \%$ $\mathrm{WO}_{\mathrm{x}} / \mathrm{ZrO}_{2}$ after calcination at $973 \mathrm{~K}$.

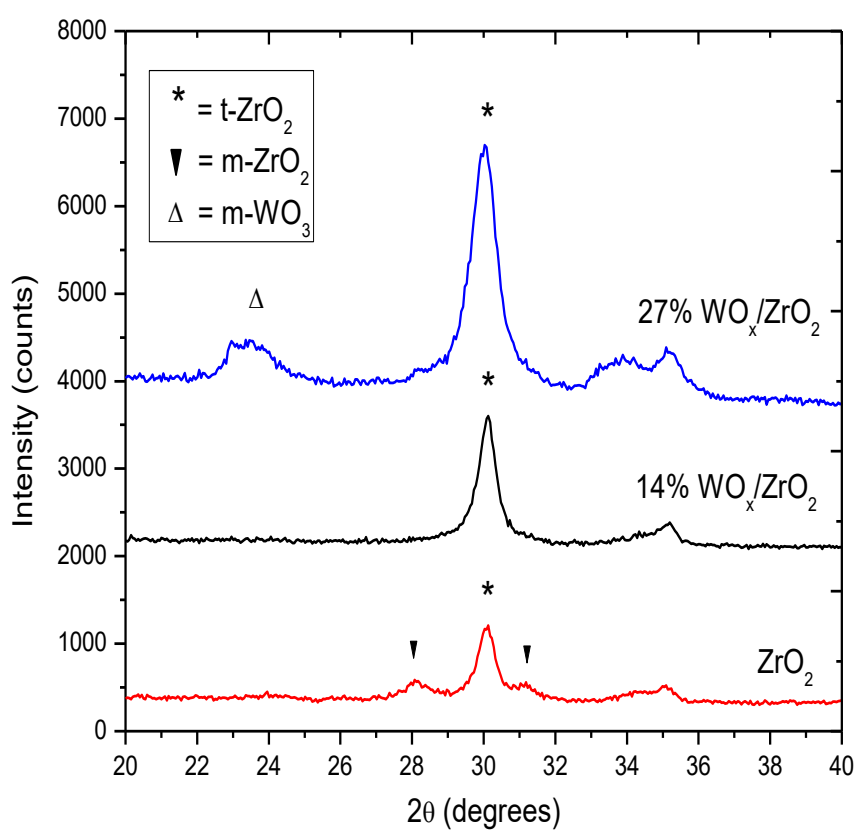

Figure 5-1. $\mathrm{XRD}$ patterns of $\mathrm{WO}_{\mathrm{x}} / \mathrm{ZrO}_{2}$ catalysts and $\mathrm{ZrO}_{2}$ support. Patterns are offset for clarity.

The amount of $\mathrm{W}$ in the $\mathrm{WO}_{\mathrm{x}} / \mathrm{ZrO}_{2}$ samples was quantified using ICP-OES and a $\mathrm{WO}_{\mathrm{x}}$ surface density was calculated using the surface area determined from $\mathrm{N}_{2}$ adsorption. Barton et al. reported that the domain size of $\mathrm{WO}_{\mathrm{x}}$ groups on the surface was tied to the $\mathrm{WO}_{\mathrm{x}}$ surface density with three distinct structural motifs characterized by surface density ranges of $0-4 \mathrm{~W} \mathrm{~nm}^{-2}, 4-8 \mathrm{~W}$ $\mathrm{nm}^{-2}$, and $>8 \mathrm{w} \mathrm{nm}^{-2}$. The $\mathrm{WO}_{\mathrm{x}} / \mathrm{ZrO}_{2}$ catalysts within these three distinct groups show a characteristic optical absorption edge energy $\left(\mathrm{E}_{\mathrm{o}}\right)$. Within the first region, $\mathrm{WO}_{\mathrm{x}}$ groups exist as dispersed $\mathrm{WO}_{\mathrm{x}}$ species that are electronically isolated from each other. These species show a 
constant absorption edge energy of roughly $3.6 \mathrm{eV}$ and are not capable of o-xylene isomerization at $523 \mathrm{~K}$. Increasing the $\mathrm{WO}_{\mathrm{x}}$ surface density leads to a monotonic increase in $\mathrm{WO}_{\mathrm{x}}$ domain size until a constant domain size is reached corresponding to a polytungstate monolayer at about $8 \mathrm{~W}$ $\mathrm{nm}^{-2}$. The absorption edge energies for these growing structures shifts linearly from roughly 3.5 to $3.2 \mathrm{eV}$. Increasing the WOx surface density further leads to the growth of $\mathrm{WO}_{3}$ crystallites and the absorption edge energy remains at $3.2 \mathrm{eV}$ [204].

In this study the $\mathrm{E}_{0}$ of the $\mathrm{WO}_{\mathrm{x}} / \mathrm{ZrO}_{2}$ catalysts, shown in Figure 5-2, were compared to various $\mathrm{WO}_{\mathrm{x}}$ standard compounds that represented different size $\mathrm{W}$ domains. The $\mathrm{E}_{\mathrm{o}}$ of the $\mathrm{WO}_{\mathrm{x}} / \mathrm{ZrO}_{2}$ catalysts was similar to that of ammonium metatungsate $\left(\mathrm{E}_{0}=3.1 \mathrm{ev}\right)$ and ammonium paratungstate $\left(\mathrm{E}_{0}=3.5 \mathrm{eV}\right)$, which represent $\mathrm{WO}_{\mathrm{x}}$ domains of intermediate $(\mathrm{nm})$ size. A comparison of the $\mathrm{E}_{0}$ values to the calculated $\mathrm{WO}_{\mathrm{x}}$ surface density values is shown in Table 5-1. The results reported in this study fall roughly within the characteristic ranges discussed by Barton et al. [204].

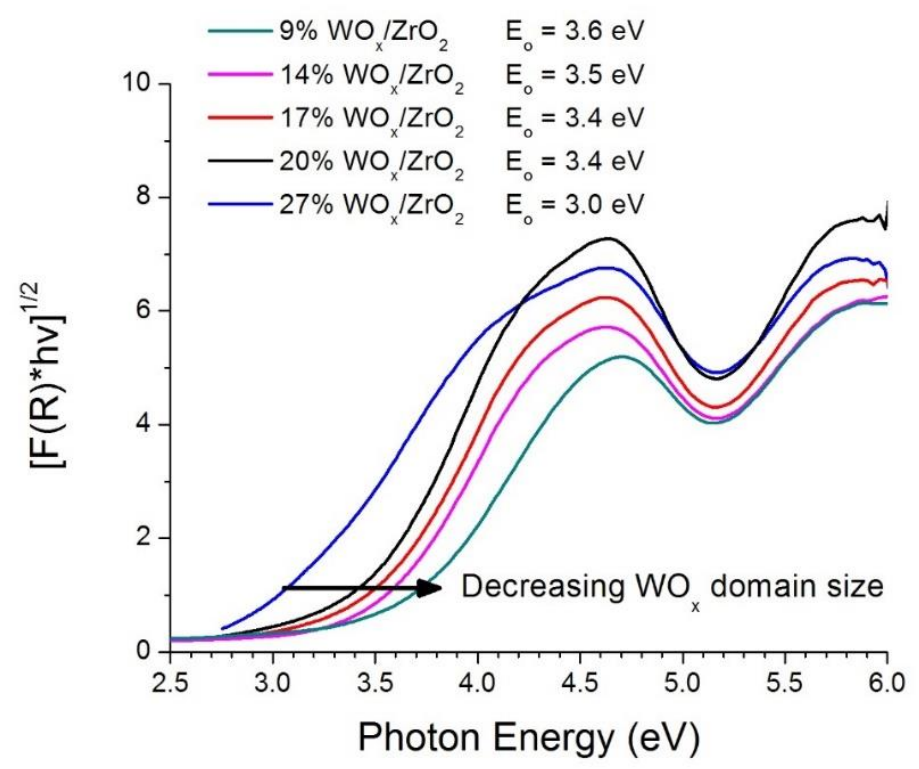

Figure 5-2. Optical absorption edge energies of $\mathrm{WO}_{\mathrm{x}} / \mathrm{ZrO}_{2}$ catalysts. 
Table 5-1. Characterization of synthesized $\mathrm{WO}_{\mathrm{x}} / \mathrm{ZrO}_{2}$ catalysts.

\begin{tabular}{cccc}
\hline $\begin{array}{c}\mathbf{W}^{\mathbf{a}} \\
(\mathbf{w t .} \%)\end{array}$ & $\begin{array}{c}\mathbf{E}_{\mathbf{o}} \mathbf{b} \\
(\mathbf{e V})\end{array}$ & $\begin{array}{c}\text { Surface Area } \\
\left(\mathbf{m}^{\mathbf{2}} \cdot \mathbf{g}\right)\end{array}$ & $\begin{array}{c}\mathbf{W ~ S u r f a c e ~ d e n s i t y ~}^{\mathbf{d}} \\
\left(\mathbf{W} \text { atoms} \cdot \mathbf{n m}^{\mathbf{2}}\right)\end{array}$ \\
\hline 9 & 3.6 & 101 & 2.6 \\
14 & 3.5 & 116 & 3.2 \\
17 & 3.4 & 127 & 3.5 \\
20 & 3.4 & 116 & 4.5 \\
27 & 3.0 & 76 & 9.1 \\
\hline
\end{tabular}

${ }^{a}$ obtained via ICP-OES

${ }^{\mathrm{b}}$ Obtained via UV-vis spectroscopy

${ }^{c}$ BET surface areas were determined by $\mathrm{N}_{2}$ adsorption

${ }^{\mathrm{d}} \mathrm{W}$ surface densities were calculated from the $\mathrm{W}$ loading and catalyst surface area

Raman spectroscopy was used to compare the $\mathrm{WO}_{x} / \mathrm{ZrO}_{2}$ catalysts, shown in Figure 5-3, to $\mathrm{WO}_{3}$ powder. The spectra showed the development of the $\mathrm{WO}_{3}$ peak at $805 \mathrm{~cm}^{-1}$ with increasing W loading. All of the characterization results confirmed that catalysts with a range of $\mathrm{WO}_{\mathrm{x}}$ domain sizes were successfully synthesized: $9 \% \mathrm{WO}_{\mathrm{x}} / \mathrm{ZrO}_{2}$ has isolated WOx clusters, 14 to $20 \%$ $\mathrm{WO}_{\mathrm{x}} / \mathrm{ZrO}_{2}$ catalysts have intermediate-sized $\mathrm{WO}_{\mathrm{x}}$ domains that increase in size with respect to $\mathrm{W}$ weight loading, and $27 \% \mathrm{WO}_{x} / \mathrm{ZrO}_{2}$ has $\mathrm{WO}_{3}$ crystallites growing on top of a polytungstate monolayer.

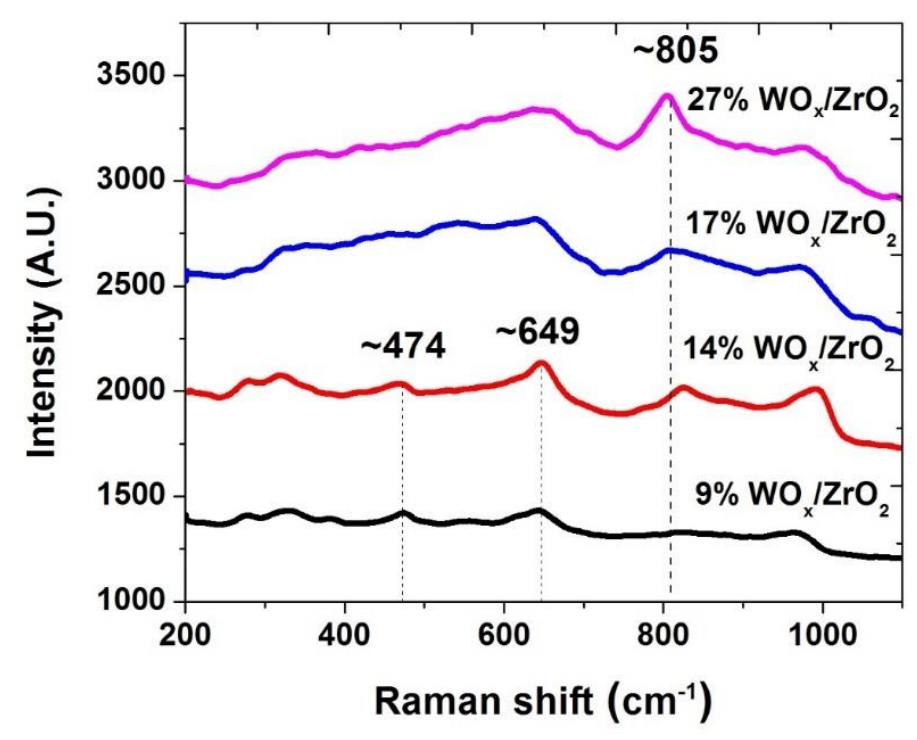

Figure 5-3. Raman spectra of $\mathrm{WO}_{\mathrm{x}} / \mathrm{ZrO}_{2}$ catalysts. Spectra offset for clarity. 


\subsubsection{Catalytic Tests}

A plot of the reactivity results over time obtained during the cracking of n-dodecane over $20 \% \mathrm{WO}_{\mathrm{x}} / \mathrm{ZrO}_{2}$ under supercritical conditions is presented in Figure 5-4. 20\% $\mathrm{WO}_{\mathrm{x}} / \mathrm{ZrO}_{2}$ exhibited $\sim 5 \%$ conversion of $\mathrm{n}$-dodecane after $10 \mathrm{~min}$ TOS, but deactivated rapidly. Similar results were seen for all synthesized catalysts, however, $20 \% \mathrm{WO}_{\mathrm{x}} / \mathrm{ZrO}_{2}$ was the most active $\mathrm{WO}_{\mathrm{x}} / \mathrm{ZrO}_{2}$ catalyst on a per weight basis.

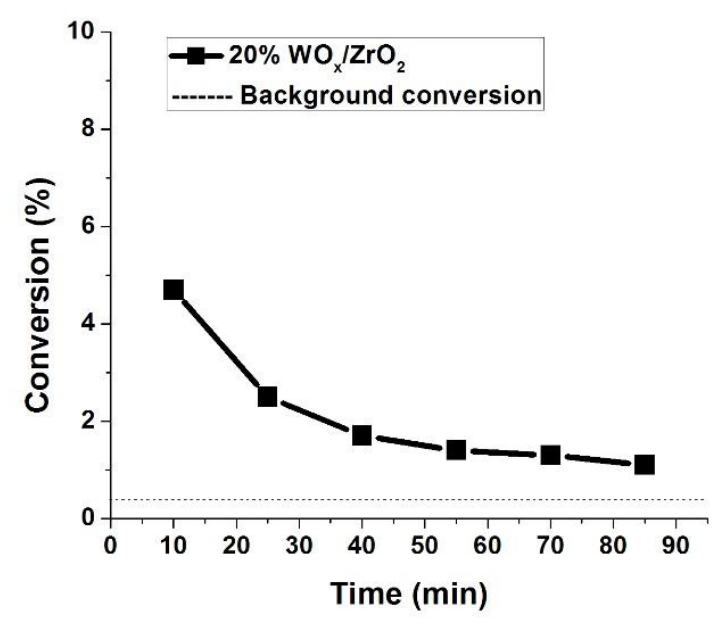

Figure 5-4. Cracking of n-dodecane over $20 \% \quad \mathrm{WO}_{\mathrm{x}} / \mathrm{ZrO}_{2}$ at supercritical conditions. Reaction conditions: $\mathrm{T}=698 \mathrm{~K}$; total system pressure $=4 \mathrm{MPa}$, liquid feed flow rate $=0.2 \mathrm{~cm}^{3} \cdot \mathrm{min}^{-1}$.

One possible cause of deactivation was the in situ carburization of the $\mathrm{WO}_{\mathrm{x}}$ domains to WC or $\mathrm{W}_{2} \mathrm{C}$ [211]. Samples of fresh and spent $20 \% \mathrm{WO}_{\mathrm{x}} / \mathrm{ZrO}_{2}$ catalyst were brought to Brookhaven National Laboratory and examined using XAS to determine the cause of deactivation. The W LIII XANES, presented in Figure 5-5, showed negligible edge shift in edge energy between fresh and spent $20 \% \mathrm{WO}_{\mathrm{x}} / \mathrm{ZrO}_{2}$ catalyst indicating the transformation of tungsten oxide to tungsten carbide was not the cause of deactivation. Another possible cause of deactivation is coke formation over the catalyst. To verify that the cause of deactivation was coke formation, thermogravimetric 
analysis (TGA) was performed. The TGA profile of the spent $20 \% \mathrm{WO}_{\mathrm{x}} / \mathrm{ZrO} 2$ catalyst is shown in Figure 5-6. The only region of weight loss started at a temperature of approximately $650 \mathrm{~K}$ and the derivative weight loss peak occurred at $787 \mathrm{~K}$.

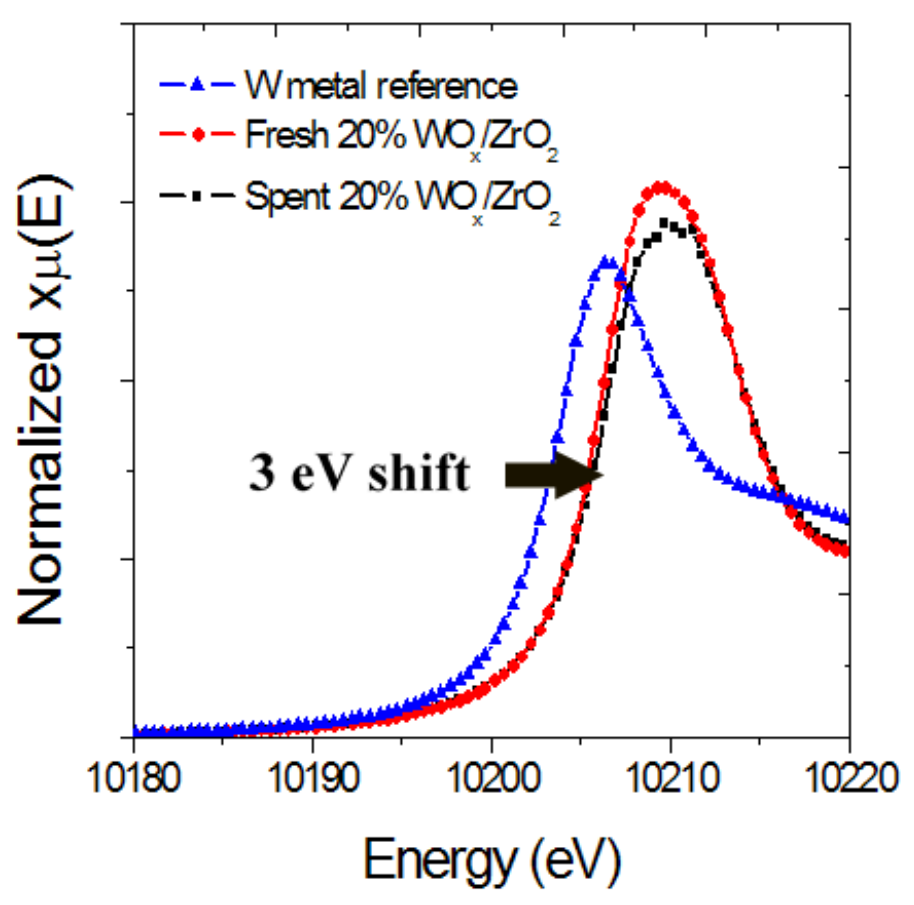

Figure 5-5. Comparison of $\mathrm{W} \mathrm{L}_{\mathrm{III}} \mathrm{XANES}$ for fresh and spent $20 \% \mathrm{WO}_{\mathrm{x}} / \mathrm{ZrO}_{2}$ catalysts compared to a reference $\mathrm{W}$ foil.

This weight loss behavior is similar to that observed by Yin et al. for the oxidation of coke generated in situ on an $\alpha$-alumina catalyst at $1323 \mathrm{~K}$ [212]. Negligible weight loss was observed from $840 \mathrm{~K}$ to the final program temperature at $1273 \mathrm{~K}$, implying that the coke was fully removed after calcination at $840 \mathrm{~K}$. Calcination of spent $20 \% \mathrm{WO}_{\mathrm{x}} / \mathrm{ZrO}_{2}$ at $873 \mathrm{~K}$ for $2 \mathrm{~h}$ resulted in complete recovery of catalyst activity. These results suggest that coke formation was the cause of deactivation. Similar results were seen in the literature where n-pentane isomerization performed in the absence of $\mathrm{H}_{2}$ showed high selectivity to cracking ( $\left.50 \%\right)$ and rapid deactivation, suggesting that $\mathrm{H}_{2}$ is necessary to maintain catalyst activity [203]. 


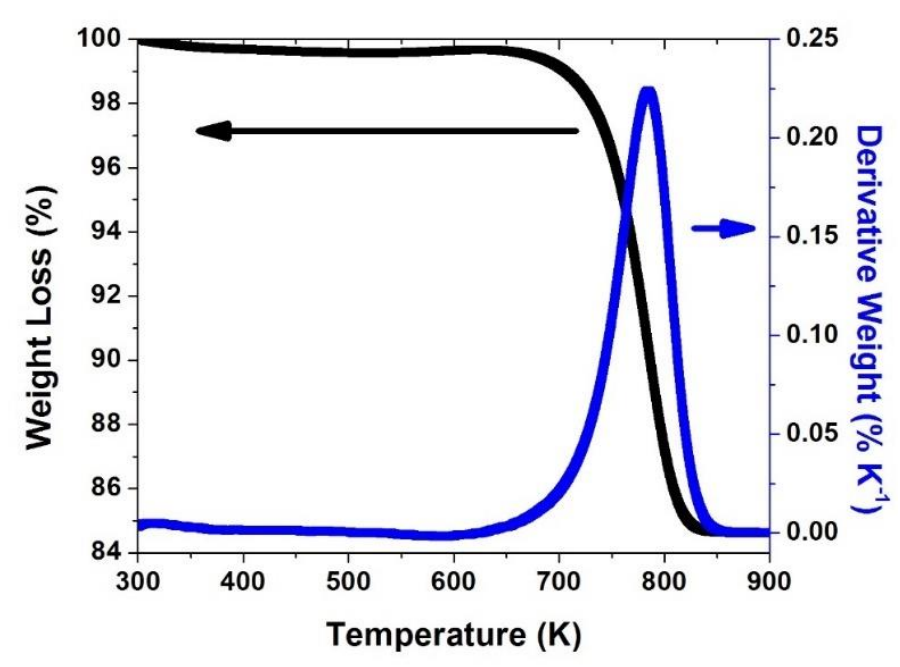

Figure 5-6. Thermogravimetric analysis (TGA) profile of spent $20 \% \mathrm{WO}_{\mathrm{x}} / \mathrm{ZrO}_{2}$ catalyst in $10 \%$ $\mathrm{O}_{2}$, balance He.

A screening of aluminosilicate catalysts (H-ZSM-5, amorphous silica-alumina, Al-MCM41, and Al-Si foam) demonstrated that aluminosilicate catalysts were much more active for ndodecane cracking than $\mathrm{WO}_{\mathrm{x}} / \mathrm{ZrO}_{2}$ catalysts on a per gram basis, shown in Figure 5-7. Rates over aluminosilicate catalysts in previous chapters were reported on a Brønsted acid site basis. However, the difficulty of quantifying the active site for $\mathrm{WO}_{\mathrm{x}} / \mathrm{ZrO}_{2}$ is well documented. Santiesteban and coworkers [213] reported a Brønsted acid density of $4 \mu \mathrm{mol} \cdot \mathrm{g}^{-1}$ for their most active $\mathrm{WO}_{\mathrm{x}} / \mathrm{ZrO}_{2}$ catalyst based on the amount of 2,6-dimethylpyridine needed to prevent $\mathrm{n}$ pentane isomerization reactions. Wong et al. [205] used pyridine adsorption to determine the Brønsted acid density of $\mathrm{WO}_{\mathrm{x}} / \mathrm{ZrO}_{2}$ catalysts and found Brønsted acid densities ranging from 10.3 $-28.8 \mu \mathrm{mol} \cdot \mathrm{g}^{-1}$. Both studies were unable to correlate catalytic activity for $\mathrm{n}$-pentane isomerization to measured Brønsted acid densities with n-pentane isomerization activity. It is expected that the number of Brønsted acid sites measured using amine adsorption underestimates the number present during reaction conditions because Brønsted acid sites on $\mathrm{WO}_{\mathrm{x}} / \mathrm{ZrO}_{2}$ cannot survive outside of a reducing environment [205,206,214]. The n-propylamine decomposition reaction that 
was used to quantify the number Brønsted acid sites over aluminosilicate catalysts in previous chapters was unable to determine the number of Brønsted acid sites over $\mathrm{WO}_{\mathrm{x}} / \mathrm{ZrO}_{2}$. Iglesia et al. reported that WOx domains on a carbide surface catalyzed propylene oligomerization and cracking reactions at $623 \mathrm{~K} \mathrm{[215].} \mathrm{This} \mathrm{is} \mathrm{consistent} \mathrm{with} \mathrm{the} \mathrm{results} \mathrm{for} \mathrm{the} \mathrm{n-propylamine} \mathrm{decomposition}$ reaction over $20 \% \mathrm{WO}_{\mathrm{x}} / \mathrm{ZrO}_{2}$, detailed in Error! Reference source not found., where side reactions resulted in other products besides propylene and ammonia.

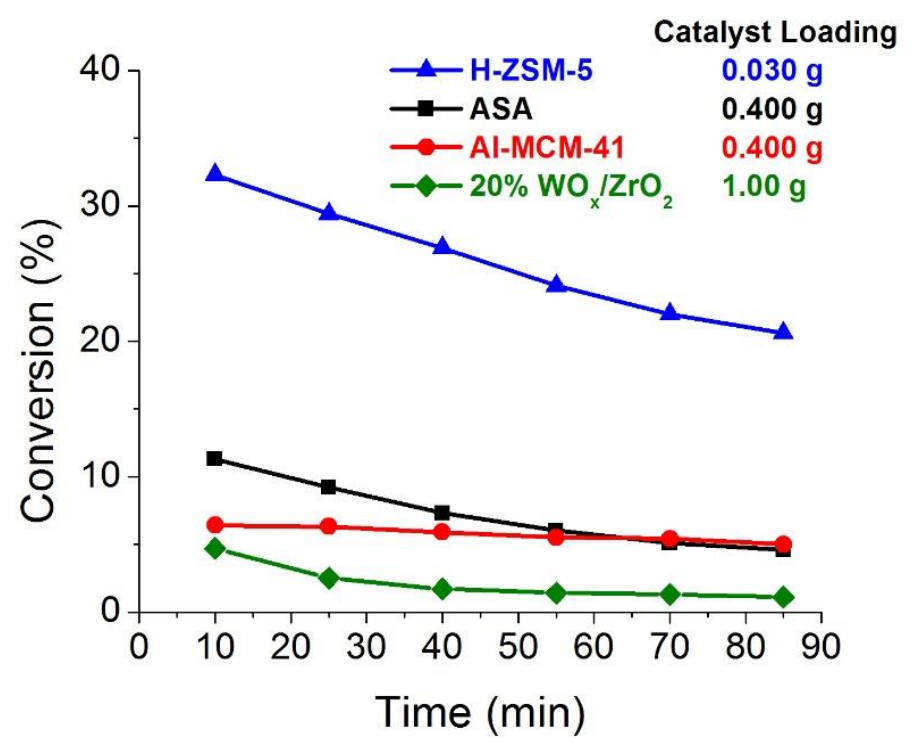

Figure 5-7. Cracking of $\mathrm{n}$-dodecane over $20 \% \mathrm{WO}_{\mathrm{x}} / \mathrm{ZrO}_{2}$ compared to aluminosilicate catalysts at supercritical conditions. Reaction conditions: $\mathrm{T}=698 \mathrm{~K}$; total system pressure $=4 \mathrm{MPa}$, liquid feed flow rate $=0.2 \mathrm{~cm}^{3} \cdot \mathrm{min}^{-1}$.

In general, the Brønsted acid densities for the tested aluminosilicate materials, found in Table 4-1, are much higher than the Brønsted acid densities for $\mathrm{WO}_{\mathrm{x}} / \mathrm{ZrO}_{2}$ catalysts reported in the literature [213,216,217]. These results suggest that the difference in activity for n-dodecane cracking on a per gram basis between $\mathrm{WO}_{\mathrm{x}} / \mathrm{ZrO}_{2}$ and aluminosilicate catalysts can be attributed to the difference in Brønsted acid density. 


\subsection{Conclusions}

In this work, we have shown that $\mathrm{WO}_{\mathrm{x}} / \mathrm{ZrO}_{2}$ catalysts with a range of $\mathrm{WO}_{\mathrm{x}}$ domain sizes were successfully synthesized. Results from cracking of n-dodecane over $\mathrm{WO}_{\mathrm{x}} / \mathrm{ZrO}_{2}$ catalysts exhibited a similar loss of activity with time on stream that was observed over aluminosilicate materials. The cause of the deactivation was investigated using XAS and TGA and was attributed to coke formation. A comparison to results from n-dodecane cracking over aluminosilicate catalysts reveals that $\mathrm{WO}_{\mathrm{x}} / \mathrm{ZrO}_{2}$ catalysts are much less active on a per gram basis than aluminosilicate catalysts. Aircraft applications are volume and weight limited and stable catalysts with high activity on a per gram basis are desired. Therefore, the results of this study demonstrate that aluminosilicate catalysts are more attractive than $\mathrm{WO}_{\mathrm{x}} / \mathrm{ZrO}_{2}$ catalysts for endothermic fuel cracking. 


\section{Conclusions and Future Directions}

\subsection{Conclusions}

The hydrocarbon cracking reaction over solid acid catalysts under supercritical conditions was investigated in this work. In particular, the interaction of linear, branched, and cyclic hydrocarbons with catalysts of micro- and mesoporosity was explored. In Chapter 2, reactions of n-hexane and n-dodecane over H-ZSM-5, H-Y, and Al-MCM-41 were performed at high pressures. The product distribution of the reaction was strongly influenced by bimolecular reactions and the hydrocarbon chain length.

Reactions of n-hexane and n-dodecane over H-ZSM-5 and n-dodecane over all three catalysts resulted in cracking with an activation energy resembling that associated with C-C bond cleavage. Reactions of n-hexane over H-Y and Al-MCM-41 resulted in primarily isomerization products and a lower apparent activation energy. A theoretical approach was used to calculate adsorption isotherms for n-dodecane and n-hexane in H-ZSM-5 and H-Y under reaction conditions. Plateaus occurred in the adsorption isotherms at pressures below saturation, which explained the zero-order kinetics observed in the experiments. The difference in product distribution for n-hexane cracking over H-ZSM-5 and H-Y was attributed to the smaller pores of H-ZSM-5. Hydride transfer reactions to release isomerized alkoxides may be restricted in H-ZSM5. In addition, diffusion coefficients for branched alkanes in H-ZSM-5 were reported to be 2-8 orders of magnitude smaller than linear alkanes. Both of these factors contribute to the secondary cracking of isomerized products over H-ZSM-5. Thus, H-ZSM-5 was the most active catalyst for the cracking of linear alkanes. 
In Chapter 3, the endothermic potential of the H-Y/JP-10 catalyst/fuel pairing was investigated using both fixed bed and micro-flow tube reactor (MFTR) systems. This comparative study aimed to bridge the gap between laboratory and industrial scale results. Results obtained in the fixed bed reactor system were used to evaluate important intrinsic kinetic parameters and mechanistic insights. These results were then compared to the results obtained at shorter residence times over catalyst coated quartz tubes in the MFTR system. The shorter residence times in the MFTR system are closer to those expected in endothermic fuel applications.

Supercritical pyrolytic cracking results in the fixed bed reactor confirmed that JP-10 was more thermally stable than n-dodecane. The product distribution from both the pyrolytic and catalytic cracking experiments revealed that cyclopentadiene and cyclopentene were primary products. GC-MS analysis of the reactor effluent at low and high levels of conversion suggested that cyclopentadiene and cyclopentene undergo molecular growth reactions to form heavier weight molecular compounds. The importance of cyclopentadiene and cyclopentene during pyrolytic and catalytic cracking of JP-10 was also observed in the MFTR system at ambient pressure.

The endothermic potential of the pyrolytic and catalytic cracking of JP-10 in the MFTR system was calculated. It was determined that at the same level of conversion (3\%), catalytic and pyrolytic cracking of JP-10 resulted in similar endothermic cooling capacities. Catalytic cracking of JP-10 failed to significantly increase endothermic cooling capacities at low conversions and exhibited a high tendency for coke formation at high conversions. These characteristics suggest that $\mathrm{H}-\mathrm{Y} / \mathrm{JP}-10$ is an unattractive catalyst/fuel pairing for endothermic fuels.

In Chapter 4, cracking of branched hydrocarbons, mixtures of branched and linear hydrocarbons, and military jet fuel, JP-8, over micro- and mesoporous aluminosilicate catalysts was investigated. In general, the TOF observed during the reaction was affected by the presence 
of branched hydrocarbons. H-ZSM-5, which was the most active catalyst for the cracking of linear alkanes, was much less active for the cracking of isooctane and isododecane. These results are consistent with results reported by Wang et al. [181] and demonstrate the diffusion limitations of branched hydrocarbons within H-ZSM-5. Branched molecules exhibited an inhibiting effect on ndodecane cracking rates during cracking of a 50/50 mol.\% mixture of n-dodecane and isooctane (50/50 mixture) over H-ZSM-5. In comparison, cracking of the 50/50 mixture over mesoporous ASA resulted in a higher TOF than for the cracking of the pure components. This promotional effect demonstrates the importance of proper catalyst/fuel pairing for endothermic fuels comprised of linear and branched molecules.

A preliminary investigation of the cracking of JP-8 over H-ZSM-5 was performed. Although gas-phase product formation rates during cracking of n-dodecane over H-ZSM-5 were stable, gas-phase product formation rates during cracking of JP-8 exhibited severe deactivation. In contrast, cracking of JP-8 over ASA demonstrated promising stability. The cracking behavior of the real military fuel suggests that larger pore materials such as wide pore zeolites or mesoporous aluminosilicates may be promising catalysts for endothermic fuels.

In Chapter 5, non-microporous $\mathrm{WO}_{\mathrm{x}} / \mathrm{ZrO}_{2}$ catalysts were synthesized, characterized, and tested for cracking of n-dodecane activity. It was hypothesized that a non-microporous solid acid catalyst would exhibit greater stability during hydrocarbon cracking under supercritical conditions. A thorough characterization of the various samples showed that a range of catalysts with varying $\mathrm{WO}_{\mathrm{x}}$ domain sizes was successfully synthesized. Cracking of n-dodecane over $\mathrm{WO}_{\mathrm{x}} / \mathrm{ZrO}_{2} \mathrm{samples}$ exhibited similar deactivation behavior as aluminosilicate catalysts. XANES and TGA results suggested that the loss of activity over time was due to coke formation. In addition, cracking of ndodecane over $\mathrm{WO}_{\mathrm{x}} / \mathrm{ZrO}_{2}$ catalyst and the activity on a per gram basis was up to several orders of 
magnitude lower than that of aluminosilicate materials. Thus, it was concluded that $\mathrm{WO}_{\mathrm{x}} / \mathrm{ZrO}_{2}$ was not a suitable catalyst for endothermic fuels.

\subsection{Future Directions}

\subsubsection{Further Investigation into Branched Fuel Mixtures}

Understanding the behavior of branched fuel mixtures is important to the rational design of catalyst/fuel pairings for endothermic fuels. In Chapter 4, catalytic reactions of JP-8 over a HZSM-5 and ASA demonstrated the impact that branched molecules could have during cracking of a real military jet fuel. A higher rate of gas phase production formation for cracking of JP-8 than n-dodecane was observed over ASA. It was inferred that branched hydrocarbons could enhance cracking rates of linear hydrocarbons by providing a source of tertiary carbon atoms. However, the pore dimensions of the catalyst must be large enough to accommodate both molecules within the pores to exhibit this promotional effect. The pore size of H-ZSM-5 was too small to readily accommodate branched fuel molecules. It was expected that a zeolite with a larger pore size would exhibit the promotional effect of a branched fuel mixture. The results shown for the cracking of a $50 / 50 \mathrm{~mol} \%$ mixture of isooctane and $\mathrm{n}$-dodecane over $\mathrm{H}-\mathrm{Y}$ were mixed. A promotional effect was seen below $\sim 663 \mathrm{~K}$, but not at higher temperatures. The reason for this temperature dependent behavior was unclear, however, it may have been an effect of operating near the critical temperature of $\mathrm{n}$-dodecane $\left(\mathrm{T}_{\mathrm{c}}=658 \mathrm{~K}\right)$. Further investigation into this phenomenon should avoid the potential effect of a phase transition by operating in a region that is well outside of the critical properties. These experiments should conclude whether a promotional effect due to branched fuel mixtures exists within a properly sized zeolite. 


\subsubsection{Hierarchal zeolites}

One of the major goals of this work was to investigate catalyst/fuel molecule pairings to gain key insights that would help optimize catalyst/fuel pairings. Hierarchal zeolites, also known as micro-mesoporous zeolites, are another solid acid material that may provide promising results for endothermic fuel cracking. The hierarchal zeolites have single-unit microporous zeolite domains connected by networks with ordered mesoporosity. These materials offer improved diffusion of reactants and products provided by mesopores and shortened diffusion lengths through micropores. These advantages have resulted in significantly higher activity in the cracking of a bulky alkylaromatic, 1,3,5-triisopropylbenzene (TIPB), compared to traditional zeolites [218,219]. Hierarchal zeolites can help ensure kinetic control and measurement of intrinsic kinetic parameters during endothermic fuel cracking experiments. 


\section{References}

1. Gascoin, N., Gillard, P., Bernard, S. \& Bouchez, M. Characterisation of coking activity during supercritical hydrocarbon pyrolysis. Fuel Process. Technol. 89, 1416-1428 (2008).

2. Hazlett, R. N. Thermal Oxidation Stability of Aviation Turbine Fuels. (Philadelphia, PA (United States); ASTM, 1991). doi:10.1520/MONO1-EB

3. Harrison, W. E. Aircraft thermal management: Report of the Joint WRDC/ASD thermal management working group, -WRDC-TR-90-2021. Ilcpoii No. TR-90-202 1, (1990).

4. Lander, H. \& Nixon, A. C. Endothermic fuels for hypersonic vehicles. J. Aircr. 8, 200-207 (1971).

5. Heneghan Harrison, W.E., S. P. JP-8+100: The development of high thermal stability jet fuel. in Proc. 6th International Conference on Stability and Handling of Liquid Fuels, Vancouver, B.C., October 13-17, 271-352 (American Institute of Aeronautics and Astronautics, 1997). doi:10.2514/6.1996-403

6. Edwards, T. USAF supercritical hydrocarbon fuels interests. in 31st Aerospace Sciences Meeting (American Institute of Aeronautics and Astronautics, 1993). doi:doi:10.2514/6.1993-807

7. Sobel, D. R. \& Spadaccini, L. J. Hydrocarbon Fuel Cooling Technologies for Advanced Propulsion. J. Eng. Gas Turbines Power 119, 344 (1997).

8. Minato, K. et al. Thermochemical and Thermophysical Properties of Advanced Fission Fuel Materials. Adv. Sci. Technol. 45, 1931-1940 (2006).

9. Maurice, L. \& Edwards, T. in Scramjet Propulsion 757-822 (American Institute of Aeronautics and Astronautics, 2001). doi:doi:10.2514/5.9781600866609.0757.0822

10. Metzler, A. J. Minimum spark-ignition energies of 12 pure fuels at atmospheric and reduced pressure, RM E53H31. (1953).

11. Lee, T.-W., Jain, V. \& Kozola, S. Measurements of minimum ignition energy by using laser sparks for hydrocarbon fuels in air: propane, dodecane, and jet-A fuel. Combust. Flame 125, 1320-1328 (2001).

12. Nagley, E. A. Fuel Composition Analysis of Endothermically Heated JP-8 Fuel For Use in a Pulse Detonation Engine. in 46th AIAA Aerospace Sciences Meeting and Exhibit 71 (American Institute of Aeronautics and Astronautics, 2008). doi:10.2514/6.2008-109

13. Yaws, C. L. Yaws' Thermophysical Properties of Chemicals and Hydrocarbons (Electronic Edition). (Knovel, 2010).

14. Venuto, P. B. \& Habib, E. T. Fluid catalytic cracking with zeolite catalysts. (Marcel Dekker, Inc.,New York, NY, 1979).

15. Greensfelder, B. S., Voge, H. H. \& Good, G. M. Catalytic and Thermal Cracking of Pure Hydrocarbons: Mechanisms of Reaction. Ind. Eng. Chem. 41, 2573-2584 (1949). 
16. Thomas, C. L. Chemistry of cracking catalysts. Ind. Eng. Chem. 41, 2564-2573 (1949).

17. Wojciechowski, B. W. \& Corma, A. Catalytic cracking: catalysts, chemistry, and kinetics. (1986).

18. Cumming, K. A. \& Wojciechowski, B. W. Hydrogen Transfer, Coke Formation, and Catalyst Decay and Their Role in the Chain Mechanism of Catalytic Cracking. Catal. Rev. 38, 101-157 (1996).

19. Corma, A. \& Orchillés, A. V. Current views on the mechanism of catalytic cracking. Microporous Mesoporous Mater. 35-36, 21-30 (2000).

20. Krannila, H., Haag, W. O. \& Gates, B. C. Monomolecular and bimolecular mechanisms of paraffin cracking: n-butane cracking catalyzed by HZSM-5. J. Catal. 135, 115-124 (1992).

21. Kotrel, S., Knözinger, H. \& Gates, B. C. The Haag-Dessau mechanism of protolytic cracking of alkanes. Microporous Mesoporous Mater. 35-36, 11-20 (2000).

22. Jentoft, F. C. \& Gates, B. C. Solid-acid-catalyzed alkane cracking mechanisms: evidence from reactions of small probe molecules. Top. Catal. 4, 1-13 (1997).

23. Stöcker, M., Karge, H. G., Jansen, J. C. \& Weitkamp, J. Advanced in zeolite science and applications. (1994).

24. Aronson, M. T., Gorte, R. J., Farneth, W. E. \& White, D. Carbon-13 NMR identification of intermediates formed by 2-methyl-2-propanol adsorption in H-ZSM-5. J. Am. Chem. Soc. 111, 840-846 (1989).

25. Bethell, D. \& Gold, V. Carbonium Ions: An Introduction. (Academic Press, 1967).

26. Pople, J. A., Lathan, W. A. \& Hehre, W. J. Molecular orbital theory of the electronic structure of organic compounds. VI. Geometries and energies of small hydrocarbons. J. Am. Chem. Soc. 93, 808-815 (1971).

27. Olah, G. A., Halpern, Y., Shen, J. \& Mo, Y. K. Electrophilic reactions at single bonds. XII. Hydrogen-deuterium exchange, protolysis (deuterolysis), and oligocondensation of alkanes with superacids. J. Am. Chem. Soc. 95, 4960-4970 (1973).

28. Olah, G. A., DeMember, J. R. \& Shen, J. Electrophilic reactions at single bonds. X. Hydrogen transfer, alkylation, and alkylolysis of alkanes with methyl and ethyl fluoroantimonate. J. Am. Chem. Soc. 95, 4952-4956 (1973).

29. Olah, G. A. \& Lin, H. C. H. Electrophilic reactions at single bonds. V. Nitration and nitrolysis of alkanes and cycloalkanes with nitronium salts. J. Am. Chem. Soc. 93, 12591261 (1971).

30. Olah, G. A., Halpern, Y., Shen, J. \& Mo, Y. K. Electrophilic reactions at single bonds. III. HD exchange and protolysis (deuterolysis) of alkanes with superacids. The mechanism of acid-catalyzed hydrocarbon transformation reactions involving the. sigma. electron pair donor ability of single bonds via . J. Am. Chem. Soc. 93, 1251-1256 (1971).

31. Charton, M. Progress in Physical Organic Chemistry. Progress in Physical Organic Chemistry 13, (John Wiley \& Sons, Inc., 1981). 
32. Corma, A., Planelles, J., Sánchez-Marín, J. \& Tomás, F. The role of different types of acid site in the cracking of alkanes on zeolite catalysts. J. Catal. 93, 30-37 (1985).

33. Kissin, Y. V. Relative reactivities of alkanes in multi-component catalytic cracking reactions. Catal. Letters 19, 181-187 (1993).

34. Haag, W. O. \& Dessau, R. M. Duality of Mechanism in Acid Catalyzed Paraffin Cracking. in the Eighth International Congress on Catalysis 305-315 (1984).

35. Planelles, J., Sanchez-Marin, J., Tomas, F. \& Corma, A. A molecular orbital approach to a comprehensive cracking mechanism for linear long chain alkanes in heterogeneous acid catalytic conditions through carbenium ion [small beta]-cleavage. J. Chem. Soc. 333-340 (1985). doi:10.1039/P29850000333

36. Buchanan, J. S., Santiesteban, J. G. \& Haag, W. O. Mechanistic Considerations in AcidCatalyzed Cracking of Olefins. J. Catal. 158, 279-287 (1996).

37. Haag, W. O., Lago, R. M. \& Weisz, P. B. Transport and reactivity of hydrocarbon molecules in a shape-selective zeolite. Faraday Discuss. Chem. Soc. 72, 317 (1981).

38. Pritchard, H. O. The Determination of Electron Affinities. Chem. Rev. 52, 529-563 (1953).

39. Brouwer, D. M. \& Oelderik, J. M. HF-SbF5 catalysed isomerization of 2-methylpentane: Kinetics and mechanism of rearrangement and hydride-ion transfer steps in alkylcarbonium ion reactions. Recl. des Trav. Chim. des Pays-Bas 87, 721-736 (1968).

40. McCaulay, D. A. Mechanism of Acid-catalyzed Isomerization of the Hexanes. J. Am. Chem. Soc. 81, 6437-6443 (1959).

41. Bartlett, P. D., Condon, F. E. \& Schneider, A. Exchanges of Halogen and Hydrogen between Organic Halides and Isoparaffins in the Presence of Aluminum Halides. J. Am. Chem. Soc. 66, 1531-1539 (1944).

42. Mcvicker, G. B. Hydride Transfer and Olefin Isomerization as Tools To Characterize Liquid and Solid Acids. Acc. Chem. Res. 19, 78-84 (1986).

43. Schulz, H. F. \& Weitkamp, J. H. Zeolite catalysts. Hydrocracking and hydroisomerization of n-dodecane. Ind. Eng. Chem. Prod. Res. Dev. 11, 46-53 (1972).

44. Weitkamp, J. in Hydrocracking and Hydrotreating 1-27 (ACS Publications, 1975). doi:10.1021/bk-1975-0020.ch001

45. Sie, S. T. Acid-catalyzed cracking of paraffinic hydrocarbons. 1. Discussion of existing mechanisms and proposal of a new mechanism. Ind. Eng. Chem. Res. 31, 1881-1889 (1992).

46. Sie, S. T. Acid-catalyzed cracking of paraffinic hydrocarbons. 2. Evidence for the protonated cyclopropane mechanism from catalytic cracking experiments. Ind. Eng. Chem. Res. 32, 397-402 (1993).

47. Sie, S. T. Acid-catalyzed cracking of paraffinic hydrocarbons. 3. Evidence for the protonated cyclopropane mechanism from hydrocracking/hydroisomerization experiments. Ind. Eng. Chem. Res. 32, 403-408 (1993). 
48. Archibald, R. C., Greensfelder, B. S., Holzman, G. \& Rowe, D. H. Catalytic hydrocracking of aliphatic hydrocarbons. Ind. Eng. Chem. 52, 745-750 (1960).

49. Narbeshuber, T. F., Vinek, H. \& Lercher, J. A. Monomolecular Conversion of Light Alkanes over H-ZSM-5. J. Catal. 157, 388-395 (1995).

50. Li, H., Kadam, S. A., Vimont, A., Wormsbecher, R. F. \& Travert, A. Monomolecular Cracking Rates of Light Alkanes over Zeolites Determined by IR Operando Spectroscopy. ACS Catal. 6, 4536-4548 (2016).

51. Vogt, E. T. C. \& Weckhuysen, B. M. Fluid catalytic cracking: recent developments on the grand old lady of zeolite catalysis. Chem. Soc. Rev. 44, 7342-7370 (2015).

52. Riekerti, L. \& Zhou, J. Q. Kinetics of cracking of n-decane and n-hexane on zeoiites HZSM-5 and HY in the temperature range 500 to 780 K. J. Catal. 137, 437-452 (1992).

53. Sanchez-Castillo, M. A. et al. Reaction Kinetics Study and Analysis of Reaction Schemes for Isobutane Conversion over USY Zeolite. J. Catal. 205, 67-85 (2002).

54. Cortright, R. D., Dumesic, J. A. \& Madon, R. J. Catalytic cycles for hydrocarbon cracking on zeolites. Top. Catal. 4, 15-26 (1997).

55. Agarwal, N., Sanchez-castillo, M. A., Cortright, R. D., Madon, R. J. \& Dumesic, J. A. Catalytic Cracking of Isobutane and 2-Methylhexane over USY Zeolite : Identification of Kinetically Significant Reaction Steps. Ind. Eng. Chem. Res. 4016-4027 (2002). doi:10.1021/ie020041z

56. Behr, A. \& Ugo, R. Theoretical Aspects of Homogeneous Catalysis. 5, (Springer Netherlands, 1995).

57. Fowden, L., Barrer, R. M. \& Tinker, P. B. Clay minerals: their structure, behaviour and use. Philos. Trans. R. Soc. London, Ser. A Math. Phys. Sci. 311, 221-432 (1984).

58. Vaughan, D. E. W. Pillared clays-a historical perspective. Catal. Today 2, 187-198 (1988).

59. Mardkhe, M. K. et al. Acid site properties of thermally stable, silica-doped alumina as a function of silica/alumina ratio and calcination temperature. Appl. Catal. A Gen. 482, 1623 (2014).

60. Hensen, E. J. M., Poduval, D. G., Magusin, P. C. M. M., Coumans, A. E. \& Veen, J. A. R. van. Formation of acid sites in amorphous silica-alumina. J. Catal. 269, 201-218 (2010).

61. Ishihara, A., Negura, H., Hashimoto, T. \& Nasu, H. Catalytic properties of amorphous silica-alumina prepared using malic acid as a matrix in catalytic cracking of n-dodecane. Appl. Catal. A Gen. 388, 68-76 (2010).

62. Olphen, H. Van \& Fripiat, J. J. Data Handbook for Clay Materials and Other Non-Metallic Minerals: Providing Those Involved in Clay Research and Industrial Application with Sets of Authoritative Data Describing the Physical and Chemical Properties and Mineralogical Composition of the Ava. (Pergamon press, 1979).

63. Plank, C. J. Differences between silica and silica-alumina gels II. A proposed mechanism for the gelation and syneresis of these gels. J. Colloid Sci. 2, 413-427 (1947). 
64. Snel, R. Control of the porous structure of amorphous silica-alumina 2. The effects of ph and reactant concentration. Appl. Catal. 12, 189-200 (1984).

65. Taguchi, A. \& Schüth, F. Ordered mesoporous materials in catalysis. Microporous Mesoporous Mater. 77, 1-45 (2005).

66. Plank, C. J. Differences between silica and silica-alumina gels II. A proposed mechanism for the gelation and syneresis of these gels. J. Colloid Sci. 2, 413-427 (1947).

67. Defosse, C. Surface characterization of silica-aluminas by photoelectron spectroscopy. $J$. Catal. 51, 269-277 (1978).

68. Peri, J. B. A model for the surface of a silica-alumina catalyst. J. Catal. 41, 227-239 (1976).

69. Leydier, F. et al. Brønsted acidity of amorphous silica-alumina: The molecular rules of proton transfer. J. Catal. 284, 215-229 (2011).

70. Abbot, J. Role of Brønsted and Lewis acid sites during cracking reactions of alkanes. Appl. Catal. 47, 33-44 (1989).

71. Basila, M. R., Kantner, T. R. \& Rhee, K. H. The Nature of the Acidic Sites on a SilicaAlumina. Characterization by Infrared Spectroscopic Studies of Trimethylamine and Pyridine Chemisorption 1. J. Phys. Chem. 68, 3197-3207 (1964).

72. Leydier, F., Chizallet, C., Costa, D. \& Raybaud, P. Revisiting carbenium chemistry on amorphous silica-alumina: Unraveling their milder acidity as compared to zeolites. J. Catal. 325, 35-47 (2015).

73. Chen, N. Y., Garwood, W. E. \& Dwyer, F. G. in Chemical Industries Series, Vol. 6 (1989).

74. Weitkamp, J. Zeolites and catalysis. Solid State Ionics 131, 175-188 (2000).

75. Derouane, E. G. Zeolites as solid solvents. J. Mol. Catal. A Chem. 134, 29-45 (1998).

76. Kokotailo, G., Lawton, S., Olson, D. \& Meier, W. M. Structure of synthetic zeolite ZSM5. Nature 272, 437-438 (1978).

77. Smit, B. Simulation of adsorption and diffusion of hydrocarbons in zeolites. Faraday Discuss 106, 93-104 (1997).

78. Vlugt, T. J. H., Krishna, R. \& Smit, B. Molecular Simulations of Adsorption Isotherms for Linear and Branched Alkanes and Their Mixtures in Silicalite. J. Phys. Chem. B 103, 11021118 (1999).

79. Smit, B. \& Maesen, T. L. M. Commensurate 'freezing' of alkanes in the channels of a zeolite. Nature 374, 42-44 (1995).

80. Smit, B. \& Siepmannt, J. I. Computer Simulations of the Energetics and Siting of n-Alkanes in Zeolites. J. Phys. Chem 98, 8442-8452 (1994).

81. Barrer, R. M. Synthesis of zeolites. Stud. Surf. Sci. Catal. 24, 1-26 (1985).

82. Martin, D. E. Synthesis of zeolites. U.S. Pat. No. 4,000,248. 28 (1976). 
83. Yu, J., Cejka, J., van Bekkum, H., Corma, A. \& Schueth, F. Synthesis of zeolites. Introd. to zeolite Sci. Pract. 168, 39 (2007).

84. Cundy, C. S. \& Cox, P. A. The hydrothermal synthesis of zeolites: Precursors, intermediates and reaction mechanism. Microporous Mesoporous Mater. 82, 1-78 (2005).

85. Cundy, C. S. \& Cox, P. A. The hydrothermal synthesis of zeolites: history and development from the earliest days to the present time. Chem. Rev. 103, 663-702 (2003).

86. Falamaki, C., Edrissi, M. \& Sohrabi, M. Studies on the Crystallization Kinetics of Zeolite ZSM-5 With 1,6-Hexanediol as a Structure-Directing Agent. Zeolites 19, 2-5 (1997).

87. Kumar, N. et al. Effect of synthesis time and mode of stirring on physico-chemical and catalytic properties of ZSM-5 zeolite catalysts. Appl. Catal. A Gen. 235, 113-123 (2002).

88. Davis, M. E. \& Lobo, R. F. Zeolite and molecular sieve synthesis. Chem. Mater. 4, 756768 (1992).

89. Pereira, C. \& Gorte, R. J. Method for distinguishing Brønsted-acid sites in mixtures of HZSM-5, H-Y and silica-alumina. Appl. Catal. A Gen. 90, 145-157 (1992).

90. Corma, A., Grande, M. S., Gonzalez-Alfaro, V. \& Orchilles, A. V. Cracking Activity and Hydrothermal Stability of MCM-41 and Its Comparison with Amorphous Silica-Alumina and a USY Zeolite. J. Catal. 159, 375-382 (1996).

91. Corma, A. et al. Hydrocracking-hydroisomerization of n-decane on amorphous silicaalumina with uniform pore diameter. Appl. Catal. A Gen. 152, 107-125 (1997).

92. Espinoza, R. L., Stander, C. M. \& Mandersloot, W. G. B. Catalytic conversion of methanol to hydrocarbons over amorphous or zeolitic silica-alumina. Appl. Catal. 6, 11-26 (1983).

93. Csicsery, S. M. Shape-selective catalysis in zeolites. Zeolites 4, 202-213 (1984).

94. Chen, N. Y., Degnan, T. F. \& Smith, C. F. Molecular transport and reaction in zeolites. (VCH, 1994).

95. Chen, N. Y. \& Garwood, W. E. Industrial Application of Shape-Selective Catalysis. Catal. Rev. 28, 185-264 (1986).

96. Gounder, R. \& Iglesia, E. Catalytic Consequences of Spatial Constraints and Acid Site Location for Monomolecular Alkane Activation on Zeolites. J. Am. Chem. Soc. 131, 19581971 (2009).

97. Gounder, R. \& Iglesia, E. The Roles of Entropy and Enthalpy in Stabilizing Ion-Pairs at Transition States in Zeolite Acid Catalysis. Acc. Chem. Res. 45, 229-238 (2011).

98. Lipscomb, G. G. Innovations in Industrial and Engineering Chemistry. ACS Symposium Series 1000, (American Chemical Society, 2008).

99. Chen, H. \& Wang, Y. Preparation of MCM-41 with high thermal stability and complementary textural porosity. Ceram. Int. 28, 541-547 (2002).

100. Cruciani, G. Zeolites upon heating: Factors governing their thermal stability and structural changes. J. Phys. Chem. Solids 67, 1973-1994 (2006). 
101. Adams, C. R. \& Voge, H. H. Aging of Silica-Alumina Cracking Catalysts. IL Electron Microscope Studies. J. Phys. Chem. 61, 722-727 (1957).

102. Ates, A. \& Hardacre, C. The effect of various treatment conditions on natural zeolites: Ion exchange, acidic, thermal and steam treatments. J. Colloid Interface Sci. 372, 130-140 (2012).

103. Petley, D. H. \& Jones, S. C. Thermal management for a Mach 5 cruise aircraft using endothermic fuel. J. Aircr. 29, 384-389 (1992).

104. Huang, H., Sobel, D. \& Spadaccini, L. in Endothermic heat-sink of hydrocarbon fuels for scramjet cooling 3871 (American Institute of Aeronautics and Astronautics, 2002). doi:doi:10.2514/6.2002-3871

105. Huang, H., Spadaccini, L. J. \& Sobel, D. R. Fuel-Cooled Thermal Management for Advanced Aeroengines. J. Eng. Gas Turbines Power 126, 284 (2004).

106. Edwards, T. \& Zabarnick, S. Supercritical fuel deposition mechanisms. Ind. Eng. Chem. Res. 32, 3117-3122 (1993).

107. Yu, J. \& Eser, S. Thermal Decomposition of Jet Fuel Model Compounds under NearCritical and Supercritical Conditions. 2. Decalin and Tetralin. Ind. Eng. Chem. Res. 37, 4601-4608 (1998).

108. Yu, J. \& Eser, S. Thermal Decomposition of C10-C14 Normal Alkanes in Near-Critical and Supercritical Regions: Product Distributions and Reaction Mechanisms. Ind. Eng. Chem. Res. 36, 574-584 (1997).

109. Yu, J. \& Eser, S. Kinetics of Supercritical-Phase Thermal Decomposition of C10-C14 Normal Alkanes and Their Mixtures. Ind. Eng. Chem. Res. 36, 585-591 (1997).

110. Daniau, E. et al. Fuel reforming for scramjet thermal management and combustion optimization. in AIAA/CIRA 13th International Space Planes and Hypersonics Systems and Technologies Conference 340, 2005 (2005).

111. Sicard, M., Raepsaet, B., Ser, F. \& Masson, C. Determination of the decomposition products of a n-alkane endothermic fuel under supercritical conditions. in AIAA/CIRA 13th International Space Planes and Hypersonics Systems and Technologies Conference 1-9 (American Institute of Aeronautics and Astronautics, 2005). doi:doi:10.2514/6.2005-3402

112. Sicard, M. et al. N-Dodecane Thermal and Catalytic Cracking Under Supercritical Conditions. Stud. Surf. Sci. Catal. 174, 1103-1106 (2008).

113. Sicard, M., Grill, M., Raepsaet, B. \& Ser, F. Comparison between thermal and catalytic cracking of a model endothermic fuel. in 15th AIAA International Space Planes and Hypersonic Systems and Technologies Conference 2622 (American Institute of Aeronautics and Astronautics, 2008). doi:doi:10.2514/6.2008-2622

114. Luo, J. \& Gorte, R. J. High Pressure Cracking of n-Hexane Over H-ZSM-5. Catal. Letters 143, 313-316 (2013).

115. Luo, J., Bhaskar, B. V., Yeh, Y.-H. \& Gorte, R. J. n-Hexane cracking at high pressures on 
H-ZSM-5, H-BEA, H-MOR, and USY for endothermic reforming. Appl. Catal. A Gen. 478, 228-233 (2014).

116. Schreiner, E. P., Teketel, S. \& Lobo, R. F. Catalytic n-pentane conversion on H-ZSM-5 at high pressure. New J. Chem. 40, 4245-4251 (2016).

117. Kissin, Y. V. Chemical mechanisms of catalytic cracking over solid acidic catalysts: alkanes and alkenes. Catal. Rev. 43, 85-146 (2001).

118. Süer, M. G., Dardas, Z., Lu, Y., Moser, W. R. \& Ma, Y. H. In-situ CIR-FTIR study of the diffusion of supercritical hydrocarbons in zeolite L. AIChE J. 43, 1717-1726 (1997).

119. Dardas, Z., Süer, M. G., Ma, Y. H. \& Moser, W. R. High-Temperature, High-Pressure in Situ Reaction Monitoring of Heterogeneous Catalytic Processes under Supercritical Conditions by CIR-FTIR. J. Catal. 159, 204-211 (1996).

120. Saim, S. \& Subramaniam, B. Chemical reaction equilibrium at supercritical conditions. Chem. Eng. Sci. 43, 1837-1841 (1988).

121. Subramaniam, B. Enhancing the stability of porous catalysts with supercritical reaction media. Appl. Catal. A Gen. 212, 199-213 (2001).

122. Mayfield, H. T. JP-8 composition and variability. Technical Report - Armstrong Laboratory (1996).

123. Parrillo, D. J., Adamo, A. T., Kokotailo, G. T. \& Gorte, R. J. Amine adsorption in H-ZSM5. Appl. Catal. 67, 107-118 (1990).

124. Farneth, W. E. \& Gorte, R. J. Methods for Characterizing Zeolite Acidity. Chem. Rev. 95, 615-635 (1995).

125. Kresnawahjuesa, O., Gorte, R. J., De Oliveira, D. \& Lau, L. Y. A simple, inexpensive, and reliable method for measuring Brønsted-acid site densities in solid acids. Catal. Letters $\mathbf{8 2}$, 155-160 (2002).

126. Barrett, E. P., Joyner, L. G. \& Halenda, P. P. The Determination of Pore Volume and Area Distributions in Porous Substances. I. Computations from Nitrogen Isotherms. J. Am. Chem. Soc. 73, 373-380 (1951).

127. Kresse, G. \& Joubert, D. From ultrasoft pseudopotentials to the projector augmented-wave method. Phys. Rev. B 59, 1758-1775 (1999).

128. Perdew, J. P., Burke, K. \& Ernzerhof, M. Generalized Gradient Approximation Made Simple. Phys. Rev. Lett. 77, 3865-3868 (1996).

129. Grimme, S. Semiempirical GGA-type density functional constructed with a long-range dispersion correction. J. Comput. Chem. 27, 1787-1799 (2006).

130. Jónsson, H., Mills, G. \& Jacobsen, K. W. Nudged elastic band method for finding minimum energy paths of transitions. Class. Quantum Dyn. Condens. Phase Simulations 385-404 (1998). doi:10.1142/9789812839664_0016

131. Henkelman, G. \& Jónsson, H. A dimer method for finding saddle points on high 
dimensional potential surfaces using only first derivatives. J. Chem. Phys. 111, 7010 (1999).

132. Bai, P., Tsapatsis, M. \& Siepmann, J. I. TraPPE-zeo: Transferable potentials for phase equilibria force field for all-silica zeolites. J. Phys. Chem. C 117, 24375-24387 (2013).

133. Lubna, N., Kamath, G., Potoff, J. J., Rai, N. \& Siepmann, J. I. Transferable potentials for phase equilibria. 8. United-atom description for thiols, sulfides, disulfides, and thiophene. J. Phys. Chem. B 109, 24100-24107 (2005).

134. Martin, M. G. \& Siepmann, J. I. Novel Configurational-Bias Monte Carlo Method for Branched Molecules. Transferable Potentials for Phase Equilibria. 2. United-Atom Description of Branched Alkanes. J. Phys. Chem. B 103, 4508-4517 (1999).

135. Allen, M. P., Tildesley, D. J. \& Banavar, J. R. Computer Simulation of Liquids. Physics Today 42, (1989).

136. Biaglow, A. I., Parrillo, D. J., Kokotailo, G. T. \& Gorte, R. J. A Study of Dealuminated Faujasites. J. Catal. 148, 213-223 (1994).

137. Baerlocher, C., McCusker, L. \& Olson, D. Atlas of zeolite framework types. Sensors 12, (Elsevier, 2007).

138. Chu, Y. et al. Mechanism of alkane H/D exchange over zeolite H-ZSM-5 at low temperature: a combined computational and experimental study. Catal. Sci. Technol. 6, 5350-5363 (2016).

139. Kissin, Y. V. Chemical Mechanism of Hydrocarbon Cracking over Solid Acidic Catalysts. J. Catal. 163, 50-62 (1996).

140. Pansing, W. F. The Catalytic Cracking of Hexadecane-Effects of Impurities, Olefins, and Steam. J. Phys. Chem. 69, 392-399 (1965).

141. Bai, P., Olson, D. H., Tsapatsis, M. \& Siepmann, J. I. Understanding the unusual adsorption behavior in hierarchical zeolite nanosheets. ChemPhysChem 15, 2225-2229 (2014).

142. Williams, B. A., Ji, W., Miller, J. T., Snurr, R. Q. \& Kung, H. H. Evidence of different reaction mechanisms during the cracking of $\mathrm{n}$-hexane on H-USY zeolite. Appl. Catal. A Gen. 203, 179-190 (2000).

143. Zhao, Y., Bamwenda, G. R. \& Wojciechowski, B. W. Cracking Selectivity Patterns in the Presence of Chain Mechanisms. The Cracking of 2-Methylpentane. J. Catal. 142, 465-489 (1993).

144. Bamwenda, G. R., Zhao, Y. X. \& Wojciechowski, B. W. The Influence of Reaction Temperature on the Cracking Mechanism of 2-Methylhexane. J. Catal. 148, 595-606 (1994).

145. Kotrel, S., Rosynek, M. P. \& Lunsford, J. H. Intrinsic Catalytic Cracking Activity of Hexane over H-ZSM-5, H- $\beta$ and H-Y Zeolites. J. Phys. Chem. B 103, 818-824 (1999).

146. Heink, W., Kärger, J., Pfeifer, H., Datema, K. \& Nowak, A. High-temperature pulsed field gradient nuclear magnetic resonance self-diffusion measurements of n-alkanes in MFl-type zeolites. J. Chem. Soc., Faraday Trans. 88, 3505-3509 (1992). 
147. Song, L. \& Rees, L. V. C. Adsorption and transport of n-hexane in silicalite-1 by the frequency response technique. J. Chem. Soc. Faraday Trans. 93, 649-657 (1997).

148. Millot, B., Méthivier, A., Jobic, H., Moueddeb, H. \& Dalmon, J. A. Permeation of linear and branched alkanes in ZSM-5 supported membranes. Microporous Mesoporous Mater. 38, 85-95 (2000).

149. Cavalcante, C. L. J. \& Ruthven, D. M. Adsorption of Branched and Cyclic Paraffins in Silicalite. 1. Equilibrium. Ind. Eng. Chem. Res. 34, 177-184 (1995).

150. Olson, D., Bisio, A. \& Breck, D. W. International Conference on Zeolites: 6th: Proceedings. (Butterworth-Heinemann, 1984).

151. Janda, A. et al. Adsorption Thermodynamics and Intrinsic Activation Parameters for Monomolecular Cracking of n -Alkanes on Brønsted Acid Sites in Zeolites. J. Phys. Chem. C 119, 10427-10438 (2015).

152. Kotrel, S., Rosynek, M. P. \& Lunsford, J. H. Origin of First-Order Kinetics during the Bimolecular Cracking of n-Hexane over H-ZSM-5 and H- $\beta$ Zeolites. J. Catal. 191, 55-61 (2000).

153. Beecher, R. \& Voorhies, A. Hexane Isomerization over a Zeolite Catalyst. Ind. Eng. Chem. Prod. Res. Dev. 8, 366-371 (1969).

154. Chica, A., Corma, A. \& Miguel, P. J. Isomerization of C5-C7 n-alkanes on unidirectional large pore zeolites: activity, selectivity and adsorption features. Catal. Today 65, 101-110 (2001).

155. Macht, J., Carr, R. T. \& Iglesia, E. Consequences of Acid Strength for Isomerization and Elimination Catalysis on Solid Acids. J. Am. Chem. Soc. 131, 6554-6565 (2009).

156. Demuth, T. et al. Catalytic isomerization of 2-pentene in H-ZSM-22-A DFT investigation. J. Catal. 214, 68-77 (2003).

157. Martens, J. A., Tielen, M. \& Jacobs, P. A. Attempts to rationalize the distribution of hydrocracked products. III. mechanistic aspects of isomerization and hydrocracking of branched alkanes on ideal bifunctional large-pore zeolite catalysts. Catal. Today 1, 435453 (1987).

158. Martens, J. A., Jacobs, P. A. \& Weitkamp, J. Attempts to rationalize the distribution of hydrocracked products. II. Relative rates of primary hydrocracking modes of long chain paraffins in open zeolites. Appl. Catal. 20, 283-303 (1986).

159. Subramaniam, B. \& McHugh, M. A. Reactions in supercritical fluids - a review. Ind. Eng. Chem. Process Des. Dev. 25, 1-12 (1986).

160. Sicard, M. et al. N-Dodecane Thermal and Catalytic Cracking Under Supercritical Conditions. Studies in Surface Science and Catalysis 174, (Elsevier, 2008).

161. Chickos, J. S. \& Zhao, H. Measurement of the vaporization enthalpy of complex mixtures by correlation-gas chromatography. The vaporization enthalpy of RP-1, JP-7, and JP-8 rocket and jet fuels at T =298.15 K. Energy and Fuels 19, 2064-2073 (2005). 
162. Rosenberg, Z. Hypersonic X-51 programme ends in success. FlightGlobal (2013). Available at: https:/www.flightglobal.com/news/articles/hypersonic-x-51-programmeends-in-success-385481/. (Accessed: 17th February 2017)

163. Cooper, M. \& Shepherd, J. E. Thermal and Catalytic Cracking of JP-10 for Pulse Detonation Engine Applications. (2002).

164. Li, G. et al. Investigations on the thermal decomposition of JP-10/iso-octane binary mixtures. Fuel 163, 148-156 (2016).

165. Xing, Y., Fang, W., Xie, W., Guo, Y. \& Lin, R. Thermal Cracking of JP-10 under Pressure. Ind. Eng. Chem. Res. 47, 10034-10040 (2008).

166. Nageswara Rao, P. \& Kunzru, D. Thermal cracking of JP-10: Kinetics and product distribution. J. Anal. Appl. Pyrolysis 76, 154-160 (2006).

167. Nakra, S., Green, R. J. \& Anderson, S. L. Thermal decomposition of JP-10 studied by micro-flowtube pyrolysis-mass spectrometry. Combust. Flame 144, 662-674 (2006).

168. Kim, S., Sasmaz, E. \& Lauterbach, J. Effect of Pt and Gd on coke formation and regeneration during JP-8 cracking over ZSM-5 catalysts. Appl. Catal. B Environ. 168, 212219 (2015).

169. Xing, Y. et al. Catalytic cracking of tricyclo [5.2.1.02.6] decane over HZSM-5 molecular sieves. Fuel 89, 1422-1428 (2010).

170. Shrestha, U., Rahimi, M., Simms, G. \& Chelliah, H. Fuel Pyrolysis in a Microflow Tube Reactor - Mesurement and Modeling Uncertainties of Ethane, n-Butane and n-Dodecane Pyrolysis. Combust. Flame (submitted Publ. (2016).

171. Wohlwend, K. et al. Thermal stability of energetic hydrocarbon fuels for use in combined cycle engines. J. Propul. Power 17, 1258-1262 ST-Thermal stability of energetic hyd (2001).

172. Groten, W. A. \& Wojciechowski, B. W. Coke and deactivation I. Stoichiometry of coke formation in the catalytic reactions of n-hexene on USHY. J. Catal. 122, 362-373 (1990).

173. Groten, W. A., Wojciechowski, B. W. \& Hunter, B. K. Coke and deactivation II. Formation of coke and minor products in the catalytic cracking of n-Hexene on USHY zeolite. J. Catal. 125, 311-324 (1990).

174. Liu, K. Identification of Coke Precursors in Heptane Reforming with a Multioutlet FixedBed Reactor and a Novel Vibrational Microbalance. J. Catal. 169, 455-468 (1997).

175. Anderson, J. R., Chang, Y. F. \& Western, R. J. Retained and desorbed products from reaction of 1-hexene over H-ZSM5 zeolite: Routes to coke precursors. J. Catal. 118, 466482 (1989).

176. Vandewiele, N. M., Magoon, G. R., Geem, K. M. Van, Green, W. H. \& Marin, G. B. Experimental and Modeling Study on the Thermal Decomposition of Jet Propellant-10. (2014).

177. Gao, C. W. et al. JP-10 combustion studied with shock tube experiments and modeled with 
automatic reaction mechanism generation. Combust. Flame 162, 3115-3129 (2015).

178. Lovestead, T. M. \& Bruno, T. J. A Comparison of the Hypersonic Vehicle Fuel JP-7 to the Rocket Propellants RP-1 and RP-2 with the Advanced Distillation Curve Method. Energy \& Fuels 23, 3637-3644 (2009).

179. Brouwer, D. M. Chemistry and Chemical Engineering of Catalytic Processes. (NATO ASI Series 39, 1980).

180. Namba, S., Sato, K., Fujita, K., Kim, J. H. \& Yashima, T. in Studies in Surface Science and Catalysis 28, 661-668 (1986).

181. Wang, Y. et al. Catalytic cracking of binary hydrocarbons of $\mathrm{n}$-dodecane and iso-dodecane under supercritical conditions. J. Anal. Appl. Pyrolysis 113, 133-136 (2015).

182. Edwards, T. et al. Fuel composition influence on deposition in endothermic fuels. in $A$ Collection of Technical Papers - 14th AIAA/AHI International Space Planes and Hypersonic Systems and Technologies Conference 1, 645-657 (American Institute of Aeronautics and Astronautics, 2006).

183. Bakker, W. J. W. et al. in Precision Process Technology SE - 32 (eds. Weijnen, M. P. C. \& Drinkenburg, A. A. H.) 425-436 (Springer Netherlands, 1993). doi:10.1007/978-94-0111759-3_32

184. Greensfelder, B. S. \& Voge, H. H. Catalytic Cracking of Pure Hydrocarbons. Cracking of Paraffins. Ind. Eng. Chem. 37, 514-520 (1945).

185. Jiang, R. et al. Supercritical thermal decompositions of normal- and iso-dodecane in tubular reactor. J. Anal. Appl. Pyrolysis 92, 292-306 (2011).

186. Eder, F. \& Lercher, J. A. On the Role of the Pore Size and Tortuosity for Sorption of Alkanes in Molecular Sieves. J. Phys. Chem. B 101, 1273-1278 (1997).

187. Eder, F., Stockenhuber, M. \& Lercher, J. A. Brønsted Acid Site and Pore Controlled Siting of Alkane Sorption in Acidic Molecular Sieves. J. Phys. Chem. B 101, 5414-5419 (1997).

188. Gounder, R. \& Iglesia, E. The catalytic diversity of zeolites: confinement and solvation effects within voids of molecular dimensions. Chem. Commun. (Camb). 49, 3491-509 (2013).

189. Gounder, R., Jones, A. J., Carr, R. T. \& Iglesia, E. Solvation and acid strength effects on catalysis by faujasite zeolites. J. Catal. 286, 214-223 (2012).

190. Vansina, H., Baltanas, M. A. \& Froment, G. F. Hydroisomerization and hydrocracking. 4. Product distribution from n-octane and 2,2,4-trimethylpentane. Ind. Eng. Chem. Prod. Res. Dev. 22, 526-531 (1983).

191. Ciapetta, F. \& Hunter, J. Isomerization of Saturated Hydrocarbons in Presence of Hydrogenation-Cracking Catalysts: Normal Pentane, Isohexanes, Heptanes, and Octanes. Ind. Eng. Chem. 45, 155-159 (1953).

192. Dvoyashkin, M., Valiullin, R., Kärger, J., Einicke, W. D. \& Gläser, R. Direct assessment of transport properties of supercritical fluids confined to nanopores. J. Am. Chem. Soc. 129, 
$10344-10345$ (2007).

193. Kobe, J. M., González, M. R., Fogash, K. B. \& Dumesic, J. A. Effects of Water on the Performance of Sulfated Zirconia Catalysts for Butane Isomerization. J. Catal. 164, 459466 (1996).

194. Kuba, S. \& Knözinger, H. Time-resolved in situ Raman spectroscopy of working catalysts: sulfated and tungstated zirconia. J. Raman Spectrosc. 33, 325-332 (2002).

195. Spielbauer, D., Mekhemer, G. A. H., Bosch, E. \& Knözinger, H. n-butane isomerization on sulfated zirconia. Deactivation and regeneration as studied by Raman, UV-VIS diffuse reflectance and ESR spectroscopy. Catal. Letters 36, 59-68 (1996).

196. Li, B. \& Gonzalez, R. D. TGA/FT-IR studies of the deactivation of sulfated zirconia catalysts. Appl. Catal. A Gen. 165, 291-300 (1997).

197. Corma, A. Solid acid catalysts. Curr. Opin. Solid State Mater. Sci. 2, $63-75$ (1997).

198. Yang, X. K., Chen, L. F., Wang, J. A., Noreña, L. E. \& Novaro, O. Study of the Keggin structure and catalytic properties of Pt-promoted heteropoly compound/Al-MCM-41 hybrid catalysts. Catal. Today 148, 160-168 (2009).

199. Bardin, B. B. \& Davis, R. J. A comparison of cesium-containing heteropolyacid and sulfated zirconia catalysts for isomerization of light alkanes. Top. Catal. 6, 77-86 (1998).

200. Devassy, B. \& Halligudi, S. Zirconia-supported heteropoly acids: Characterization and catalytic behavior in liquid-phase veratrole benzoylation. J. Catal. 236, 313-323 (2005).

201. Essayem, N. et al. Comparative study of n-pentane isomerization over solid acid catalysts, heteropolyacid, sulfated zirconia, and mordenite: dependence on hydrogen and platinum addition. J. Catal. 219, 97-106 (2003).

202. Rabindran Jermy, B., Khurshid, M., Al-Daous, M. A., Hattori, H. \& Al-Khattaf, S. S. Optimizing preparative conditions for tungstated zirconia modified with platinum as catalyst for heptane isomerization. Catal. Today 164, 148-153 (2011).

203. Hino, M. \& Arata, K. Synthesis of solid superacid of tungsten oxide supported on zirconia and its catalytic action for reactions of butane and pentane. J. Chem. Soc. Chem. Commun. 1259 (1987). doi:10.1039/c39880001259

204. Barton, D. G., Shtein, M., Wilson, R. D., Soled, S. L. \& Iglesia, E. Structure and Electronic Properties of Solid Acids Based on Tungsten Oxide Nanostructures. J. Phys. Chem. B 103, 630-640 (1999).

205. Soultanidis, N. et al. Relating n-pentane isomerization activity to the tungsten surface density of $\mathrm{WO}(\mathrm{x}) / \mathrm{ZrO} 2$. J. Am. Chem. Soc. 132, 13462-71 (2010).

206. Barton, D. G., Soled, S. L. \& Iglesia, E. Solid acid catalysts based on supported tungsten oxides. Top. Catal. 6, 87-99 (1998).

207. Zhou, W. et al. Identification of active $\mathrm{Zr}$-WOx clusters on a $\mathrm{ZrO} 2$ support for solid acid catalysts. Nat. Chem. 1, 722-728 (2009). 
208. Spivey, J. J. Review: Dehydration Catalysts for the Methanol/Dimethyl Ether Reaction. Chem. Eng. Commun. 110, 123-142 (1991).

209. Brunauer, S., Emmett, P. H. \& Teller, E. Adsorption of Gases in Multimolecular Layers. J. Am. Chem. Soc. 60, 309-319 (1938).

210. Ravel, B., Newville, M. ATHENA, ARTEMIS, HEPHAESTUS: data analysis for X-ray absorption spectroscopy using IFEFFIT. J. Synchrotron Radiat. 12, 537-541 (2005).

211. Giraudon, J.-M. et al. Synthesis of Tungsten Carbides by Temperature-Programmed Reaction with $\mathrm{CH} 4-\mathrm{H} 2$ Mixtures. Influence of the $\mathrm{CH} 4$ and Hydrogen Content in the Carburizing Mixture. J. Solid State Chem. 154, 412-426 (2000).

212. Mahamulkar, S. et al. In Situ Generation of Radical Coke and the Role of Coke-Catalyst Contact on Coke Oxidation. Ind. Eng. Chem. Res. 55, 5271-5278 (2016).

213. Vartuli, J. C. et al. Characterization of the Acid Properties of Tungsten/Zirconia Catalysts Using Adsorption Microcalorimetry and n-Pentane Isomerization Activity. J. Catal. 187, 131-138 (1999).

214. Lin, Q., Shimizu, K. \& Satsuma, A. Redox property of tungstated-zirconia analyzed by time resolved in situ UV-vis spectroscopy. Appl. Catal. A Gen. 365, 55-61 (2009).

215. Iglesia, E., Ribeiro, F. H., Boudart, M. \& Baumgartner, J. E. Synthesis, characterization, and catalytic properties of clean and oxygen-modified tungsten carbides. Catal. Today 15, 307-337 (1992).

216. Soultanidis, N. et al. Relating n-pentane isomerization activity to the tungsten surface density of $\mathrm{WO}(\mathrm{x}) / \mathrm{ZrO} 2$. J. Am. Chem. Soc. 132, 13462-71 (2010).

217. Wilson, R. D., Barton, D. G., Baertsch, C. D. \& Iglesia, E. Reaction and Deactivation Pathways in Xylene Isomerization on Zirconia Modified by Tungsten Oxide. J. Catal. 194, 175-187 (2000).

218. Ivanova, I. I., Kuznetsov, A. S., Yuschenko, V. V. \& Knyazeva, E. E. Design of composite micro/mesoporous molecular sieve catalysts. Pure Appl. Chem. 76, 1647-1657 (2004).

219. Qi, J., Zhao, T., Xu, X., Li, F. \& Sun, G. High activity in catalytic cracking of large molecules over a novel micro-micro/mesoporous silicoaluminophosphate. J. Porous Mater. 18, 69-81 (2010).

220. Kubelka, P. \& Munk, F. An Article on Optics of Paint Layers. (1931).

221. Tittensor, J. \& Gorte, R. J. Isopropylamine adsorption for the characterization of acid sites in silica-alumina catalysts. J. Catal. 138, 714-720 (1992).

222. Biaglow, A. I., Gittleman, C., Gorte, R. J. \& Madon, R. J. 2-Propanamine adsorption on a fluid catalytic cracking catalyst. J. Catal. 129, 88-93 (1991). 


\section{Appendix A Supporting Information for Chapter 2}

Table A-1. Results at 10 min TOS from conversion of n-hexane on H-ZSM-5.

\begin{tabular}{|c|c|c|c|}
\hline $\begin{array}{c}\text { Pressure } \\
\text { (MPa) }\end{array}$ & \multicolumn{3}{|c|}{6} \\
\hline $\begin{array}{c}\text { Temperature } \\
\text { (K) }\end{array}$ & 558 & 573 & 588 \\
\hline $\begin{array}{c}\text { Conversion } \\
(\%)\end{array}$ & 3.7 & 4.1 & 2.8 \\
\hline $\begin{array}{c}\text { TOF } \\
\left(\mathbf{s}^{-1}\right)\end{array}$ & 0.04 & 0.14 & 0.24 \\
\hline \multicolumn{4}{|c|}{ Molar Selectivity (\%) } \\
\hline Methane & trace & trace & trace \\
\hline Ethylene & trace & trace & trace \\
\hline Ethane & trace & trace & trace \\
\hline Propylene & 0.1 & 0.3 & 0.5 \\
\hline Propane & 7.8 & 9.3 & 11 \\
\hline Isobutane & 13 & 11 & 11 \\
\hline C4 species & 19 & 18 & 20 \\
\hline C5 species & 28 & 29 & 29 \\
\hline C6 species* & 17 & 17 & 16 \\
\hline $\mathrm{C}_{7}$ species & 8.4 & 8.5 & 7.1 \\
\hline C8 species & 4.3 & 4.0 & 3.5 \\
\hline C9 species & 1.9 & 2.1 & 1.6 \\
\hline C10 species & 0.6 & 0.5 & 0.3 \\
\hline
\end{tabular}

${ }^{*} \mathrm{C}_{6}$ species do not include the n-hexane feed and are mainly 2- and 3-methylpentanes. 
Table A-2. Results at 10 min TOS from conversion of n-hexane on H-Y.

\begin{tabular}{|c|c|c|c|}
\hline $\begin{array}{l}\text { Pressure } \\
\text { (MPa) }\end{array}$ & \multicolumn{3}{|c|}{4} \\
\hline $\begin{array}{c}\text { Temperature } \\
\text { (K) }\end{array}$ & 623 & 648 & 673 \\
\hline $\begin{array}{c}\text { Conversion } \\
(\%)\end{array}$ & 7.0 & 7.8 & 6.7 \\
\hline $\begin{array}{c}\text { TOF } \\
\left(\mathbf{s}^{-1}\right)\end{array}$ & 0.04 & 0.05 & 0.08 \\
\hline \multicolumn{4}{|c|}{ Molar Selectivity (\%) } \\
\hline Methane & 0.1 & 0.4 & 0.3 \\
\hline Ethylene & 0.1 & 0.2 & 0.1 \\
\hline Ethane & 0.3 & 0.7 & 0.4 \\
\hline Propylene & trace & 0.1 & trace \\
\hline Propane & 1.2 & 4.0 & 4.6 \\
\hline Isobutane & 0.9 & 2.3 & 3.3 \\
\hline $\mathrm{C}_{4}$ species & 0.6 & 1.1 & 1.9 \\
\hline C5 species & 2.3 & 3.2 & 5.3 \\
\hline C6 species* & 94 & 87 & 82 \\
\hline $\mathrm{C}_{7}$ species & 0.4 & 0.6 & 1.1 \\
\hline C8 species & 0.1 & 0.1 & 0.8 \\
\hline C9 species & trace & trace & 0.4 \\
\hline C10 species & trace & trace & trace \\
\hline $\begin{array}{l}{ }^{*} \mathrm{C}_{6} \text { species do not } \\
2,3 \text {-dimethylbutane }\end{array}$ & n-hex: & mainly & lpenta \\
\hline
\end{tabular}


Table A-3. Results at 10 min TOS from conversion of n-hexane on H-Y.

\begin{tabular}{|c|c|c|c|c|}
\hline $\begin{array}{c}\text { Pressure } \\
\text { (MPa) }\end{array}$ & \multicolumn{4}{|c|}{6} \\
\hline $\begin{array}{c}\text { Temperature } \\
\text { (K) }\end{array}$ & 623 & 648 & 673 & 698 \\
\hline $\begin{array}{c}\text { Conversion } \\
(\%)\end{array}$ & 1.4 & 2.1 & 3.5 & 3.0 \\
\hline $\begin{array}{c}\text { TOF } \\
\left(\mathrm{s}^{-1}\right)\end{array}$ & 0.03 & 0.05 & 0.08 & 0.14 \\
\hline \multicolumn{5}{|c|}{ Molar Selectivity (\%) } \\
\hline Methane & trace & trace & 0.1 & 0.4 \\
\hline Ethylene & trace & trace & trace & 0.2 \\
\hline Ethane & trace & 0.1 & 0.1 & 1.0 \\
\hline Propylene & trace & trace & trace & 0.7 \\
\hline Propane & 2.3 & 4.1 & 6.9 & 13 \\
\hline Isobutane & 4.9 & 4.9 & 4.8 & 6.4 \\
\hline $\mathrm{C}_{4}$ species & 2.2 & 2.8 & 3.8 & 5.3 \\
\hline $\mathrm{C}_{5}$ species & 5.0 & 5.6 & 11 & 13 \\
\hline C6 species* & 78 & 78 & 70 & 59 \\
\hline $\mathrm{C}_{7}$ species & 1.5 & 0.6 & 0.6 & 0.1 \\
\hline C8 species & 2.4 & 1.4 & 0.6 & -- \\
\hline C9 species & 2.7 & 1.6 & 1.6 & 1.0 \\
\hline C10 species & 0.8 & 0.8 & 0.3 & 0.4 \\
\hline
\end{tabular}

* $\mathrm{C}_{6}$ species do not include the n-hexane feed and are mainly 2- and 3methylpentanes and 2,3-dimethylbutane. 
Table A-4. Results at $10 \mathrm{~min}$ TOS from conversion of n-hexane on Al-MCM-41.

\begin{tabular}{|c|c|}
\hline Pressure & 6 \\
\hline $\begin{array}{c}\text { Temperature } \\
\text { (K) }\end{array}$ & 598 \\
\hline $\begin{array}{c}\text { Conversion } \\
(\%)\end{array}$ & 0.8 \\
\hline $\begin{array}{c}\text { TOF } \\
\left(\mathbf{s}^{-1}\right)\end{array}$ & 0.005 \\
\hline \multicolumn{2}{|c|}{ Molar Selectivity (\%) } \\
\hline Methane & 1.2 \\
\hline Ethylene & 0.7 \\
\hline Ethane & 1.6 \\
\hline Propylene & 4.3 \\
\hline Propane & 21 \\
\hline Isobutane & 5.2 \\
\hline $\mathrm{C}_{4}$ species & 9.3 \\
\hline $\mathrm{C}_{5}$ species & 9.3 \\
\hline C6 species* & 47 \\
\hline $\mathrm{C}_{7}$ species & trace \\
\hline Cs species & trace \\
\hline C9 species & 0.4 \\
\hline C10 species & trace \\
\hline \multicolumn{2}{|c|}{$\begin{array}{l}* \mathrm{C}_{6} \text { species do not include the } \mathrm{n} \text {-hexane } \\
\text { feed and are mainly } 2 \text { - and } 3 \text { - } \\
\text { methylpentanes }\end{array}$} \\
\hline
\end{tabular}


Table A-5. Effect of pressure on results at $10 \mathrm{~min}$ TOS from conversion of $n$-hexane on H-ZSM-5.

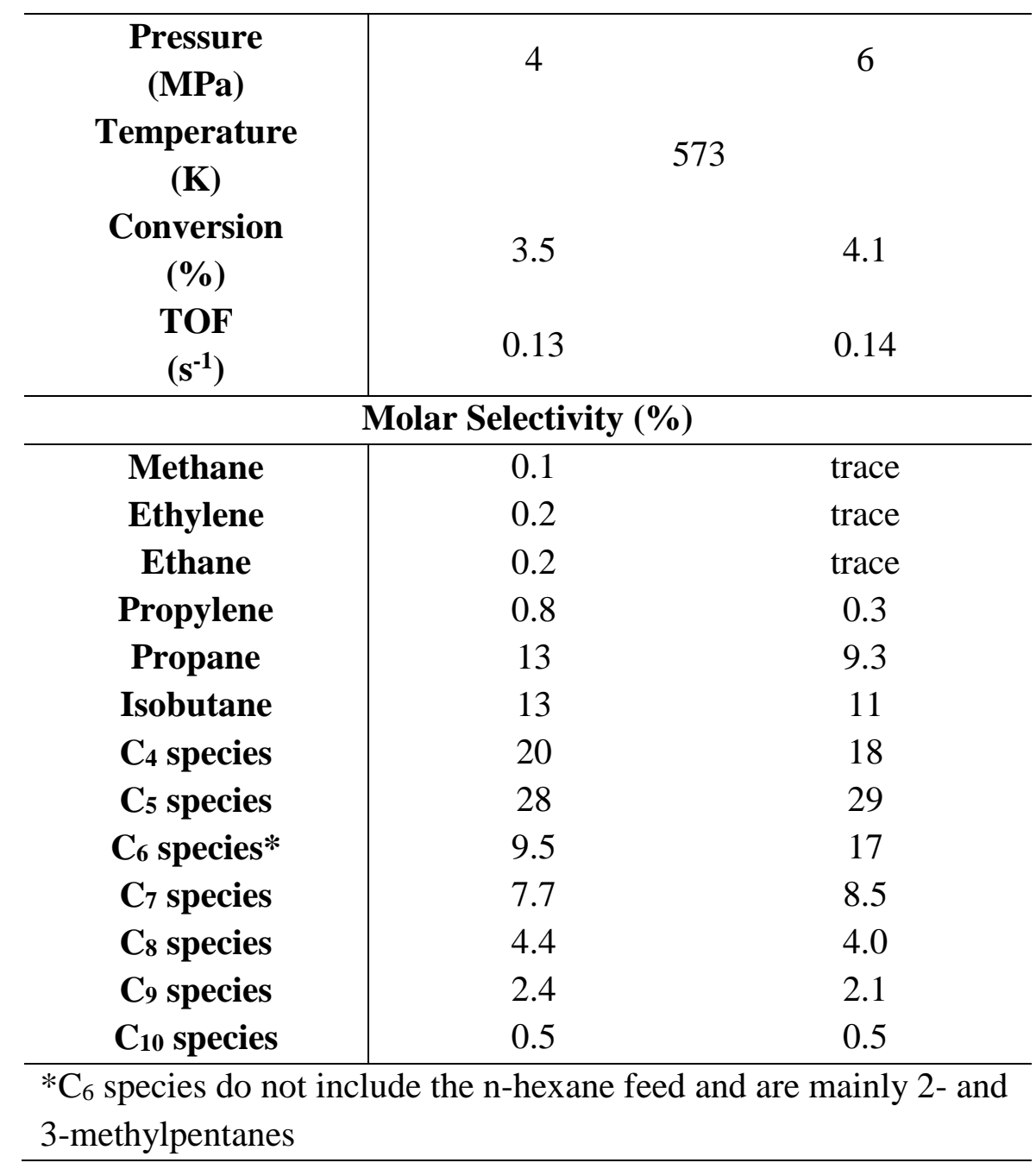


Table A-6. Effect of pressure on results at $10 \mathrm{~min}$ TOS from conversion of $n$-hexane on $H$-Y.

\begin{tabular}{c|cc}
\hline $\begin{array}{c}\text { Pressure } \\
\text { (MPa) } \\
\text { Temperature } \\
\text { (K) }\end{array}$ & 4 & 6 \\
Conversion & & \\
$(\%)$ & & \\
TOF & 6.7 & 3.5 \\
$\left(\mathbf{s}^{-1}\right)$ & & \\
& 0.08 & 0.08 \\
\hline Methane & Molar Selectivity (\%) & \\
Ethylene & 0.3 & 0.1 \\
Ethane & 0.2 & trace \\
Propylene & 0.4 & 0.1 \\
Propane & 0.1 & trace \\
Isoutane & 4.6 & 7.0 \\
C4 species & 3.3 & 4.8 \\
C5 species & 1.9 & 3.8 \\
C6 species* & 5.3 & 10.9 \\
C7 species & 82 & 70 \\
C8 species & 1.1 & 0.6 \\
C9 species & 0.8 & 0.6 \\
C10 species & 0.4 & 1.6 \\
\hline C6 5 Species do not include the & $n-h e x a n e$ feed and are mainly 2- and \\
3-methylpentanes and 2,3-dimethylbutane. & \\
\hline
\end{tabular}


Table A-7. Results at 10 min TOS from conversion of n-dodecane on H-ZSM-5.

\begin{tabular}{|c|c|c|c|c|}
\hline Pressure & \multicolumn{4}{|c|}{6} \\
\hline $\begin{array}{c}\text { Temperature } \\
\text { (K) }\end{array}$ & 558 & 573 & 588 & 698 \\
\hline $\begin{array}{c}\text { Conversion } \\
(\%)\end{array}$ & 3.7 & 4.4 & 5.4 & 8.1 \\
\hline $\begin{array}{l}\text { TOF } \\
\left(\mathbf{s}^{-1}\right)\end{array}$ & 0.03 & 0.24 & 0.44 & 1.4 \\
\hline \multicolumn{5}{|c|}{ Molar Selectivity (\%) } \\
\hline Methane & trace & trace & trace & trace \\
\hline Ethylene & trace & trace & trace & trace \\
\hline Ethane & trace & trace & trace & 0.1 \\
\hline Propylene & 0.3 & 0.5 & 0.4 & 0.9 \\
\hline Propane & 6.7 & 7.6 & 5.6 & 6.8 \\
\hline Isobutane & 5.4 & 4.9 & 4.2 & 5.7 \\
\hline $\mathrm{C}_{4}$ species & 16 & 17 & 16 & 18 \\
\hline C5 species & 24 & 25 & 24 & 25 \\
\hline C6 species & 18 & 18 & 19 & 17 \\
\hline $\mathrm{C}_{7}$ species & 12 & 11 & 12 & 11 \\
\hline C8 species & 9.7 & 8.8 & 9.3 & 8.3 \\
\hline C9 species & 5.9 & 5.3 & 6.1 & 4.2 \\
\hline C10 species & 1.5 & 2.1 & 2.5 & 2.8 \\
\hline C11 species & 0.5 & 0.1 & 0.2 & 0.5 \\
\hline
\end{tabular}


Table A-8. Results at 10 min TOS from conversion of n-dodecane on H-Y.

\begin{tabular}{|c|c|c|c|}
\hline $\begin{array}{c}\text { Pressure } \\
\text { (MPa) }\end{array}$ & \multicolumn{3}{|c|}{6} \\
\hline $\begin{array}{c}\text { Temperature } \\
\text { (K) }\end{array}$ & 663 & 678 & 693 \\
\hline $\begin{array}{c}\text { Conversion } \\
(\%)\end{array}$ & 4.8 & 4.4 & 5.4 \\
\hline $\begin{array}{c}\text { TOF } \\
\left(\mathbf{s}^{-1}\right)\end{array}$ & 0.13 & 0.24 & 0.44 \\
\hline \multicolumn{4}{|c|}{ Molar Selectivity (\%) } \\
\hline Methane & trace & trace & trace \\
\hline Ethylene & trace & trace & trace \\
\hline Ethane & trace & trace & 0.2 \\
\hline Propylene & 0.5 & 0.7 & 1.1 \\
\hline Propane & 3.9 & 5.4 & 5.2 \\
\hline Isobutane & 13 & 14 & 13 \\
\hline $\mathrm{C}_{4}$ species & 7.8 & 8.6 & 9.6 \\
\hline C5 species & 25 & 24 & 23 \\
\hline C6 species & 17 & 18 & 19 \\
\hline $\mathrm{C}_{7}$ species & 12 & 12 & 13 \\
\hline C8 species & 7.1 & 7.5 & 7.8 \\
\hline Co species & 2.9 & 2.2 & 2.2 \\
\hline C10 species & 8.2 & 3.8 & 2.6 \\
\hline C11 species & 2.7 & 3.6 & 3.8 \\
\hline
\end{tabular}


Table A-9. Results at 10 min TOS from conversion of n-dodecane on Al-MCM-41.

\begin{tabular}{|c|c|c|c|}
\hline $\begin{array}{c}\text { Pressure } \\
\text { (MPa) }\end{array}$ & & 6 & \\
\hline $\begin{array}{l}\text { Temperature } \\
\text { (K) }\end{array}$ & 653 & 668 & 683 \\
\hline $\begin{array}{c}\text { Conversion } \\
(\%)\end{array}$ & 5.9 & 4.3 & 5.6 \\
\hline $\begin{array}{c}\text { TOF } \\
\left(\mathbf{s}^{-1}\right)\end{array}$ & 0.04 & 0.08 & 0.19 \\
\hline \multicolumn{4}{|c|}{ Molar Selectivity (\%) } \\
\hline Methane & trace & trace & trace \\
\hline Ethylene & trace & trace & trace \\
\hline Ethane & trace & 0.1 & 0.3 \\
\hline Propylene & 0.8 & 2.1 & 1.9 \\
\hline Propane & 6.2 & 7.4 & 6.7 \\
\hline Isobutane & 12 & 9.7 & 9.2 \\
\hline $\mathrm{C}_{4}$ species & 15 & 18 & 16 \\
\hline C5 species & 27 & 26 & 25 \\
\hline C6 species & 17 & 17 & 17 \\
\hline $\mathrm{C}_{7}$ species & 9.4 & 9.7 & 11 \\
\hline C8 species & 6.5 & 6.3 & 7.1 \\
\hline Co species & 2.9 & 2.5 & 4.0 \\
\hline C10 species & 1.3 & 0.7 & 0.9 \\
\hline C11 species & 1.1 & 0.6 & 1.3 \\
\hline
\end{tabular}



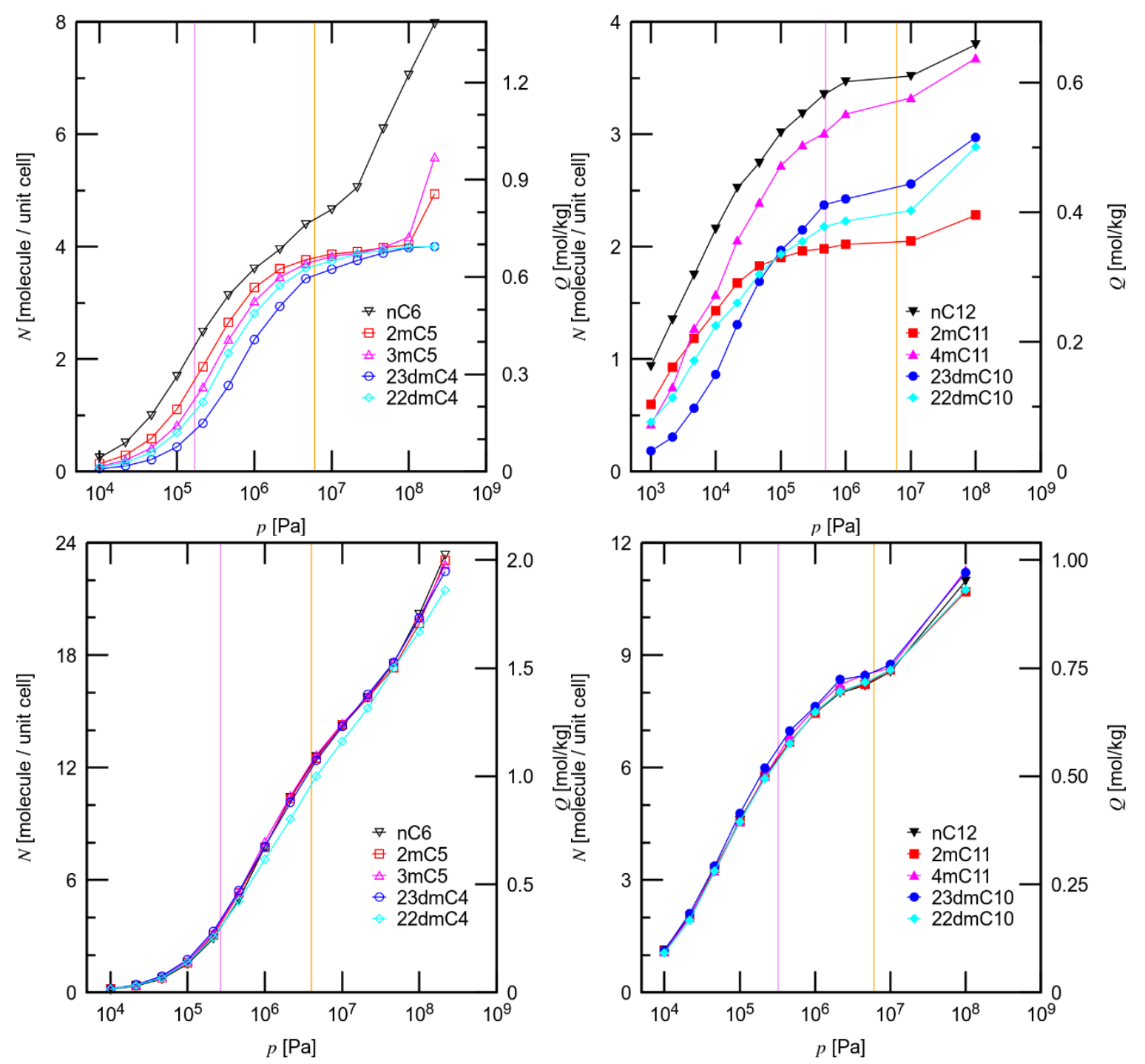

Figure A-1. Adsorption isotherms of hexane (left column) and dodecane (right column) isomers in H-ZSM-5 at $T=590 \mathrm{~K}$ (top row) and in H-Y at $T=675$ and $695 \mathrm{~K}$ (bottom row), respectively. The orange lines denote the feed pressure, while the violet lines indicate the upper limit of the partial pressure for the isomer products, by assuming that linear alkanes are only converted via isomerization reactions. 


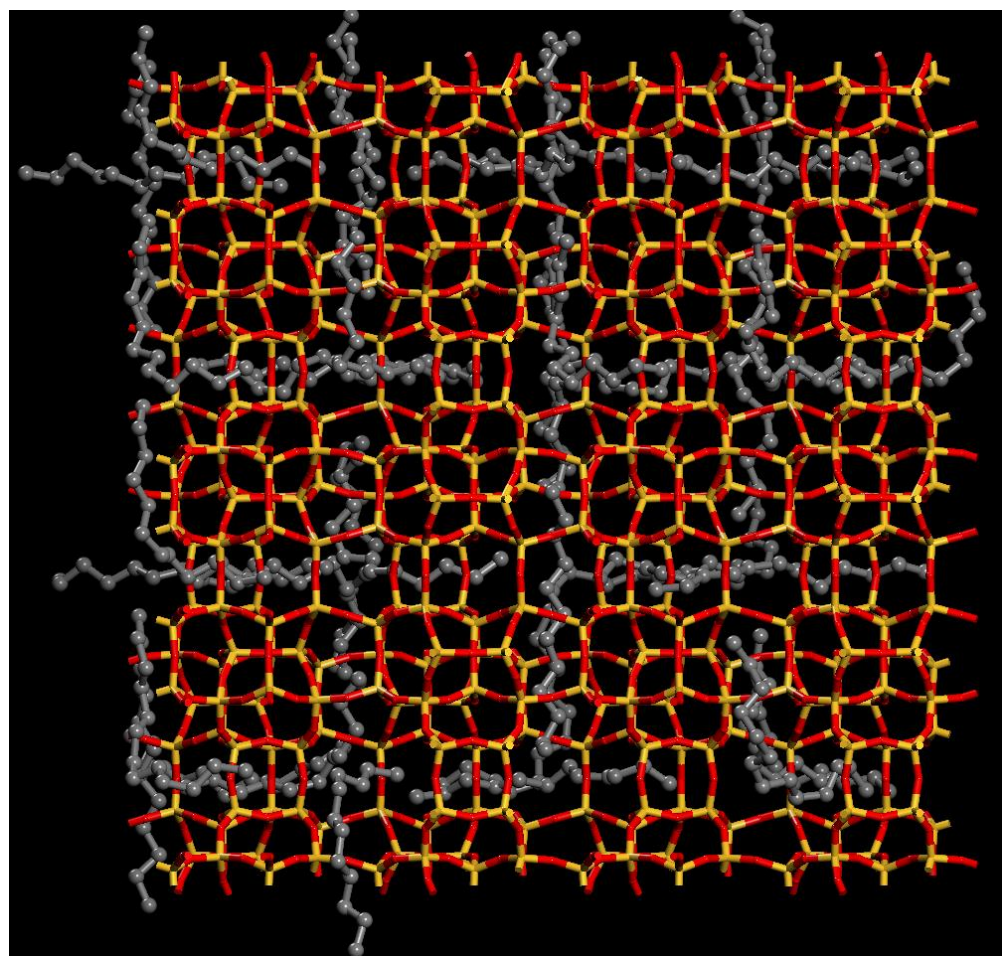

Figure A-2. A representative snapshot of adsorbed n-dodecane molecules in H-ZSM-5 at $T=590$ $\mathrm{K}$ and $p=10 \mathrm{MPa}$. The silicon, oxygen, and carbon atoms are shown in yellow, red, and gray, respectively, and hydrogen atoms are omitted for clarity. In order to maximize packing and further saturate the channels, n-dodecane has to be localized either within two zig-zag or two straight channels (I-shape), or within a zig-zag channel and a straight channel (L-shape). 


\begin{tabular}{|c|c|c|c|c|}
\hline \multicolumn{5}{|c|}{$\begin{array}{l}\text { Table A-10. Results at } 10 \mathrm{~min} \text { TOS from cracked products during conversior } \\
\text { of n-hexane on } \mathrm{H}-\mathrm{Y}^{*} \text {. }\end{array}$} \\
\hline $\begin{array}{c}\text { Pressure } \\
(\mathrm{MPa})\end{array}$ & \multicolumn{4}{|c|}{6} \\
\hline $\begin{array}{l}\text { Temperature } \\
\text { (K) }\end{array}$ & 623 & 648 & 673 & 698 \\
\hline $\begin{array}{c}\text { Conversion } \\
(\%)\end{array}$ & 0.4 & 0.5 & 0.9 & 1.0 \\
\hline $\begin{array}{c}\text { TOF } \\
\left(\mathbf{s}^{-1}\right)\end{array}$ & 0.005 & 0.006 & 0.02 & 0.05 \\
\hline \multicolumn{5}{|c|}{ Molar Selectivity (\%) } \\
\hline Methane & 0.1 & 0.2 & 0.3 & 0.9 \\
\hline Ethylene & trace & 0.1 & 0.1 & 0.5 \\
\hline Ethane & 0.1 & 0.6 & 0.3 & 2.5 \\
\hline Propylene & trace & 0.2 & 0.1 & 1.7 \\
\hline Propane & 8.7 & 19 & 23 & 30 \\
\hline Isobutane & 18 & 23 & 16 & 16 \\
\hline $\mathrm{C}_{4}$ species & 8.5 & 13 & 13 & 13 \\
\hline $\mathrm{C}_{5}$ species & 19 & 25 & 37 & 32 \\
\hline C6 species & $\mathrm{n} / \mathrm{a}$ & $\mathrm{n} / \mathrm{a}$ & $\mathrm{n} / \mathrm{a}$ & $\mathrm{n} / \mathrm{a}$ \\
\hline $\mathrm{C}_{7}$ species & 5.8 & 1.6 & 1.9 & 0.3 \\
\hline Cs species & 9.3 & 6.4 & 1.9 & -- \\
\hline C9 species & 17 & 7.4 & 5.5 & 2.4 \\
\hline C10 species & 13 & 3.6 & 1.1 & 1.0 \\
\hline
\end{tabular}




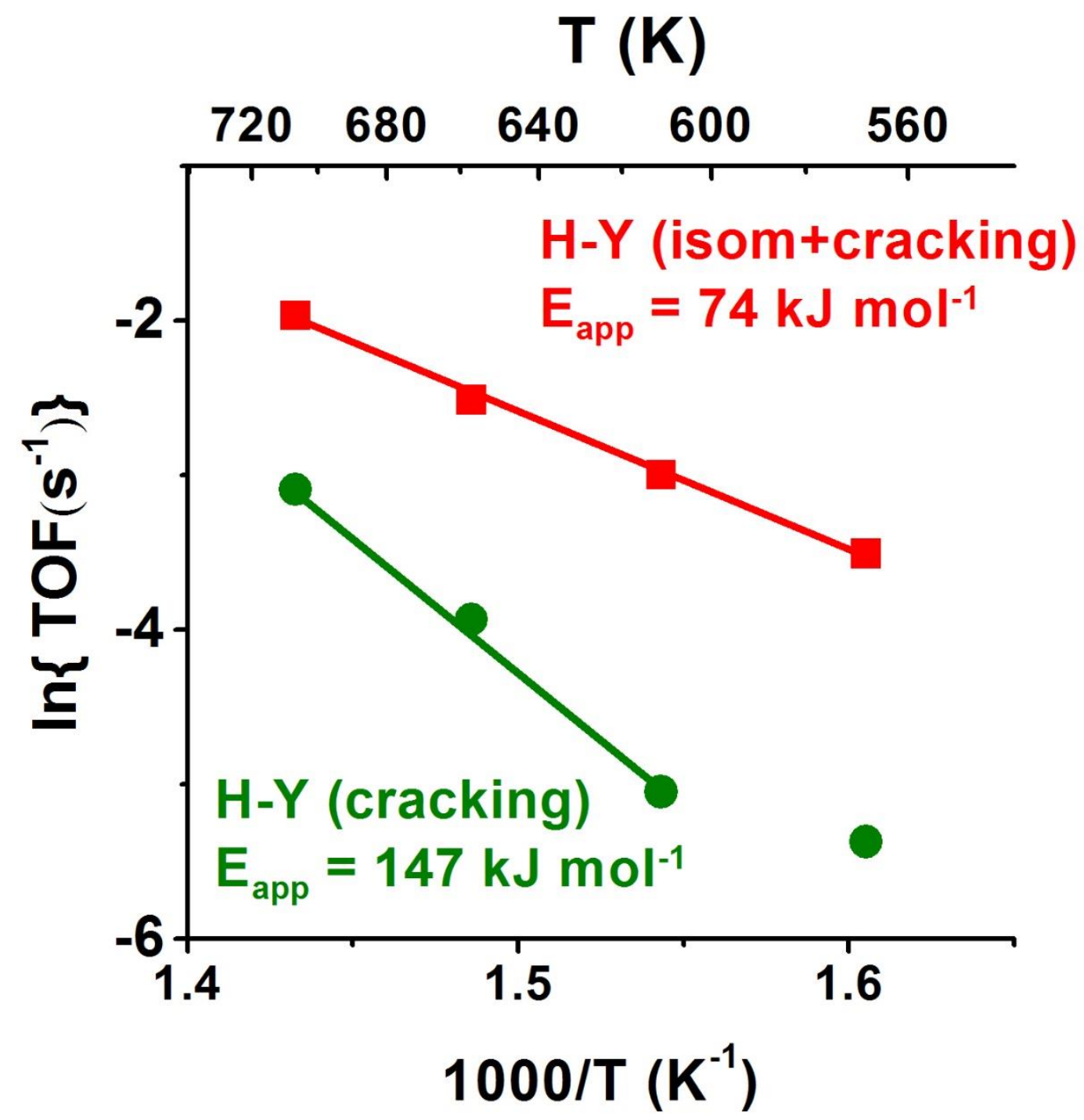

Figure A-3. Arrhenius-type plot for reactions of n-hexane over $\mathrm{H}-\mathrm{Y}$ at $6 \mathrm{MPa}$. TOFs calculated from the products of isomerization and cracking reactions are represented by ( $\square)$. TOFs calculated from only the products of cracking reactions are represented by $(\bullet)$. 


\section{Appendix B Supporting Information for Chapter 3}

\section{Cracking of JP-10 over H-ZSM-5 and H-Y}

Cracking of JP-10 over H-Y revealed excellent conversion of the hydrocarbon relative to H-ZSM-5. Cracking of JP-10 over H-ZSM-5 resulted in negligible conversion, shown in Table B-1. This was expected as the kinetic diameter of JP-10 $(0.6 \mathrm{~nm})$ is larger than the pore diameter of H-ZSM-5 ( 0.55 nm). Therefore, JP-10 cannot access the interior of the zeolite. H-Y has a pore diameter $(0.74 \mathrm{~nm})$ large enough to accommodate JP-10, thus emphasizing the importance of proper catalyst/fuel pairing.

Table B-1. Cracking of JP-10 over H-ZSM-5 and H-Y at $733 \mathrm{~K}$ and $6 \mathrm{MPa}$.

\begin{tabular}{ccccc}
\hline Catalyst & $\begin{array}{c}\text { Conv. } \\
(\%)\end{array}$ & $\begin{array}{c}\text { Loading in } \\
\text { reactor } \\
(\mathbf{m g})\end{array}$ & $\begin{array}{c}\text { Brønsted } \\
\text { Acid Sites in } \\
\text { reactor } \\
(\boldsymbol{\mu m o l})\end{array}$ & TOF \\
$\left(\mathbf{s}^{\mathbf{- 1}}\right)$ \\
\hline H-ZSM-5 & 0.2 & 20 & 11 & 0.02 \\
H-Y & 3.0 & 15 & 2.4 & 3.3 \\
\hline
\end{tabular}

\section{Cracking of JP-10 over Al-MCM-41}

Catalytic conversion of JP-10 over Al-MCM-41 and H-Y was performed under supercritical conditions. The transient performance of the two samples at $718 \mathrm{~K}$ is demonstrated in Figure B-1. H-Y was a more active catalyst for JP-10 cracking than Al-MCM-41, as evidenced by the difference in TOF. A mild deactivation of the catalyst was observed over Al-MCM-41 after 
40 minutes, whereas a faster rate of deactivation was seen over $\mathrm{H}-\mathrm{Y}$. The product distribution during cracking of JP-10 over Al-MCM-41 is detailed in Table B-2. Cracking of JP-10 over AlMCM-41 and H-Y (refer to Table 3-4) shared several characteristics. Butene, cyclopentadiene, cyclopentene, cyclohexadiene, benzene, toluene, substituted indenes, and naphthalenes were the major products during cracking of JP-10. A high apparent activation energy $\left(\sim 190 \mathrm{~kJ} \mathrm{~mol}^{-1}\right)$ was observed for this reaction over both Al-MCM-41 and H-Y, shown in Figure B-2. This observation suggests that $\mathrm{C}-\mathrm{C}$ bond cleavage is the kinetically-relevant step over both catalysts.

Table B-2. Results at 10 min TOS from the conversion of JP-10 over Al-MCM-41 in a fixed bed flow reactor at $6 \mathrm{MPa}$.

\begin{tabular}{|c|c|c|c|}
\hline Temperature & 688 & 703 & 718 \\
\hline $\begin{array}{c}\text { Conversion } \\
(\%)\end{array}$ & 2.1 & 2.9 & 3.0 \\
\hline $\begin{array}{c}\text { TOF } \\
\left(\mathbf{s}^{-1}\right)\end{array}$ & 0.087 & 0.17 & 0.33 \\
\hline \multicolumn{4}{|c|}{ Molar Selectivity (\%) } \\
\hline Methane & 0.1 & 0.1 & 0.1 \\
\hline Ethylene & 0.1 & 0.1 & 0.2 \\
\hline Ethane & trace & trace & 0.1 \\
\hline Propylene & 0.3 & 1.0 & 1.0 \\
\hline Propane & 2.9 & 2.3 & 2.5 \\
\hline Butene/Butadiene & 12 & 7.4 & 7.6 \\
\hline Other $\mathrm{C}_{4}$ species & 2.8 & 3.9 & 3.9 \\
\hline $\mathrm{C}_{5}$ species $^{1}$ & 15 & 17 & 17 \\
\hline C6 $_{6}$ species $^{2}$ & 14 & 11 & 11 \\
\hline $\mathrm{C}_{7}$ species $^{3}$ & 9.9 & 9.2 & 9.2 \\
\hline C8 species $^{4}$ & 4.4 & 7.0 & 6.9 \\
\hline C9 species & 2.1 & 0.9 & 0.9 \\
\hline JP-10 isomers 5 & 7.9 & 10 & 9.9 \\
\hline Other $\mathrm{C}_{10}$ species $^{6}$ & 28 & 29 & 29 \\
\hline$>\mathrm{C}_{10}$ species & 0.9 & 0.5 & 0.5 \\
\hline \multicolumn{4}{|c|}{ Experiments were performed at a liquid JP-10 feed flow rate of $1.2 \mathrm{~cm}^{3} \mathrm{~min}^{-1}$. } \\
\hline \multicolumn{4}{|c|}{ 1. $\mathrm{C}_{5}$ species are mainly cyclopentene/cyclopentane, and cyclopentadiene. } \\
\hline \multicolumn{4}{|c|}{ 2. $\mathrm{C}_{6}$ species are mainly cyclohexadiene, 1,3 -hexadiene, and benzene. } \\
\hline \multicolumn{4}{|c|}{ 3. $\mathrm{C}_{7}$ species are toluene and other unknown species. } \\
\hline \multicolumn{4}{|c|}{ 4. $\mathrm{C}_{8}$ species are ethylbenzenes, xylene, and other unknown species. } \\
\hline \multicolumn{4}{|c|}{$\begin{array}{l}\text { 5. JP-10 isomers do not include the JP-10 feed and the adamantane and endo-isomer } \\
\text { impurities within the feed has been subtracted. }\end{array}$} \\
\hline
\end{tabular}


6. Other $\mathrm{C}_{10}$ species do not include the JP-10 feed and are substituted indenes and naphthalene
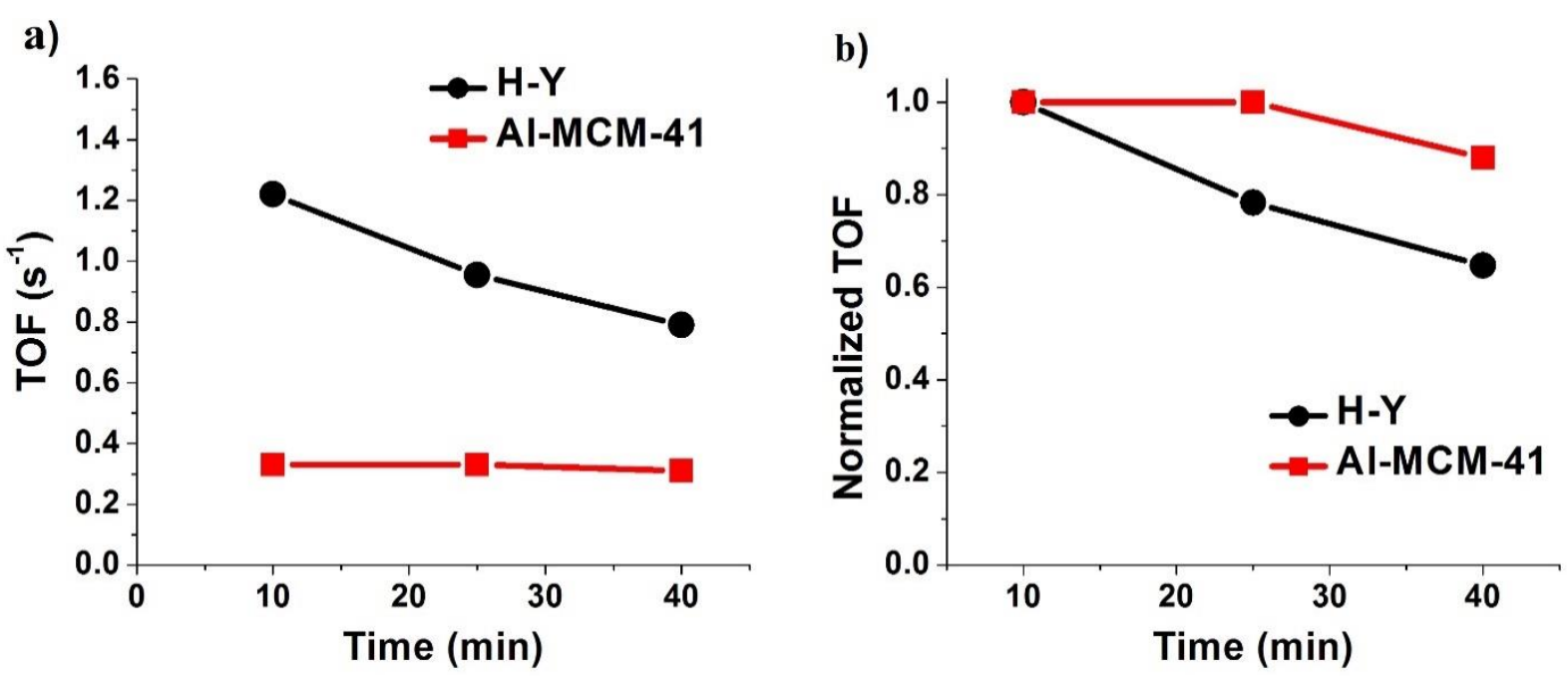

Figure B-1. a) TOF and b) normalized TOF of JP-10 cracking versus time on stream over H-Y $(\bullet)$ and $\mathrm{Al}-\mathrm{MCM}-41(\bullet)$ at $718 \mathrm{~K}$ and $6 \mathrm{MPa}$ and $\sim 3 \%$ conversion.

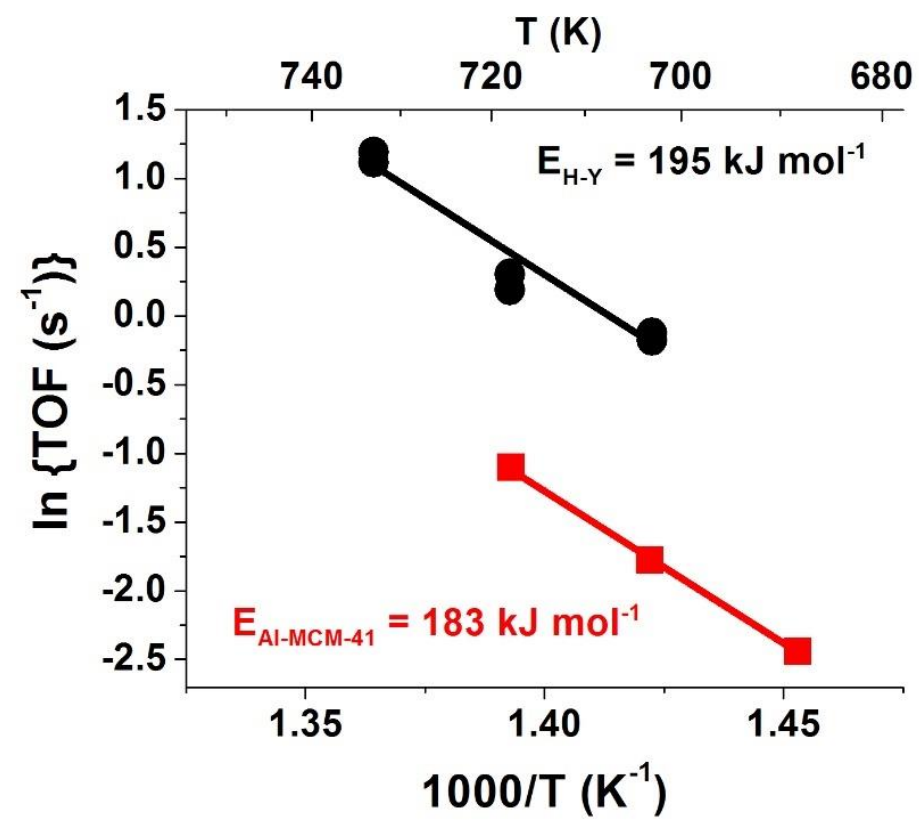

Figure B-2. Arrhenius-type plots for reactions of JP-10 over H-Y (•) and Al-MCM-41 (ש) at 6 MPa. 
Gas Chromatography Mass Spectrometry (GC-MS) analysis of JP-10 cracking products at high and moderate levels of conversion

The reactor effluent from the cracking of JP-10 over H-Y at high (78\%) and moderate (16\%) levels of conversion was sent to Galbraith Laboratories and analyzed via GC-MS. Products were identified via MS and the FID response areas from similar products were summed and listed in Table B-3. The product distribution shifts from predominantly methyl indenes at moderate conversion to substituted benzenes, naphthalenes, and phenanthrenes at high conversion.

Table B-3. Notable products during moderate and high conversion of JP-10 over H-Y.*

\begin{tabular}{lll}
\hline & Moderate & High \\
\hline Product & \% of Total FID Response Area \\
\hline Dimethyl benzenes & 4.4 & 2.3 \\
Trimethyl-benzenes & 3.5 & 4.5 \\
Diethyl-benzenes & 1.4 & 9.4 \\
Methyl-indenes & 14 & 5.6 \\
Naphthalenes & 7.5 & 5.6 \\
Methyl-naphthalenes & -- & 4.4 \\
Dimethyl-naphthalenes & -- & 3.5 \\
Ethyl-naphthalenes & -- & 1.4 \\
Phenanthrenes & -- & 0.9 \\
Methyl-phenanthrenes & -- & 2.0 \\
\hline $\begin{array}{l}\text { Dimethyl-phenanthrenes } \\
\text { Product analysis was performed by Galbraith Laboratories using GC-MS. }\end{array}$ & \\
\hline
\end{tabular}




\section{Appendix C Supporting Information for Chapter 4}

Cracking of isooctane, n-dodecane, and a 50/50 mol.\% mixture of isooctane and n-dodecane over H-ZSM-5 under supercritical conditions

Product distributions during cracking of isooctane, n-dodecane, and a 50/50 mol.\% mixture of isooctane and n-dodecane (50/50 mixture) over H-ZSM-5 at $698 \mathrm{~K}$ and $3 \mathrm{MPa}$ are shown in Table C-1. It was assumed that only n-dodecane was cracked during cracking of the 50/50 mixture because cracking of isooctane over H-ZSM-5 resulted in negligible conversion. In addition, the product distribution during cracking of the 50/50 mixture was very similar to that of n-dodecane.

Table C-1. Cracking of isooctane, n-dodecane, and a 50/50 mol.\% mixture of isooctane and n-dodecane over H-ZSM-5 at $698 \mathrm{~K}$ and $3 \mathrm{MPa}$.

\begin{tabular}{|c|c|c|c|}
\hline Reactant & Isooctane & n-Dodecane & 50/50 Mixture \\
\hline $\begin{array}{c}\text { Conversion } \\
(\%)\end{array}$ & trace & 6.9 & 1.8 \\
\hline $\begin{array}{c}\text { TOF } \\
\left(\mathbf{s}^{-1}\right)\end{array}$ & -- & 1.2 & $0.31^{\dagger}$ \\
\hline \multicolumn{4}{|c|}{ Molar Selectivity (\%) } \\
\hline$\leq \mathbf{C}_{2}$ & -- & 0.7 & 0.8 \\
\hline $\mathrm{C}_{3}$ & -- & 11 & 5.7 \\
\hline $\mathrm{iC}_{4}{ }^{*}$ & -- & 9.9 & 12 \\
\hline $\mathrm{C}_{4}$ & -- & 14 & 15 \\
\hline $\mathrm{C}_{5}$ & -- & 23 & 25 \\
\hline $\mathrm{C}_{6}$ & -- & 15 & 16 \\
\hline $\mathbf{C}_{7}$ & -- & 10 & 9.3 \\
\hline $\mathrm{C}_{8}$ & -- & 8.0 & 8.7 \\
\hline $\mathrm{C}_{9}$ & -- & 4.9 & 4.0 \\
\hline $\mathrm{C}_{10}$ & -- & 2.4 & 3.0 \\
\hline $\mathrm{C}_{11}$ & -- & 0.7 & 0.4 \\
\hline
\end{tabular}

${ }^{\dagger}$ TOF for cracking of the 50/50 mixture was calculated based on the assumption that only n-dodecane was cracked.

$* \mathrm{iC}_{4}$ is predominantly isobutane. Only trace amounts of isobutene were detected. 
Cracking of isooctane, n-dodecane, and a 50/50 mol.\% mixture of isooctane and n-dodecane over amorphous silica-alumina (ASA) under supercritical conditions

Product distributions during cracking of isooctane, n-dodecane, and a 50/50 mixture over ASA at $698 \mathrm{~K}$ and $3 \mathrm{MPa}$ are shown in Table C-2. In contrast to the results over H-ZSM-5, ASA was able to effectively catalyze isooctane cracking. The product distribution during cracking of the 50/50 mixture has characteristics of both isooctane and n-dodecane cracking.

Table C-2. Cracking of isooctane, n-dodecane, and a 50/50 mol.\% mixture of isooctane and n-dodecane over ASA at $698 \mathrm{~K}$ and $3 \mathrm{MPa}$.

\begin{tabular}{|c|c|c|c|}
\hline Reactant & Isooctane & n-Dodecane & 50/50 Mixture \\
\hline $\begin{array}{c}\text { Conversion } \\
(\%)\end{array}$ & 2.6 & 11 & 15 \\
\hline $\begin{array}{c}\text { TOF } \\
\left(\mathbf{s}^{-1}\right)\end{array}$ & 0.01 & 0.03 & $0.04^{\dagger}$ \\
\hline \multicolumn{4}{|c|}{ Molar Selectivity (\%) } \\
\hline$\leq \mathbf{C}_{2}$ & 1.9 & 0.9 & 3.9 \\
\hline $\mathbf{C}_{3}$ & 8.1 & 9.8 & 19 \\
\hline $\mathrm{iC}_{4}{ }^{*}$ & 60 & 11 & 19 \\
\hline $\mathbf{C}_{4}$ & 1.3 & 17 & 1.1 \\
\hline $\mathrm{C}_{5}$ & 17 & 26 & 22 \\
\hline $\mathrm{C}_{6}$ & 6.0 & 16 & 12 \\
\hline $\mathrm{C}_{7}$ & 5.0 & 8.1 & 6.1 \\
\hline $\mathrm{C} 8$ & 0.9 & 5.3 & 1.7 \\
\hline C9 & -- & 3.1 & 2.0 \\
\hline $\mathbf{C}_{10}$ & -- & 1.7 & 0.8 \\
\hline $\mathbf{C}_{11}$ & -- & 1.6 & 0.2 \\
\hline
\end{tabular}

$\dagger$ TOF for cracking of the 50/50 mixture was calculated based on the assumption that both isooctane and n-dodecane were cracked.

$*_{\mathrm{iC}}$ is predominantly isobutane. Only trace amounts of isobutene were detected. 


\section{Cracking of n-dodecane over H-Y under subcritical and supercritical conditions}

Product distributions during cracking of n-dodecane above and below the critical temperature of $n$-dodecane $\left(\mathrm{T}_{\mathrm{c}}=658 \mathrm{~K}\right)$ are shown in Table $\mathrm{C}-3$. No major shift in product distribution was observed during the transition from subcritical to supercritical conditions.

Table C-3. Results at 10 min TOS from conversion of $\mathbf{n}$-dodecane on H-Y.

\begin{tabular}{|c|c|c|c|c|c|}
\hline Pressure & \multicolumn{5}{|c|}{6} \\
\hline $\begin{array}{c}\text { Temperature } \\
\text { (K) }\end{array}$ & 633 & 648 & 663 & 678 & 693 \\
\hline $\begin{array}{c}\text { Conversion } \\
(\%)\end{array}$ & 3.1 & 4.6 & 4.8 & 4.4 & 5.4 \\
\hline $\begin{array}{c}\text { TOF } \\
\left(\mathbf{s}^{-1}\right)\end{array}$ & 0.062 & 0.080 & 0.13 & 0.24 & 0.44 \\
\hline \multicolumn{6}{|c|}{ Molar Selectivity (\%) } \\
\hline Methane & trace & trace & trace & trace & trace \\
\hline Ethylene & trace & trace & trace & trace & trace \\
\hline Ethane & trace & trace & trace & trace & 0.2 \\
\hline Propylene & 0.3 & 0.3 & 0.5 & 0.7 & 1.1 \\
\hline Propane & 5.6 & 3.5 & 3.9 & 5.4 & 5.2 \\
\hline Isobutane & 13 & 13 & 13 & 14 & 13 \\
\hline $\mathrm{C}_{4}$ species & 8.1 & 6.8 & 7.8 & 8.6 & 9.6 \\
\hline C5 species & 25 & 25 & 25 & 24 & 23 \\
\hline C6 species & 19 & 19 & 17 & 18 & 19 \\
\hline $\mathrm{C}_{7}$ species & 14 & 13 & 12 & 12 & 13 \\
\hline C8 species & 7.6 & 7.2 & 7.1 & 7.5 & 7.8 \\
\hline C9 species & 2.9 & 3.0 & 2.9 & 2.2 & 2.2 \\
\hline C10 species & 3.4 & 7.0 & 8.2 & 3.8 & 2.6 \\
\hline C11 species & 1.1 & 2.7 & 2.7 & 3.6 & 3.8 \\
\hline
\end{tabular}




\section{Gas Chromatography (GC) analysis of JP-8}

A GC chromatogram of JP-8 is shown in Figure C-1. GC analysis of the liquid phase products of JP-8 was not possible due to the number of components in JP-8.

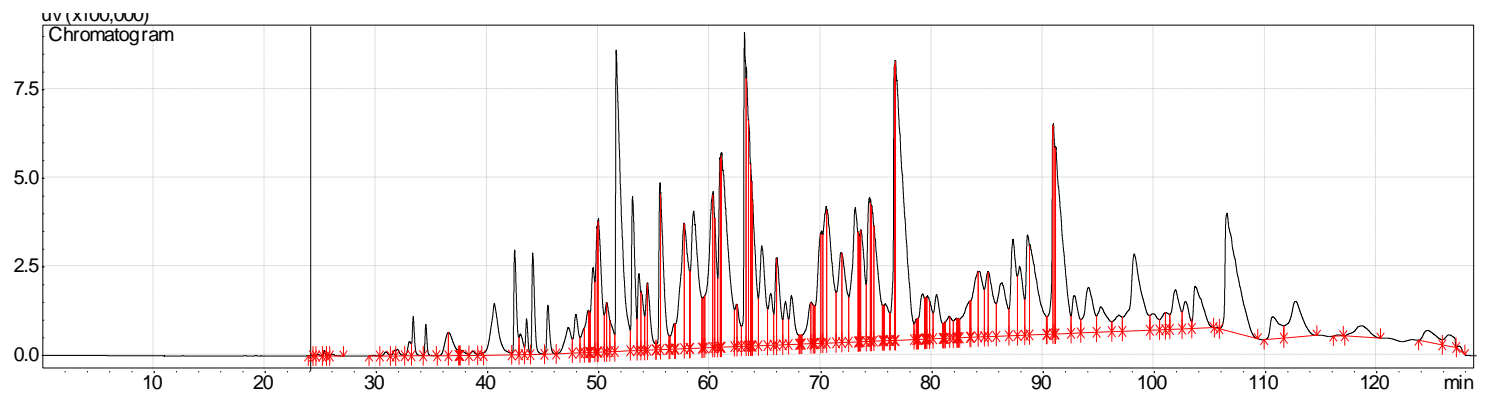

Figure C-1. GC Chromatogram for JP-8. 


\section{Appendix D Supporting Information for Chapter 5}

Method for determining UV-visible absorption edge energy ( $\left.E_{0}\right)$ adapted from Barton et al. [204].

Ultraviolet-visible diffuse reflectance spectra of the $\mathrm{WO}_{\mathrm{x}} / \mathrm{ZrO}_{2}$ samples were collected on a Cary 3E UV-VIS spectrometer with an attached Labsphere DRA-CA-30 diffuse reflectance apparatus. Equation D-2 represents the Kubelka-Monk function for infinitely thick samples, $\mathrm{F}\left(R_{\infty}\right)$ [220]. $\mathrm{F}\left(R_{\infty}\right)$ was used to convert reflectance spectra $\left(R_{\text {sample }}\right)$ into equivalent absorption spectra using the reflectance of Labsphere Spectralon reflectance standard (USRS-99-020) as a reference $\left(R_{\text {reference }}\right)$.

$$
\begin{aligned}
& R_{\infty}=\frac{R_{\text {sample }}}{R_{\text {reference }}} \\
& F\left(R_{\infty}\right)=\frac{\left(1-R_{\infty}\right)^{2}}{2 R_{\infty}}=\frac{\alpha(\text { absorption coefficient })}{S(\text { scattering coefficient })}
\end{aligned}
$$

A plot of $(\mathrm{F}(R \infty) \cdot h v)^{1 / \eta}$ vs $h v$ was used to determine the absorption edge energy $\left(\mathrm{E}_{0}\right)$. $\mathrm{E}_{0}$ can be determined from the y-intercept of a linear fit to the absorption edge from $\mathrm{F}(R \infty) \cdot h v)^{1 / \eta}$ vs $h v$. An appropriate choice of $\eta$ results in a plot that is linear near the absorption edge. Barton et al. [204] used $\eta=2$ to define the absorption edge for $\mathrm{WO}_{\mathrm{x}} / \mathrm{ZrO}_{2}$ samples. An example of this determination is shown in Figure D-1. 


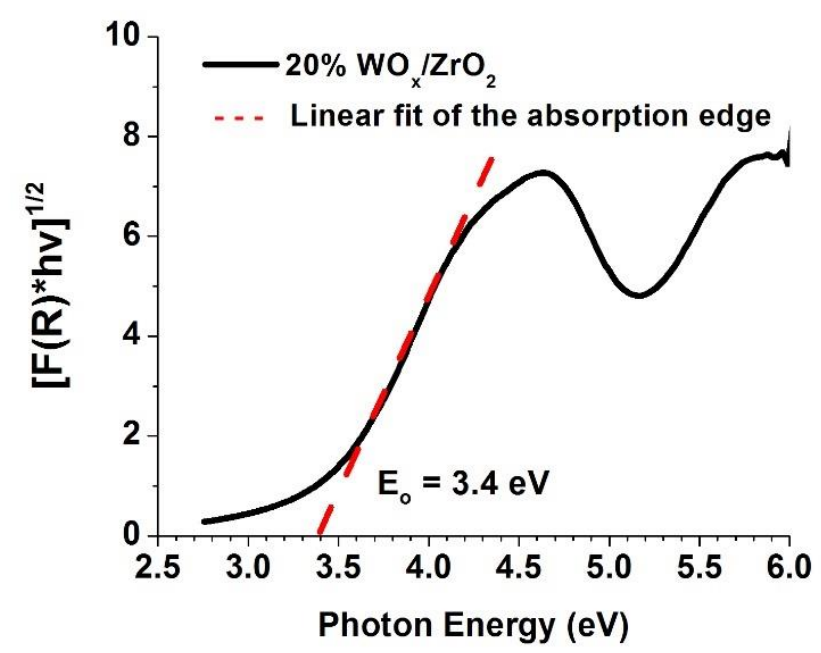

Figure D-1. Absorption edge energy $\left(\mathrm{E}_{0}\right)$ of $20 \% \mathrm{WO}_{\mathrm{x}} / \mathrm{ZrO}_{2}$ determined by the intercept of a linear fit to the absorption edge.

The $\mathrm{E}_{0}$ of various $\mathrm{WO}_{\mathrm{x}}$ standard compounds was measured in-house and compared to values reported by Barton et al. [204], presented in Table D-1. The values measured by Barton et al. were higher than those measured in-house by $\sim 0.1 \mathrm{eV}$.

Table D-1. Absorption edge energies $\left(E_{0}\right)$ of various $W_{\mathrm{x}}$ standard compounds

\begin{tabular}{c|cccc}
\hline & $\mathbf{W O}_{3}^{(\mathbf{a})}$ & $\mathbf{A M T}^{(\mathbf{b})}$ & $\mathbf{A P T}^{(\mathbf{c})}$ & $\mathbf{N a}_{2} \mathbf{W O}_{4}{ }^{(\mathbf{d})}$ \\
\hline $\boldsymbol{E}_{\mathbf{0}}$ & 2.5 & 3.1 & 3.5 & 4.7 \\
$\boldsymbol{E}_{\mathbf{0}}{ }^{(\mathrm{e})}$ & 2.59 & 3.23 & 3.54 & 4.89 \\
\hline
\end{tabular}

(a) $\mathrm{WO}_{3}$ represents an extended 3-d crystalline network of distorted octahedra

(b) Ammonium metatungstate $(\mathrm{AMT})$ : $\left(\mathrm{NH}_{4}\right)_{6} \mathrm{H}_{2} \mathrm{~W}_{12} \mathrm{O}_{40}$ represents $\mathrm{WO}_{\mathrm{x}}$ domains of intermediate $(\mathrm{nm})$ size $\left(\mathrm{W}_{12}\right)$

(c) Ammonium paratungstate (APT): $\left(\mathrm{NH}_{4}\right)_{10} \mathrm{H}_{2} \mathrm{~W}_{12} \mathrm{O}_{41}$ represents $\mathrm{WO}_{\mathrm{x}}$ domains of intermediate $(\mathrm{nm})$ size $\left(\mathrm{W}_{12}\right)$

(d) $\mathrm{Na}_{2} \mathrm{WO}_{4}$ represents isolated $\mathrm{W}^{6+}$ centers

(e) Values reported by Barton et al. [204] 


\section{Raman spectra of reference compounds $\mathrm{WO}_{3}$ and $\mathrm{m}-\mathrm{ZrO}_{2}$.}

Raman spectra of $\mathrm{m}-\mathrm{ZrO}_{2}$ (prepared from $\mathrm{ZrO}_{\mathrm{x}}(\mathrm{OH})_{4-2 \mathrm{x}}$ ) and $\mathrm{WO}_{3}$ powder (Sigma-Aldrich, 99.9\%) were collected as references for $\mathrm{WO}_{\mathrm{x}} / \mathrm{ZrO}_{2}$ samples and presented in Figure D-2. Characteristic peaks for $\mathrm{WO}_{3}$ were seen at $\sim 805$ and $\sim 719 \mathrm{~cm}^{-1}$. Characteristic peaks for $\mathrm{m}-\mathrm{ZrO} 2$ were observed at $\sim 649$ and $\sim 474 \mathrm{~cm}^{-1}$.

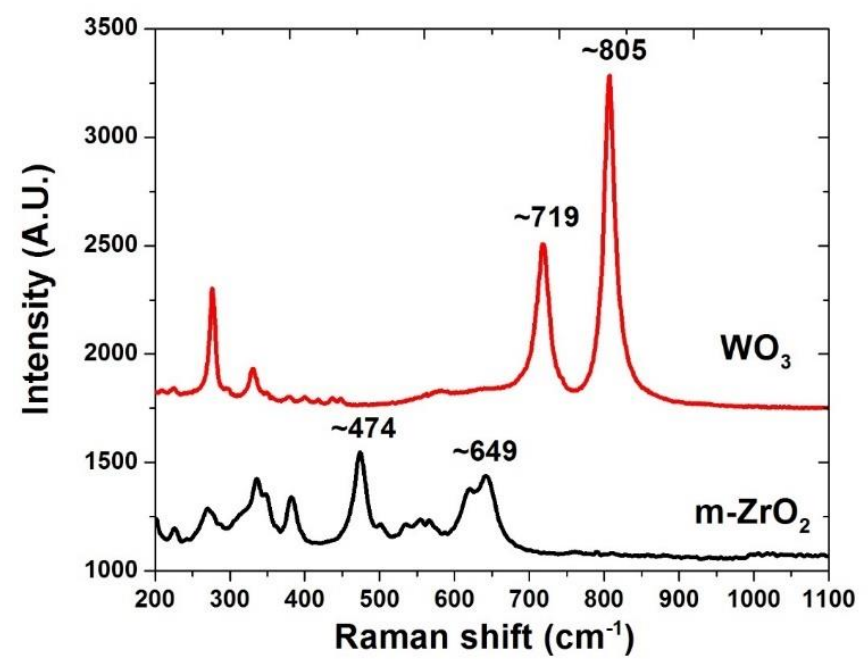

Figure D-2. Raman spectra of $\mathrm{m}-\mathrm{ZrO}_{2}$ and $\mathrm{WO}_{3}$. 


\section{Procedure for n-propylamine decomposition experiments and analysis of the results over $\mathrm{WO}_{\mathrm{x}} / \mathrm{ZrO}_{2}$}

Gorte and coworkers $[89,221,222]$ demonstrated that alkylamines are protonated by Brønsted acid sites and decompose to alkenes and ammonia at $\sim 650 \mathrm{~K}$ via a Hoffmann-elimination reaction, shown below:

$$
\begin{aligned}
\mathrm{HRNH}_{2}+\mathrm{ZOH} & \rightarrow \mathrm{HRNH}_{3}^{+} \cdots \mathrm{ZO}^{-} \\
\mathrm{HRNH}_{3}^{+} \cdots \mathrm{ZO}^{-} & \rightarrow \mathrm{R}+\mathrm{NH}_{3}+\mathrm{ZOH}
\end{aligned}
$$

Thus, a Brønsted-acid site density can be quantified from the amount of amine that reacts over a sample. A schematic of the setup used to obtain the Brønsted-acid site density measurements is shown in Figure E-2. The design for the setup was adapted from Kresnawahjuesa et al. [125].

A larger sample and longer catalyst bed of $\mathrm{WO}_{x} / \mathrm{ZrO}_{2}$ relative to aluminosilicate materials was required to obtain a measurable propylene signal $(\mathrm{m} / \mathrm{z}=41)$ during $\mathrm{n}$-propylamine decomposition experiments. For example, $100 \mathrm{mg}$ of H-ZSM-5 was used compared to $1830 \mathrm{mg}$ of $\mathrm{WO}_{\mathrm{x}} / \mathrm{ZrO}_{2}$. It is likely that the longer residence time during $\mathrm{WO}_{\mathrm{x}} / \mathrm{ZrO}_{2}$ n-propylamine decomposition experiments resulted in secondary reactions of propylene. This is supported by the presence of a heavier mass peak $(\mathrm{m} / \mathrm{z}=56)$ corresponding to hexane or hexene molecules. This peak was not observed during experiments over aluminosilicate samples. It is likely that other products were also formed, but only mass peaks corresponding to ammonia $(\mathrm{m} / \mathrm{z}=17)$, npropylamine $(\mathrm{m} / \mathrm{z}=30)$, propylene $(\mathrm{m} / \mathrm{z}=41)$, and hexene/hexane $(\mathrm{m} / \mathrm{z}=56)$ were tracked. The MS traces for propylene and hexene/hexane are shown in Figure D-3. Figure D-4 and Table D-2 demonstrate the determination of the Brønsted-acid site density for H-ZSM-5. 


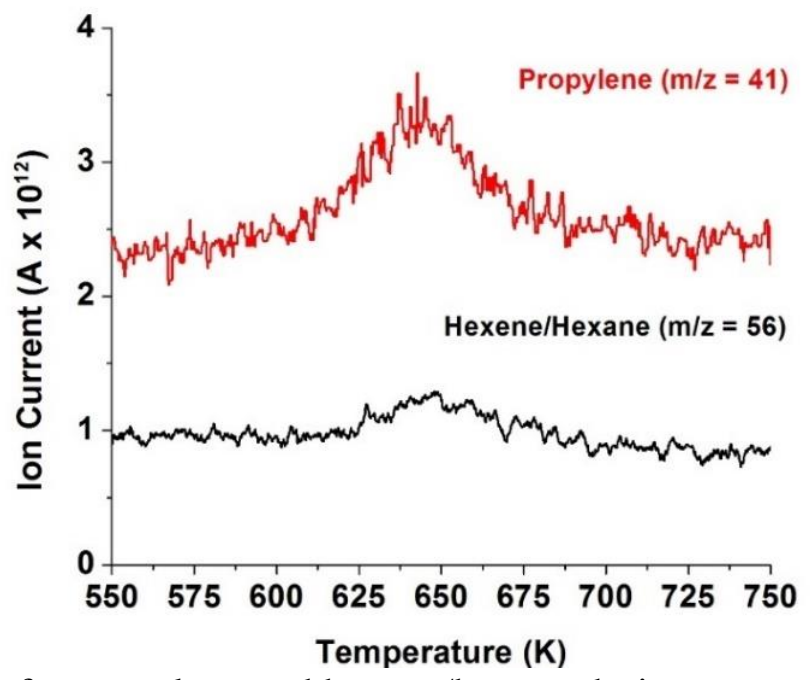

Figure D-3. MS traces for propylene and hexene/hexane during n-propylamine decomposition over $20 \% \mathrm{WO}_{\mathrm{x}} / \mathrm{ZrO}_{2}$.
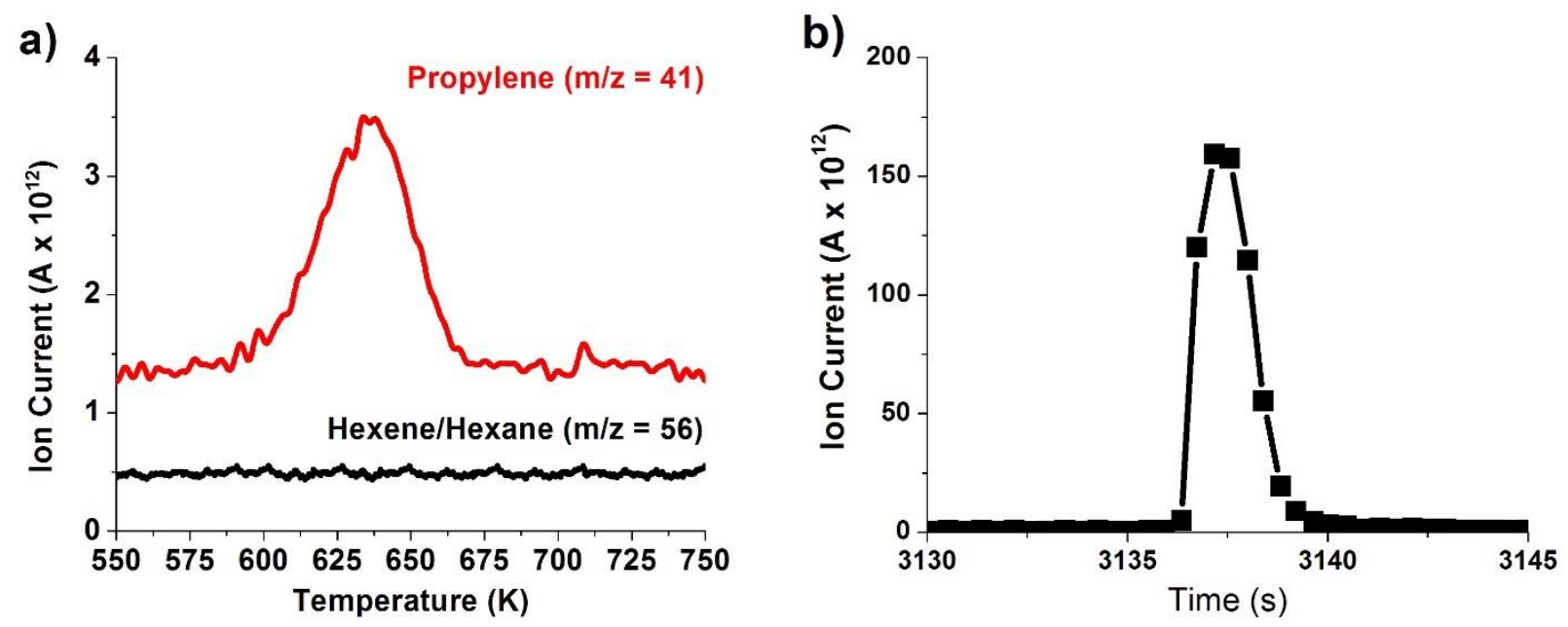

Figure D-4. a) MS traces for propylene and hexene/hexane during n-propylamine decomposition over H-ZSM-5. b) MS trace for a propylene pulse used to calibrate the propylene MS signal.

Table D-2. Measurement of Brønsted-acid site density of H-ZSM-5.

\begin{tabular}{cc|cc}
\hline \multicolumn{2}{c|}{ Propylene pulse for calibration } & \multicolumn{2}{c}{ Propylene detected during experiment } \\
\hline $\begin{array}{c}\text { Moles of propylene } \\
\text { Area of peak }\end{array}$ & $\begin{array}{c}\text { Area of Peak } \\
\text { Area/mole }\end{array}$ & $\begin{array}{c}\text { Moles of propylene } \\
\text { Catalyst loading } \\
(\mathrm{g})\end{array}$ & $1.99 \times 10^{-10}$ \\
& $3.63 \times 10^{-10}$ & $\begin{array}{c}\text { Bronsted Acid } \\
\text { Density } \\
\left.(\mu \mathrm{mol} \mathrm{g})^{-1}\right)\end{array}$ & 0.100 \\
& & & 550 \\
\end{tabular}




\section{Cracking of n-dodecane over $20 \% \mathrm{WO}_{\mathrm{x}} / \mathrm{ZrO}_{2}$ under supercritical conditions}

The product distribution during cracking of n-dodecane over $20 \% \mathrm{WO}_{\mathrm{x}} / \mathrm{ZrO}_{2}$ under supercritical conditions is shown in Table D-3. Overall, the product distribution was similar to that seen during cracking of $\mathrm{n}$-dodecane over aluminosilicate materials under supercritical conditions (Table A-7, Table A-8, and Table A-9), however, the selectivity toward $\leq \mathrm{C}_{2}$ products was higher during cracking of n-dodecane over $20 \% \mathrm{WO}_{\mathrm{x}} / \mathrm{ZrO}_{2}$.

Table D-3. Results at $10 \mathrm{~min}$ TOS from conversion of n-dodecane over $20 \% \mathrm{WO}_{\mathrm{x}} / \mathrm{ZrO}_{2}$ at $698 \mathrm{~K}$ and $4 \mathrm{MPa}$.

\begin{tabular}{c|c}
\hline $\begin{array}{c}\text { Conversion } \\
(\boldsymbol{\%})\end{array}$ & 4.7 \\
\hline Molar Selectivity (\%) & \\
\hline Methane & 3.7 \\
Ethylene & 0.2 \\
Ethane & 2.1 \\
Propylene & 1.5 \\
Propane & 11 \\
Isobutane & 18 \\
C4 species & 8.0 \\
C5 species & 20 \\
C6 species & 14 \\
C7 species & 10 \\
C8 species & 7.2 \\
C9 species & 2.0 \\
C10 species & 1.7 \\
C11 species & 0.7 \\
\hline
\end{tabular}




\section{Appendix E Experimental Details}

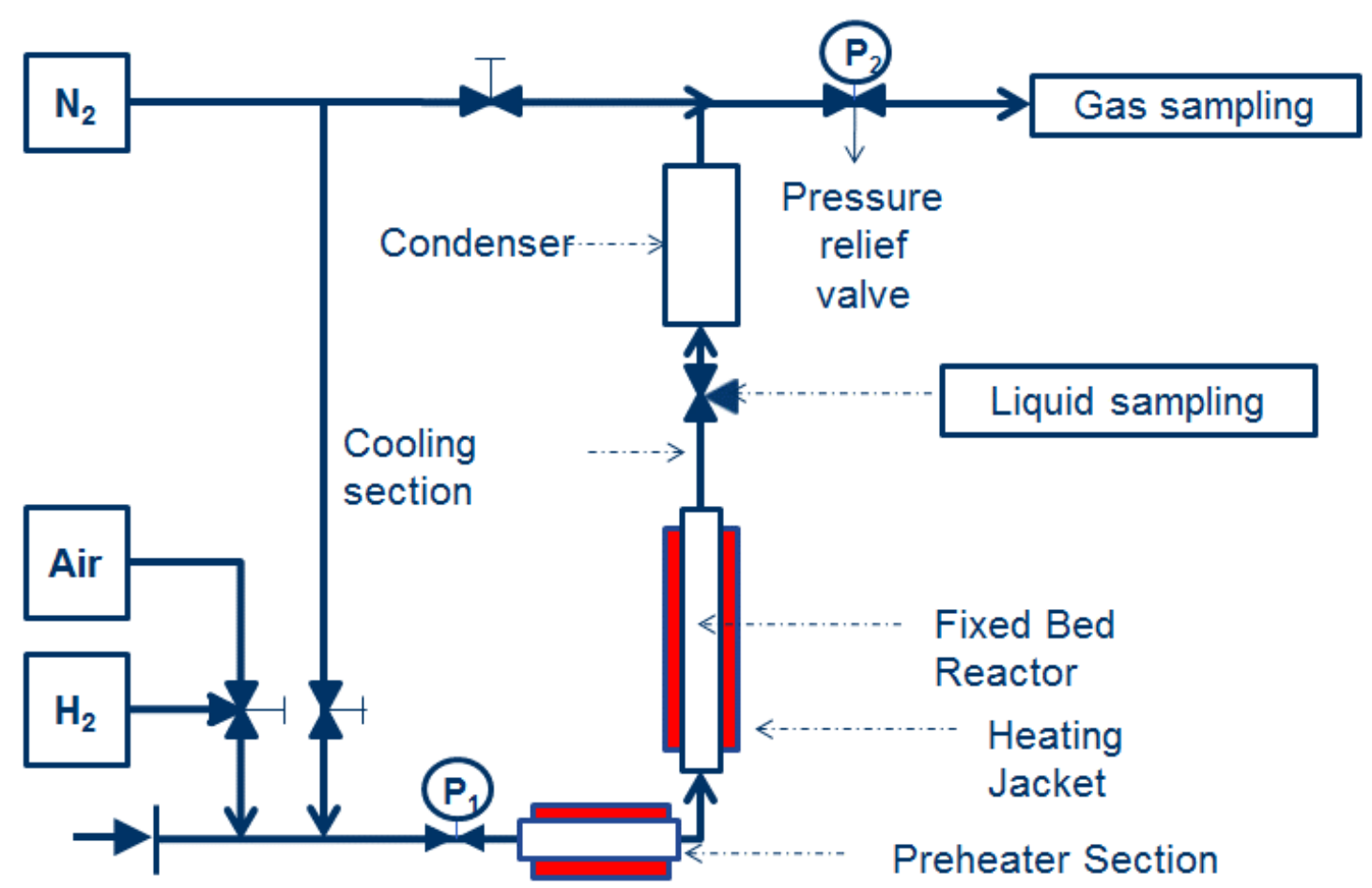

High pressure syringe pump

feeding liquid feed

Figure E-1. Schematic diagram of the upward-flow fixed bed reactor.

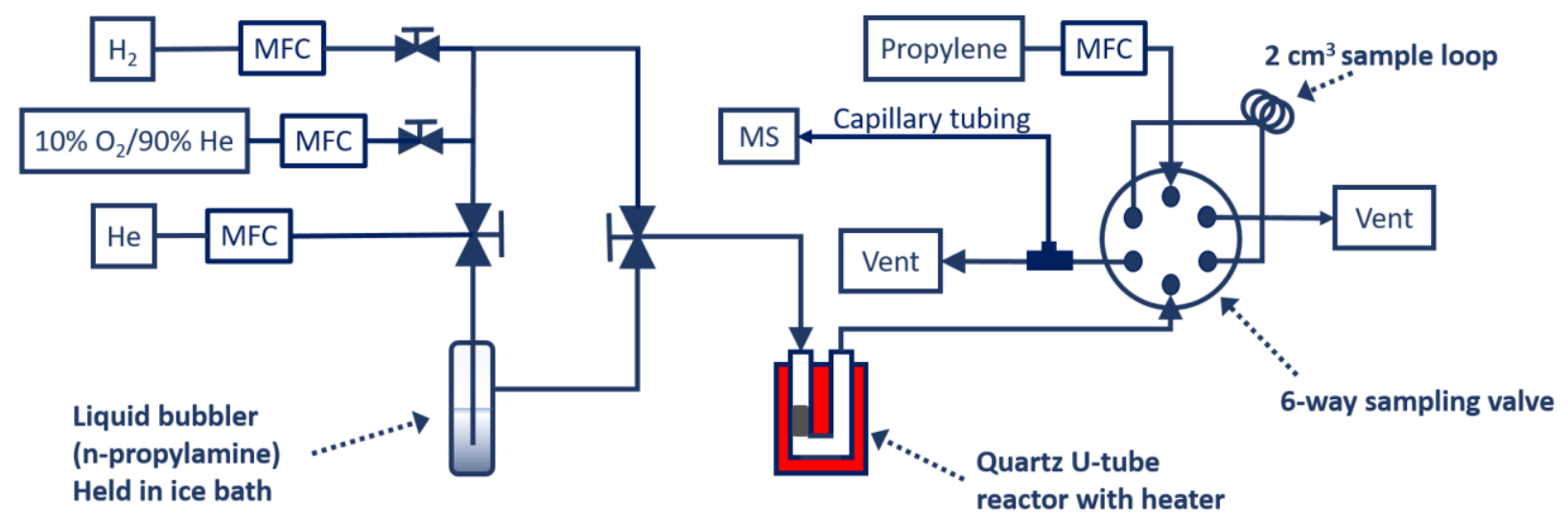

Figure E-2. Schematic diagram of setup used for the n-propylamine decomposition experiments. Gas flows were measured using mass flow controllers (MFCs) and decomposition products were analyzed using a mass spectrometer (MS). 